GA-A 13140

UC-77

\title{
RESULTS OF THE GENERAL ATOMIC DEPOSITION LOOP PROGRAM
}

\author{
by \\ D. L. HANSON
}

Prepared under

Contract AT(04-3)-167

Project Agreement No. 51

for the

San Francisco Operations Office

U.S. Energy Research and Development Administration

GENERAL ATOMIC PROJECT 3219

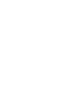

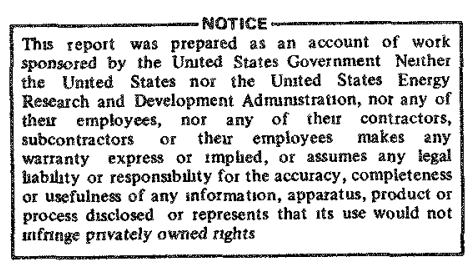

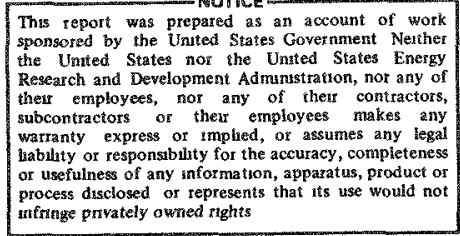




\section{DISCLAIMER}

This report was prepared as an account of work sponsored by an agency of the United States Government. Neither the United States Government nor any agency Thereof, nor any of their employees, makes any warranty, express or implied, or assumes any legal liability or responsibility for the accuracy, completeness, or usefulness of any information, apparatus, product, or process disclosed, or represents that its use would not infringe privately owned rights. Reference herein to any specific commercial product, process, or service by trade name, trademark, manufacturer, or otherwise does not necessarily constitute or imply its endorsement, recommendation, or favoring by the United States Government or any agency thereof. The views and opinions of authors expressed herein do not necessarily state or reflect those of the United States Government or any agency thereof. 


\section{DISCLAIMER}

Portions of this document may be illegible in electronic image products. Images are produced from the best available original document. 
$\bullet$

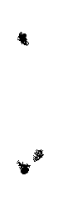

$\gamma$

$\bullet$ 
ABSTRACT

The transport behavior of fission products in flowing helium streams has been studied to determine their deposition and re-entrainment characteristics. Such information is required for the design and safety analysis of high-temperature gas-cooled reactors (HTGRs). A small highpressure, high-temperature 10op was constructed for deposition studies at near-HTGR conditions. Five loop experiments were performed to determine the plateout distribution of iodine, strontium, and cesium. In general, the plateout activity showed an exponential decrease with distance from the source with enhanced plateout at flow disturber locations (contractions, bends, etc.) and especially in a chill section where the surface was cooled.

Blowdown tests were performed on selected loop specimens to determine the amount of re-entrainment caused by abnormally high wall shear stresses. The liftoff fraction (fractional amount removed) was shown to vary approximately linearly with the shear ratio (defined as the ratio of the steady state wall shear stress under blowdown conditions to that under normal operating conditions). Blowdown results are also reported for pipe sections taken from the GAIL-IV in-pile 1oop.

Attempts were made to correlate these plateout data with the PAD code (Plateout Activity Distribution) which was developed for prediction of plateout distribution in an HTGR primary circuit. Because of inadequate modeling of the effects of the chill section, the agreement was generally poor. Consequent1y, to test further the PAD code, a review of the available plateout literature was made. Plateout distributions in the Peach Bottom and Dragon HTGRs and the Battelle Memorial Institute out-of-pile loop were successfully modeled. 
?

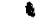


CONTENTS

ABSTRACT . . . . . . . . . . . . . . . . . . . . . . iii

1. INTRODUCTION . . . . . . . . . . . . . . . . . . . 1

2. EXPERIMENTAL METHODS . . . . . . . . . . . . . . . . . 10

2.1. Deposition Loop . . . . . . . . . . . . . . . . 10

2.1.1. Design of Deposition Loop ............ 10

2.1.2. Operation of Deposition Loop........... 26

2.2. Design and Operation of Blowdown Apparatus . . . . . . . 28

3. RESULTS . . . . . . . . . . . . . . . . . . . . 34

3.1. Experimental Results . . . . . . . . . . . . . . 34

3.1.1. Deposition Loop Plateout Distributions . . . . . . 38

3.1.2. Blowdown/Wipedown Results . . . . . . . . 48

3.2. Calculational Results ................ 62

3.2.1. Correlation of Deposition Loop Data . . . . . . . 62

3.2.2. Correlation of P1ateout Distributions from the Literature . . . . . . . . . . . 70

4. DISCUSSION . . . . . . . . . . . . . . . . . 87

4.1. Blowdown/Wipedown Tests . . . . . . . . . . . . 87

4.2. Deposition Loop Results . . . . . . . . . . . . . . 89

4.3. Battelle Memorial Institute Out-of-Pile Loop . . . . . . . . 94

4.4. Dragon HTGR . . . . . . . . . . . . . . . . 98

4.5. Peach Bottom HTGR ................. 102

5. CONCLUSIONS AND RECOMMENDATIONS . . . . . . . . . . . . 104

5.1. Conclusions .................. . . 104

5.2. Recommendations ................ 106 APPENDIX A: DERIVATION OF SHEAR RATIO FORMULAS FOR BLOWDOWN
CALCULATIONS . . . . . . . . . . . . . . 107

$\begin{array}{ll}\text { APPENDIX B: } & \text { REVIEW OF THE MATHEMATICAL MODEL EMPLOYED BY THE } \\ & \text { PAD CODE . . . . . . . . . . . . . . . . . . . } 114\end{array}$

APPENDIX C: APPLICATION OF PAD CODE TO BMI DEPOSITION OF RESULTS • • 125

APPENDIX D: PAD MODELING OF THE DRAGON HTGR . . . . . . . . . . 140 
APPENDIX E: PAD MODELING OF THE CS-137 DISTRIBUTION IN THE PEACH BOTTOM HTGR . . . . . . . . . . . . . . 150

APPENDIX F: DERIVATION OF CESIUM SORPTION ISOTHERMS . . . . . . . 158 ACKNOWLEDGMENTS . . . . . . . . . . . . . . . . . . 162 REFERENCES ............................ 163

\section{FIGURES}

1. GA Fission product deposition loop . . . . . . . . . . . 3

2. Deposition loop (no chill block) . . . . . . . . . . . . 13

3. Deposition loop and autoclave (horizontal position for loading) . . . . . . . . . . . . . . . . . . 14

4. Deposition loop (with chill block) . . . . . . . . . . 15

5. Details of copper chill block for deposition loop . . . . . . . . 16

6. Details of deposition loop source heater . . . . . . . . . . 17

7. As built source heater . . . . . . . . . . . . . . . 18

8. Fission product deposition loop pneumatic system . . . . . . . . 20

9. Five-foot vertical autoclave power supply and control system . . 21

10. Five-foot vertical autoclave electrical control console . . . . 22

11. Source heater and loop blower controls . . . . . . . . . . 23

12. Loop and autoclave pneumatic control system . . . . . . . . . . . 24

13. Temperature monitoring console . . . . . . . . . . . . 25

14. GA blowdown apparatus . . . . . . . . . . . . . . . . 29

15. Modified GA blowdown apparatus . . . . . . . . . . . . . 30

16. Details of sample holding fixture . . . . . . . . . . . . . 31

17. Filter holder with $0.3 \mu$ Millipore paper . . . . . . . . . . . 32

18. Cs-137 plateout distribution, loop No. 1 . . . . . . . . . 39

19. Sr-85 and $\mathrm{Cs}-137$ plateout distribution, dust added . . . . . 40

20. I-131 plateout distribution . . . . . . . . . . . . . . 41

21. Cs-137 plateout distribution . . . . . . . . . . . . 42

22. Sr-85 plateout distribution, graphite corrosion . . . . . . . . 43

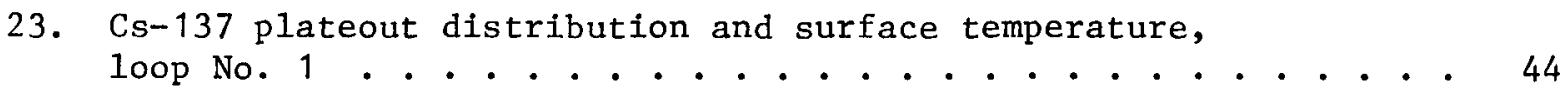

24. Plateout distribution and surface temperature for deposition

25. Plateout distribution and surface temperature, loop No. 3. . . 46 
FIGURES (Continued)

26. Plateout distribution, loop No. 4. . . . . . . . . . . 47

27. Pipe sections from GA in-pile loop, blowdown duration -

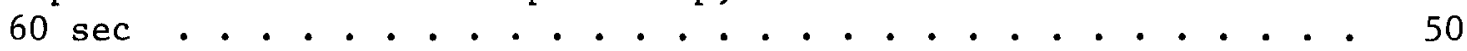

28. I-131 blowdown results, loop No. 3 . . . . . . . . . . . 54

29. Cs-137 blowdown results, loop No. 4............. . 55

30. Sr-85 blowdown results, loop No. 5 . . . . . . . . . . 56

31. Comparison of $\mathrm{Cs}-137$ blowdown results . . . . . . . . . . . 60

32. PAD code simulation of loop No. 1. . . . . . . . . . . . 63

33. PAD code simulation of loop No. 2 . . . . . . . . . . . . . 64

34. PAD code simulation of loop No. 3............... . 65

35. PAD code simulation of loop No. 4.............. . 66

36. PAD code simulation of loop No. 5 . . . . . . . . . . . 67

37. Distribution of $\mathrm{Ba}-\mathrm{La} 140$ and $\mathrm{Ce}-141+\mathrm{Ce}-144$ activity in portions of experiment 10 loop . . . . . . . . . . . . 72

38. Distribution of $\mathrm{Zr}-95$ and $\mathrm{Ru}-103$ activity in portions of experiment 10 loop . . . . . . . . . . . . . . . 73

39. Distribution of $\mathrm{Cs}-137$ and $\mathrm{Te}-129$ activity in portions of experiment 10 loop ................... 74

40. Distribution of I-131 activity in portions of experiment 10 loop....................... 75

41. Distribution of Ba-La 140 and $\mathrm{Ce}-141+\mathrm{Ce}-144$ activity in portions of experiment 10 loop . . . . . . . . . . . . 77

42. Distribution of $\mathrm{Zr}-95$ and $\mathrm{Ru}-103$ activity in portions of experiment 10 loop . . . . . . . . . . . . . . . 79

43. Distribution of $\mathrm{Cs}-137$ and $\mathrm{Te}-129$ activity in portions of experiment 10 loop . . . . . . . . . . . . . . 80

44. Distribution of I-131 activity in portions of experiment 10 loop . . . . . . . . . . . . . . . . . . . 81

45. Plateout of $\mathrm{Cs}-137$ in Dragon primary circuit . . . . . . . 82

46. Cs-137 plateout in Peach Bottom . . . . . . . . . . . . 85

47. Cs-137 plateout in Peach Bottom . . . . . . . . . . . . 86

A-1. Section of loop tubing . . . . . . . . . . . . . . 108

A-2. Modified blowdown geometry . . . . . . . . . . . . . 108

B-1. Basic mass-transport volume element . . . . . . . . . . . . 115

C-1. Layout of experiment 10 loop-section numbers . . . . . . . . 126

$\mathrm{C}-2$. Distribution of gross gamma activity in experiment 10 loop . . . 129 


\section{FIGURES (Continued)}

D-1. General assembly of Dragon reactor . . . . . . . . . . . 141

D-2. Positions of swab samples from heat exchanger $E$ and circulator E . . . . . . . . . . . . . . . . . . . 142

D-3. Heat exchangers $\mathrm{C}$ and E Cs-137 deposition profiles . . . . . . 148

E-1. Isometric of Peach Bottom primary coolant system . . . . . . . . 151

F-1. Deposition of cesium on 304 stainless stee1 . . . . . . . . . . . 159

F-2. Deposition of cesium on oxidized 304 stainless steel . . . . . 160

\section{TABLES}

1. Comparison of operating conditions for deposition loop and $1160 \mathrm{MW}(\mathrm{e}) \mathrm{HTGR}$. . . . . . . . . . . . . . . . . . 11

2. Summary of deposition loop experiments . . . . . . . . . 35

3. GAIL IV operating conditions . . . . . . . . . . . . . . 36

4. GAIL IV blowdown/wipedown results............. . 49

5. Blowdown test results . . . . . . . . . . . . . . 51

6. Wipedown test results . . . . . . . . . . . . . . . 53

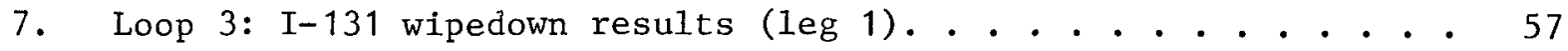

8. Loop 4: Cs-137 wipedown results (1eg 2) . . . . . . . . . . 58

9. Loop 5: Sr-85 wipedown results . . . . . . . . . . . . . . 59

10. Comparison of wipedown results . . . . . . . . . . . . . 61

C-1. Operating parameters for fission-product deposition experiment 10 . . . . . . . . . . . . . . . 130

D-1. Dragon primary circuit . . . . . . . . . . . . . . 144

$\mathrm{D}-2$. Deposition on heat exchangers $\mathrm{C}$ and $\mathrm{E}$ and circulators $\mathrm{C}, \mathrm{E}$, and $\mathrm{D}$ as measured on swabs ................ 146

D-3. Fractional release on fission products into the primary circuit...................... 149

E-1. Summary of activities found on Peach Bottom primary circuit large ducts - 1971 . . . . . . . . . . . . . . . 152

E-2. Summary of activities found on Peach Bottom primary circuit large ducts -1972 . . . . . . . . . . . . . . . 153

E-3. Cs-137 partial pressures from diffusion probes . . . . . . . 156 


\section{INTRODUCTION}

The transport behavior of fission products in the primary coolant of a high-temperature gas-cooled reactor (HTGR) is of fundamental importance to reactor design and safety analysis. For example, the amount and distribution of fission products in the primary circuit influence shielding requirements, maintenance procedures, and shipping requirements. In addition, the reentrainment of plateout activity during a hypothesized depressurization accident can contribute significantly to the total release of radioactivity to the environment. Therefore, a thorough understanding of the deposition and re-entrainment characteristics of condensible fission products in flowing helium is essential as are adequate analytical tools for correlation and prediction of transport behavior. Unfortunately, these phenomena are so complex that reliance on empirical methods is presently required. The purpose of this report is to develop these empirical methods and to outline the experimental evidence on which they are based.

The importance of fission product deposition and re-entrainment has long been recognized at General Atomic Company. Both experimental and theoretical investigations have been undertaken to elucidate the transport behavior of fission product nuclides. Among the earliest experimental programs were a series of liftoff tests performed on pipe sections taken from the General Atomic In-pile Loop (GAIL; Ref. 1). A simple apparatus was constructed to subject pipe specimens (about 2 in. Iong) to considerably higher wall shear stresses than those that prevailed during normal loop operation; information on the re-entrainment characteristics of plateout was inferred from the amount of activity lifted off. It was observed that the liftoff fraction (fraction removed) increased approximately linearly with the shear ratio (defined as the ratio of the steady state wall shear stress under blowdown conditions to that under normal loop operating conditions). Cs-137 appeared to be the most tenaciously held nuclide with only $3 \%$ of the deposited activity blown off at a shear ratio of 7.5 . Under 
comparable conditions, $48 \%$ of the $\mathrm{Ce}-144$ was removed; the re-entrainment of $\mathrm{Sr}-90$ was intermediate $(28 \%$ removed). Since the maximum calculated shear ratios for postulated depressurization accidents in an HTGR are about 1.2 , it is predicted that very modest amounts of plateout activity will be lifted off $(\leq 1 \%)$ under these conditions. Results of these measurements were reported previously (Ref. 2).

To investigate further transport behavior, an out-of-pile fission product deposition loop was constructed at $\mathrm{GA}$, and a series of deposition experiments was performed under conditions approaching those in the evaporator-economizer sections of an HTGR steam generator [these sections account for about $36 \%$ of the total plateout surface area in the primary circuit of a $1160 \mathrm{IN}(\mathrm{e}) \mathrm{HTGR}$. High pressure helium (about $20 \mathrm{~atm}$ ) circulated in fully developed turbulent flow (Re $\geq 10,000$ ) in a closed loop. The loop was constructed from a 0.93 in. i.d. tube of low alloy steel (T2 - 1/2 Cr, 1/2 Mo). As shown schematically in Fig. 1, the entire loop assembly was inserted into a high-pressure, high-temperature autoclave. Four large autoclave heaters were the primary heat source for the assembly; loop surface temperatures ranged from a low of about $50^{\circ} \mathrm{C}$ when a water-cooled chill block was clamped to portions of the loop tubing to a high of about $500^{\circ} \mathrm{C}$ when the chill block was omitted.

Deposition of cesium, strontium, and iodine was investigated. Cesium tagged with Cs-137 and strontium tagged with Sr-85 impregnated on graphite powder and $\mathrm{PdI}_{2}$ tagged with $\mathrm{I}-131$ were used as source materials; the sources were loaded in porous graphite crucibles. These charged crucibles (typically, five in number) were then placed in an electrical resistance source heater located centrally in the helium flow path. Evaporation of the source material from the graphite surfaces into the flowing helium provided a realistic source of fission product nuclides.

The main objectives of this deposition loop program were to obtain plateout distribution data and to provide specimens for subsequent blowdown 
comparable conditions, $48 \%$ of the Ce-144 was removed; the re-entrainment of Sr-90 was intermediate ( $28 \%$ removed). Since the maximum calculated shear ratios for postulated depressurization accidents in an HTGR are about 1.2, it is predicted that very modest amounts of plateout activity will be lifted off $(\leq 1 \%)$ under these conditions. Results of these measurements were reported previously (Ref. 2).

To investigate further transport behavior, an out-of-pile fission product deposition loop was constructed at GA, and a series of deposition experiments was performed under conditions approaching those in the evaporator-economizer sections of an HTGR steam generator [these sections account for about $36 \%$ of the total plateout surface area in the primary circuit of a 1160 IN(e) HTGR]. High pressure helium (about 20 atm) circulated in fully developed turbulent flow (Re $\geq 10,000$ ) in a closed loop. The loop was constructed from a $0.93 \mathrm{in.}$ i.d. tube of low alloy steel ( $\mathrm{T} 2-1 / 2 \mathrm{Cr}, 1 / 2 \mathrm{Mo}$ ). As shown schematically in Fig. 1, the entire loop assembly was inserted into a high-pressure, high-temperature autoclave. Four large autoclave heaters were the primary heat source for the assembly; loop surface temperatures ranged from a low of about $50^{\circ} \mathrm{C}$ when a water-cooled chill block was clamped to portions of the loop tubing to a high of about $500^{\circ} \mathrm{C}$ when the chill block was omitted.

Deposition of cesium, strontium, and iodine was investigated. Cesium tagged with Cs-137 and strontium tagged with Sr-85 impregnated on graphite powder and $\mathrm{PdI}_{2}$ tagged with $\mathrm{I}-131$ were used as source materials; the sources were loaded in porous graphite crucibles. These charged crucibles (typically, five in number) were then placed in an electrical resistance source heater located centrally in the helium flow path. Evaporation of the source material from the graphite surfaces into the flowing helium provided a realistic source of fission product nuclides.

The main objectives of this deposition 1oop program were to obtain plateout distribution data and to provide specimens for subsequent blowdown 

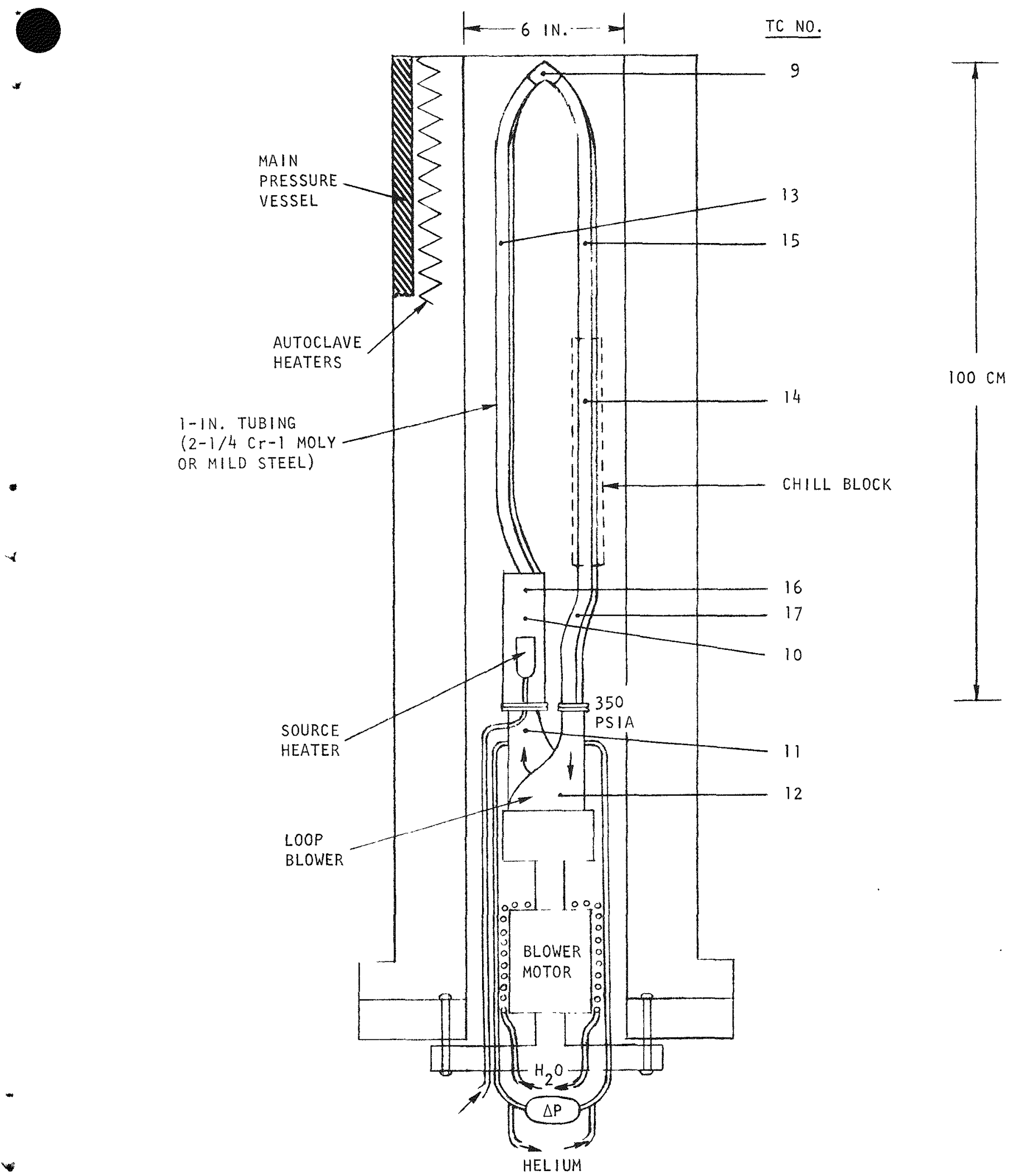

Fig. 1. GA Fission product deposition loop 
tests. These tests were performed with the same blowdown apparatus used for the GAIL tests described earlier. Preliminary results of these plateout and liftoff experiments have been reported periodically in HTGR Base Program Quarterly Progress Reports (Refs.3-7). One of the main objectives of this document is to summarize the loop plateout data and all blowdown data, including the GAIL data, under one heading.

In addition to the integral testing outlined above, complementary differential laboratory experiments have also been performed at GA. of these experiments, the static sorption measurements are probably most relevant to the elucidation of deposition phenomena. It has been observed in the laboratory and in out-of-pile loops that at elevated temperatures $\left(>400^{\circ} \mathrm{C}\right.$ ) graphite and steel surfaces have a limited capacity for certain condensible fission product nuclides; i.e., at a given partial pressure of, for example, iodine over carbon steel at a given surface temperature, there exists an equilibrium surface concentration beyond which no further accumulation occurs. Experiments have been performed at GA to characterize the sorption of iodine on the low alloy steel T2 (Ref. 8) and of cesium on SS304 stainless steel and on carbon steel (Refs. 9, 10). While considerably more sorption work is required to define the sorptivities of pertinent primary circuit materials under reactor conditions, these initial screening expeximents have clearly demonstrated the nongenerality of the perfect sink assumption for reactor surfaces.

Another laboratory experiment studied the re-entrainment of iodine from a dust-covered steel specimen (Refs. 2, 11). The iodine-dust-stee1 system was equilibrated 14 days before blowdown tests were performed; 1ess than $1 \%$ of the deposited iodine could be blown off with high-velocity helium. Additional tests showed that only $10 \%$ of the iodine was removed when the surface was wiped clean with a tissue. Other experiments measured the desorption rate of iodine at $400^{\circ} \mathrm{C}$ and determined that less than $0.1 \%$ of the plateout iodine would be desorbed during a depressurization accident. 
While experimental programs have been performed to generate physical data, appropriate mathematical models are essential to extrapolate these results for reactor analysis. Since the phenomena are complex and the data are incomplete, GA has necessarily adopted an empirical approach to modeling deposition and re-entrainment processes. The present blowdown model is based upon the presumption that the fractional removal of plateout activity is proportional to the ratio of wall shear stresses under blowdown conditions to those under normal operating conditions. This shear ratio in turn is related to the pressure, temperature, and velocity under the two sets of conditions; details are developed in Appendix A.

The approach taken in modeling deposition is more mechanistic. The transfer of mass from a flowing stream to a surface is essentially a convective mass transfer problem for which a number of theoretical models with a variety of boundary conditions have been offered (Refs. 12-15).

Usually the deposition process is visualized as a two-step process: gaseous diffusion to the wall and a wall effect, typically an adsorption process, because experiments have shown that under certain circumstances surfaces can have a limited capacity for certain fission product species. In the simplest of models, molecules are transported from the bulk stream concentration through a resistance $1 / k$, where $k$ is a mass transfer coefficient analogous to a film heat transfer coefficient, to the interface concentration. From the interface the molecules go to the surface through a resistance $1 / k_{w}$ where $k_{w}$ is a wall coefficient. This wall coefficient describes the effects of imperfect retention at the wall: $k_{w}$ equal to infinity corresponds to a perfect sink condition, and $k_{w}$ equal to zero corresponds to no retention at the surface (Refs. 13, 16).

More sophisticated models have been developed which are mechanistically more satisfying. Raines et a1. (Ref. 14) obtained a finite 
difference solution to the two-dimensional continuity equation in cylindrical coordinates. This solution replaced the gas phase mass transfer coefficient $k$ with a turbulent diffusivity $D_{t}$ but retained the linearized wall coefficient.

On the other hand, the PAD code (Ref. 15) couples the gaseous diffusion process as described by a mass transfer coefficient with an equilibrium sorption process. The assumption is that the kinetics of adsorption are rapid compared to the gaseous diffusion process. The PAD code is a transient one-dimensional mass transfer code; a finite difference solution is obtained for the coupled, nonlinear differential equations describing the conservation of mass with a convective boundary condition. The coolant and surface concentrations are coupled by a concentrationdependent sorption process (either Langmuir or Freundich isotherms may be employed). The code allows for production by precursor decay and treats recirculation in a closed loop. The PAD code has three options for treating deposition: 0 - no sorption (e.g., a nonadsorbing noble gas); 1 no desorption (the surface is a perfect sink; the vapor pressure over the surface is zero for all surface concentrations); and 2 - desorption (an adsorption isotherm is employed such that at a given surface temperature and partial pressure, an equilibrium surface concentration exists beyond which no further accumulation occurs).

The mathematical basis for the PAD code is documented in Ref. 12; however, for convenience, this formulation is reviewed in Appendix $B$.

Obviously, the relative merits of these proposed plateout models are contingent upon their ability to correlate the available experimental plateout data. Indeed, one of the purposes of building the GA deposition loop was to provide data with which to assess the validity of the PAD code. Since initial attempts to model the results of deposition loop experiment 
No. 1 (Ref. 6) were rather unsuccessful, the scope of the investigation was broadened to include a general review of the plateout literature. It was intended that this review would assist in interpretation of the deposition loop data and to provide further opportunities for testing the validity of the PAD code.

Considerable plateout information has been reported in the literature; Silverman and Mills have prepared an excellent bibliography (Ref. 17). Unfortunately, the primary interest in the majority of these studies was fission product release so that typically very little analysis of the plateout data has been reported. There are, however, some notable exceptions.

The following review is not meant to be complete. It is simply a synopsis of that information found useful in attempting to evaluate the deposition loop results and to assess the validity of the PAD code.

Probably the most comprehensive plateout experiments reported to date are those performed by Raines et a1. (Refs. 14, 18) at Batelle Memorial Institute (BMI) in the early 1960s. Helium was circulated at high temperature $\left(300\right.$ to $690^{\circ} \mathrm{C}$ ) and high pressure $(20 \mathrm{~atm})$ through a simple loop constructed of SS316 stainless stee1; fission products were introduced to the helium by an electrically heated specimen of irradiated $\mathrm{UC}_{2}$ fuel. Plateout distributions of Ce-141-144, Ba-La-140, Zr-95, Ru-103, Cs-137, Te129, and I-131 were measured in a high-temperature isothermal zone, a variable-temperature zone, and a low-temperature isothermal zone. Details of the experiments are summarized in Appendix C. In genera1, the profiles showed an exponential decrease in specific activity with increasing distance from the source; however, the behavior of Cs-137 and I-131 was notably different with deposition occurring preferentially in the colder sections of the 1oop. Since the geometry was simple and the operating conditions well known, these loop results afforded an excellent opportunity 
to test the validity of plateout models. To that end, deposition profiles were predicted with the PAD code for comparison with the experimental data; details of the analysis are developed in Appendix C. In general, excellent agreement was obtained by treating the surfaces as perfect sinks for $\mathrm{Zr}-95$, Ru-103, Ce-144, and Te-129 and as imperfect sinks for $I-131$ and Cs-137.

An out-of-pile loop has also been constructed at ORNL (Ref. 17). This loop was designed to study deposition from turbulent helium streams under isothermal conditions. A variety of experiments have been performed including the iodine deposition work of Kress and Neill (Refs, 19, 20). More recently the facility was modified to study the transport of cesium through graphite (Ref, 13).

The most detailed in-pile plateout data available are probably that obtained by Dragon researchers. Considerable data have been obtained by analysis of the primary circuit of the Dragon helium-cooled reactor. Their efforts have included disassembly of primary heat exchangers to measure the plateout distributions of such important fission products as Cs-137 and I131 (see, for example, Refs, 21 and 22). Since much of these plateout data are available in Dragon Project reports, an analysis was made applying the PAD code to predict the distribution of Cs-137 in the Dragon HTGR; details are presented in Appendix $D$. The specific activity in the heat exchangers was predicted to within about $\pm 50 \%$ and in the cold return leg to within a factor of about five.

While the Dragon data are probably the most comprehensive in-pile measurements, some estimates have been made by ORNL personnel of the plateout activity in the Peach Bottom HTGR by external gamma scanning of accessible ducts and by extrapolation of diffusion probe results (see, for example, Ref. 23). While this work has not yet been completed, the subject of plateout is of sufficient importance (and in-pile data of sufficient scarcity) that these tentative results merited analysis. Consequently, the 
Cs-137 distribution was predicted with the PAD code for comparison; details of the modeling are presented in Appendix E. Although some ambiguity exists regarding the total cesium inventory in the primary circuit at the time of the measurements, good agreement was realized between predicted and specific activity in the ducts when assuming about $25 \mathrm{Ci}$ of $\mathrm{Cs}-137$ had been released.

While the above introduction to fission product deposition and reentrainment is by no means exhaustive, it is intended to be sufficiently complete so that the reader may view the subject in the proper context; namely, as a developing field requiring extensive additional experimental work and theoretical analysis before definition of fundamental processes. In that context, the experimental methods employed at GA for deposition and re-entrainment experiments are outlined in Section 2. The results of these experimental programs, with particular emphasis on the GA deposition loop data, are outlined in Section 3 along with the PAD code modeling of the BMI deposition loop and the Dragon and Peach Bottom HTGRs. The results are discussed in Section 4, and the conclusions and recommendations are presented in Section 5. 


\section{EXPERIMENTAL METHODS}

\subsection{DEPOSITION LOOP}

\subsubsection{Design of Deposition Loop}

The primary design criteria for the deposition loop were that HTGR primary circuit thermal and flow conditions be reproduced as much as practicable. In addition, since the loop was to provide specimens for blowdown tests, the design had to facilitate such sample procurement with minimum disturbance of the deposits. Consequent1y, the experimental assembly was constructed so that the plateout loop consisted only of a source, some thin-walled tubing, and a simple blower. The entire 1oop was then enclosed in a 5-ft-long, high-pressure, high-temperature autoclave. The thick-walled piping typically associated with high-pressure loops was thus avoided by operating with a differential pressure across the loop of less than 5 psig; this feature considerably simplified the sectioning of the loop tubing for blowdown specimens. The loop is shown schematically in Fig. 1, and its operating capabilities are compared with commercial HTGR operating conditions in Table 1. Taken as a whole, the deposition loop offers a reasonable representation of the environment of the economizer sections of a large HTGR steam generator.

The basic features of the loop are illustrated in Fig. 1. Helium at 350 psia is circulated by a centrifugal blower with a squirre1 cage impeller. The blower is driven by a small electric motor, which is prom tected from excessive heat by external water-cooling coils. Pressure taps measure the pressure drop across the blower, which has been calibrated to give the flow rate. The fully turbulent gas sweeps over an electrical resistance source heater from which condensible species can be volatilized. The contaminated gas then divides between two parallel legs, which serve as 
TABLE 1

COMPARISON OF OPERATING CONDITIONS FOR DEPOSITION LOOP AND 1160 MW(e) HTGR

\begin{tabular}{|c|c|c|}
\hline Conditions & $\begin{array}{l}\text { Deposition } \\
\text { Loop }\end{array}$ & $1160 \mathrm{MW}(\mathrm{e}) \mathrm{HTGR}$ \\
\hline He pressure (atm) & 23.8 & $49.3($ Peach Bottom $=23.8)$ \\
\hline Reynolds No. & 12,000 & 40,000 (steam generator) \\
\hline He temperature $\left({ }^{\circ} \mathrm{C}\right)$ & $90-500$ & $340-780$ \\
\hline Surface temperature $\left({ }^{\circ} \mathrm{C}\right)$ & $50-500$ & $\begin{array}{l}220-780 \\
(220-425 \text { in } \\
\text { Evap-Econ sections })\end{array}$ \\
\hline Surface material & $\begin{array}{l}\text { Chromaloy } \\
(1 / 2 \mathrm{Cr}, 1 / 2 \mathrm{Mo})\end{array}$ & $\begin{array}{l}\text { Chromaloy } \\
(1 / 2 \mathrm{Cr}, 1 / 2 \text { Mo in } \\
\text { Econ section) }\end{array}$ \\
\hline
\end{tabular}


the primary plateout surfaces; the legs are constructed of 0.93 in. i.d. chromaloy tubing (ASME SA213 GRT2: $1 / 2 \% \mathrm{Cr}, 1 / 2 \% \mathrm{Mo}$ ). After a straight run of about $70 \mathrm{~cm}$, the tubing undergoes a 180-deg bend (accommodated by a 45deg arc, a right angle bend at the apex of the 1oop, and another $45 \mathrm{deg}$ arc) and then proceeds straight for another $70 \mathrm{~cm}$. Two inlet ports return the gas to the common blower housing, which completes the circuit. Each parallel leg of the loop is about $185 \mathrm{~cm}$ long and is replaced after each experiment along with the source heater. Because the blower is used repeatedly, it is contaminated by long-lived Cs-137. Photographs of the as-built loop are shown in Figs. 2 and 3. To allow a wider range of surface temperatures, a water-cooled chill block was clamped to a section of the loop tubing in the first three experiments as shown in Fig. 4. The design is such that the chilled section of the loop is made of a continuous piece of tubing so that no mechanical flow disturbers are introduced. However, as shown in Fig. 5, the chill block did not cover the entire circumference of the tubes because of space limitations; this approach introduces some disturbing uncertainties about the radial temperature distribution in the chill section.

Experiments were performed to characterize the deposition and reentrainment of cesium, strontium, and iodine. Source material - Cs-137 tagged cesium and Sr-85 tagged strontium impregnated on $\mathrm{H} 327$ graphite powder or I-131 tagged $\mathrm{PdI}_{2}$ crystals - was loaded in thin-walled graphite crucibles. The crucibles, typically five in number, were in turn placed in an electrical resistance source heater as shown in Figs. 6 and 7 . The heater element was of $32 \mathrm{mil}$ Nichrome wire, and a centrally-located thermocouple was provided for temperature measurement. The heater was intended for prolonged operation at $1100^{\circ} \mathrm{C}$ to assure adequate strontium evaporation rates; however, heater life was short for operation above $1000^{\circ} \mathrm{C}$. Heater failure lead to early termination of several experiments. Several design changes were instituted but none proved totally satisfactory. 


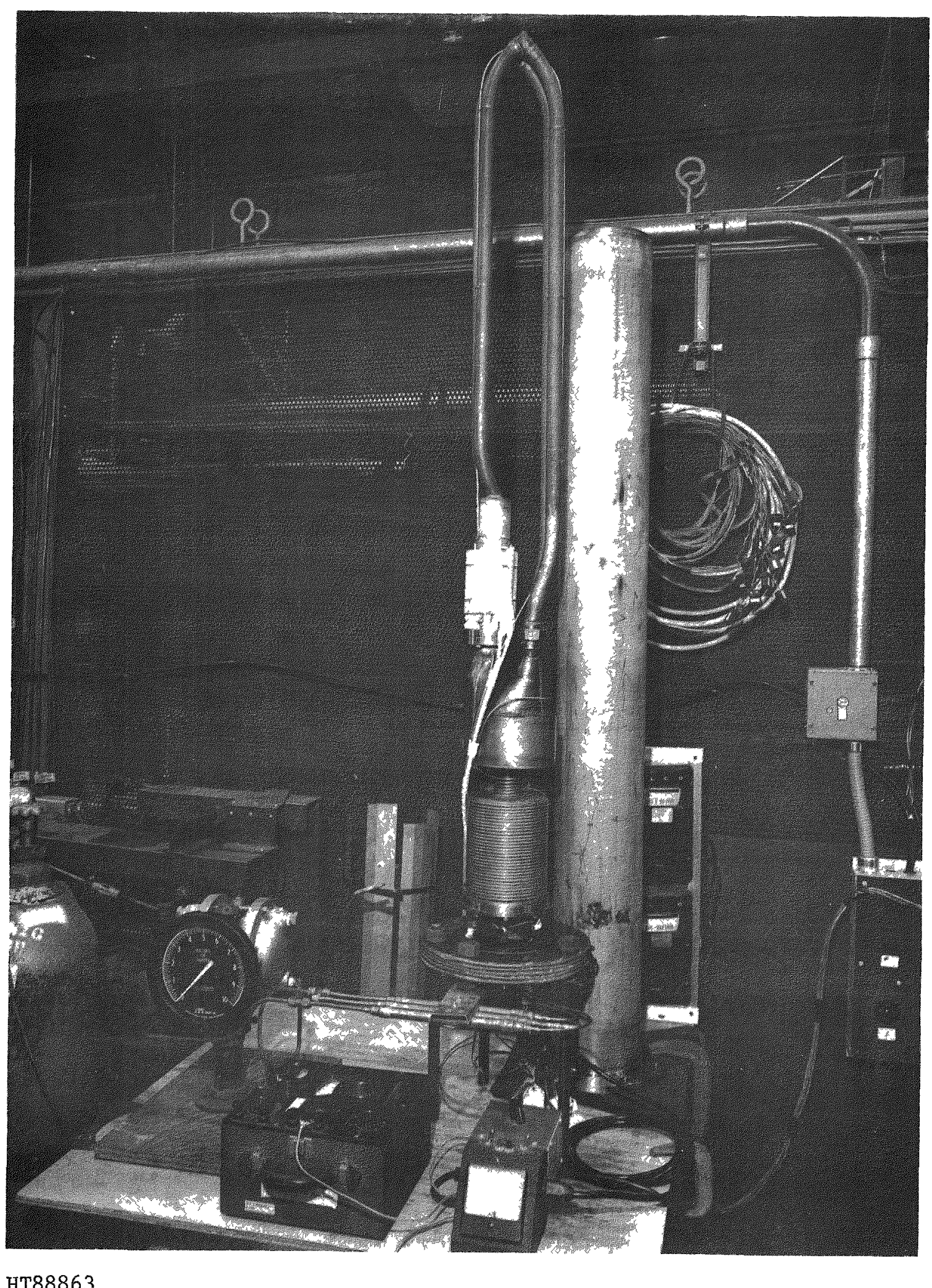

Fig. 2. Deposition 1oop (no chill block) 


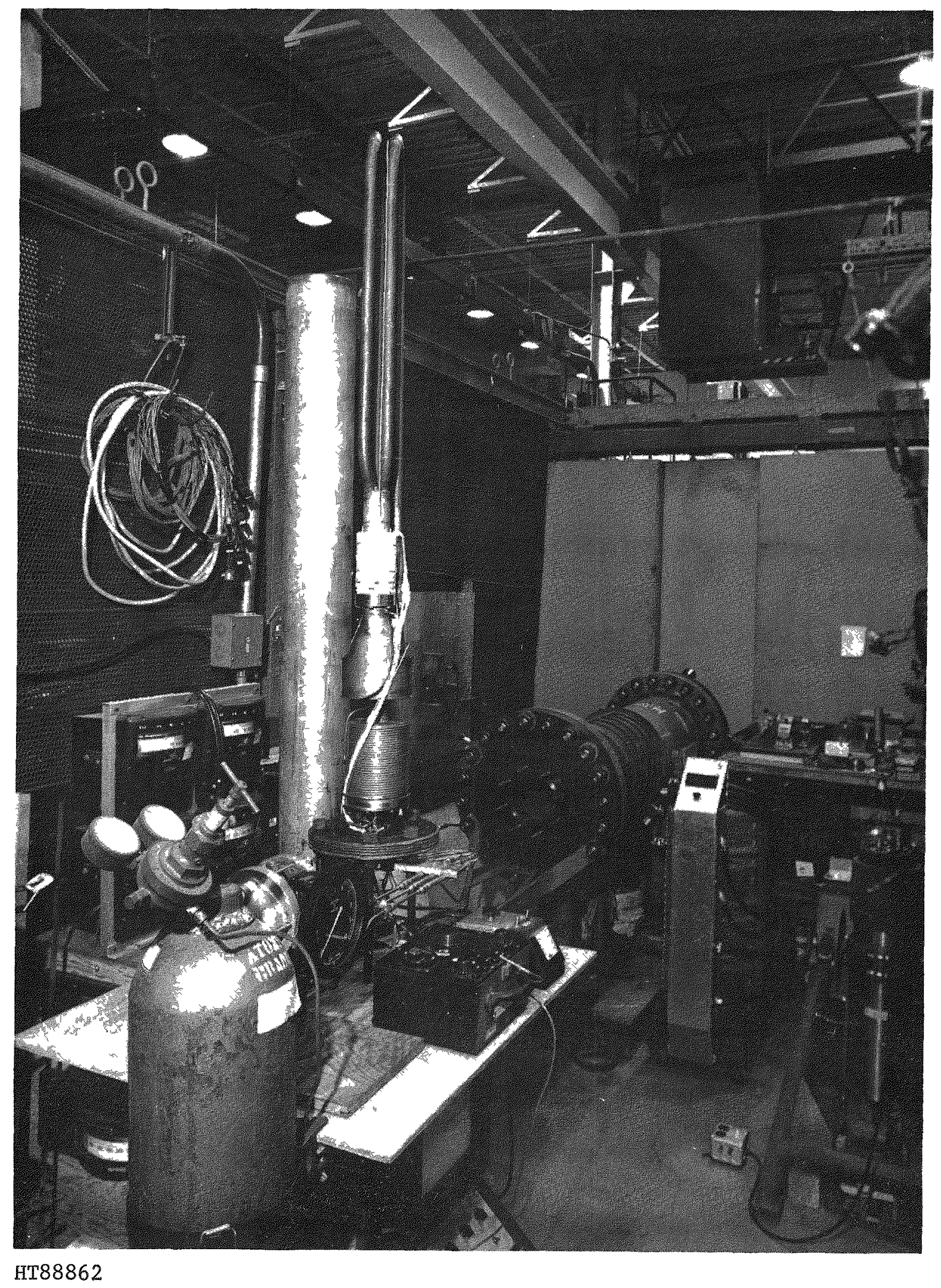

Fig. 3. Deposition loop and autoclave (horizontal position for loading) 


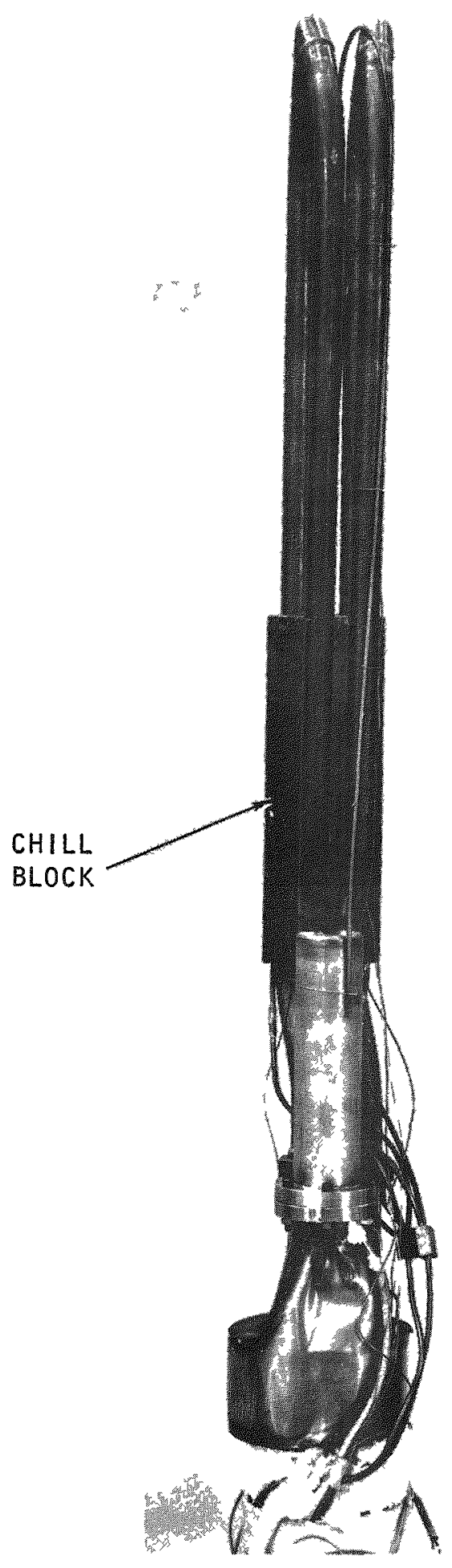

Fig. 4. Deposition loop (with chill block) 
NOTE: HELIUM AT T, $=300-500^{\circ} \mathrm{F}$

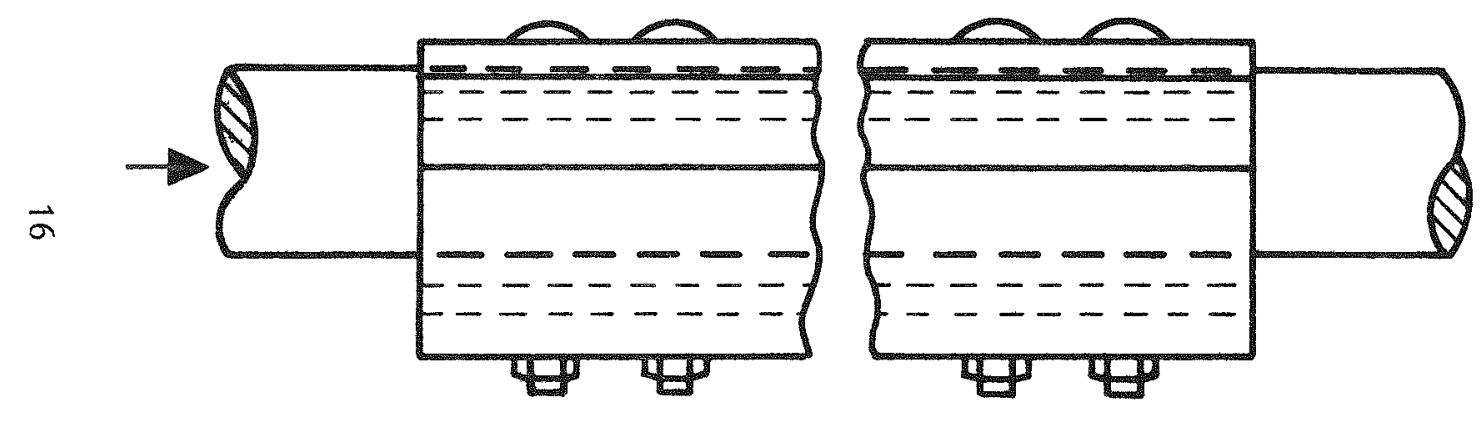

$20.8 \mathrm{iN}$

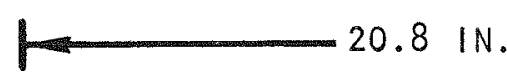

$\mathrm{H}_{2} \mathrm{O}$ COOLANT HOLES
$\%$ SURFACE EXPOSED

$0.875 / \pi=28 \%$

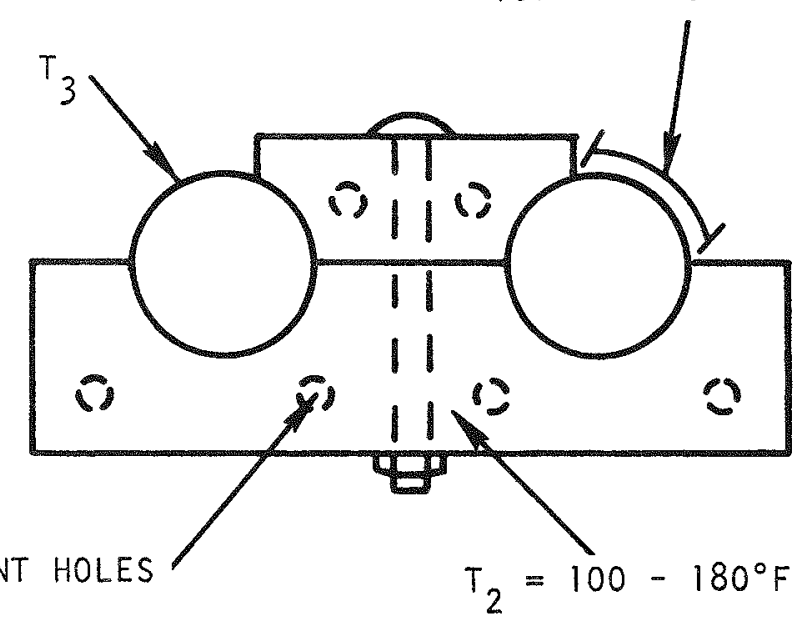

Fig. 5. Details of copper chill block for deposition loop 

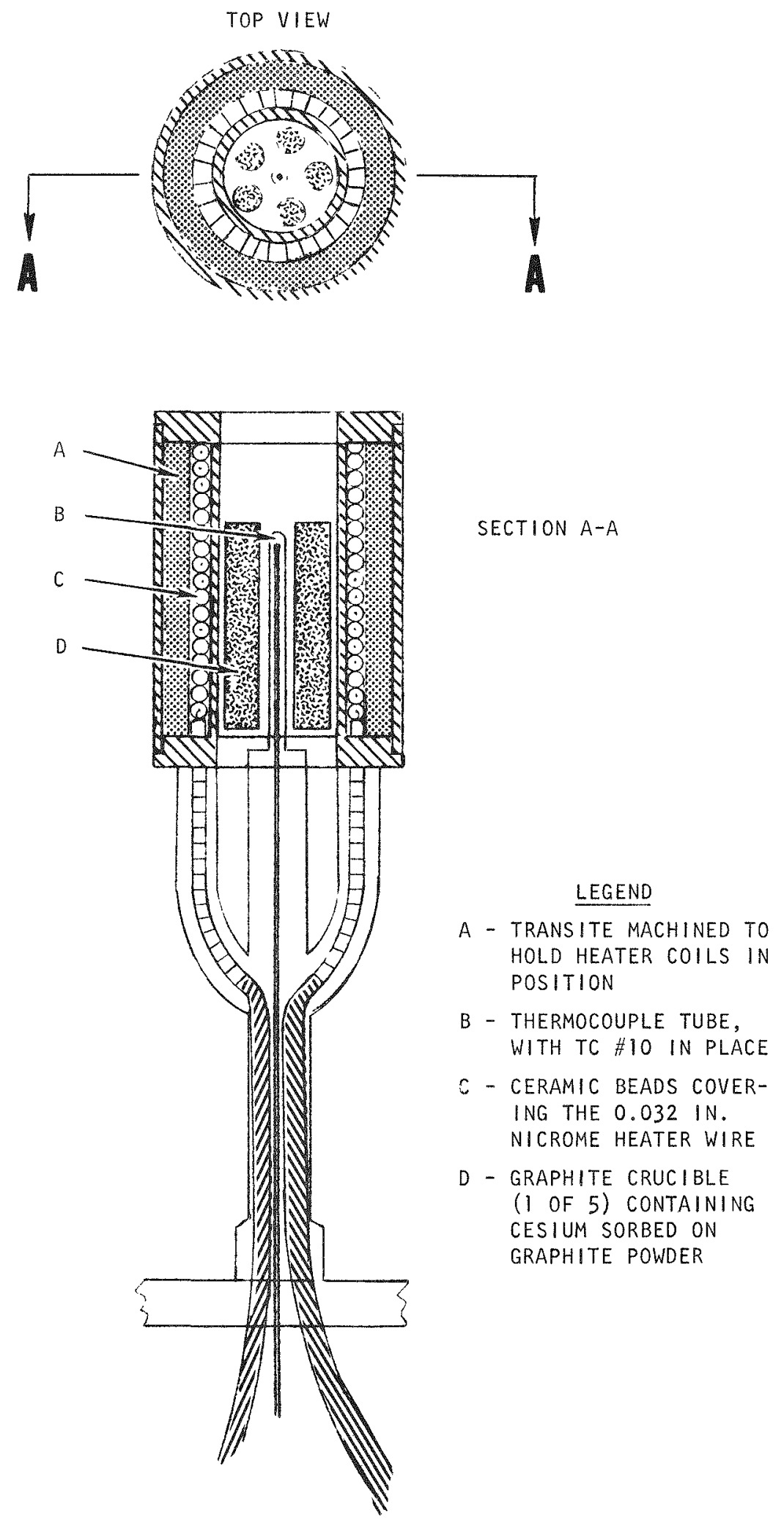

Fig. 6. Details of deposition loop source heater 


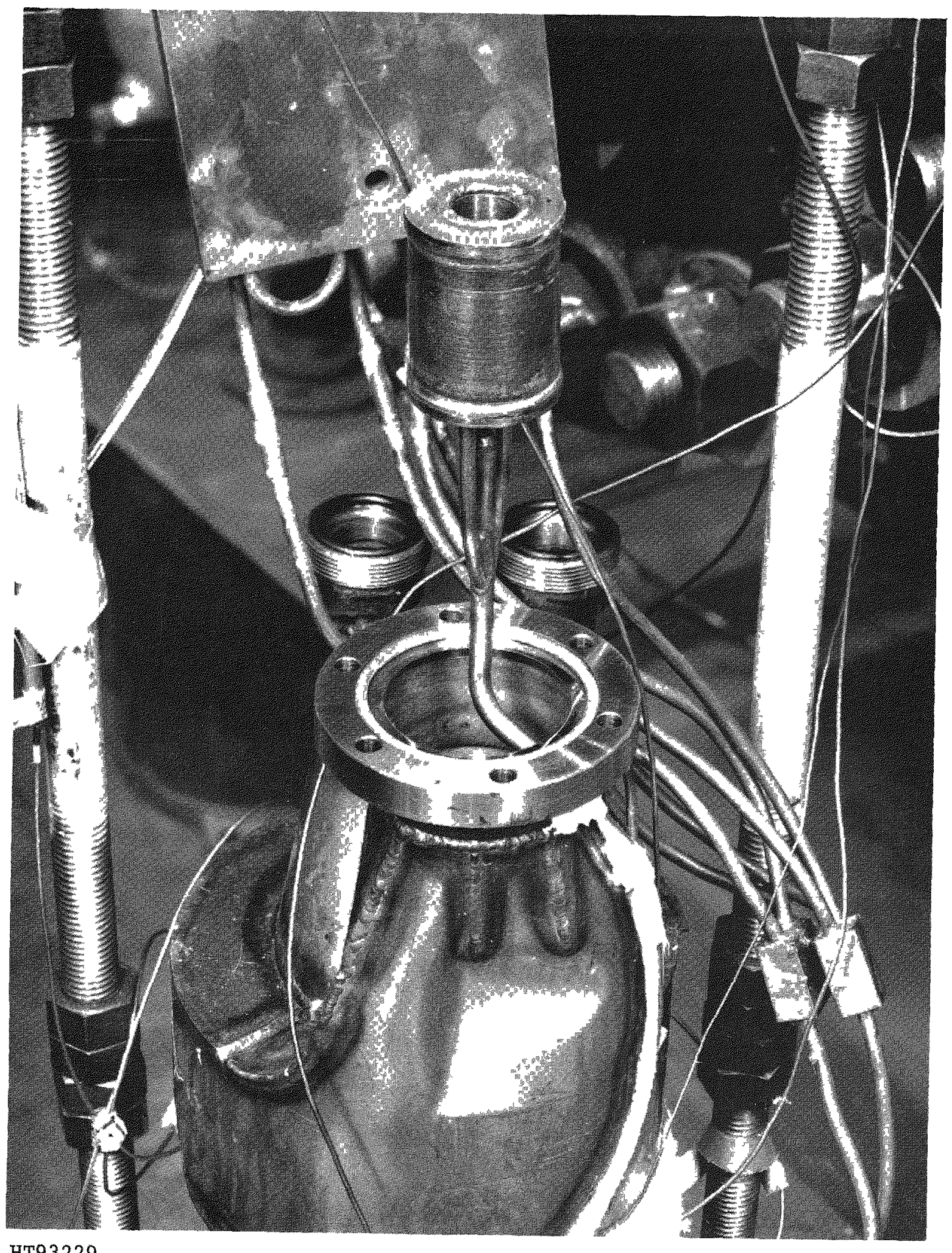

HT93229

F1g. 7. As built source heater 
Upon assembly, the entire loop was mounted in a 5-ft, dual-chambered, vertical autoclave designed to operate at high temperatures and pressures. The outer chamber of the autoclave is a pressure vessel containing four banks of electrical resistance heaters and Kaowool insulation. The inner chamber, containing the deposition loop, is a thin-walled test chamber with an independent atmosphere which is maintained at a small negative pressure differential with respect to the outer chamber. Furthermore, the pressure in the deposition loop can also be regulated Independently. Details of the design and operation of the autoclave have been documented previously (Ref. 24). Therefore, the description given here will be only to the extent considered relevant to the interpretation of the loop data. Schematics of the apparatus' pneumatic control system, the autoclave power supply and control system, and the autoclave electrical control console are repreduced in Figs. 8, 9, and 10, respectively. Photographs of the as-built systems are shown in Figs. 11,12 , and 13.

The pneumatic control system allowed for automatic control of pressures throughout the system by maintaining a specified pressure in the inner chamber (typically 335 psig) and specified negative pressure differentials from the inner to outer chambers ( 4 to 9 psig) and from the inner chamber to the deposition loop ( 3 to $5 \mathrm{psig}$ ). The objective was to limit contamination by assuring that helium leakage was from the inner chamber to the loop. Makeup helium was supplied automatically from a manifold of $1 \mathrm{~A}$ cylinders; Liquid Carbonic Corporation industrial grade helium was used untreated.

Loop and autoclave temperatures were monitored by a series of type $\mathrm{K}$ sheathed thermocouples. All penetrations of the autoclave (except the pressure relief valve) were via the bottom head flange. Consequently, the total number of thermocouples was fixed at 18, of which 8 to 10 were associated with the loop. Temperatures were monitored on a multipoint strip chart recorder. As indicated in Fig. 1, TC No, 10 measured source 


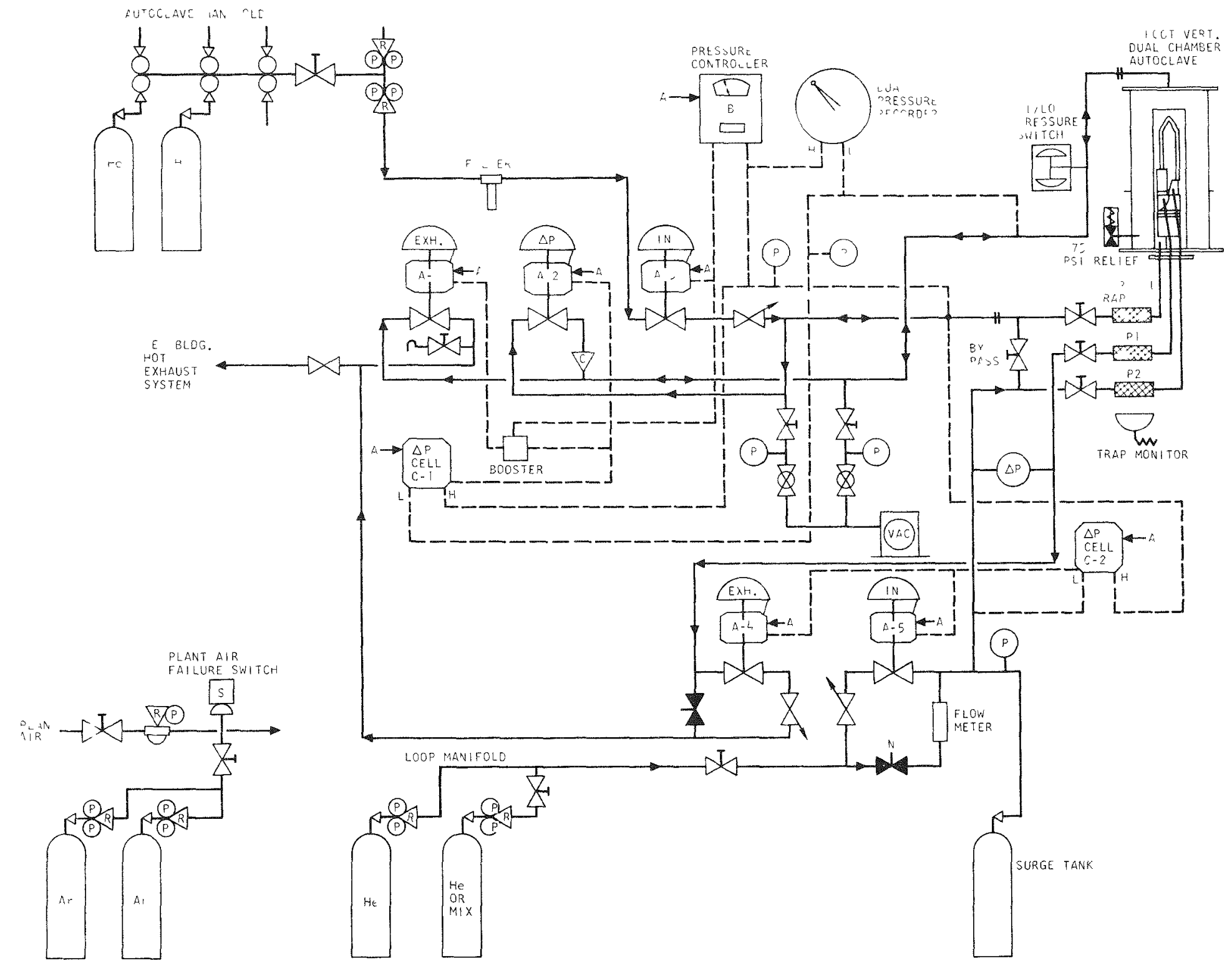

Fig. 8. Fission product deposition loop pneumatic system (Ref. 24) 


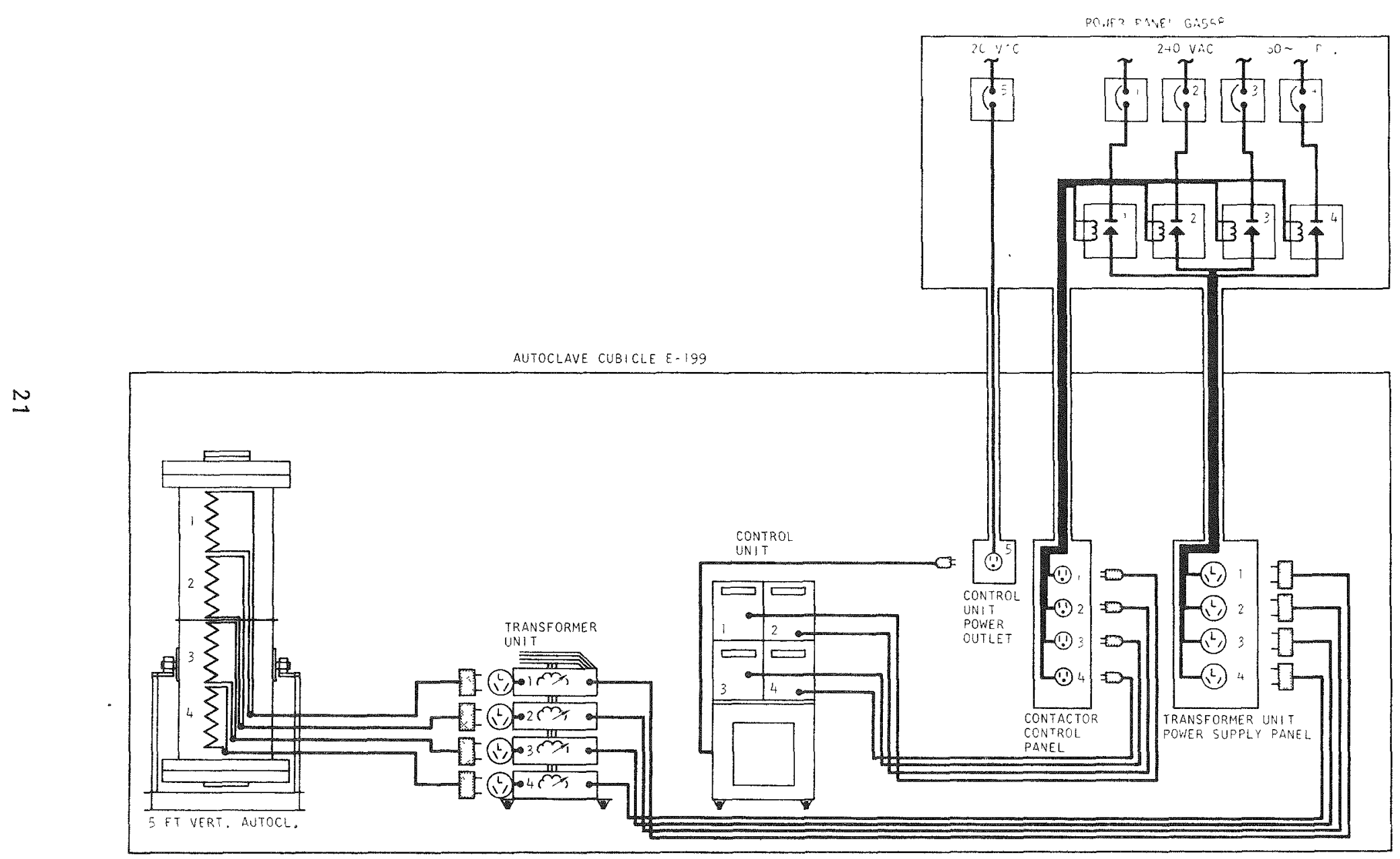

Fig. 9. Five-foot vertical autoclave power supply and control system (Ref. 24) 


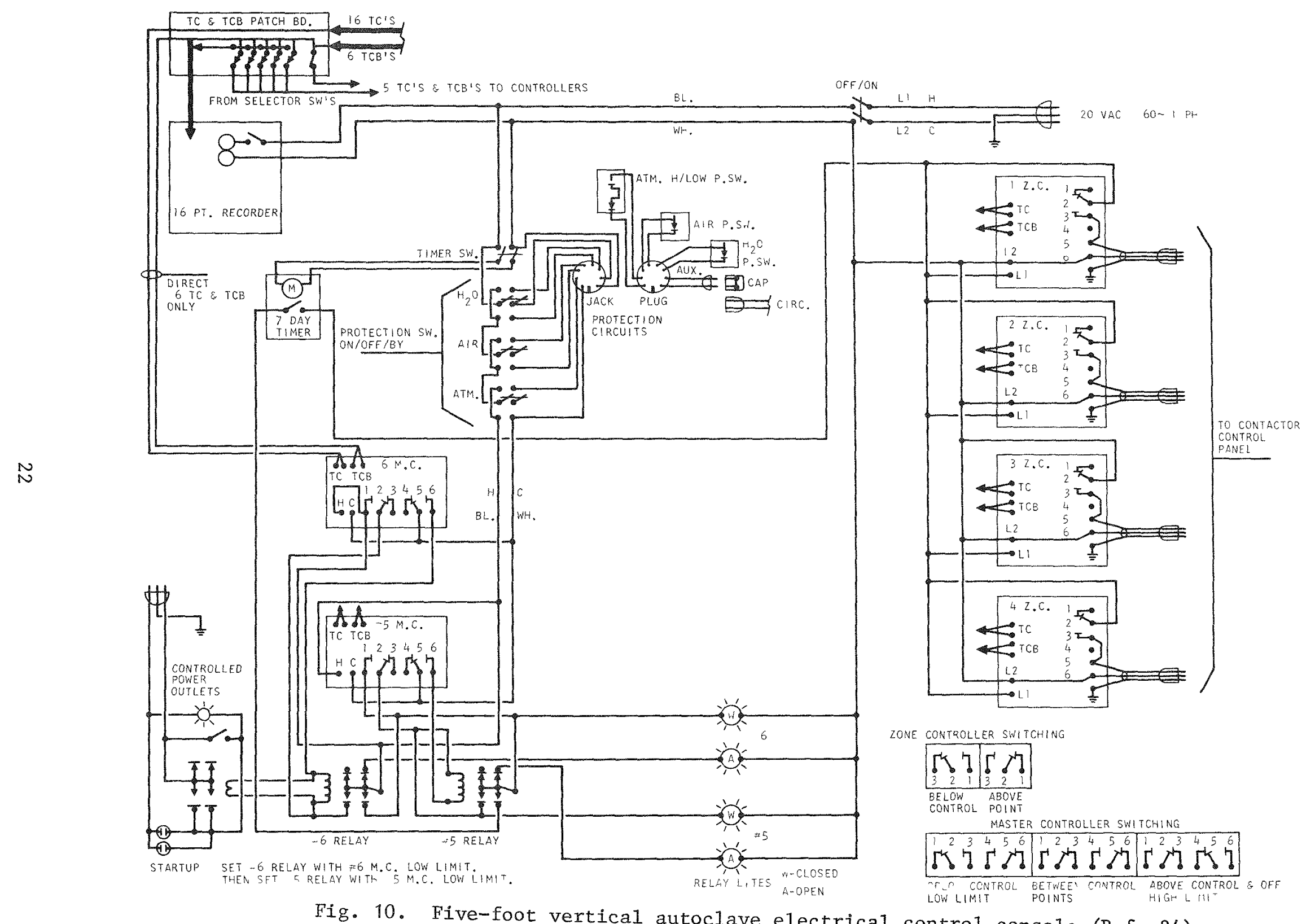

Fig. 10. Five-foot vertical autoclave electrical control console (Ref. 24) 


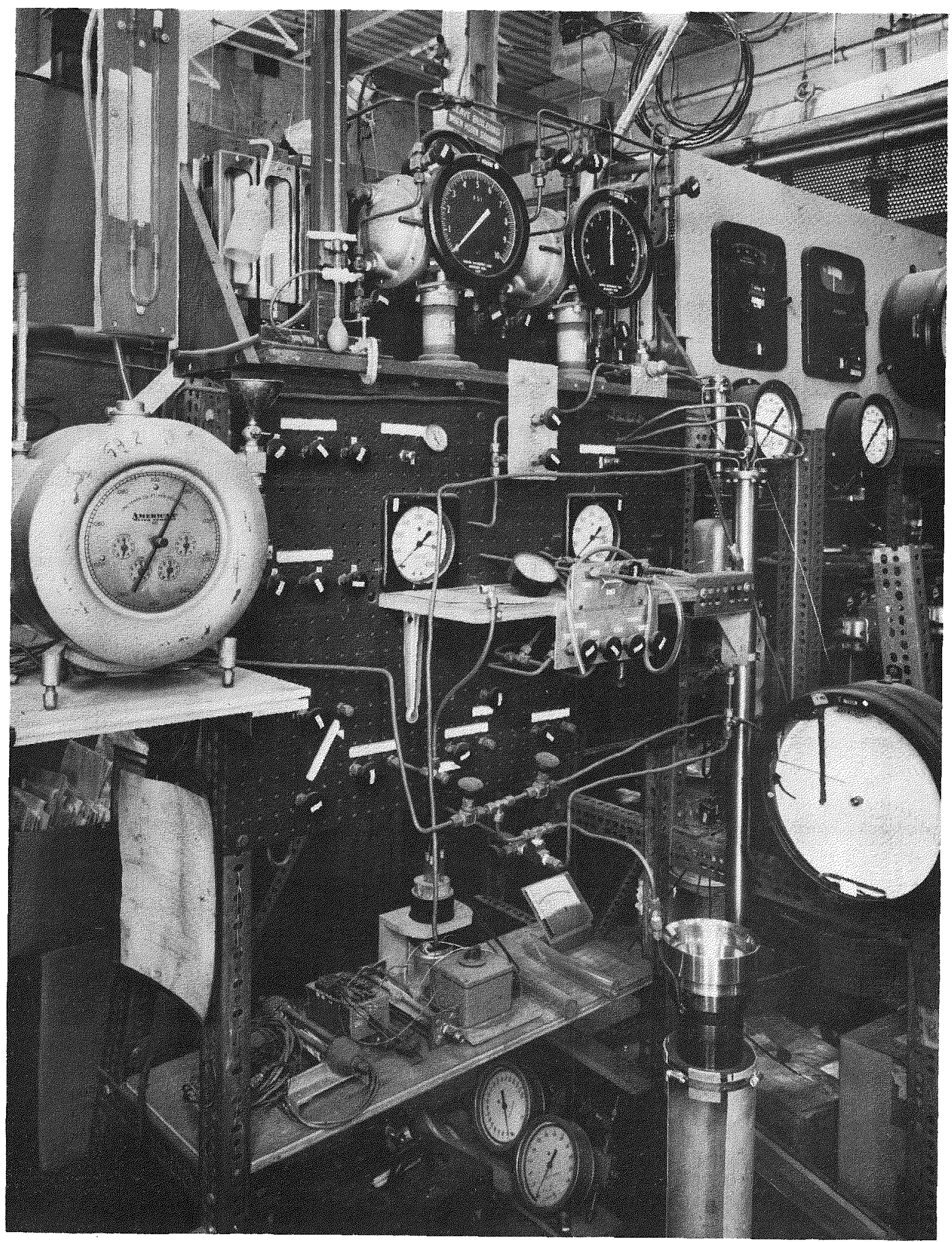

HT93232

Fig. 11. Source heater and loop blower controls 


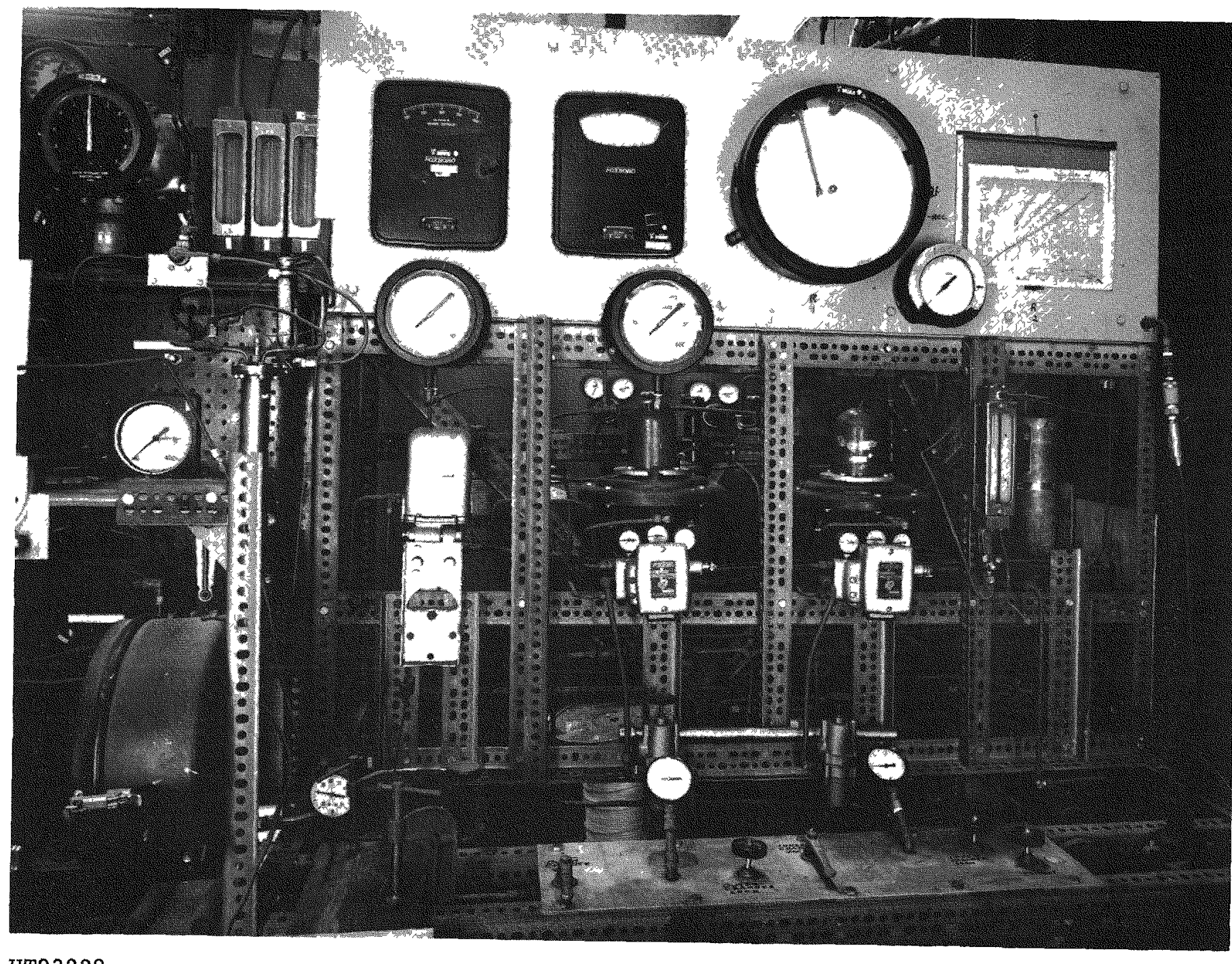

HT93228

Fig. 12. Loop and autoclave pneumatic control system 


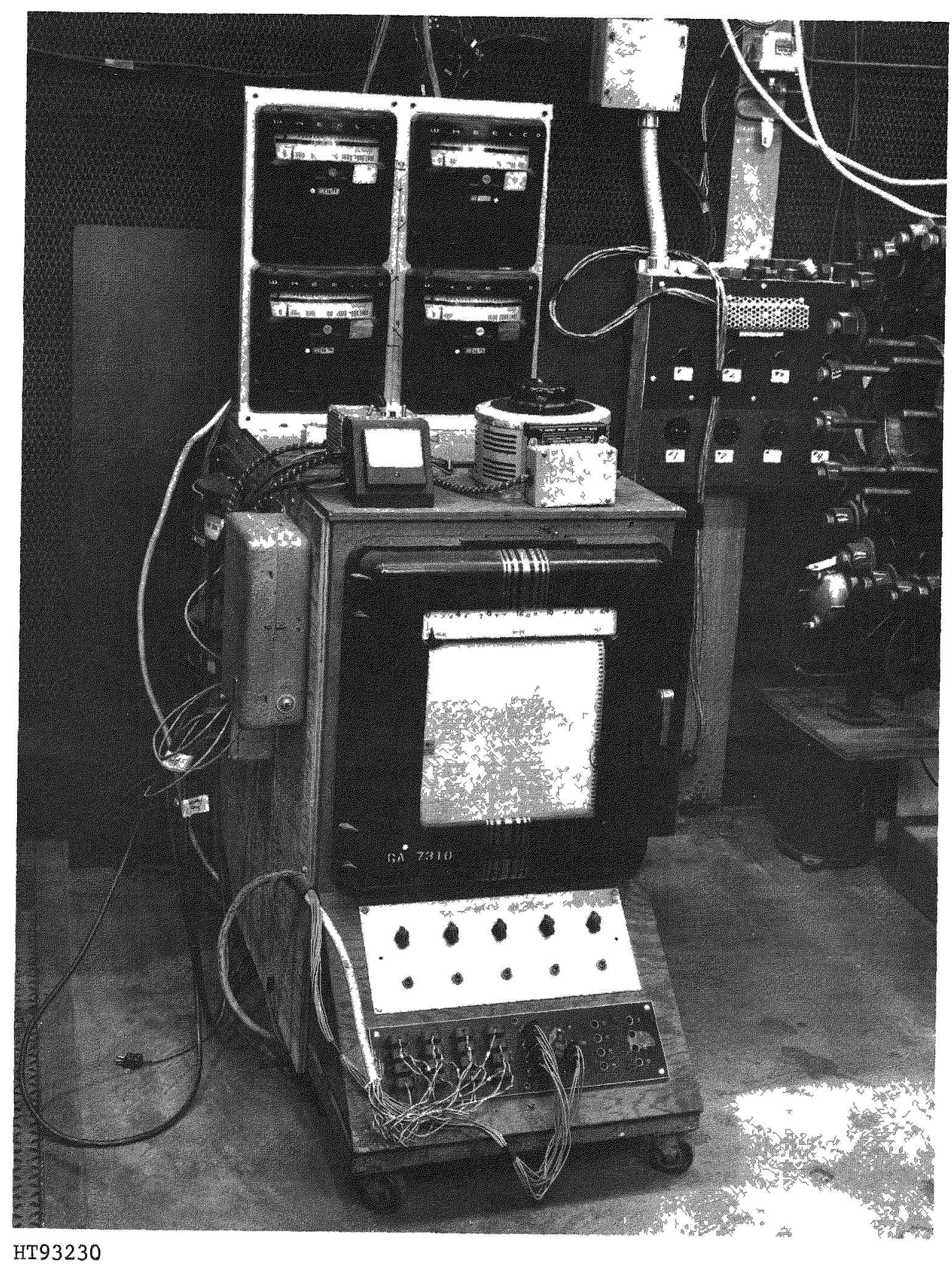

Fig. 13. Temperature monitoring console 
heater temperature and TC No. 11 penetrated the blower housing to measure gas temperature just prior to entry of the source chamber. The remaining six to eight thermocouples were positioned along the two parallel legs of the loop. In the first four experiments they were simply mechanically wired in place. In the fifth (and final) experiment, they were silverbrazed to the loop tubing. In elther case, some inaccuracies could be expected because of radiation and free convective heat transfer in the inner chamber. When the water-cooled chill block was used (Loops 1-3), TC No. 14 was removed from the loop tubing and relocated in a well in the chill block as a safety precaution.

\subsubsection{Operation of Deposition Loop}

The first step in conducting a deposition 1oop experiment was preparation of source material. In the case of cesium or strontium, aqueous solution of stable isotopes tagged with $\mathrm{Cs}-137$ or $\mathrm{Sr}-85$, respectively, were used to impregnate $\mathrm{H} 327$ graphite powder. After drying, the charge was calcined in vacuum at $1400^{\circ} \mathrm{C}$ for $4 \mathrm{hrs}$ to give the corresponding carbide. I-131 tagged $\mathrm{PdI}_{2}$ crystals were purchased from ICN Pharmaceuticals, Inc., Irvine, Ca., and used directly. The source material was then placed in H327 graphite crucibles, which in turn were placed in the source heater.

Construction and assembly of the deposition loop began in parallel with source preparation. As-received T2 tubing was degreased with acetone and 100 sely adherent surface deposits were removed with a fine wire brush. Sections of the loop were formed, washed with acetone, arc-welded, and helium leak-checked. Prior to introduction of the source, the entire loop was assembled and helium leak-checked. Since the clearances between the loop and the inner chamber were excessively small, much effort was expended during each assembly to ensure a proper fit.

At the beginning of the experiment, the source crucibles were placed in the source heater and the loop was sucessively evacuated and backfilled 
with helium three times. After checking for leaks, the loop was mounted in the autoclave and secured in place via the bottom flange. The autoclave was then successively evacuated and backfilled with helium three times. With all heat sources off, the autoclave was manually pressurized to between 175 and 180 psig (at which pressure the automatic control actuates) while making periodic leak checks. Then with the loop blower on and the source heater off, the autoclave heaters were activated and the specified operating conditions were established over a period of several hours. Upon reaching thermal equilibrium, the source heater was turned on, initiating the run.

An experimental run lasted from 3 to 5 days and was typically terminated by component failure - usually the source heater. Thermocouple readings were recorded constantly and loop pressure drop was measured periodically. Most measurements held reasonably constant throughout the run except the source heater temperature. Power input to the source heater was increased periodically throughout the run thereby gradually raising the temperature to maximize the release of source material. Usually the gross migration of activity could be detected by counting along the length of the autoclave outer surface with a GM detector.

Upon termination of an experiment, the system was gradually depressurized and allowed to cool. The loop was then carefully removed from the autoclave. The loop tubing was separated from the blower housing at the flanges and cut into 2-in. sections in a hood with a jeweler's saw. Due care was taken to minimize disturbance of the deposits and to record the identity and orientation of each specimen. The specimens were then counted with a $\mathrm{Ge}(\mathrm{I} i)$ system to determine the plateout activity distribution; some specimens were used for blowdown tests and others for wipedown tests. 


\subsection{DESIGN AND OPERATION OF BLOWDOWN APPARATUS}

The GA blowdown rig is a simple apparatus designed to provide liftoff data by subjecting small sections of contaminated piping to high wall shear stresses. The apparatus was originally constructed to perform tests on specimens from the GAIL-IV in-pile loop (Ref. 2) and, with minor modification, was used later throughout the deposition loop program. Main features are a helium supply provided by two 1A size cylinders manifolded together, coarse and fine flow control valves, full flow rotameter, temperature and pressure gauges, a test specimen holder, full flow filter, and a vent line to a hood. The original apparatus is shown in Fig. 14, and the modified apparatus in Fig. 15. The only changes were the addition of a fine adjustment flow control valve and a second pressure gauge at the inlet of the specimen holder. Details of the specimen holder are shown in Fig. 16. Notice that a concentric plug is inserted in the test specimen to reduce flow area providing high velocities at minimum volumetric flow rates. Finally, the filter holder is shown in Fig. 17. The Millipore filter paper is $14 \mathrm{in}$. in diameter and has a cut size of 0.3 micron.

The execution of a lift-off test was quite simple. A 0.93-in.-i.d. by 2-in.-long section of deposition loop tubing was counted with a Ge(Li) detector. The specimen was placed in the decontaminated sample holder along with a central plug of appropriate diameter (as determined by the desired flow velocity); care was taken to maintain the same direction of flow as prevailed in the loop. A clean filter paper was placed in the filter holder. Control valves were manipulated to establish flow at the desired rotameter setting. The duration of the blowdown was $60 \mathrm{sec}$; typically, 5 to $10 \mathrm{sec}$ were required to establish steady flow conditions. If a significant initial overshoot or large fluctuations were observed on the rotometer, the abnormality was recorded; pressure and temperature were also recorded. Following the blowdown, both the test specimen and the filter paper were removed, visually inspected, and counted. To preserve the counting geometry, the filter paper was carefully wadded up and placed in a 


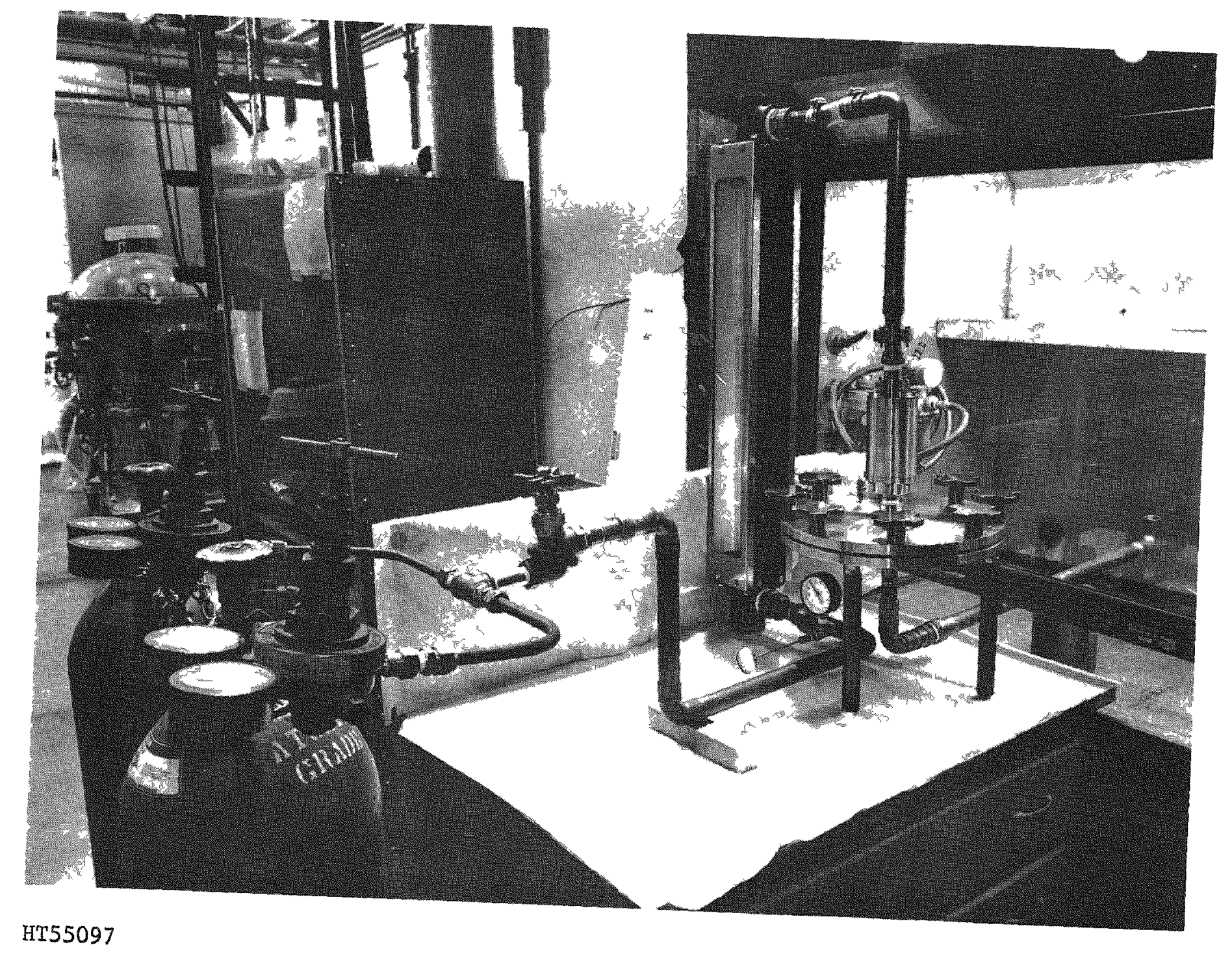

Fig. 14. GA blowdown apparatus 


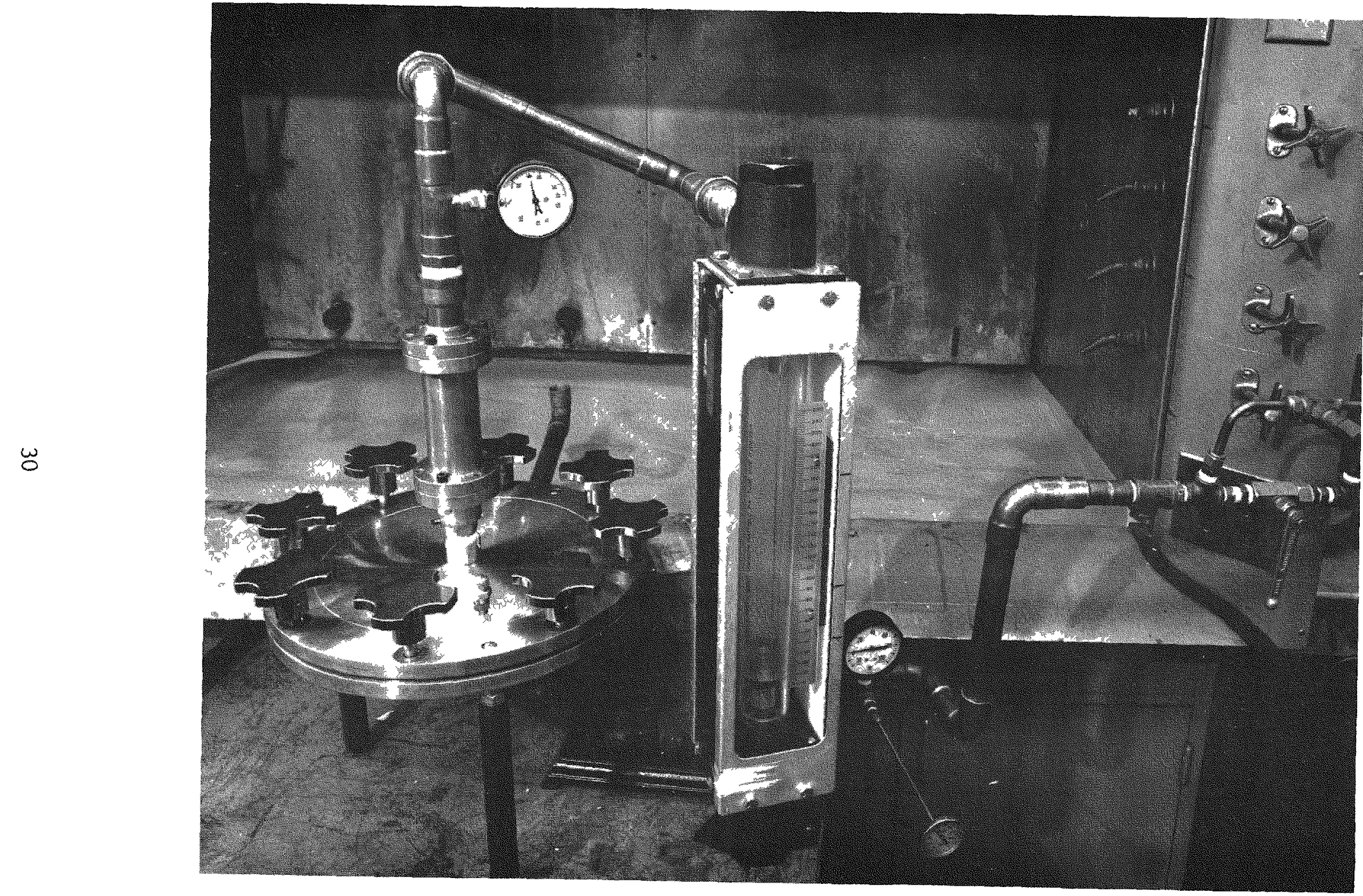

HT93223

Fig. 15. Modified GA blowdown apparatus 


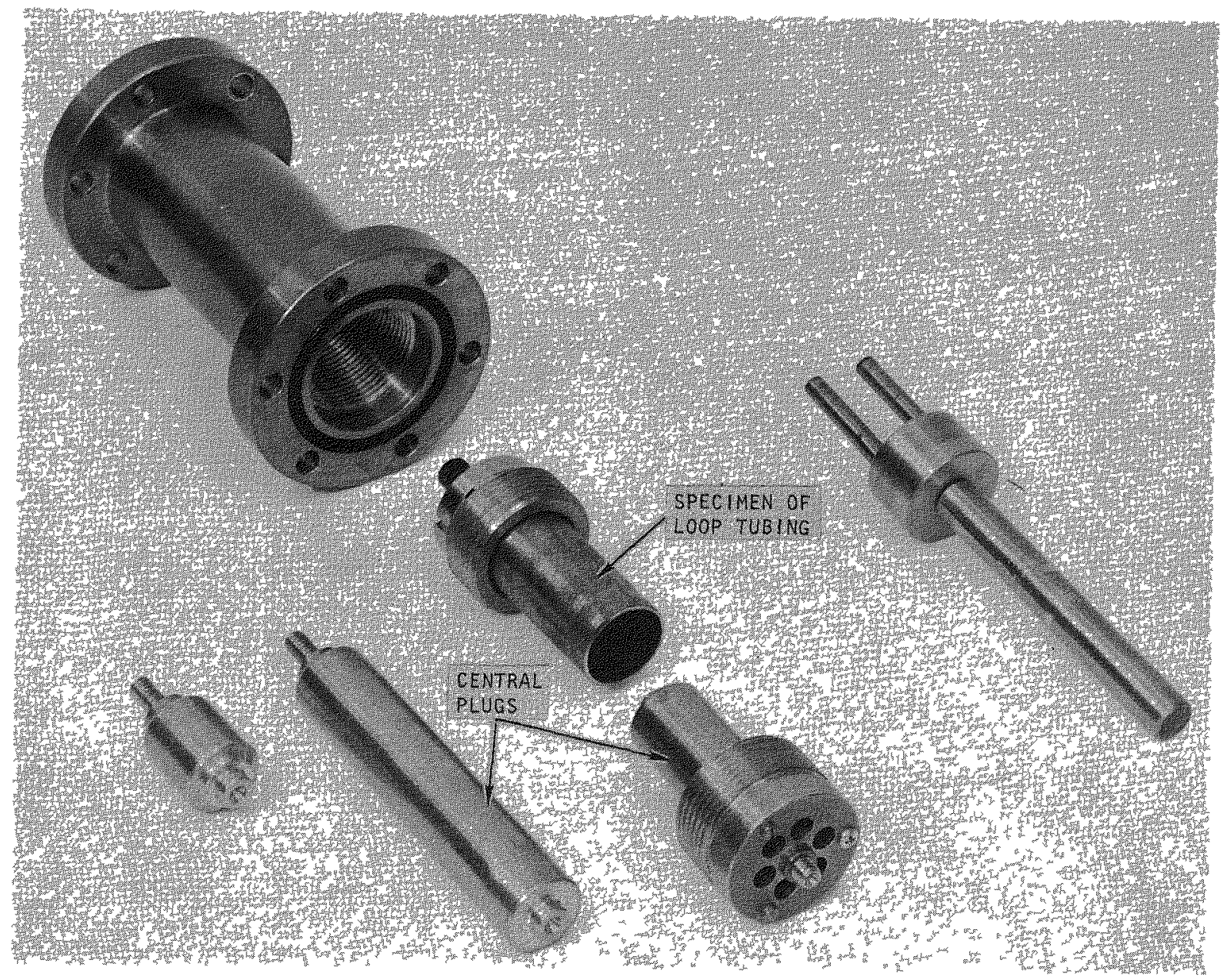

Fig. 16. Details of sample holding fixture 


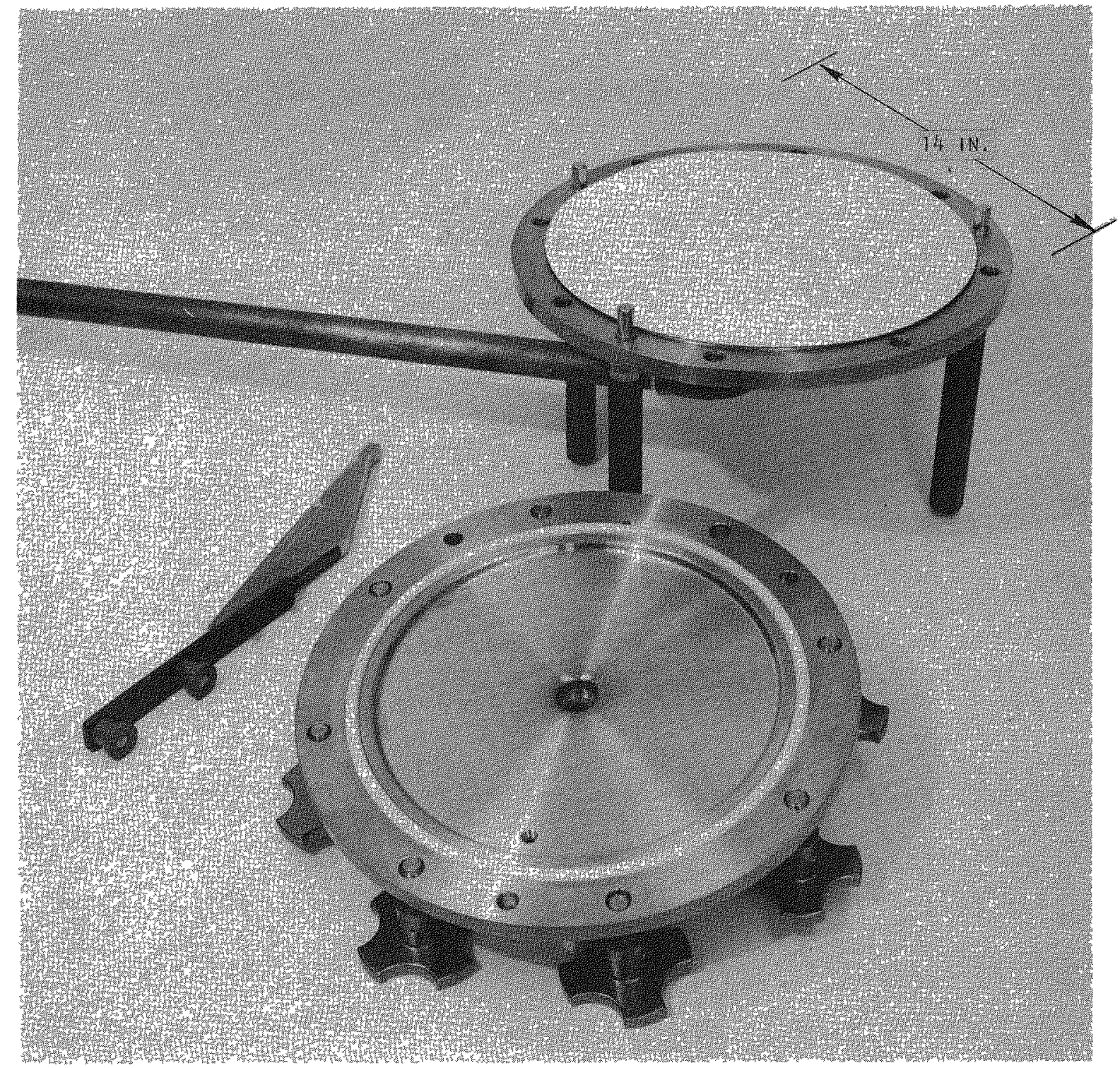

Fig. 17. Filter holder with $0.3 \mu$ Millipore paper 
clean piece of tubing having the same dimensions as the test specimen. The relative count rates then provided a measure of the fractional re-entrainment, which correlated with the shear ratio as developed in Appendix A. 


\section{RESULTS}

\subsection{EXPERIMENTAL RESULTS}

Five deposition loop experiments were completed in which the deposition and re-entrainment characteristics of cesium, iodine, and strontium were investigated. The results of these experiments are summarized herein as are the GAIL IV blowdown tests, which were reported earlier (Ref. 2). The experimental conditions for the deposition loops are summarized in Table 2, and relevant conditions for the GAIL in-pile loop are reviewed in Table 3.

Loop No. 1 was a shakedown experiment wherein the depositing species was Cs-137-tagged cesium. Since the water-cooled chill block was used, the operating temperatures were very modest. Although the experiment was terminated after only 19 hours by loss of plant air pressure (which resulted in automatic shutdown of the autoclave), most of the cesium was released.

After successful execution of Loop No. 1, a strontium loop was attempted next. Since the same source heater was used again, and since the blower was not easily decontaminated, the loop contained some residual Cs137 activity. In addition, four cross-flow disturbers (small diameter tubes placed perpendicular to the direction of flow) were positioned in the loop tubing upstream of the source. In addition, about $1 / 2 \mathrm{~g}$ of graphite powder, ranging from 1 to $10 \mu \mathrm{m}$ in diameter, was poured into the blower housing just prior to final assembly to assess the effects of dust on plateout and liftoff. Although the experiment ran for almost five days before source heater failure, very small amounts of Sr-85 were released from the source. In fact, the amount of Cs-137 contamination from Loop No. 1 equalled or exceeded the Sr-85 release. Upon disassembly, it was observed that two of the five graphite source crucibles had ruptured. At 
TABLE 2

SUMMARY OF DEPOSITION LOOP EXPERTMENTS

\begin{tabular}{|c|c|c|c|c|c|}
\hline Parameter & Loop 1 & Loop $2^{(a)}$ & Loop 3 & Loop 4 & Loop 5 \\
\hline $\begin{array}{l}\text { Experiment Description } \\
\text { Radionuclide } \\
\text { Dust? } \\
\text { Chill? }\end{array}$ & $\begin{array}{l}\text { Cs }-137 \\
\text { No } \\
\text { Yes }\end{array}$ & $\begin{array}{l}\text { Sr-85 }(b) \\
\text { Mechanically } \\
\quad \text { added (c) } \\
\text { Yes }\end{array}$ & $\begin{array}{l}\mathrm{T}-131 \\
\text { No } \\
\text { Yes }\end{array}$ & $\begin{array}{l}\text { Cs }-137 \\
\text { No } \\
\text { No }\end{array}$ & $\begin{array}{l}\text { Sr-85 } \\
\text { Graphite } \\
\text { corrosion } \\
\text { No }\end{array}$ \\
\hline $\begin{array}{l}\text { Operating Variables } \\
\text { Pressure (atm) } \\
\left.\text { Loop } \Delta \mathrm{P} \text { (in } \mathrm{H}_{2} \mathrm{O}\right) \\
\text { Mass flow }(\mathrm{g} / \mathrm{sec}) \\
\text { Coolant temperature }\left({ }^{\circ} \mathrm{C}\right) \\
\text { Surface temperature }\left({ }^{\circ} \mathrm{C}\right) \\
\text { Duration (sec) }\end{array}$ & $\begin{array}{l}23.4 \\
2.6 \\
28 \\
90-130 \\
50-260 \\
6.8 \times 10^{4}\end{array}$ & $\begin{array}{l}24.0 \\
3.5(a) \\
28 \\
90-130 \\
50-200_{5} \\
4 \times 10^{5}\end{array}$ & $\begin{array}{l}23.8(e) \\
3.6 \\
34 \\
80-120 \\
50-200 \\
4 \times 10^{5}\end{array}$ & $\begin{array}{l}23.8 \\
2.2 \\
22 \\
380-450 \\
350-450 \\
3 \times 10^{5}\end{array}$ & $\begin{array}{l}23.8 \\
2.3 \\
20 \\
425-500 \\
400-500 \\
5 \times 105\end{array}$ \\
\hline $\begin{array}{l}\text { Source Loading } \\
\text { Stable (mg/g) } \\
\left.\text { Radioactive ( } \mu \mathrm{Ci}_{i}\right)\end{array}$ & $\begin{array}{l}4.0 \\
10\end{array}$ & $\begin{array}{l}0.7 \\
10\end{array}$ & $\begin{array}{l}22.3^{(f)} \\
1000\end{array}$ & $\begin{array}{l}1.1 \\
50\end{array}$ & $\begin{array}{l}65.2 \\
7300\end{array}$ \\
\hline $\begin{array}{l}\text { Total Release } \\
\text { Stable (mg) } \\
\text { Radioactive ( } \mu \mathrm{C} i \text { ) }\end{array}$ & $\begin{array}{l}3.5 \\
8.5\end{array}$ & $\begin{array}{l}<0.1 \\
<1\end{array}$ & $\begin{array}{l}22.3 \\
1000\end{array}$ & $\begin{array}{l}20.5 \\
250\end{array}$ & $\begin{array}{l}<0.1 \\
<1\end{array}$ \\
\hline $\begin{array}{l}\text { Blowdown/Wipedown Tests } \\
\text { Blowdown gas } \\
\text { Shear ratio range } \\
\text { Liftoff fraction range } \\
\text { Wipeoff fraction range }\end{array}$ & $\begin{array}{l}\text { He/Air } \\
1-102 \\
0-0.02 \\
0.15-0.85\end{array}$ & $\begin{array}{l}\text { He } \\
0.7-8.1 \\
-(g) \\
0.07-0.95\end{array}$ & $\begin{array}{l}\mathrm{He} / \mathrm{Air} \\
1-10 \\
0.001-0.02 \\
0.25-0.50\end{array}$ & $\begin{array}{l}\mathrm{He} \\
1.3-11 \\
0-0.003 \\
0.02-0.50\end{array}$ & $\begin{array}{l}\text { He } \\
1.3-12 \\
0.13-0.70 \\
0.80-0.95\end{array}$ \\
\hline
\end{tabular}

(a) Four cross-flow disturbers were added.

(b) $\mathrm{Cs}-137$ contamination from previous experiment.

(c) $1 / 2$ gram of graphite $(1-10 \mu \mathrm{m})$ was mechanically added initially; two of the five graphite crucibles also corroded.

(d) All five graphite crucibles showed evidence of corrosion.

(e) Pressure spuriously high.

(f) $31.7 \mathrm{mg}$ of $\mathrm{PdI}_{2}$ crystals.

(g) No Sr-85 liftoff fractions could be calculated because of low $\mathrm{Sr}$ release and poor counting statistics.

(h) Results not applicable to HTGR because source material was transported throughout loop following corrosion of graphite crucibles. 
TABLE 3

GAIL IV OPERATING CONDITIONS (REF. 25)

\begin{tabular}{l|r|r}
\hline Parameter & Hot Leg & Cold Leg \\
\hline He temperature $\left({ }^{\circ} \mathrm{C}\right)$ & 650 & 260 \\
Pressure (atm) & 23.1 & 23.1 \\
Mass flow (g/sec) & 33 & 33 \\
Velocity (cm/sec) & 2957 & 1372 \\
Reynolds No. & 28,400 & 36,800 \\
Diameter (cm) & 3.40 & 3.81 \\
\hline
\end{tabular}


the time, the failure was attributed to thermal stresses or machining flaws (Ref. 26).

After repairing the source heater, a third experiment was executed with I-131 tagged iodine. No dust was added nor were any crossflow disturbers added. Since the $\mathrm{PdI}_{2}$ source decomposes at about $350^{\circ} \mathrm{C}$ to give elemental iodine, the required heater performance was very modest, and essentially all the iodine was volatilized from the source. Again use of the chill resulted in very low temperatures. One complication marred the otherwise routine operation: the loop pressure drop held constant at 3.6 in $\mathrm{H}_{2} \mathrm{O}$ - or some $40 \%$ higher than in Loop No. 1 for which all other operating conditions were equal. This difficulty was not resolved; for conservatism in blowdown calculations, the measured $\triangle \mathrm{P}$ was assumed accurate although pressure gauge decalibration is suspected.

After reviewing the results of the first three experiments, it was concluded that the operating temperatures were undesirably low: therefore, the chill block was eliminated raising the maximum surface temperature from $200-260^{\circ} \mathrm{C}$ to $450-500^{\circ} \mathrm{C}$. Loop No. 4, using Cs -137 , was essentially a repeat of Loop No. 1 without the chill and thus at higher temperatures. Most of the cesium evaporated from the source before the run was terminated after 3.5 days by heater failure. Results were as expected except that the plateout levels were consistently higher in one of the two parallel loops. No definitive explanation was found.

After fabricating a new source heater, another attempt was made to perform a strontium experiment. Source loading was increased by a factor of 100 , and the source heater was maintained at $1000^{\circ} \mathrm{C}$ or above for almost 5 days. This time the run was terminated by blower fallure. Upon disassembly, it was observed that all of the five source crucibles had undergone some degree of corrosion; two of them had almost completely disintegrated. It is suggested that the cause of the failure was strontium 
metal-catalyzed graphite oxidation by trace amounts of water and oxygen in the helium. The surfaces of the loop were very dirty, and the amount of Sr -85 activity was 1 ow (comparable to the Cs-137 contamination from experiment Nos. 1 and 4 ).

Another attempt was made to obtain strontium data. The loop blower was repaired, the source heater was rebuilt and modified to increase the purge flow over the crucibles, and an activated charcoal trap was installed to remove oxidants from the helium. During preoperational checkouts, a short resulted that burned out the blower motor; at this point the deposition loop program was terminated.

\subsubsection{Deposition Loop Plateout Distributions}

The as-measured plateout activity distributions for Loops 1 through 5 are plotted in Figs. 18 through 22, respectively, on semi-log coordinates [the simplest transport model predicts an exponential decrease in activity with increased distance (Ref. 13)]. For comparison, the profiles for Loops 1 through 4 are replotted in Cartesian coordinates in Figs. 23 through 26, respectively.

In the first experiment, the radioactivity was counted with a mobile detector. By using suitable shielding, the gamma field was collimated to 1-in. intervals. In the other experiments, the loop tubing was sectioned in 1 to 2 in. Iengths and counted with a scintillation detector. In all cases background was properly accounted for. Although no attempts were made to quantitatively determine counting efficiency, it was estimated to be 1 to $10 \%$. Therefore, the plateout profiles presented herein are relative distributions.

A number of trends are apparent in the data. The specific activity (e.g., $\mathrm{cpm} / \mathrm{cm}$ or $\mathrm{Ci} / \mathrm{cm}^{2}$ ) generally decreases with distance from the source. 


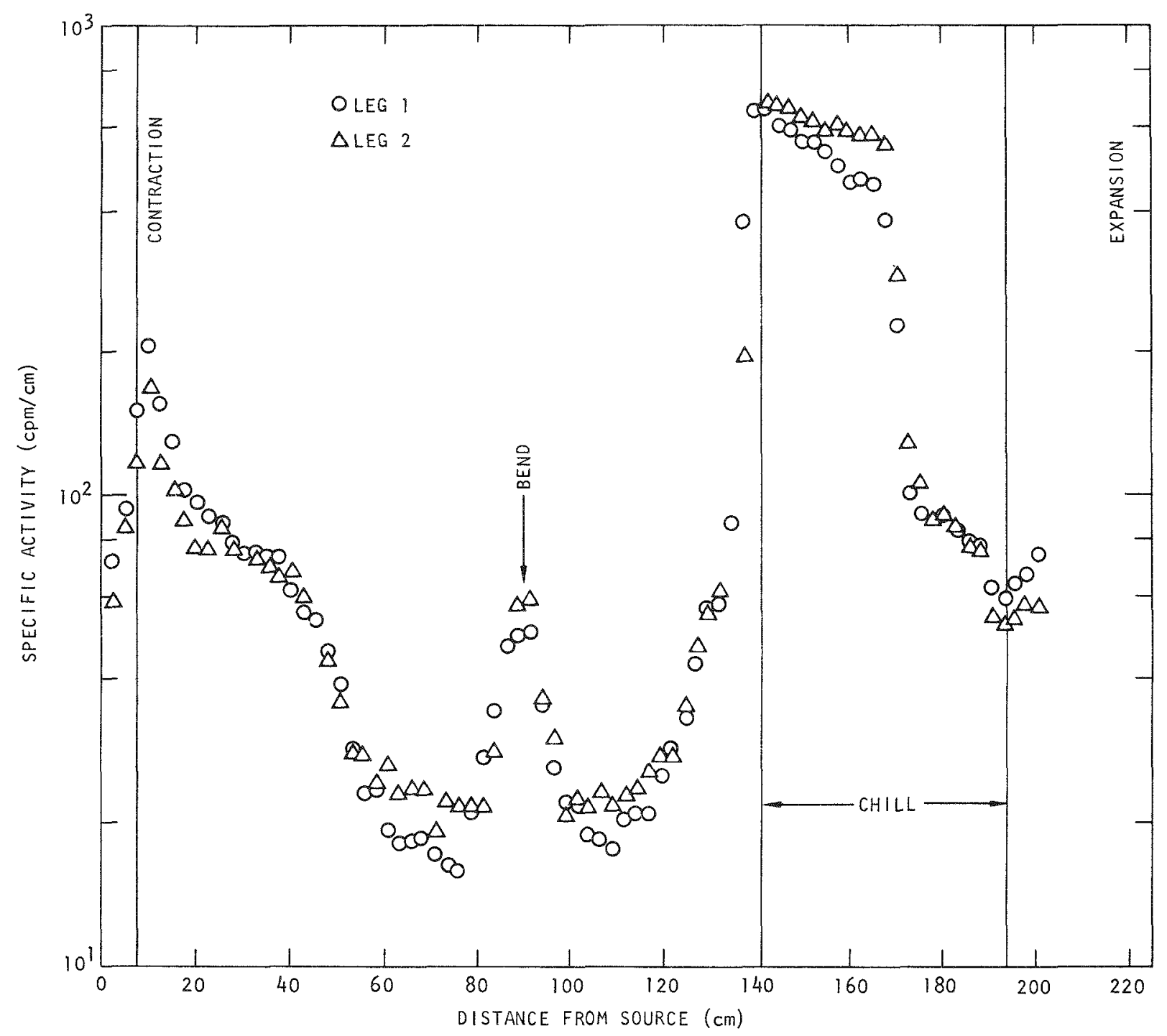

Fig. 18. Cs-137 plateout distribution, 1oop No. 1 


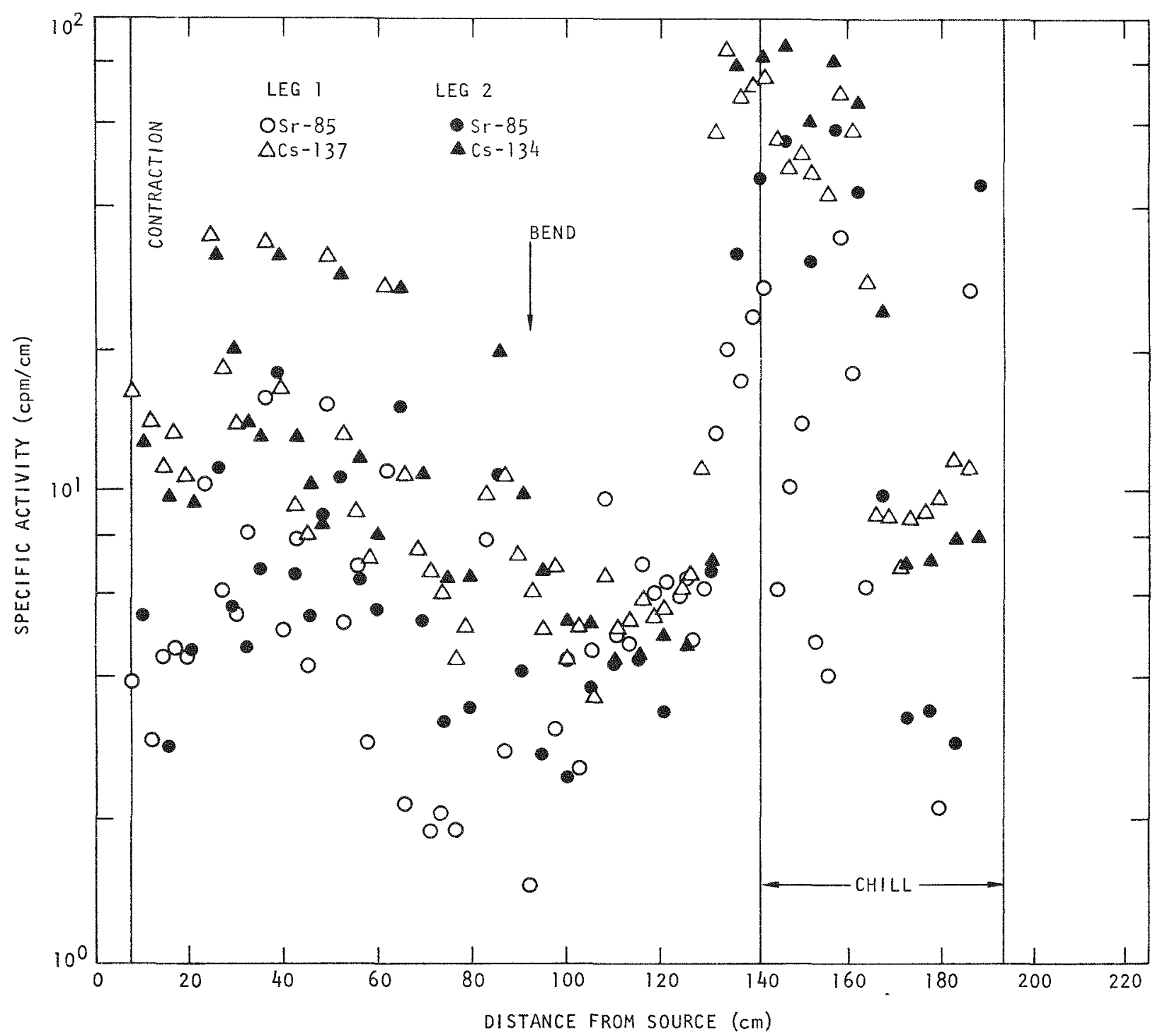

Fig. 19. Sr-85 and Cs-137 plateout distribution, dust added 


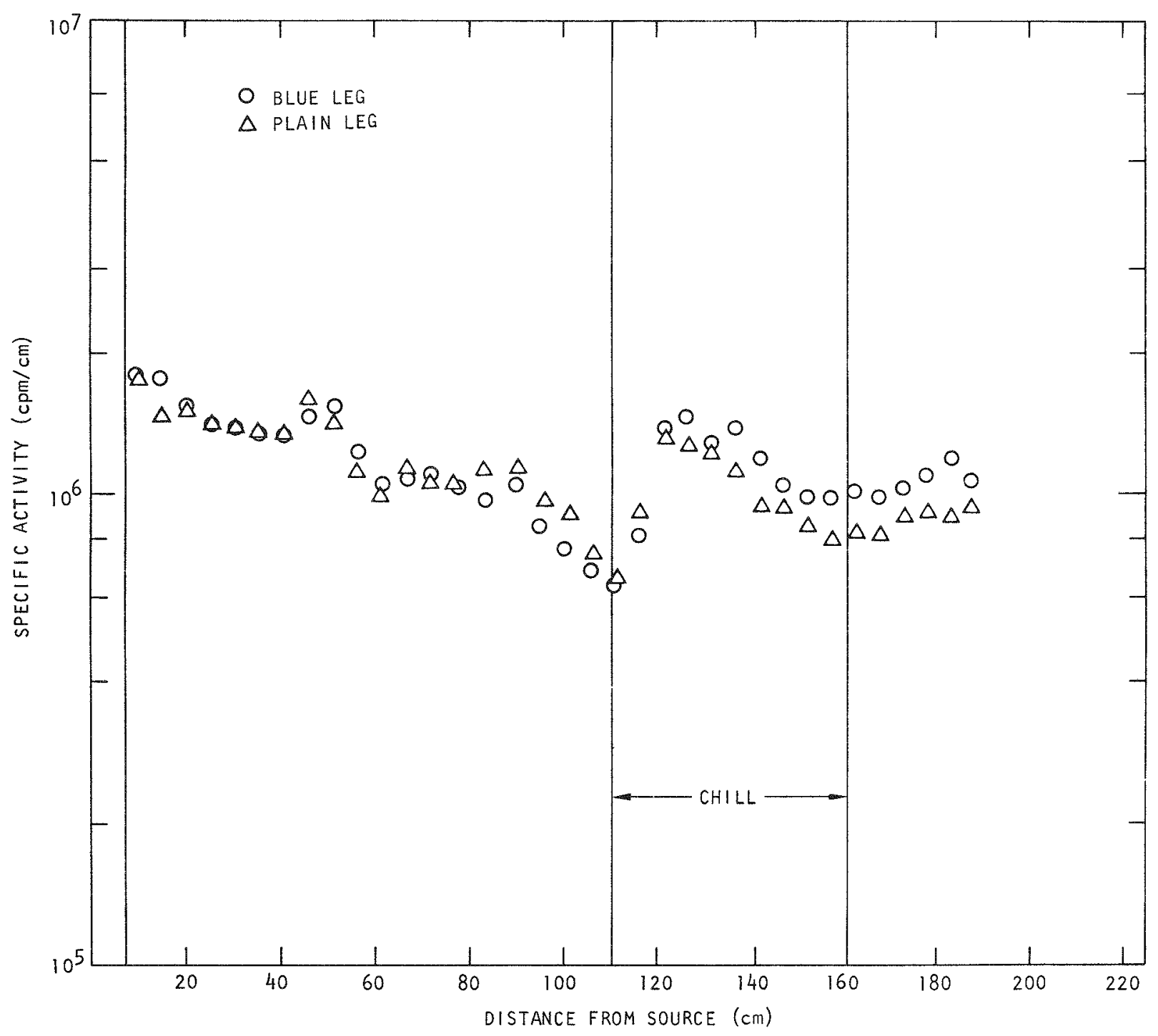

Fig. 20. I-131 plateout distribution 


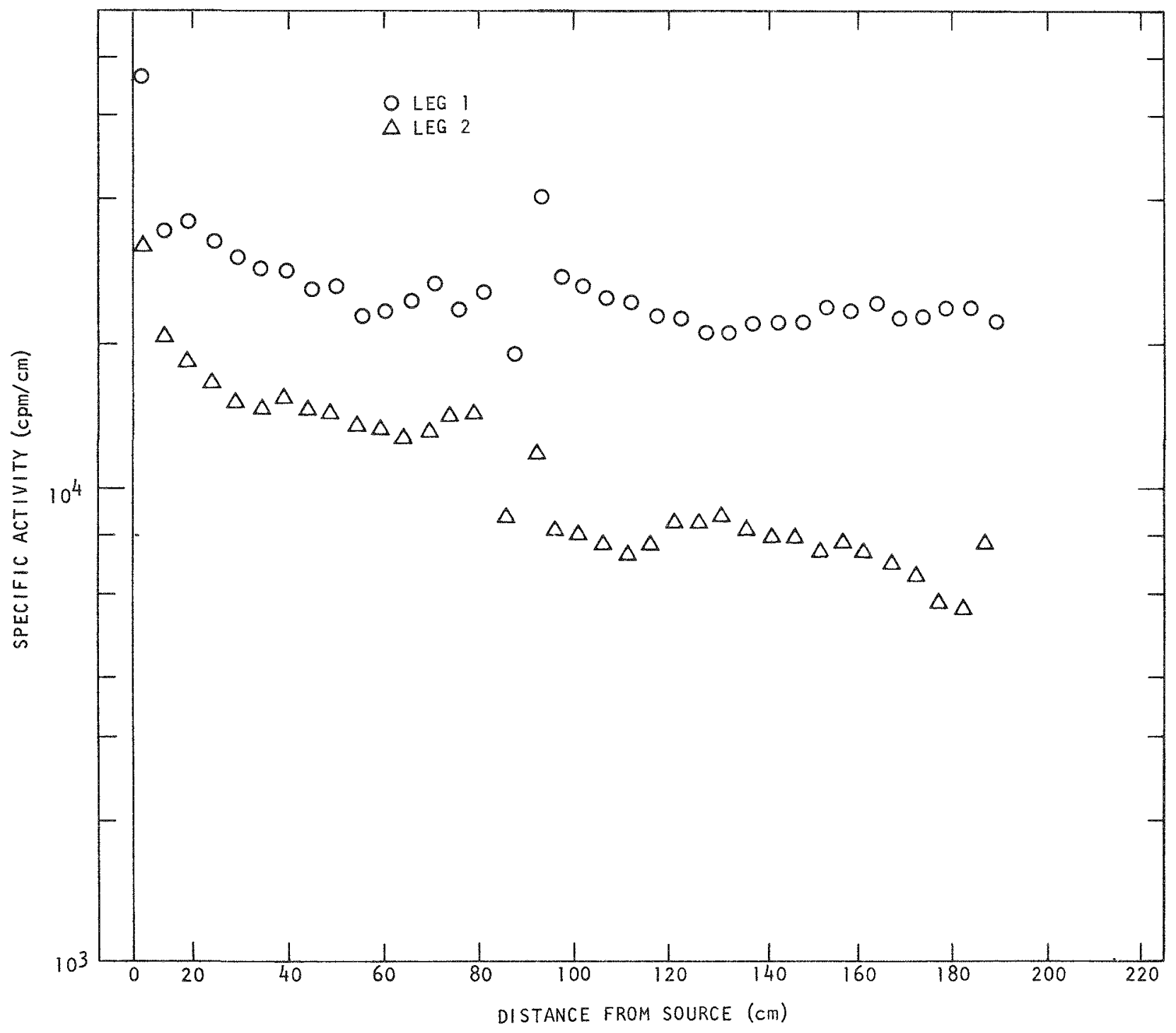

Fig. 21. Cs-137 plateout distribution 


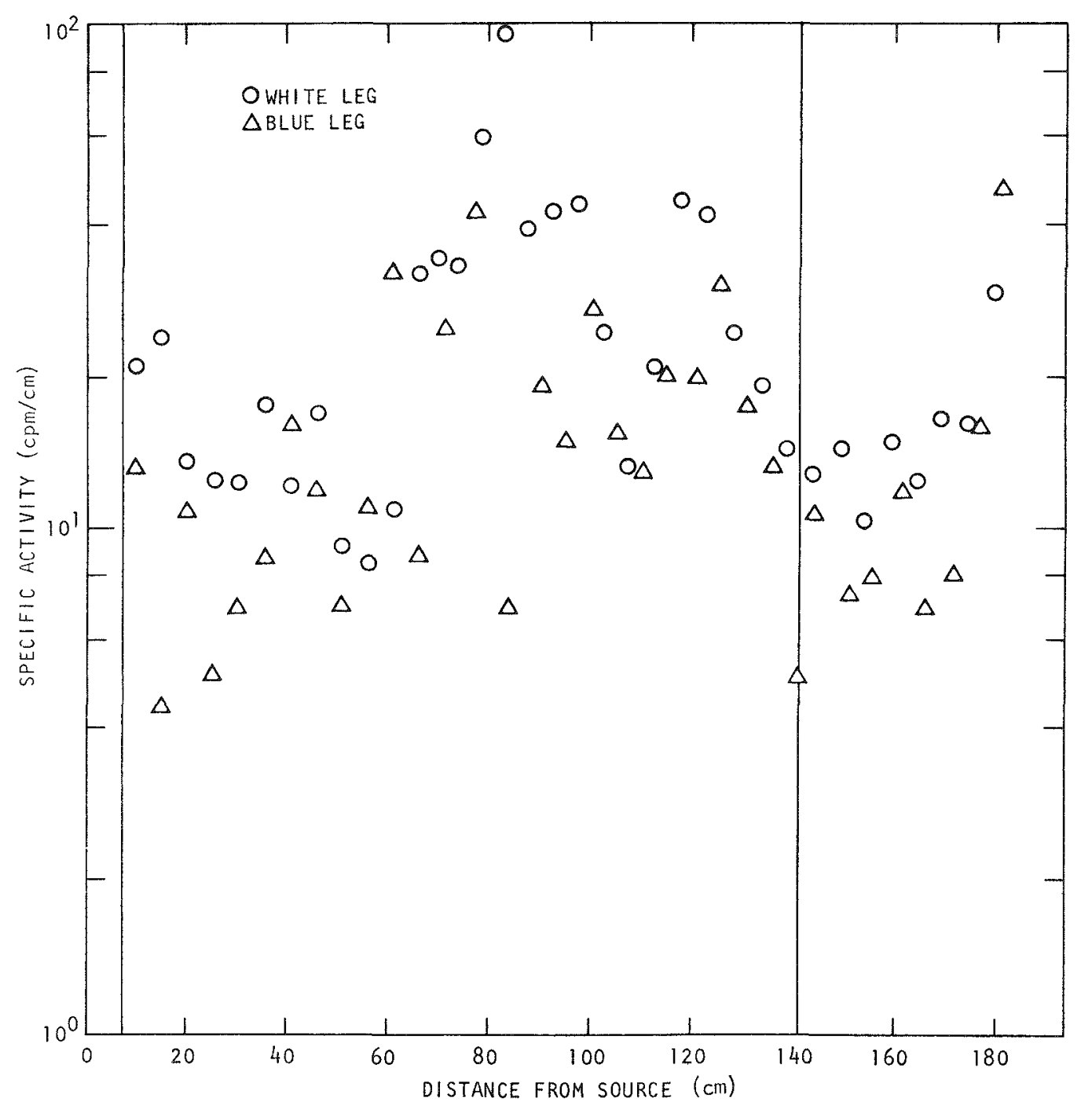

Fig. 22. Sr-85 plateout distribution, graphite corrosion 


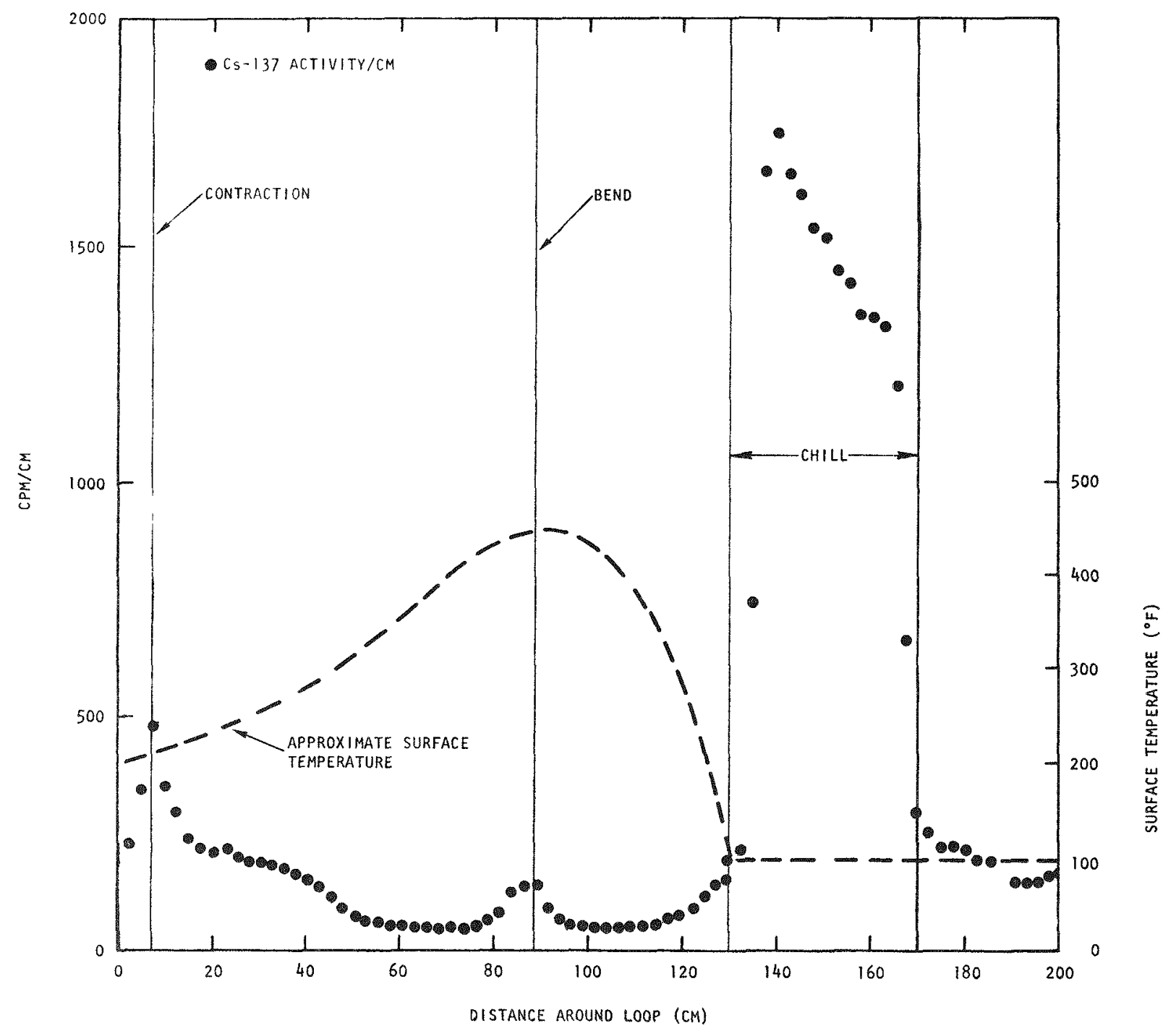

Fig. 23. Cs-137 plateout distribution and surface temperature for loop No. 1 


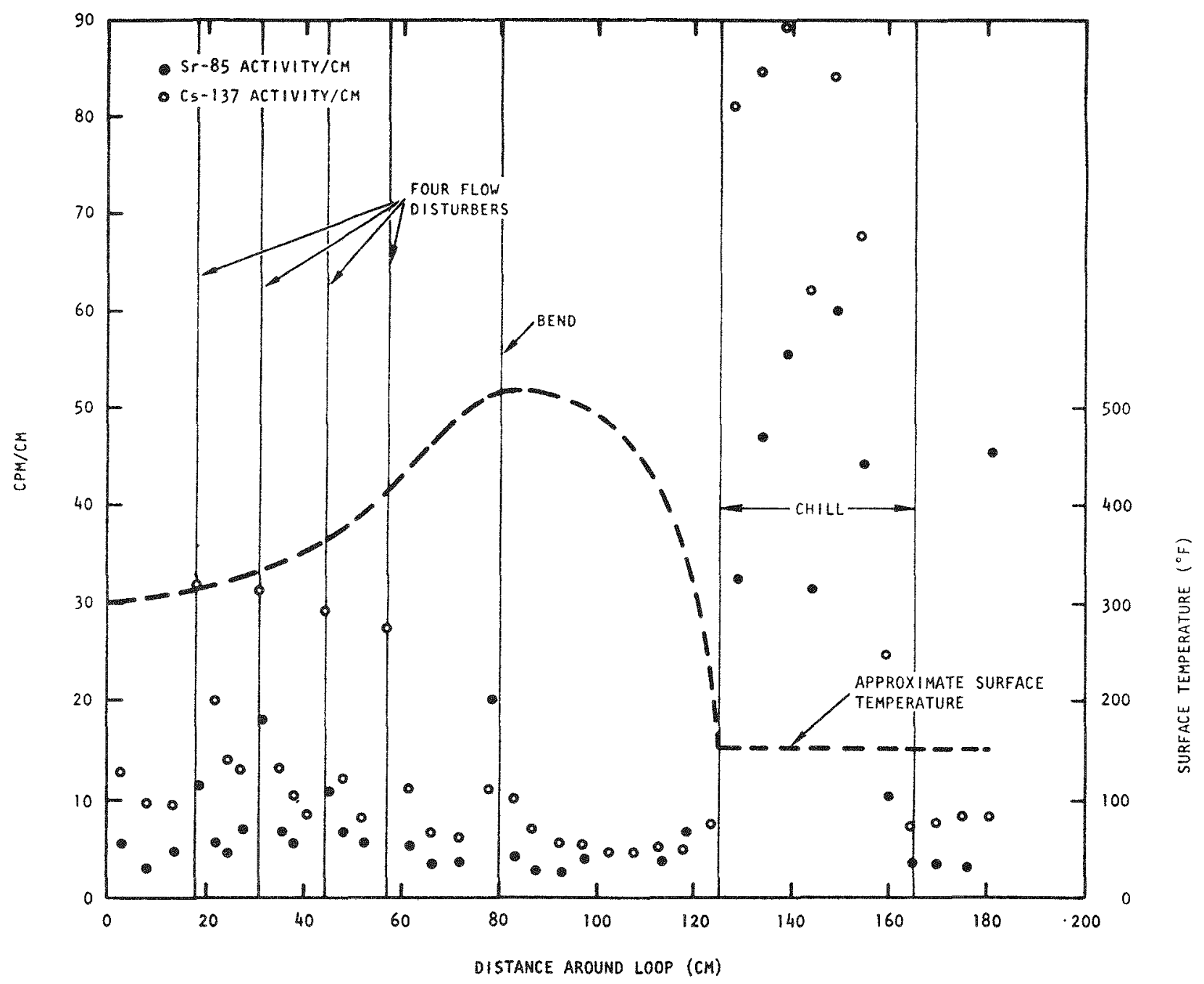

Fig. 24. Plateout distribution and surface temperature for deposition loop No. 2 


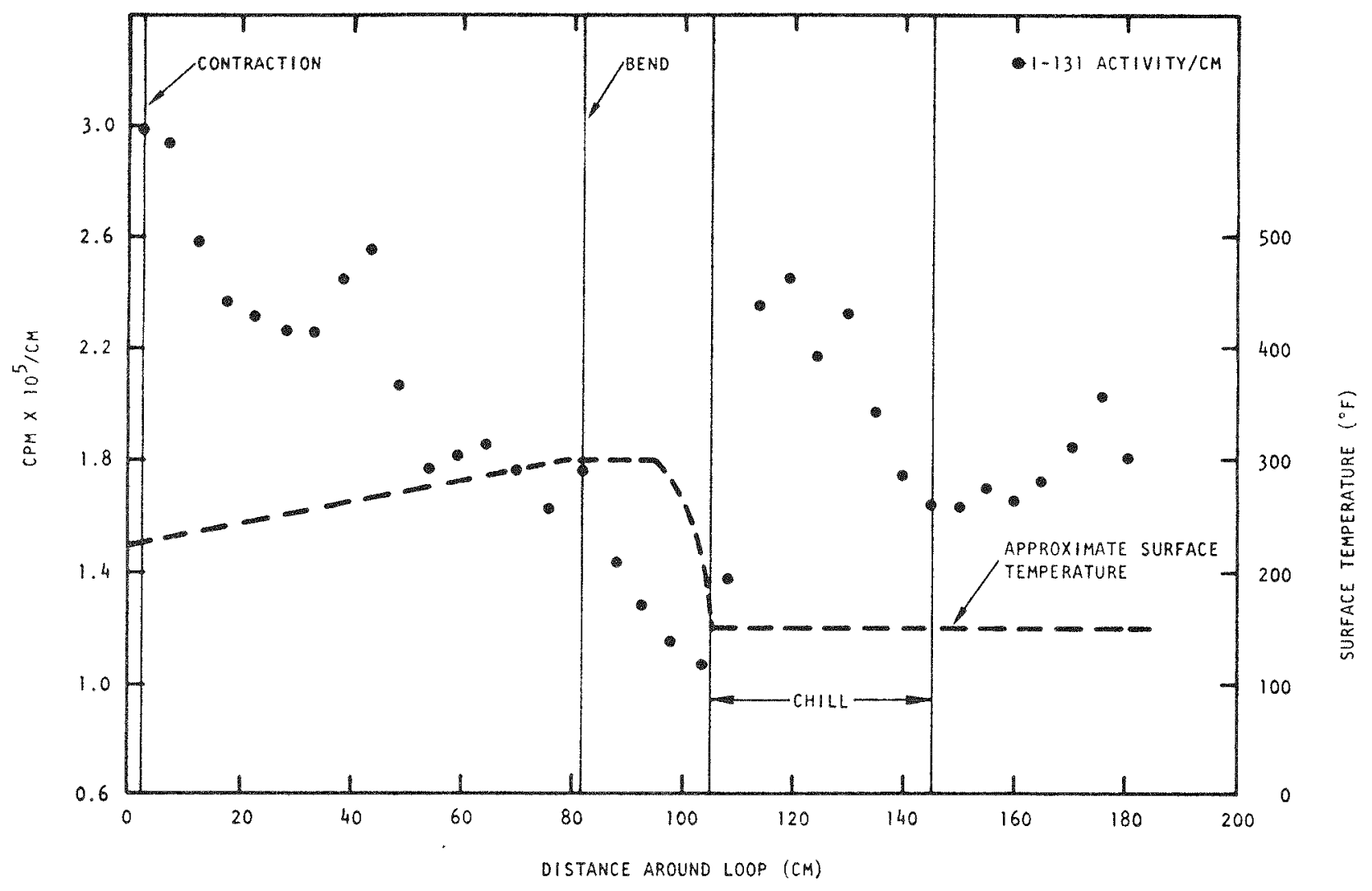

Fig. 25. Plateout distribution and surface temperature, loop No. 3 


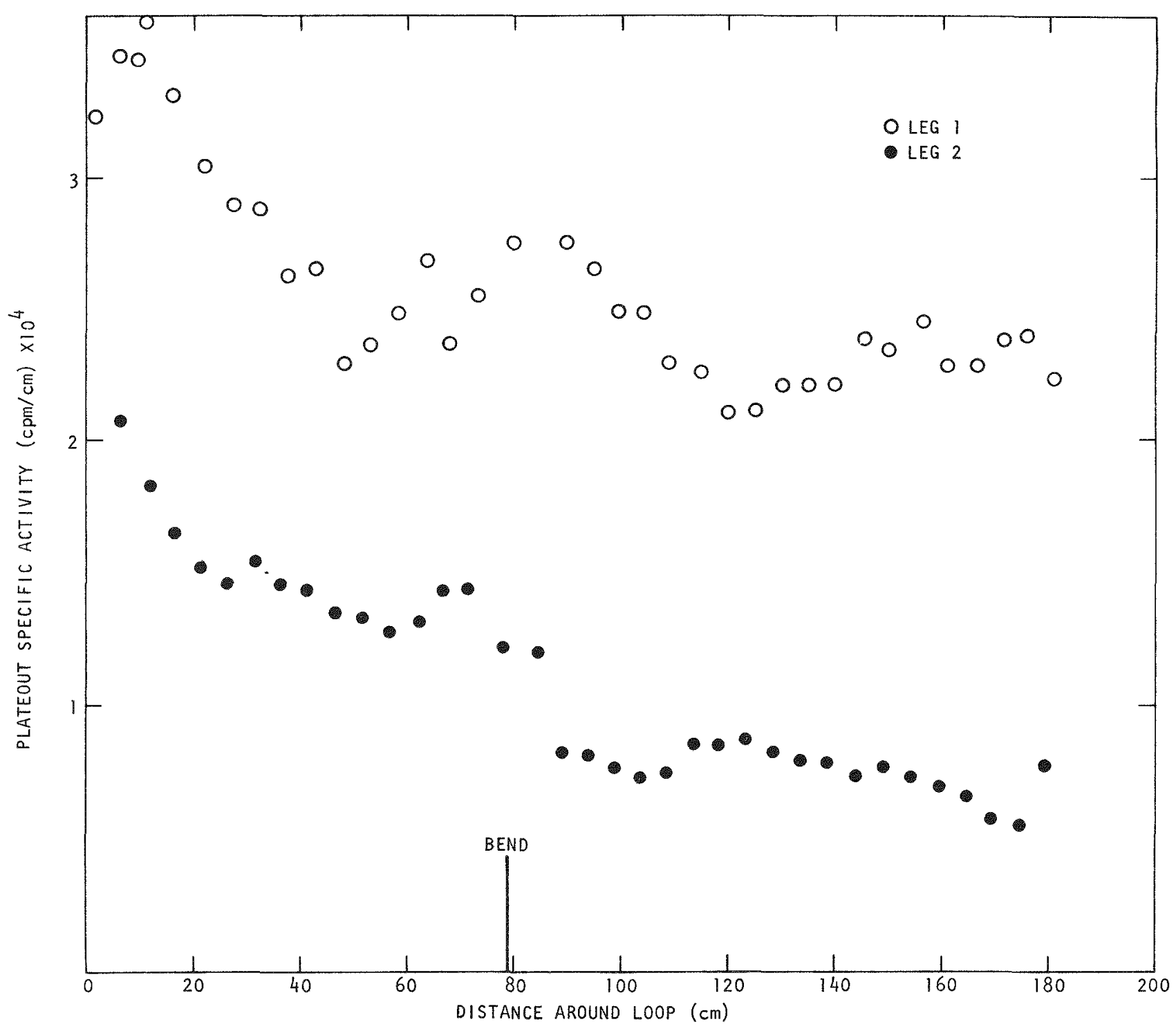

Fig. 26. Cs-137 plateout distribution, loop No. 4 
The enhanced mass transfer at flow disturbers - contractions, bends, etc. is clearly evidenced by local peaks in the profiles immediately downstream of the disturbances. Far more dramatic, however, is the effect of the chill block on the plateout process; the effect appears to be more pronounced for cesium (Loops 1 and 2) and strontium (Loop 2) than for iodine (Loop 3). Also evident is the effect of dust on plateout distributions. The data for Loop 2 (dust added) and Loop 5 (dust generated) are much more scattered and the profiles flatter.

\subsubsection{Blowdown/Wipedown Results}

3.1.2.1. GAIL IV Results. Pipe specimens from both the hot and cold legs of the GAIL-IV loop were blown down in the apparatus described in Section 2.2. Subsequently, the specimens were wiped with a muslin cloth under moderate finger pressure to determine semi-quantitatively the amount of additional activity that could be removed. The fractional liftoff was then correlated with the shear ratio (Appendix A). Results of these experiments are summarized in Table 4; liftoff results for $\mathrm{Sr}-90, \mathrm{Cs}-137$, and Ce-144 are plotted in Fig, 27.

Although the data exhibit considerable scatter, general trends are evident. Ce-144 activity is the most readily removed by either high velocity helium or by mechanical wiping, and $\mathrm{Cs}-137$ is the most adherent; the adherence of Sr-90 activity is intermediate. For each nuclide the fractional liftoff increased approximately linearly with increased shear ratio.

\subsubsection{Deposition Loop Results. Blowdown experiments were} performed on the specimens from each deposition loop using essentially the same apparatus and procedures. Unlike the GAIL IV tests, different specimens were generally used for blowdown and for wipedown tests. Blowdown results for Loops 1 and 2 are summarized in Table 5 ; companion 
TABLE 4

GAII IV BLOWDOWN/WIPEDOWN RESULTS (REF, 2)

\begin{tabular}{|c|c|c|c|c|c|c|c|c|c|c|c|c|c|}
\hline \multirow[b]{2}{*}{$\begin{array}{l}\text { Time } \\
\text { (min) }\end{array}$} & \multirow[b]{2}{*}{$\begin{array}{l}\text { Test } \\
\text { No. }\end{array}$} & \multirow[b]{2}{*}{ Line } & \multirow{2}{*}{$\begin{array}{c}\text { Test } \\
\text { Velocity } \\
\text { (ft/sec) }\end{array}$} & \multirow[b]{2}{*}{$\mathrm{V}_{\mathrm{T} / \mathrm{V}_{\mathrm{L}}}^{(\mathrm{a})}$} & \multirow[b]{2}{*}{$\mathrm{F}_{\mathrm{T} /} \mathrm{F}_{\mathrm{L}}^{(\mathrm{b})}$} & \multicolumn{2}{|c|}{$\mathrm{Ce}-144$} & \multicolumn{2}{|c|}{$\mathrm{Cs}-137$} & \multicolumn{2}{|c|}{$\mathrm{Sr}-90$} & \multicolumn{2}{|c|}{$C s-134$} \\
\hline & & & & & & $\begin{array}{c}\text { Removed } \\
\text { by flow (\%) }\end{array}$ & $\begin{array}{c}\text { Wiped } \\
\text { Off }(\%)(c)\end{array}$ & $\begin{array}{c}\text { Removed } \\
\text { by flow (\%) }\end{array}$ & $\begin{array}{l}\text { Wiped } \\
\text { Off (\%)(c) }\end{array}$ & $\begin{array}{c}\text { Removed } \\
\text { by flow (\%) }\end{array}$ & $\begin{array}{l}\text { Wiped } \\
\text { off }(\%)(c)\end{array}$ & $\begin{array}{c}\text { Removed } \\
\text { by flow (\%) }\end{array}$ & $\begin{array}{c}\text { Wiped } \\
\text { off }(\%)(c)\end{array}$ \\
\hline 1 & 1 & cold & 175 & 3.8 & 3.6 & 3.3 & 22.0 & 1.4 & 11.0 & 3.5 & 36 & $\ldots$ & - \\
\hline 1 & 2 & hot & 391 & 4.4 & 7.5 & 46.0 & 98.0 & 3.0 & 16.0 & 29.0 & 71 & 3.3 & 15 \\
\hline 1 & 3 & hot & 390 & 4.4 & 7.5 & 44.0 & 100.0 & 1.5 & 9.4 & 26.0 & 70 & 2.1 & 11 \\
\hline 1 & 4 & hot & 296 & 3.3 & 4.5 & 22.0 & 91.0 & 1.4 & 14.0 & 17.0 & 72 & 1.2 & 3 \\
\hline 1 & 5 & cold & 255 & 5.6 & 7.1 & 3.3 & 16.0 & 1.0 & 5.1 & - & -- & - & -- \\
\hline 1 & 6 & hot & 149 & 1.7 & 1.02 & 3.6 & 100.0 & 0.20 & 9.2 & - & -- & - & - \\
\hline 4 & 7 & hot & 149 & 1.7 & 1.02 & 5.4 & 100.0 & 0.33 & 12.0 & -- & -- & -- & -- \\
\hline
\end{tabular}

(a) Ratio of the velocity in the test to the normal operating GAIL velocity.

(b) Ratio of the steady state wall shear stress in the test to the wall shear stress in GAIL at normal operating conditions.

(c) Wiped off values include that removed by the high velocity helium flow in the test. 


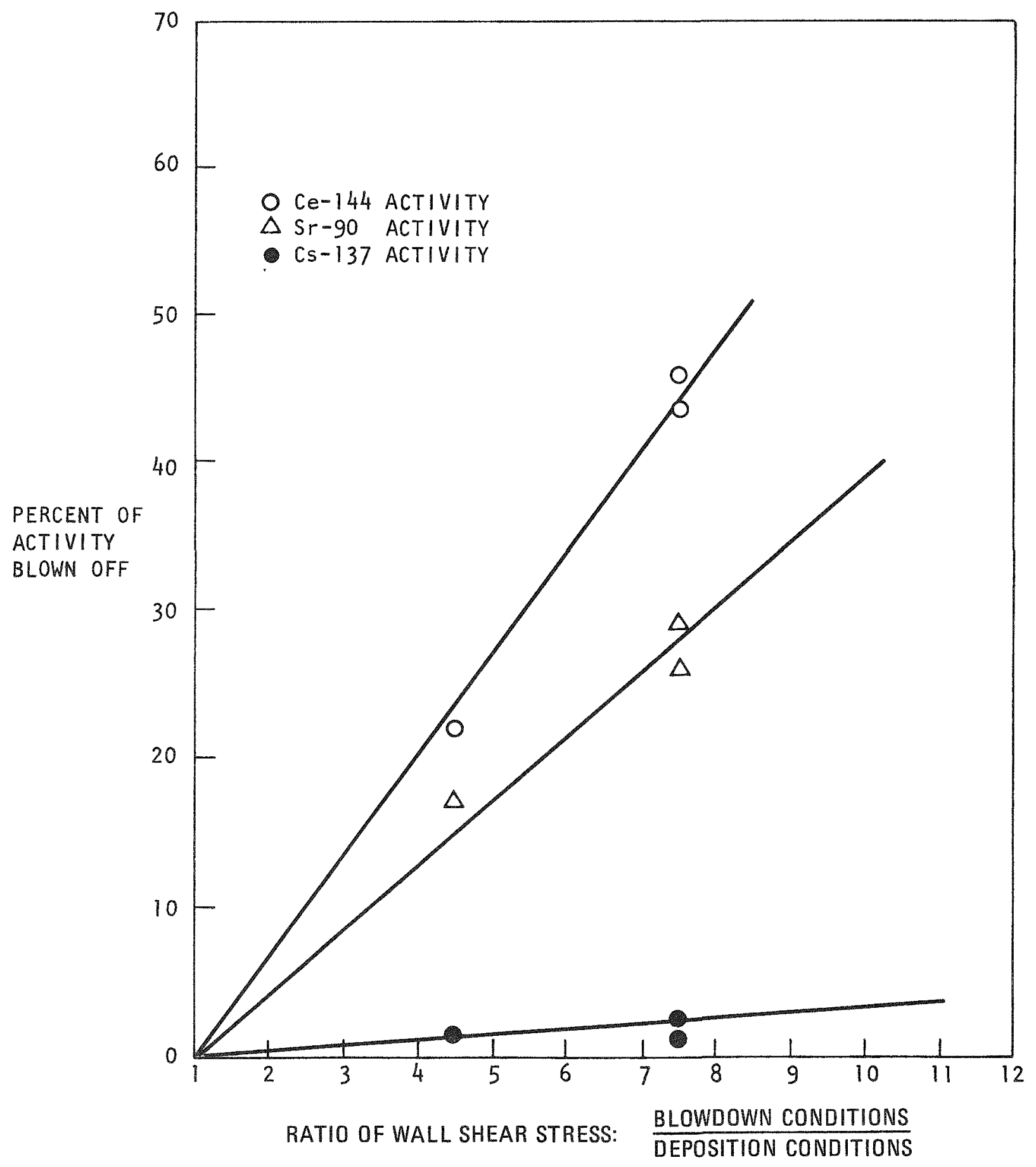

Fig. 27. Pipe sections from GA in-pile loop, blowdown duration $60 \mathrm{sec}$ 
TABLE 5

BLOWDOWN TEST RESULTS

\begin{tabular}{l|c|c|c}
\hline \multicolumn{2}{c|}{ Loop 1(a) } & \multicolumn{2}{|c}{ Loop 2(b) } \\
\hline $\begin{array}{l}\text { Shear } \\
\text { Ratio }\end{array}$ & $\begin{array}{c}\text { Blowdown } \\
\text { Percentage }\end{array}$ & $\begin{array}{c}\text { Shear } \\
\text { Ratio }\end{array}$ & $\begin{array}{c}\text { Blowdown } \\
\text { Percentage }\end{array}$ \\
\hline $1.5^{(\mathrm{c})}$ & 0.0 & $0.7^{(\mathrm{d})}$ & 1.3 \\
4.1 & 0.0 & $0.7^{(\mathrm{d})}$ & 2.5 \\
$6.2^{(\mathrm{c})}$ & 0.0 & 1.6 & 1.4 \\
$6.2^{(\mathrm{c})}$ & 0.0 & $2.3^{(\mathrm{d})}$ & 2.4 \\
18.3 & 0.0 & $2.3^{(\mathrm{d})}$ & 2.7 \\
35.1 & 0.0 & $2.3^{(\mathrm{d})}$ & 4.5 \\
35.1 & 0.0 & $3.6^{(\mathrm{d})}$ & 5.8 \\
35.1 & 0.0 & 4.2 & 4.1 \\
35.1 & 0.0 & 4.2 & 8.8 \\
54.2 & 0.0 & 4.2 & 10.0 \\
82.7 & 1.6 & 8.1 & 2.3 \\
82.7 & 1.6 & 8.1 & 8.1 \\
82.7 & 1.5 & & \\
82.7 & 1.7 & & \\
102.3 & 1.1 & & \\
\hline
\end{tabular}

(a) Depositing specie: Cs-137. No dust added.

(b) Depositing species: Cs-137, Sr-85 (only Cs-137 blowdown data obtained). 0.5 gram of 1-10 $\mathrm{\mu m}$ size graphite dust was added $\left(\sim 125 \mu \mathrm{g} / \mathrm{cm}^{2}\right)$.

(c) Air was used for the blowdown test.

(d) Blowdown samples contained crossflow tubes. 
wipedown tests are reported in Table 6. Blowdown results for Loops 3 through 5 are plotted in Figs. 28 through 30, respectively; wipedown results are given in Tables 7 through 9, respectively. It should be noted that all strontium data are compromised by poor counting statistics because of low activity levels: no strontium liftoff fractions could be calculated from Loop 2 data, and the Loop 5 measurements are suspect.

It is evident that blowdown/wipedown data are typically very scattered. The adherence of plateout activity is clearly a function of the chemical nature of the depositing species and apparently of the deposition conditions as well. Cesium appears to be most tenaciously held at a metallic surface, while cerium is the least; strontium is intermediate and the adherence of iodine approaches that of cesium. The rationale for this behavior has yet to be determined, but one important factor appears to be the relative amount of deposited particulate matter - particularly carbonaceous dust - present in the system. For instance, the liftoff characteristics of Cs-137 activity deposited under different conditions are compared in Fig. 31: at a given shear ratio, the fractional liftoff of Cs137 from Loop 4 specimens (or, for that matter, from Loop 1 specimens) which were relatively dust-free was considerably lower than that from Loop 2 specimens, which were quite dusty: the Iiftoff of Cs-137 from GAIL-IV specimens (also believed to be relatively clean) was intermediate. A similar ordering is apparent from contrasting strontium liftoff from Loop 5 (dusty) to that from GAIL IV (clean). However, if the ease of removal is a measure of the extent of association with dust, then Ce-144 activity would seem to be on dust even on the relatively clean GAIL specimens.

The apparent relationship between dust levels and ease of removal is further evidenced from comparison of wipedown results as summarized in Table 10. Cesium and strontium activity deposited under dusty conditions appeared to be more easily removed than activity deposited under relatively cleaner conditions. These wipedown results are generally consistent with 
TABLE 6

WIPEDOWN TEST RESULTS

\begin{tabular}{|c|c|c|c|}
\hline $\begin{array}{l}\text { Loop } 1 \\
\text { Sample } \\
\text { No. }\end{array}$ & $\begin{array}{c}(\text { Cs-137 Data })(a) \\
\text { Wiped off } \\
(\%)\end{array}$ & $\begin{array}{c}\text { Loop } 2 \\
\text { Sample } \\
\text { No. }\end{array}$ & $\begin{array}{c}(\text { Cs-137 Data) } \\
\text { Wiped off } \\
(\%)\end{array}$ \\
\hline \multirow[t]{3}{*}{$1^{(b)}$} & 15.2 & $1^{(c)}$ & 88.4 \\
\hline & 17.6 & & 93.0 \\
\hline & & & 95.3 \\
\hline \multirow[t]{3}{*}{$2^{(b)}$} & 9.0 & $2^{(c)}$ & 73.7 \\
\hline & 19.0 & & 84.6 \\
\hline & 33.5 & & 90.3 \\
\hline \multirow[t]{3}{*}{$3^{(c)}$} & 43.5 & $3^{(c)}$ & 6.7 \\
\hline & 58.6 & & 27.5 \\
\hline & 70.1 & & 45.8 \\
\hline \multirow[t]{3}{*}{$4^{(c)}$} & 68.0 & & \\
\hline & 79.5 & & \\
\hline & 85.6 & & \\
\hline
\end{tabular}

(a) Cumulative fraction removed by successive wipes.

(b) Wipedown tests conducted soon after deposition.

(c) Wipedown tests conducted several months after deposition. 


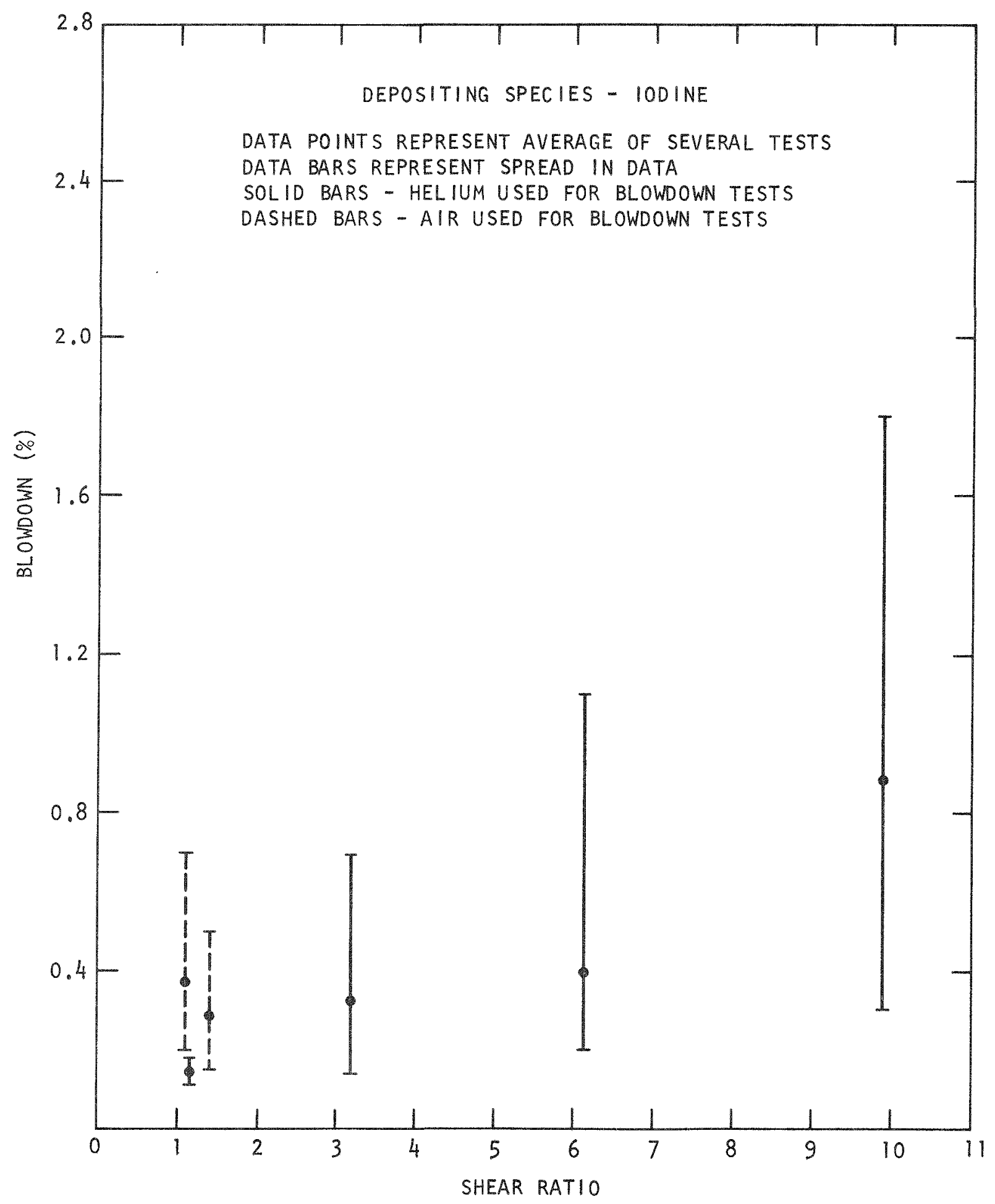

Fig. 28. I-131 blowdown results, 1oop No. 3 


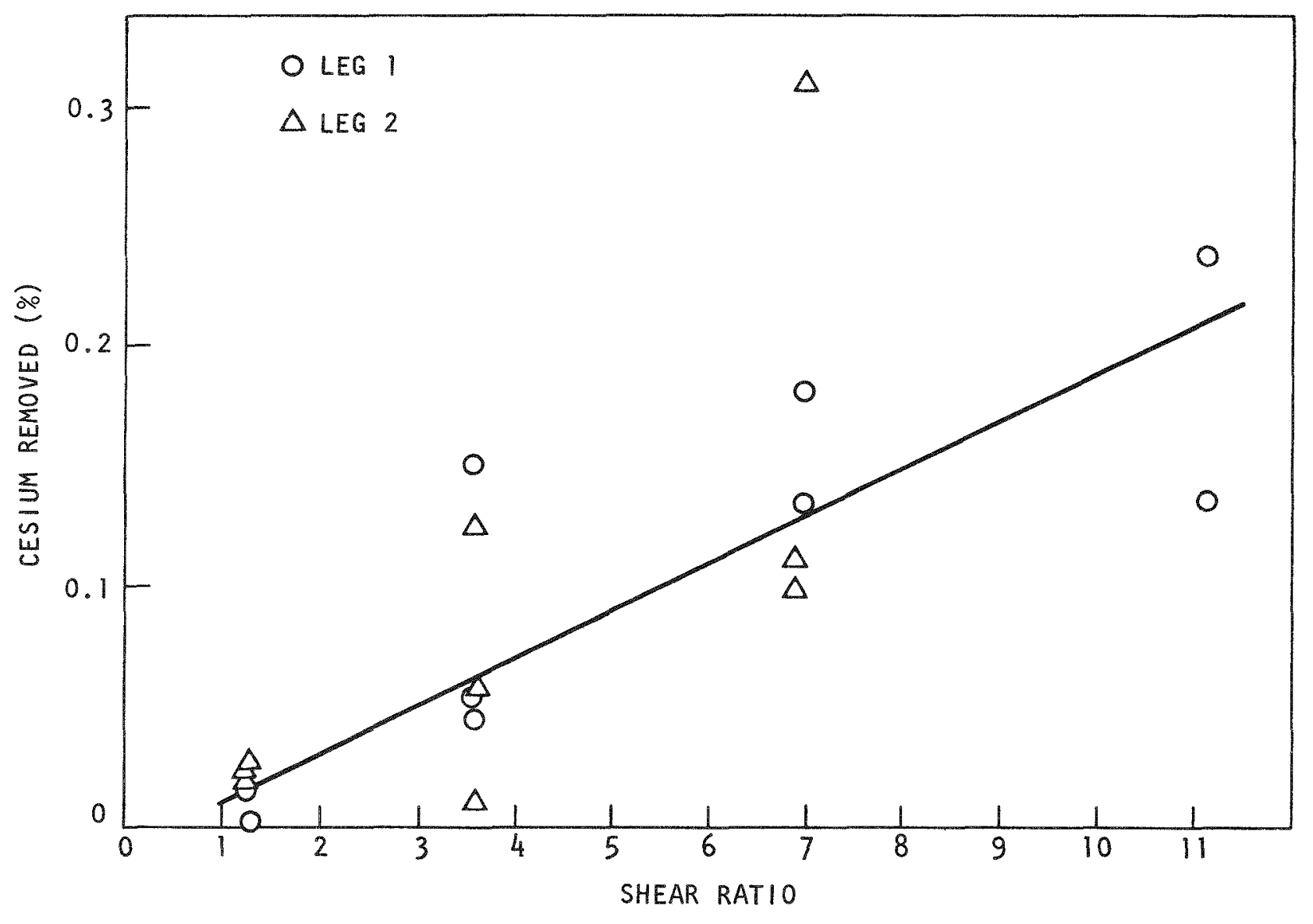

Fig. 29. Cs-137 blowdown results, loop No. 4 


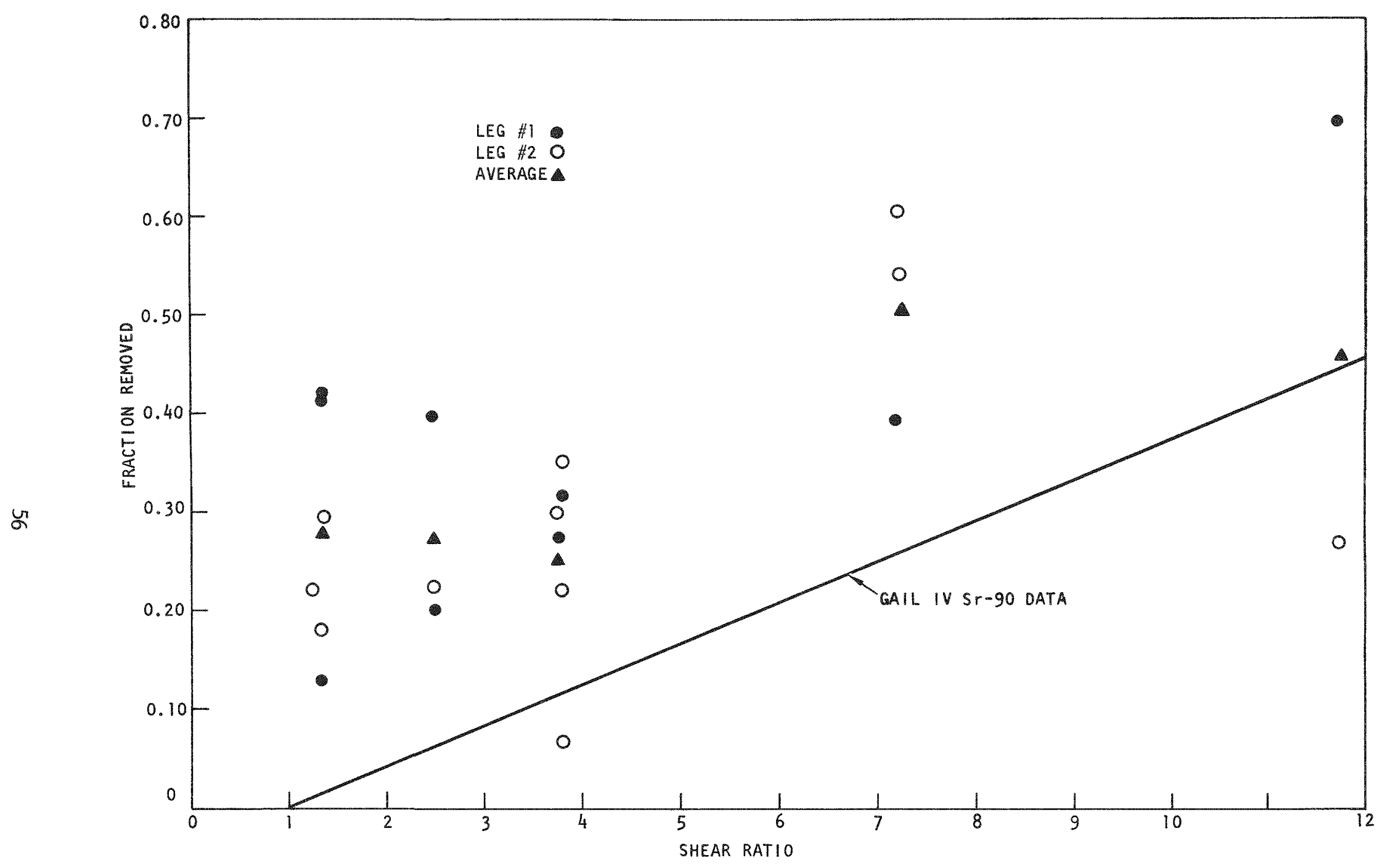

Fig. 30. Sr-85 blowdown results, 1oop No. 5 
TABLE 7

LOOP 3: I-131 WIPEDOWN RESULTS (LEG 1)

\begin{tabular}{c|c|c|c}
\hline $\begin{array}{c}\text { Test } \\
\text { Sample }\end{array}$ & $\begin{array}{c}\text { Initial } \\
\text { Value }\left(\mathrm{x} 10^{5}\right)(\mathrm{cpm})\end{array}$ & $\begin{array}{c}\text { Value After } \\
\text { 1st Wipe (cpm) }\end{array}$ & $\begin{array}{c}\text { Wiped off } \\
(\%)\end{array}$ \\
\hline 1 & 1.368 & 0.675 & 50.7 \\
2 & 1.562 & 0.610 & 61.0 \\
13 & 0.959 & 0.784 & 18.3 \\
17 & 0.655 & 0.436 & 33.5 \\
31 & 0.871 & 0.387 & 55.6 \\
32 & 0.997 & 0.577 & 42.1 \\
& & & Average \\
& & \multicolumn{2}{|c}{43.5} \\
\hline
\end{tabular}

(a) Count rate. 
TABLE 8

LOOP 4: CS-137 WIPEDOWN RESULTS (LEG 2)

\begin{tabular}{c|c|c|c}
\hline $\begin{array}{c}\text { Sample } \\
\text { No. }\end{array}$ & $\begin{array}{c}\text { Act. Before } \\
(\mathrm{cpm})\end{array}$ & $\begin{array}{c}\text { Act. After } \\
(\mathrm{cpm})\end{array}$ & $\begin{array}{c}\text { Wiped Off } \\
(\%)\end{array}$ \\
\hline 0 & 34,974 & 24,427 & 30.2 \\
1 & 27,732 & 24,694 & 11.0 \\
2 & 28,875 & 25,154 & 12.9 \\
3 & 33,035 & 31,299 & 5.3 \\
4 & 36,074 & 35,067 & 2.8 \\
5 & 37,281 & 33,876 & 9.1 \\
7 & 37,580 & 36,704 & 2.3 \\
10 & 42,156 & 41,382 & 1.8 \\
13 & 43,280 & 34,106 & 21.2 \\
17 & 36,824 & 33,930 & 7.9 \\
18 & 38,866 & 36,544 & 6.0 \\
19 & 44,007 & 42,264 & 4.0 \\
20 & 78,554 & 37,765 & 51.9 \\
21 & 64,681 & 50,239 & 22.3 \\
22 & 67,308 & 50,869 & 24.4 \\
26 & 70,144 & 63,849 & 9.0 \\
30 & 73,747 & 64,022 & 13.2 \\
32 & 85,959 & 74,170 & 13.7 \\
33 & 89,344 & 82,185 & 8.0 \\
34 & 96,326 & 66,227 & 31.2 \\
35 & 134,627 & 100,905 & 25.0 \\
& & & \\
& & & 14.9 \\
\hline
\end{tabular}


TABLE 9

LOOP 5: Sr-85 WIPEDOWN RESULTS

\begin{tabular}{c|c|c|c}
\hline $\begin{array}{c}\text { Sample } \\
\text { No. }\end{array}$ & $\begin{array}{c}\text { Before } \\
(\mathrm{cpm})\end{array}$ & $\begin{array}{c}\text { After } \\
(\mathrm{cpm})\end{array}$ & $\begin{array}{c}\text { Wiped off } \\
(\%)\end{array}$ \\
\hline B8 & 81.0 & 7.8 & 90.3 \\
B9 & 58.0 & 8.5 & 85.3 \\
W23 & 210.0 & 6.2 & 97.0 \\
W24 & 138.0 & 7.6 & 94.5 \\
W26 & 83.3 & 11.0 & 86.8 \\
W29 & 53.0 & 9.6 & 81.8 \\
& & & Average .89 .3 \\
\hline
\end{tabular}




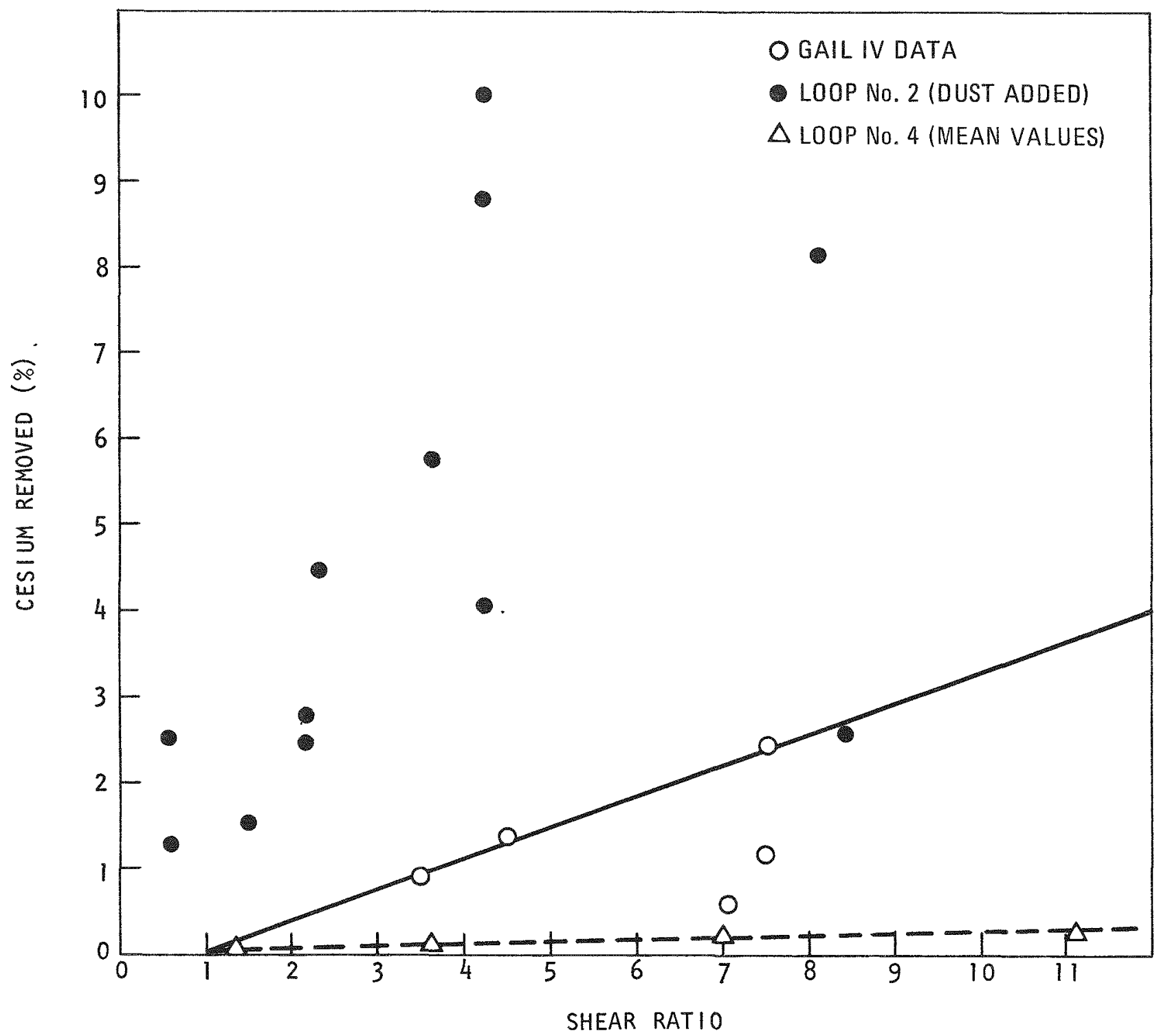

Fig. 31. Comparison of $\mathrm{Cs}-137$ blowdown results 
COMPARISON OF WIPEDOWN RESULTS

\begin{tabular}{c|c|c|c}
\hline Nuclide & Experiment & Dust & $\begin{array}{c}\text { Average } \\
\text { Wiped off (\%) }\end{array}$ \\
\hline Cs-137 & GAIL IV & No & 11 \\
Cs-137 & Loop 1 & No & 33 \\
Cs-137 & Loop 2 & Yes & 56 \\
Cs-137 & Loop 4 & No & 15 \\
Sr-90 & GAIL IV & No & 62 \\
Sr-85 & Loop 5 & Yes & 89 \\
Ce-144 & GAIL IV & No & 75 \\
I-131 & Loop 3 & No & 44 \\
& & & \\
\hline
\end{tabular}


the blowdown results; however, there is an exception. As illustrated in Fig. 31, the fractional liftoff of Cs-137 from GAIL samples was significantly higher than from Loop 4 samples, but Table 10 shows that they were wiped clean with equal ease. This discrepancy should not be given too much weight because wipedown tests are semi-quantitative at best - and, in fact, the two sets of data were obtained by two different technicians.

\subsection{CALCULATIONAL RESULTS}

\subsubsection{Correlation of Deposition Loop Data}

One of the objectives of the deposition loop program was to provide experimental plateout data for testing the validity of the $P A D$ code (Appendix B). To that end, PAD code models of each experiment were prepared from operational data summarized in Table 2. Predicted and measured plateout distributions are compared for Loops 1 through 5 in Figs. 32 through 36 , respectively.

As developed earlier, graphitic and metallic surfaces have a finite capacity at elevated temperatures $\left(>400^{\circ} \mathrm{C}\right)$ for certain volatile fission product nuclides, particularly iodine and cesium. Freundlich (concentration-dependent) adsorption isotherms have been derived to describe these sorption phenomena. Currently, the required experimental sorption data are very limited; sufficient data exist to define quantitatively the behavior of cesium on SS304 stainless steel (some carbon steel data are also available) and of iodine on Chromaloy steel. Details are given in Appendix $F$. Thus the iodine isotherm is directly applicable to the deposition loop but the cesium isotherm is applicable only by inference. In summary, provision for possible sorption effects was made in modeling cesium and iodine deposition; all plateout surfaces were considered perfect sinks for strontium. As a matter of fact, the surface 


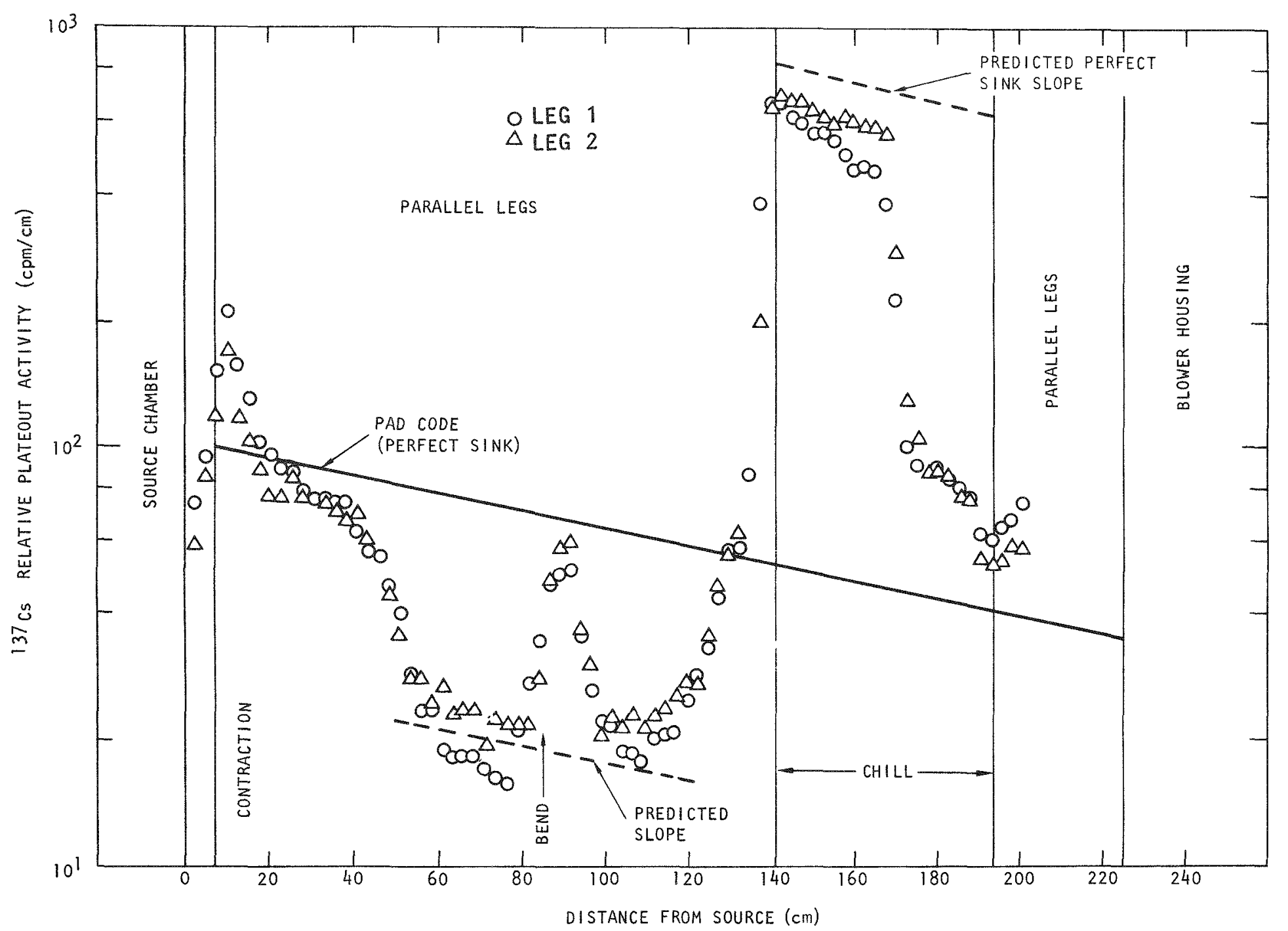

Fig. 32. PAD code simulation of loop No. 1 


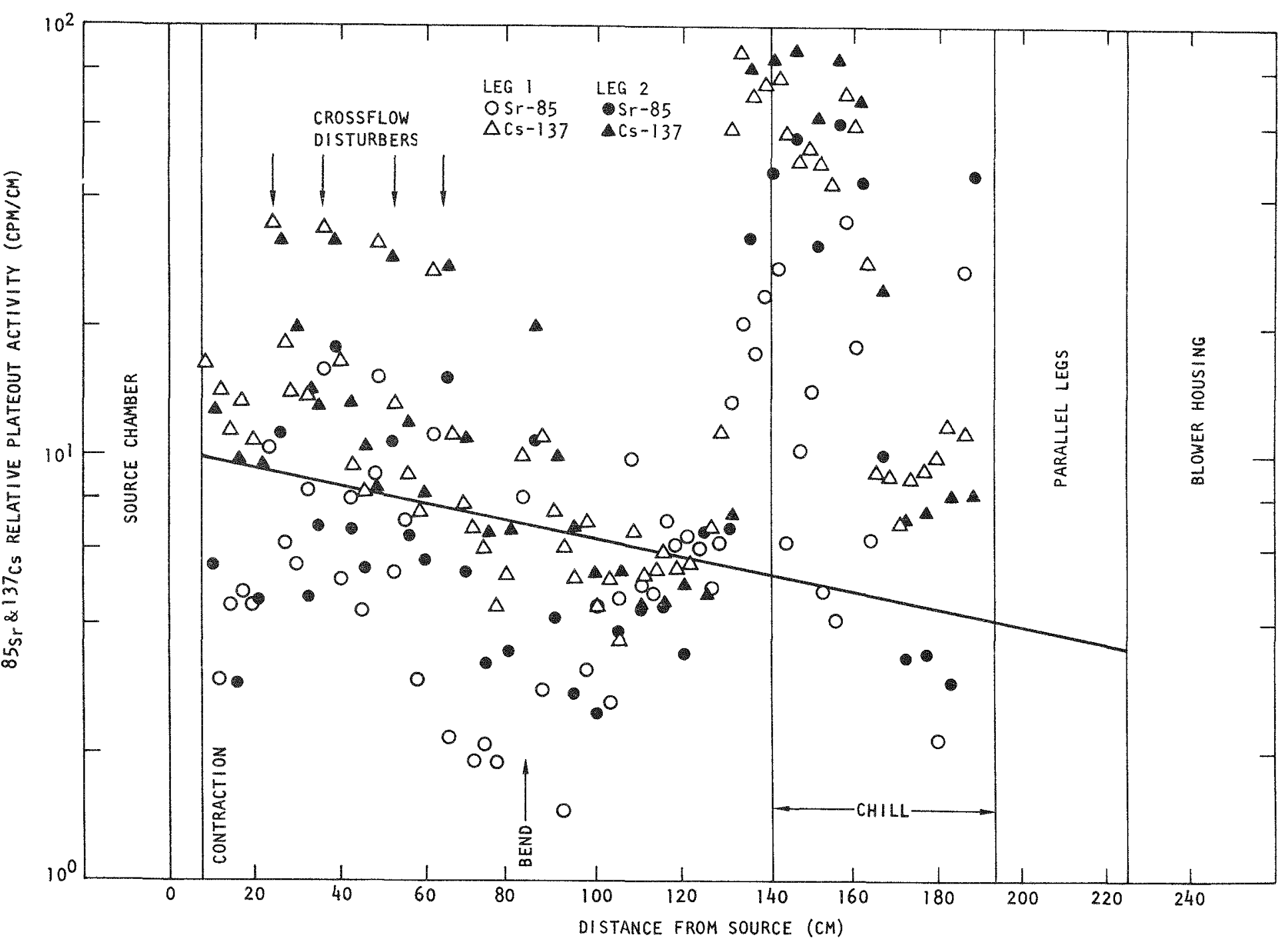

Fig. 33. PAD code simulation of 1oop No. 2 


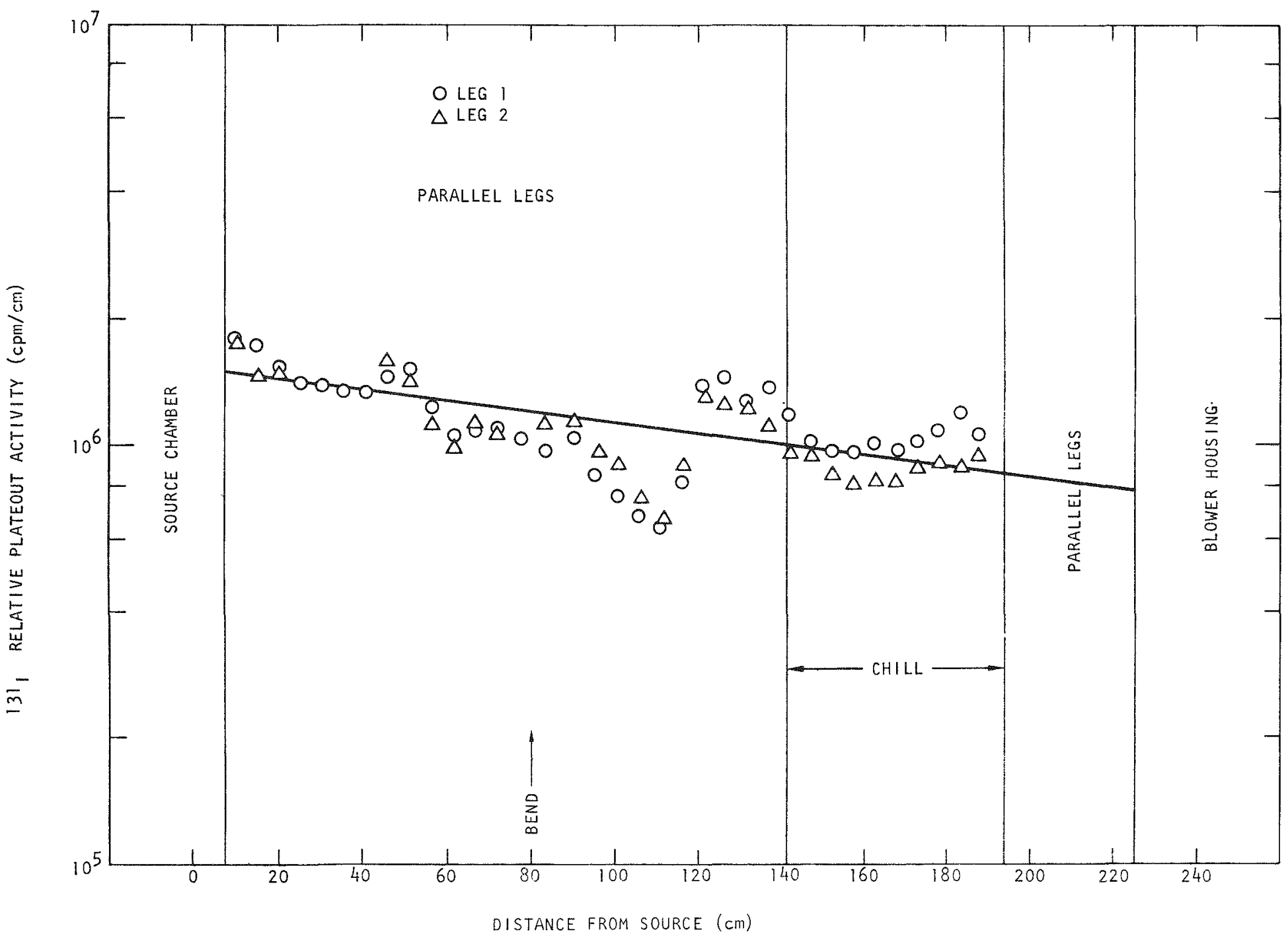

Fig. 34. PAD code simulation of loop No. 3 


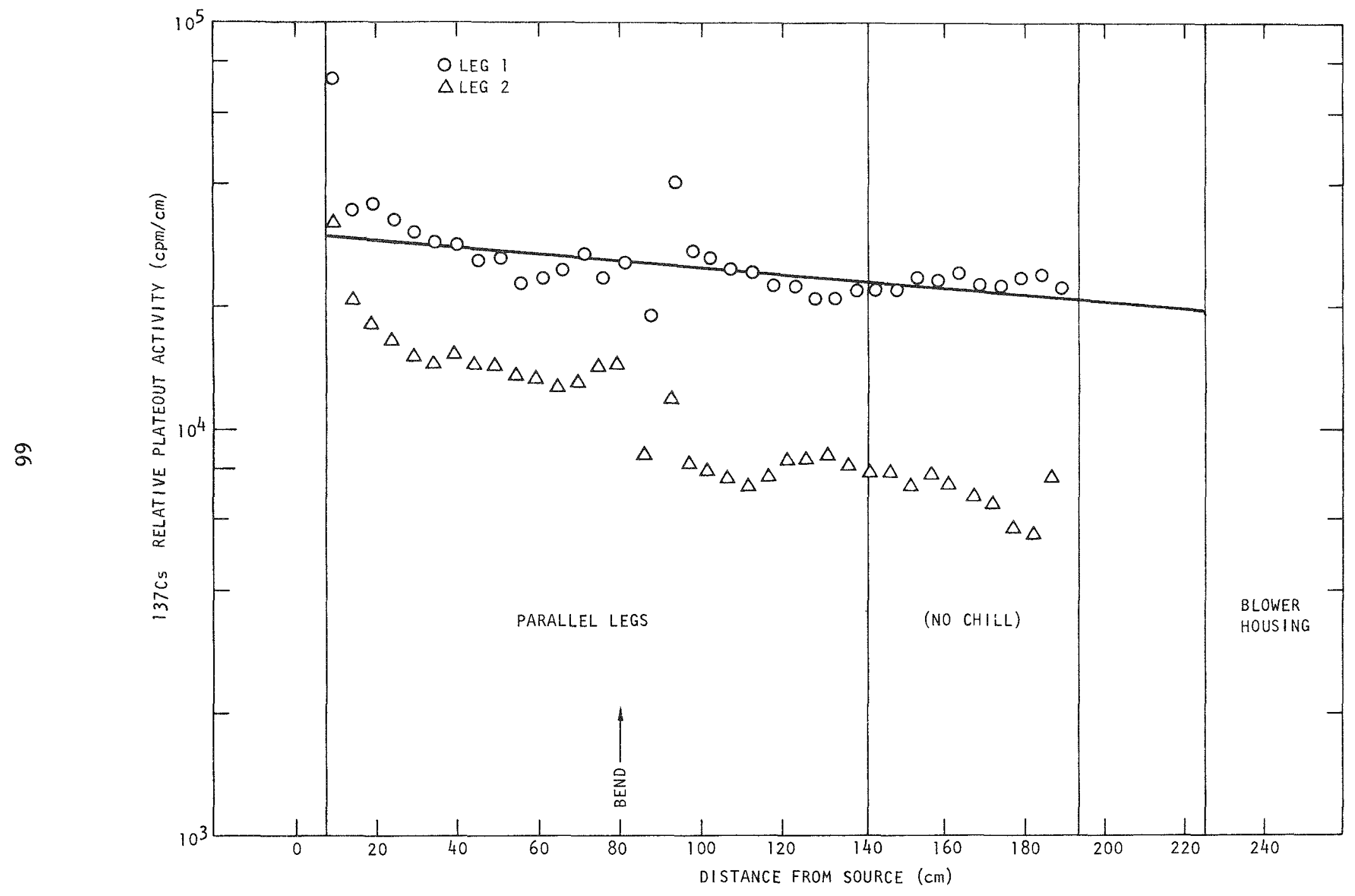

Fig. 35. PAD code simulation of loop No. 4 


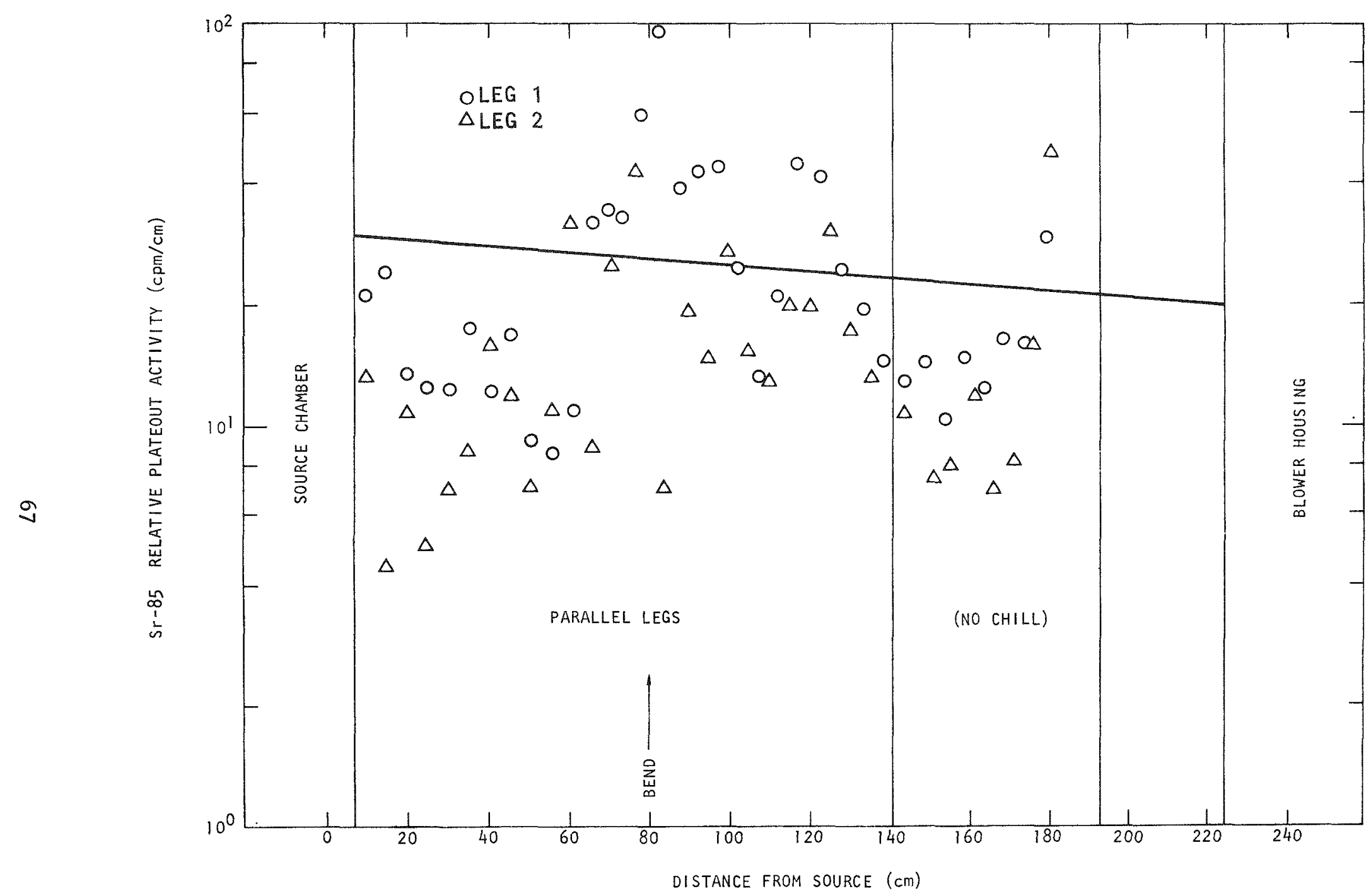

Fig. 36. PAD code simulation of loop No. 5 
coverages and temperatures prevailing in the deposition loop experiments were low enough so that in all cases the cesium and iodine desorption pressures as calculated from the reference isotherms were negligible compared to the partial pressures; therefore, the perfect sink simplification could have been applied. Consequently, the plateout distributions are independent of the surface concentration and thus the total inventory. This simplification makes comparison of the predicted and measured profiles easier because only the relative distributions are important. Thus, PAD code calculations are done assuming $100 \%$ release of source material and the resulting profile is normalized to give approximately the measured activity at the source chamber exit (which circumvents questions of counting efficiency).

Before reviewing the results of the code modeling, one other foreword is necessary. It has long been observed that flow disturbances that disrupt fully-developed boundary layers tend to enhance convective heat and mass transfer. Such enhancement was clearly demonstrated by the profiles obtained with the deposition 1oop. As developed in Appendix B, the PAD code does have an option of predicting this effect on the basis of an empirical correlation derived from a limited amount of heat transfer data. This option has not been exploited in modeling the loop results since the validity of this correlation is viewed as a separate problem of secondary importance to establishing the overall validity of the code. Modest discrepancies can then be expected at flow disturber locations and indeed are observed.

Inspection of Fig. 32 shows large discrepancies between the predicted and measured profiles. The slope of the experimental profile over the first $50 \mathrm{~cm}$ of tubing is much steeper than predicted, yet at other locations (see dotted lines) the slope is about as expected. Far more distressing, however, is the large but unpredicted increase of plateout levels in the chill section. The cause of this increase is unknown as is 
the reason for the abrupt decrease in activity, which occurs about half-way through the chill. Since the as-measured surface temperatures are low (s $260^{\circ} \mathrm{C}$ ), the predicted profile shows a monotonic decrease from the source.

The profile obtained in Loop 2 is only a little less surprising. The slope of the profile for the first $120 \mathrm{~cm}$ is about as predicted. The relatively higher specific activities on the cross-flow tubes could also have been expected based upon other observations by Silverman (Ref. 17). Nevertheless, the unexplained increased plateout in the chill section is again evident despite the scatter in the data. Another complication is the exact role played by the graphite dust poured into the 1oop: that a portion of the activity was associated with the dust is known, that it was transported on the dust is not. Furthermore, it is not known whether the Sr-85 activity volatilized or if small quantities of source material were entrained because of broken source crucibles.

The I-131 plateout profile obtained in Loop 3 is in good agreement with the predicted profile. The iodine profile is most interesting when compared to the cesium profile from Loop 1. The operating conditions of these two loops were quite similar, although Loop 3 did have a $20 \%$ higher mass flow rate and slightly lower surface temperatures (20 to $60^{\circ} \mathrm{C}$ lower). The effect of flow disturbers (particularly at the entrance contraction and 90-deg bend at the apex) seems much less pronounced on the iodine profile compared to the cesium profile. But more surprising, the chill section seems to have had much less effect on iodine than on cesium and strontium a strange effect indeed since iodine is the most volatile. The experimental profile decreases monotonically for the first $80 \mathrm{~cm}$, passes through a distinct valley, and then climbs to an abrupt peak at about 120 $\mathrm{cm}$. Since the profiles from the two parallel legs agree closely, the effect is not easily dismissed. The valley does occur at roughly the hottest location in the 10op, which suggests a sorption effect, but the following peak could be rationalized only if the chill entrance were 
located at about $110 \mathrm{~cm}$. Review of the experimental logs does not support the contention. Taken as a whole, the code-fit of the data is reassuringly good.

PAD code modeling of Loop 4 is confused by the disparity of the measured cesium profiles from the ostensibly identical legs. The predicted profile based upon nominal operating conditions (solid line in Fig. 35) is in excellent agreement with one of the experimental profiles. If the mass flow rates were substantially different in the two parallel legs, then the different slopes of the plateout distributions could be explained. For example, if the mass flow rate were halved, then the profile shown as a dashed line would be obtained. However, since the mass flow rate varies as the square root of the resistances, such a large flow mismatch is difficult to rationalize.

The amount of scatter in the Loop 5 strontium data makes comparison with code predictions meaningless. Figure 36 is included simply for completeness.

Taken as a whole, the quality of the deposition loop data is inadequate to provide a definitive test of the PAD code. While agreement with Loops 3 and 4 is reasonable, the chill effect in Loops 1 and 2 was not predicted or, for that matter, explained.

\subsubsection{Correlation of Plateout Distributions from the Literature}

Given the ambiquities in the deposition loop plateout distributions, a general review of the literature was undertaken. The primary reason was to obtain additional experimental data with which to test the validity of the PAD code. A secondary objective was to hopefully gain new insight into results of the deposition loop program, particularly the effect of the chill. 
3.2.2.1. PAD Modeling of BMI Out-of-Pile Deposition Loop. The BMI out-of-pile deposition loop experiments are reviewed in some detail in Appendix C. Plateout distributions for Ce-144, Ce-141 + Ce-144, Zr-95, Ru103, Cs-137, Te-129, and I-131 were reported (Refs, 14, 18). These profiles are reproduced in Figs. 37 through 40; the thin solid lines in these figures represent the BMI researchers' attempt to correlate the data, and the other curves represent the writer's attempt.

Since the loop geometry was simple and since the loop operating conditions were well documented, PAD code simulation of the loop was relatively straightforward. However, as discussed in Appendix C, two difficulties did arise. First, no surface temperatures were measured, only gas temperatures; fortunately, sufficient data were reported so that a simple thermal analysis could be performed. The uncertainty in the assumed temperatures is estimated to be less than $\pm 20^{\circ} \mathrm{C}$. Another complication was that no counting efficiencies were reported and that the complete plateout distribution was not reported. Such information is required for cesium and iodine because their plateout behavior is concentration-dependent. Nevertheless, their plateout inventories were estimated from the specified burnup of the fuel source upon assumption of $100 \%$ release from the uncoated $\mathrm{UC}_{2}$ fuel particles. The uncertainties are of the order of $\pm 100 \%$.

Preliminary parameter studies were performed with the PAD code using reference physical data as a base. Good qualitative agreement was realized when treating the surface as a perfect sink for Ce-144, $\mathrm{Zr}-95, \mathrm{Ru}-103$, and Te-129 and when employing extrapolated adsorption isotherms for $I-131$ and Cs-137. To obtain the proper cesium distribution, it was necessary to presume that the SS316 surfaces of the BMI Lop had a cesium sorptivity 1/333 that of oxidized SS304 for which laboratory sorption data are available (see Appendix F). Furthermore, it was necessary to assume that the iodine sorptivity of SS316 is about 1/10 that of chromaloy steel. Results are plotted as heavy lines in Figs. 37 through 40 . 


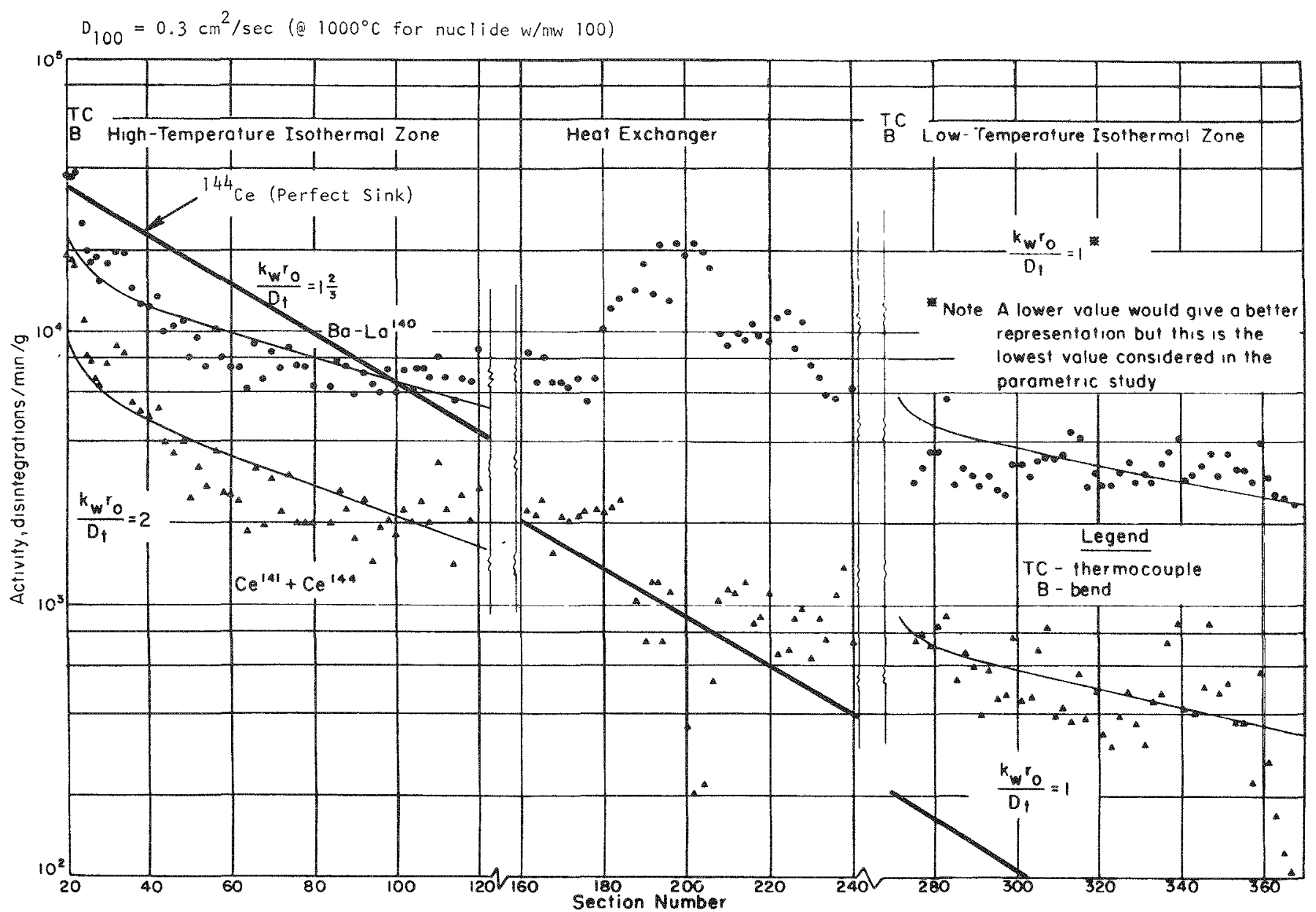

Fig. 37. Distribution of Ba-La 140 and $\mathrm{Ce}-141+\mathrm{Ce}-144$ activity in portions of experiment 10 loop 


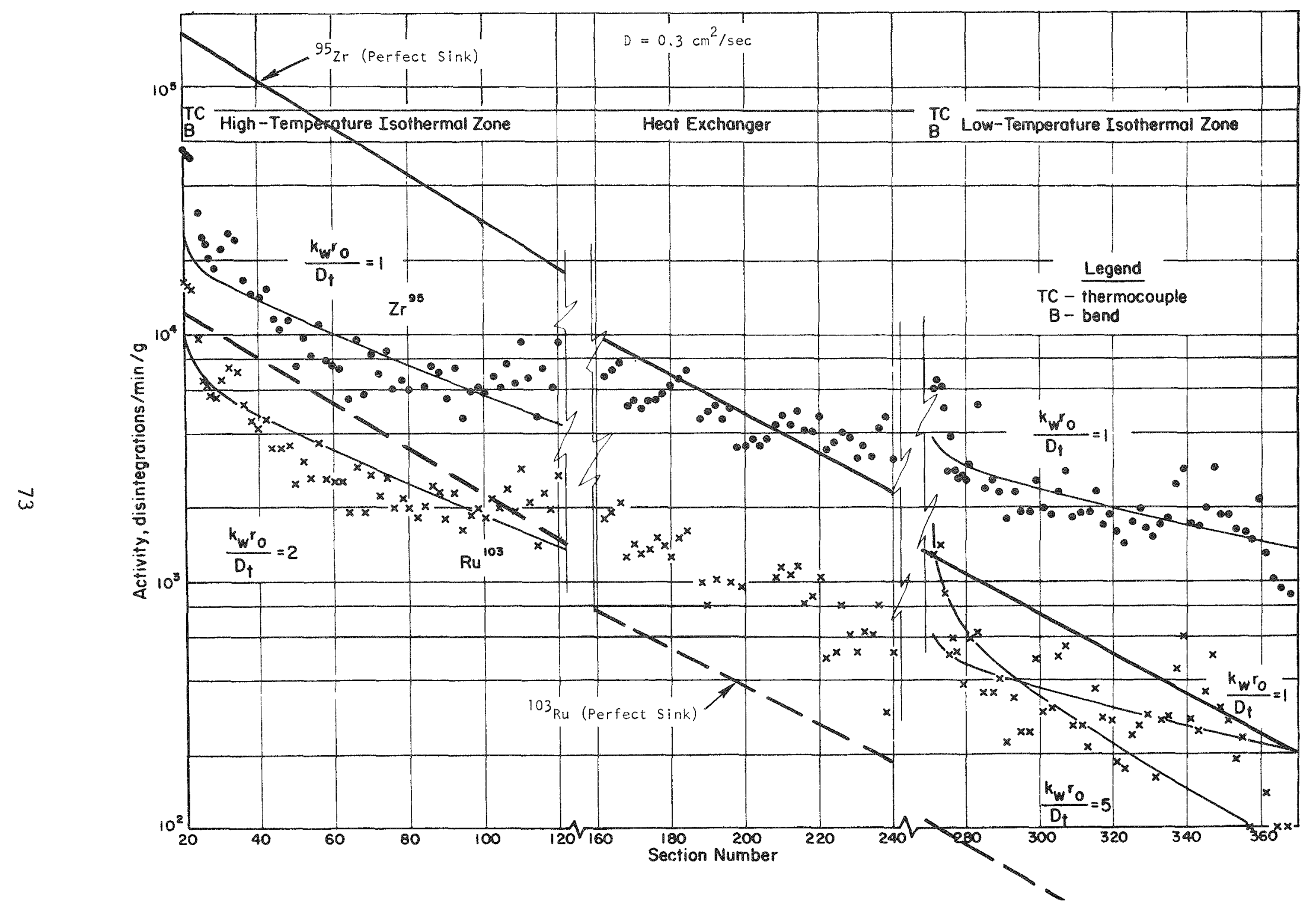

Fig. 38. Distribution of $\mathrm{Zr}-95$ and Ru-103 activity in portions of experiment 10 1oop (Ref. 18) 


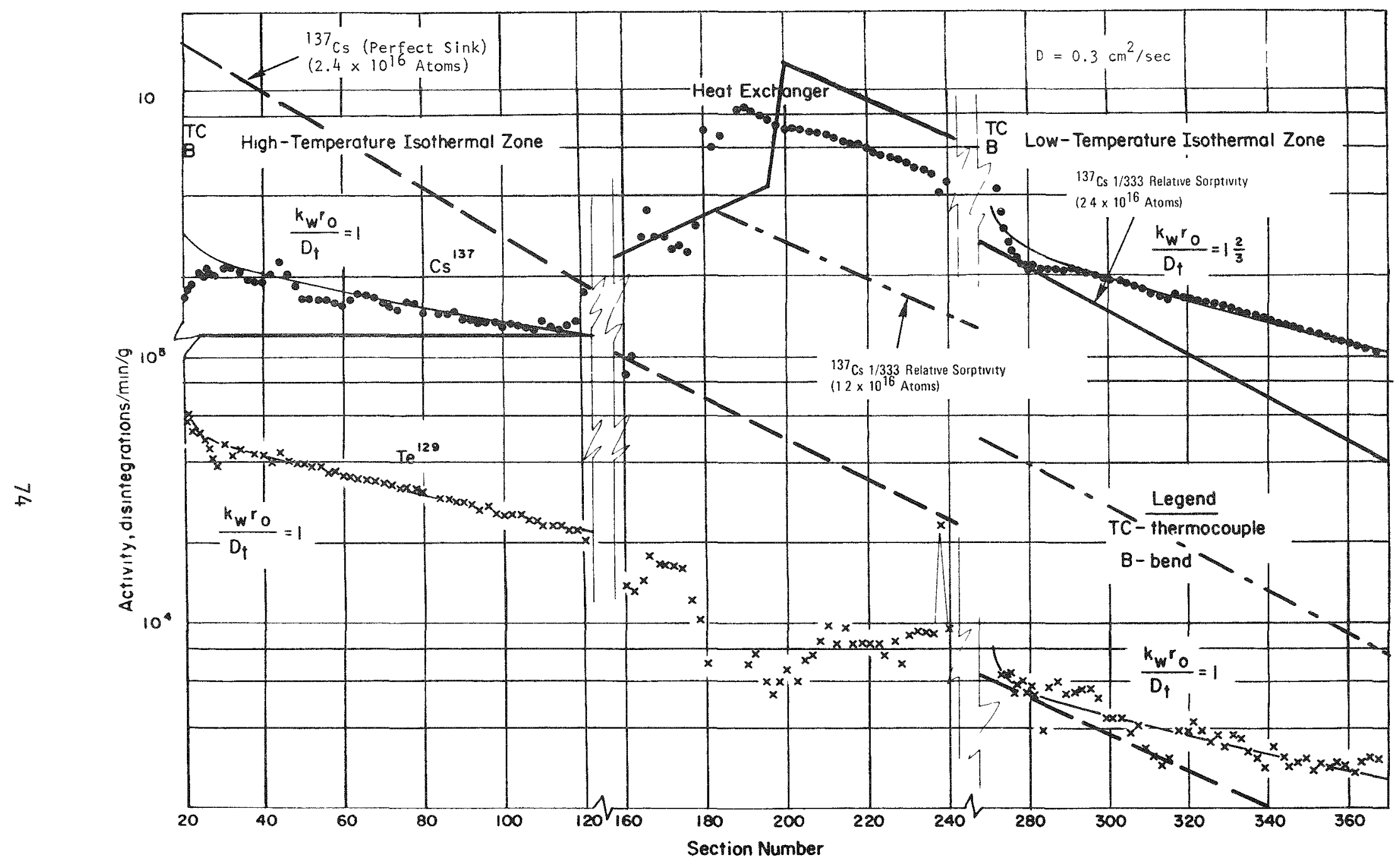

Fig. 39. Distribution of $\mathrm{Cs}-137$ and Te-129 activity in portions of experiment 10 1oop (Ref. 18) 


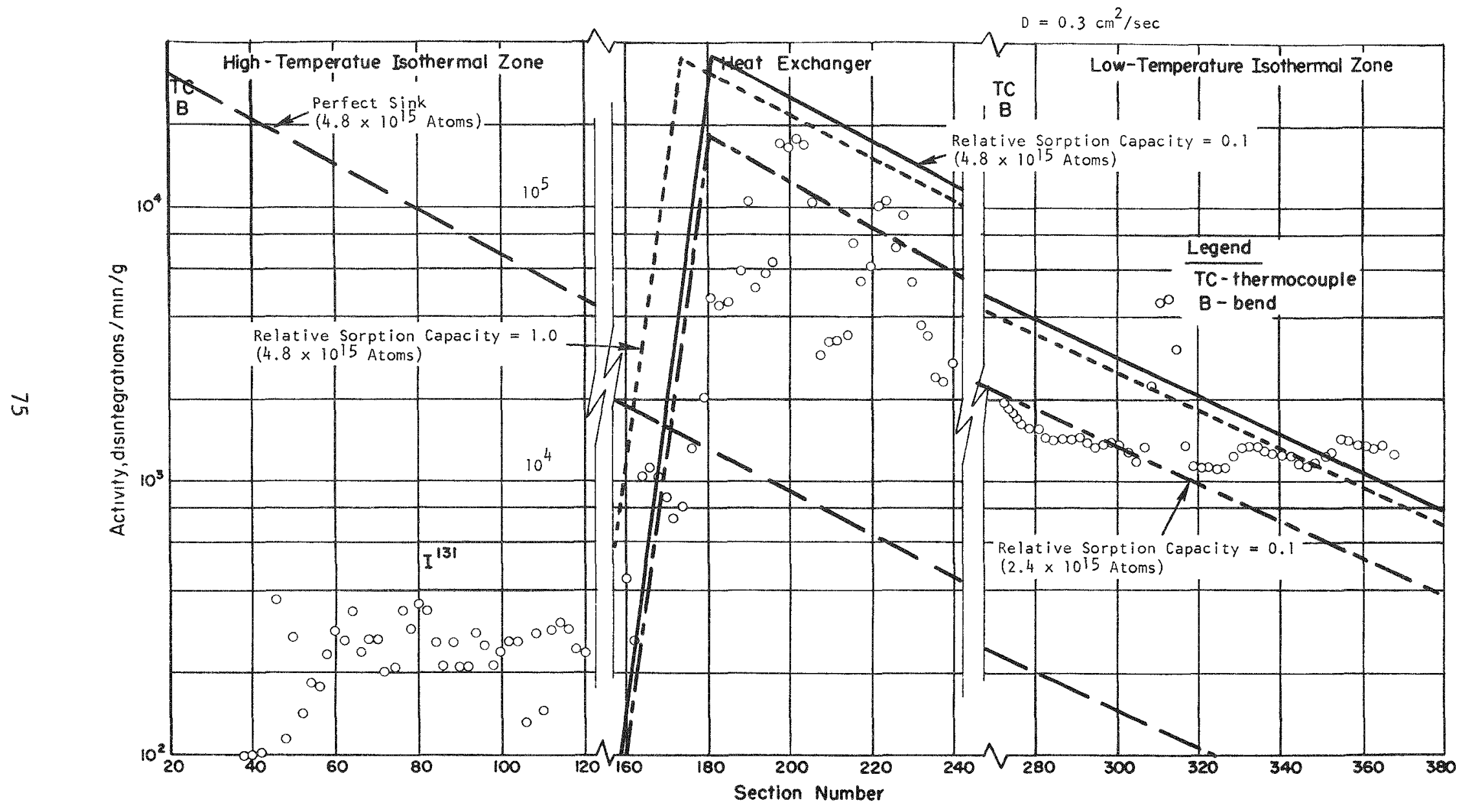

Fig. 40. Distribution of I-131 activity in portions of experiment 10 loop (Ref. 18) 
While the agreement is qualitatively good, the slopes of the predicted profiles are consistently steeper than that of the observed ones by 60 to $80 \%$. Under perfect sink conditions, the slope of the theoretical profile on semi- $\log$ coordinates is $-4 \mathrm{k} / \mathrm{Vd}$ where $\mathrm{k}$ is the mass transfer coefficient, $\mathrm{V}$ the velocity, and $\mathrm{d}$ the inside diameter (Refs. 13, 14, 19). Thus, the reasonable conclusion is that the mass transfer coefficient has been overestimated. This coefficient is calculated from the empirical correlation, which was derived from data with Re from 2000 to 35,000 , Sc from 0.6 to 2.5, and gas pressures from 0.1 to 3 atm (Ref. 27):

$$
\mathrm{Sh}=0.023 \operatorname{Re}^{0.83} \mathrm{Sc}^{0.44}
$$

or

$$
\frac{\mathrm{kd}}{\mathrm{D}}=0.023\left(\frac{\rho \mathrm{d}}{\mu}\right)^{0.83}\left(\frac{\mu}{\rho \mathrm{D}}\right)^{0.44}
$$

It follows that

$$
k \alpha(\rho)^{0.39}(V)^{0.83}(\mathrm{~d})^{-0.17}(\mu)^{-0.39}(\mathrm{D})^{0.56}
$$

The error in the mass transfer coefficient may result from an error in the physical data or the empirical correlation may be in error because of the high gas pressures and/or low Re numbers (about 5200) prevailing in the BMI 1oop. The most uncertain physical properties are the diffusivities of fission product nuclides in helium. Since $k \propto D^{0.56}$, the apparent 60 to $80 \%$ deviation in slope is equivalent to an error of about 2.5 to 3.0 in the diffusivity (not unreasonable). The explanation notwithstanding, the fit of the data is improved by a smaller mass transfer coefficient. For simplicity in code calculations, this reduction was accomplished by dividing the reference diffusivity by 2.5. Results are given in Figs. 41 


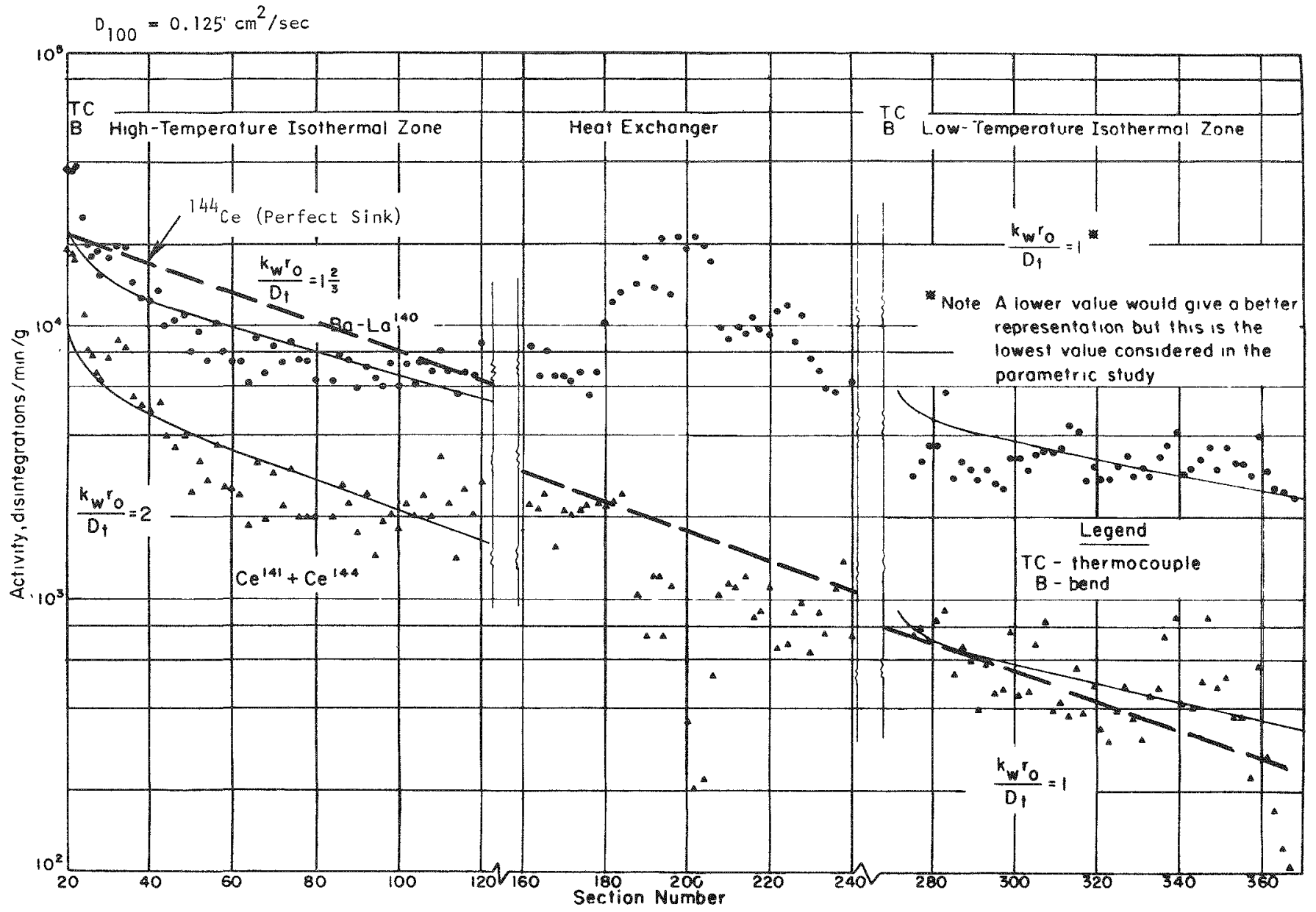

Fig. 41. Distribution of Ba-La 140 and Ce-141 + Ce-144 activity in portions of experiment 10 loop (Ref. 18) 
through 44. The apparent agreement is judged remarkably good although the slope of the profile is still slightly too high, and the plateout in the transition zones (not shown) is still over-estimated for some nuclides. It is also important to note that the PAD code considers a fully-developed boundary layer; i.e., it ignores end effects. It must also be emphasized that this apparent agreement does not prove that the reference diffusivities are too high, but simply that the mass transfer coefficient was overpredicted by about $60 \%$.

\subsubsection{PAD Modeling of the Cs-137 Plateout Distribution in the} Dragon HTGR. With the data described in Appendix $D$, the plateout distribution of $\mathrm{Cs}-137$ in the Dragon HTGR after fuel charge II was predicted with the $\mathrm{PAD}$ code for comparison with the experimental results.

From Table D-3, it is observed that about $220 \mathrm{mCi}$ of $\mathrm{Cs}-137$ were estimated to have been released into the Dragon primary circuit during fuel charges I and II and that about $90 \%$ of the total was released from fuel charge II. Furthermore, it is seen that less than $2 \%$ was estimated to have resulted from decay of Xe-137. Therefore, for simplicity, it was assumed that al1 $220 \mathrm{mCi}$ of $\mathrm{Cs}-137$ were released under fuel charge II conditions (i.e., that fuel charge II operated for a period $10 \%$ longer than it actually did) and that all plateout cesium had been directly released (i.e., production from noble gas parent decay was ignored). With these assumptions and time-average $R / B^{*} s^{*}($ Table $D-3)$, a series of PAD runs was made; results are summarized in Fig. 45.

Since laboratory experiments have shown that both graphite and steel surfaces have a finite capacity for cesium at elevated temperatures, it would be highly desirable to infer the importance of sorption effects from the Dragon plateout results. Such an analysis is complicated by the following factors: (1) materials in the Dragon primary circuit are different than those used in laboratory sorption experiments; (2) the plateout data

\footnotetext{
*Ratio of fission gas release rate to fission gas birth rate, at steady state.
} 


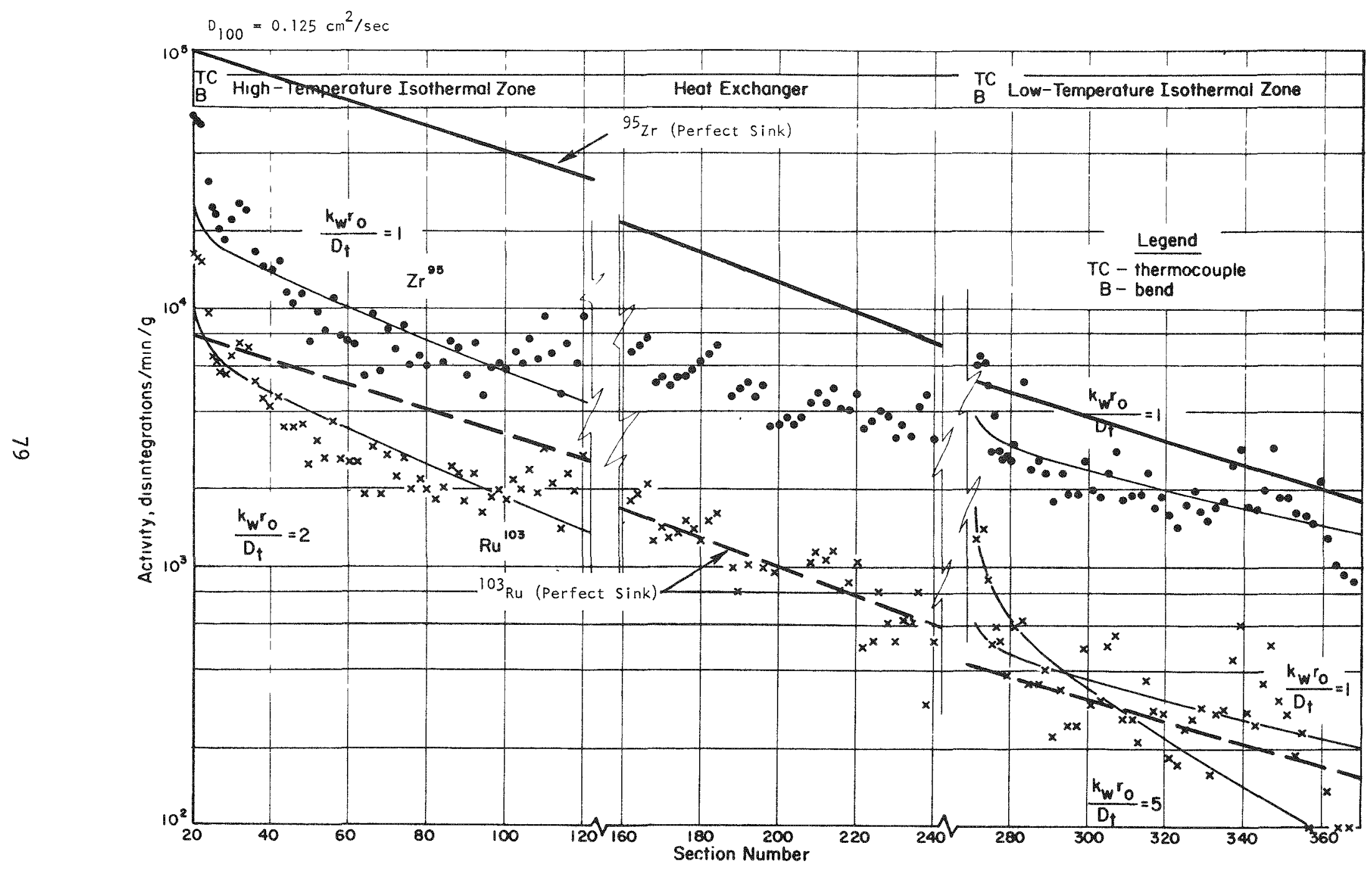

Fig. 42. Distribution of $\mathrm{Zr}-95$ and Ru-103 activity in portions of experiment 10 loop (Ref. 18) 


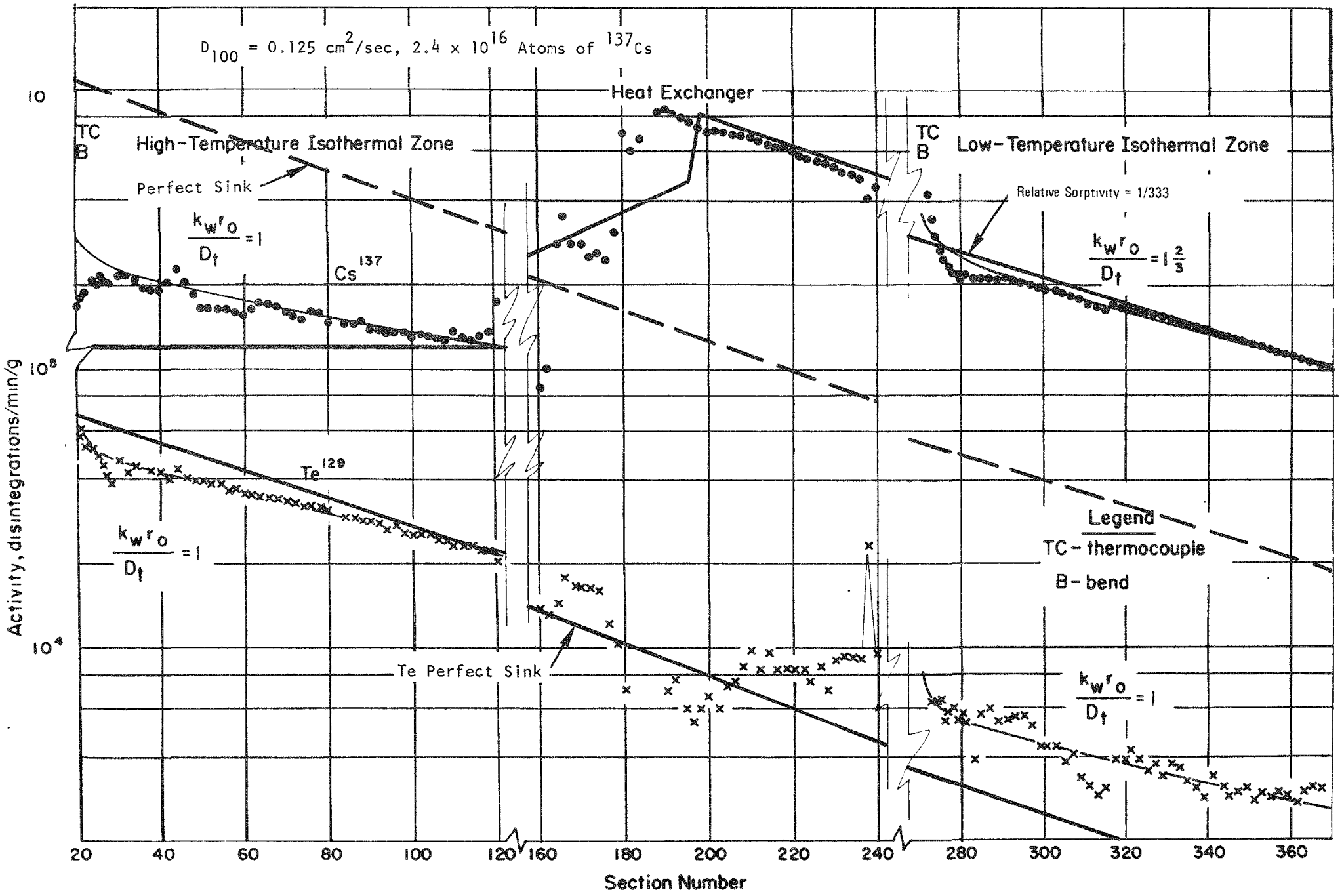

Fig. 43. Distribution of $\mathrm{Cs}-137$ and Te-129 activity in portions of experiment 10 10op (Ref. 18) 


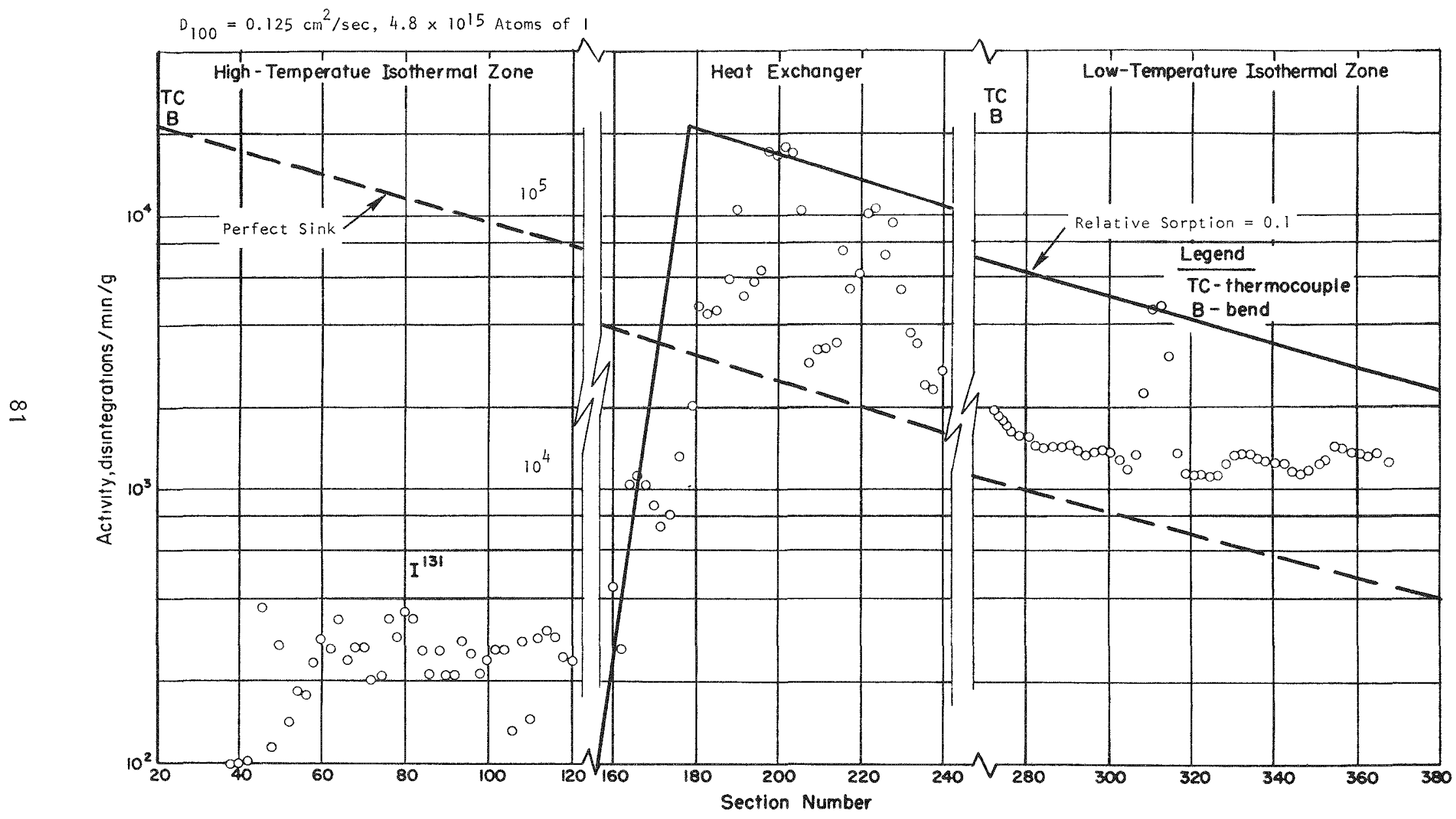

Fig. 44. Distribution of I-131 activity in portions of experiment 10 loop (Ref. 18) 


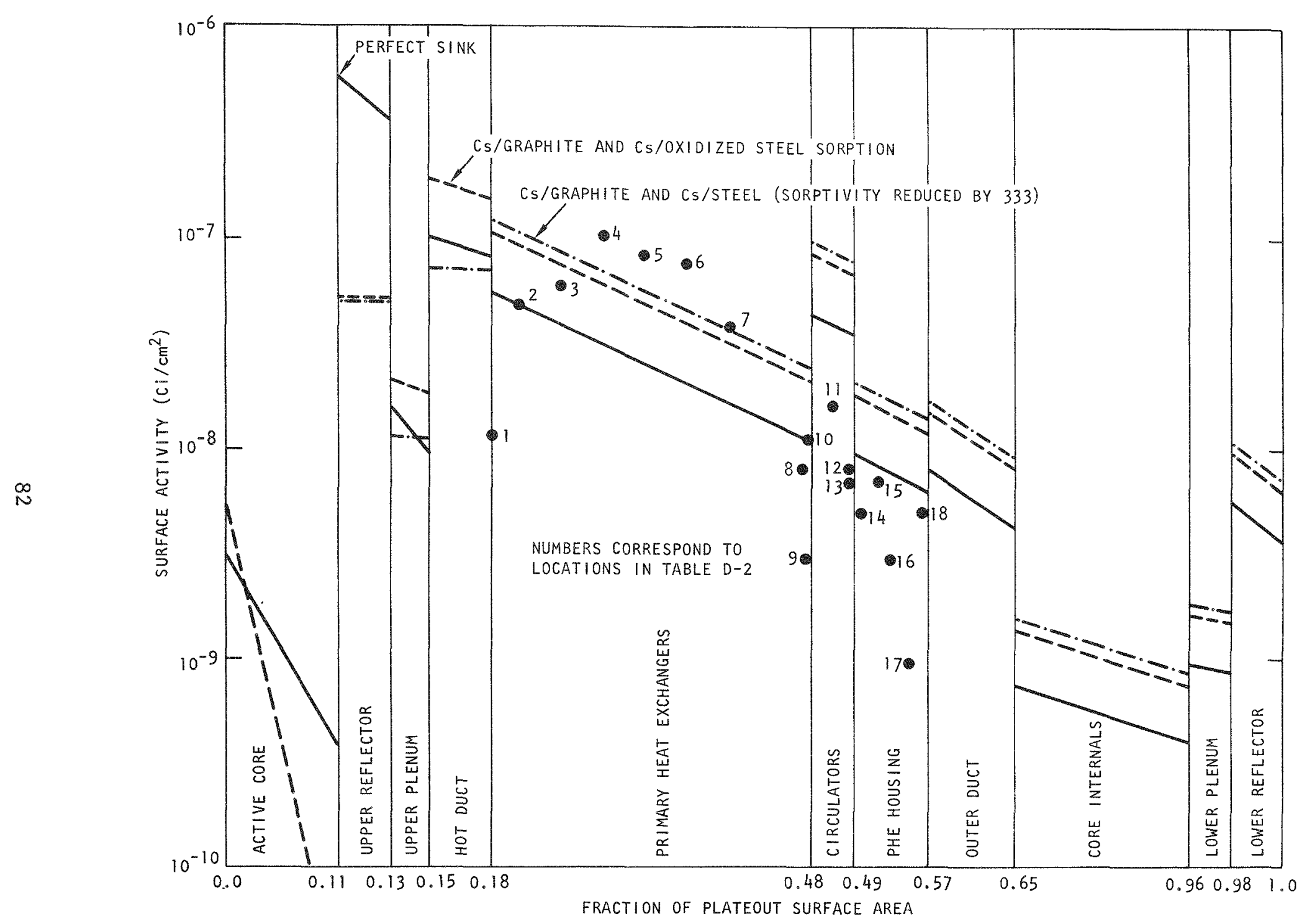

Fig. 45. Plateout of Cs-137 in Dragon primary circuit 
are concentrated in the primary exchanger where most surface temperatures are below $350^{\circ} \mathrm{C}$ (Refs. 5, 7); and (3) the total release of cesium is small. Nevertheless a parametric study was performed and four cases were considered: (1) perfect sink conditions throughout the circuit, (2) cesium/graphite and cesium/oxidized steel sorption, (3) case 2 with metal sorptivity reduced by a factor of 33, and (4) case 2 with metal sorptivity reduced by a factor of 333. In all cases, the primary heat exchanger tube bundle and cold leg were treated as perfect sinks because the reported surface temperatures were less than $350^{\circ} \mathrm{C}$ (Refs. 28, 29). However, it is obvious that at the entrance of the tube bundle the surface temperatures must exceed $350^{\circ} \mathrm{C}$; in fact a value of $460^{\circ} \mathrm{C}$ has been suggested (Ref. 29). Results are summarized in Fig. 45. (Actually, cases 2 and 3 were identical because the metal surface concentrations were too low to produce any sorption effects.)

The numbered data points in Fig. 45 correspond to experimentally determined surface activities from Table D-2 (Ref. 30) and the numbers identify positions indicated in Fig. C-2. Although the results do not clearly demonstrate sorption effects, the predicted results are in excellent agreement with the data; in fact, the discrepancies are generally within the estimated experimental error (factor of 2 in the heat exchangers and factor of 5 in the circulator and heat exchanger housing; Ref. 21).

\subsubsection{PAD Modeling of the Cs-137 Plateout Distribution in the}

Peach Bottom HTGR. No major components of the Peach Bottom HTGR primary circuit have had to be replaced during its operational life with the exception of some Core 1 fuel elements (Ref. 30). Therefore no definitive information regarding the plateout activity distribution presently exists. However, several external gamma surveys have been made by ORNL personnel (Ref. 23); this information together with some diffusion probe measurements (Refs. 23, 31) provide a tentative estimate of the plateout distribution in Peach Bottom. These preliminary data may serve as a provisional test of the PAD code. 
As developed in Appendix $E$, there is ambiguity regarding not only the relative plateout but also the total plateout inventory of important nuclides. While several different estimates of the Cs-137 inventory have been made, it is the writer's opinion that the actual inventory is probably between 10 and $100 \mathrm{Ci}$ of $\mathrm{Cs}-137$ and likely between 10 and $30 \mathrm{Ci}$.

Using a modified version of a PAD model of the Peach Bottom primary circuit prepared earlier by Mears (Ref. 32), the distribution of Cs-137 after Core 1 was predicted for total releases of 10 and $50 \mathrm{Ci}$. For each plateout level, three parametric cases were considered: (1) perfect sink conditions throughout the circuit; (2) cesium/graphite and cesium/steel sorption in the hot leg (with a metal sorptivity equal to that of oxidized SS304 (see Appendix F); and (3) case 2 with the metal sorptivity reduced to $1 / 100$ of that of case 2. Results are summarized in Figs. 46 and 47; the case 2 results are not plotted because the metal sorptivity was sufficiently high to cause essentially perfect sink behavior. Also plotted on the figures are some gamma scan measurements for Cs-137, Cs-134, and Ce-144; the cerium data were scaled up by a factor of 25 for ease of comparison and appear to indicate perfect sink behavior.

From comparison of the predicted and measured Cs-137 distributions, it is clear that the perfect sink assumption is inconsistent with the data. The apparent best fit of the data is obtained by assuming a total release of about $25 \mathrm{Ci}$ and a metal sorptivity about $1 / 15$ of that of oxidized SS304; the result is shown in Fig. 47. Upon assumption of isotopic scrambling, the Cs-134 data can also be compared with the Cs-137 prediction by direct scaling. Comparing the cesium data with the Ce-144 data reveals evidence of cesium sorption effects in the hot duct, but the conclusion is weakened by the uncertainties in the cesium inventories, the cesium distribution in the remainder of the circuit (particularly the steam generator), the role of minute quantities of fuel dust released during Core 1 failure (Ref. 30), and the effect of Core 2 operation prior to the data acquisition. 


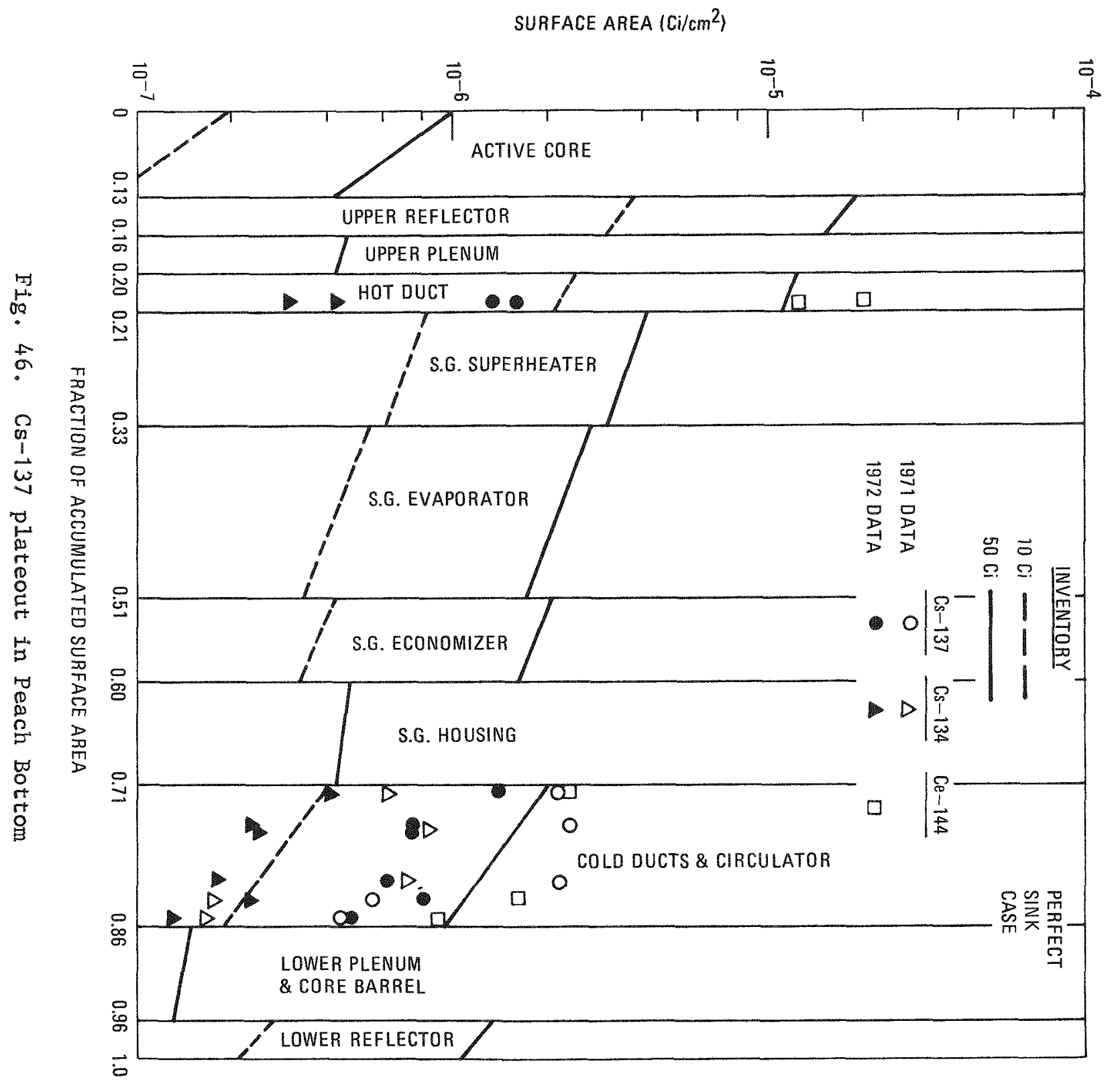




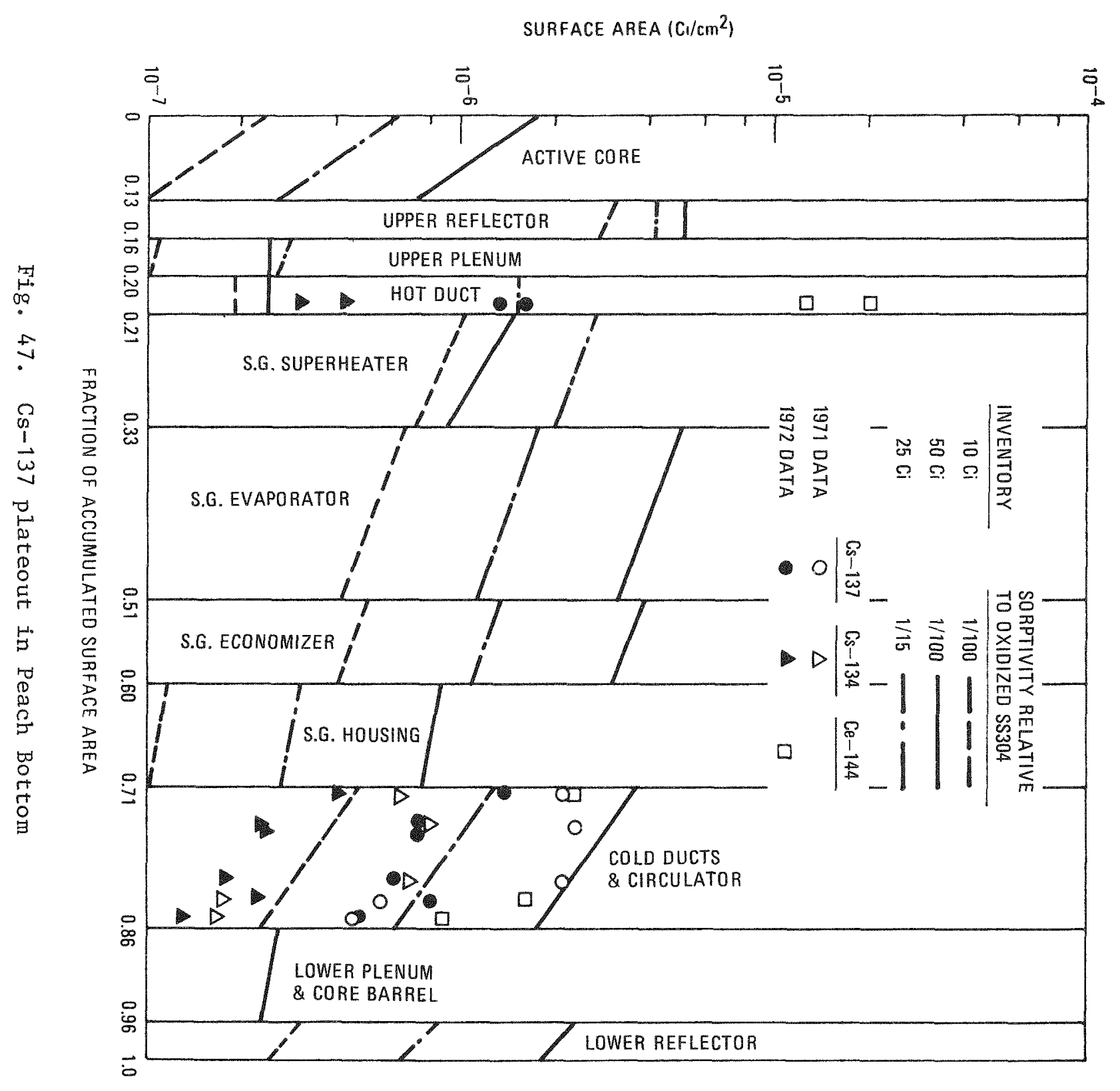




\section{DISCUSSION}

\subsection{BLOWDOWN/WIPEDOWN TESTS}

The blowdown tests reported herein demonstrate that very modest amounts of plateout activity $(<1 \%$ ) would be lifted off during a design basis depressurization accident if the primary circuit is relatively dust free. If the circuit contains large quantities of circulating and/or deposited carbonaceous particulate matter, then the situation is somewhat unclear. The blowdown and wipedown results of Loops 2 and 5 indicate that the presence of dust increases the ease of removal of deposited activity. However, great care must be taken in extrapolating the results of shortterm deposition loop experiments ( 1 to 5 days) to longer times (e.g., 40 years) because of possible migration of the dustborne activity from the deposited particulate matter to the base metal.

As reviewed earlier, laboratory experiments at GA have shown that when dusty metal specimens were exposed to iodine vapor, sorption occurred primarily $(>90 \%)$ on the metal surface. These results are also somewhat difficult to extrapolate to reactor conditions. By necessity laboratory experiments are conducted with iodine partial pressures typically from $10^{-9}$ atm to $10^{-6}$ atm; under these conditions and at temperatures less than about $400^{\circ} \mathrm{C}$, substantial quantities of volatile iron iodides are formed. On the other hand, iodine pressure of $10^{-15}$ to $10^{-13}$ atm are projected for the reactor; at these lower pressures, iron lodide formation is expected to be relatively unimportant (Ref. 33). Furthermore, the laboratory studies employed graphite powder ( 1 to $10 \mu \mathrm{m}$ ); but the circulating particulate matter in the Peach Bottom HTGR contains both crystalline (graphitic) and amorphous carbon, some of it as sma11 as $0.01 \mu \mathrm{m}$ (Ref. 23). Since the distribution of a given chemical species between dust and metal will depend upon the nature of the dust (among other things), the generality of the laboratory results may be questioned. 
Similar laboratory studies were performed for strontium (Refs. 34, 35). Probably the most definitive experiments were those in which Incoloy 800 tube specimens were mechanically loaded with graphite dust impregnated with strontium tagged with $\mathrm{Sr}-85$. Two sets of test specimens were then annealed at temperatures from $450^{\circ} \mathrm{C}$ to $900^{\circ} \mathrm{C}$ and for periods of 5.6 days and 135 days, respectively. After annealing, the samples were "blown down" (by rapid evacuation) and subsequently wiped with several acetone-soaked tissues. In a11 cases, significant fractions of the strontium (up to 1.0) migrated from the graphite and adhered to the metal surfaces, the rate of migration depending upon the annealing temperature. Again extrapolation to reactor conditions is compromised by uncertainties about the nature of the particulate matter. Dragon researchers have also suggested that strontium and cesium would migrate from carbonaceous dust to the metal oxide films (Ref. 36). Although the phenomena have yet to be quantified, the preference of strontium and cesium for metal oxides over carbonaceous dust is credible considering their high affinity for oxygen.

Another ambiguity regarding blowdown tests is the nature of the activity that is re-entrained. Conceivably, activity sorbed on both deposited particulate matter and loosely adherent oxide scale could be lifted off by high shear stresses. Since the lifted-off activity observed in the blowdown experiments was never accurately characterized, it is impossible to decide whether the liftoff fraction characterizes the amount of deposited activity associated with particulate matter or associated with removable surface deposits.

Other questions have been raised regarding the method of blowdown data correlation and extrapolation (Ref. 37). The introduction of the shear ratio concept implies that the adhesive forces bonding the depositing particle to the surface varies with the prevailing wall shear forces (or more precisely, the particle momentum) in such a manner that the subsequent shear force required to re-entrain the particle is a constant percentage 
greater than the shear force under deposition conditions. An alternative presumption is that the adhesive forces are relatively insensitive to the deposition conditions and the force required for re-entrainment is proportional to the absolute magnitude of the blowdown shear forces.

Comparison of the cesium liftoff data for GAIL IV and for Loop 4 (Fig. 31) demonstrates that for a given shear ratio, considerably higher fractional liftoffs were observed for the GAIL specimens. Since the deposition shear stresses in the GAIL 1oop were higher than in the deposition 1oop, the blowdown shear stresses (at a common shear ratio) were indeed higher in the GAIL tests in support of the latter blowdown model. However, when the fractional liftoffs were replotted as a function of blowdown shear stress, higher fractional liftoffs were again observed for the GAIL specimens of a common blowdown shear stress. Therefore, neither blowdown model can explain the discrepancy.

It is suggested that the explanation for the above discrepancy is that the nature of the deposited activity and thus the adhesive forces were different in the two sets of samples. With the GAIL samples, a relatively larger fraction of the plateout activity was associated with loosely adherent particulate matters and/or oxide scale. The real difficulty in extrapolating blowdown data is anticipating the nature of deposited activity to prevail in the reactor and then to reproduce those conditions in small scale configurations in which re-entrainment characteristics can be determined. In any case, considerable experimentation will be required to elucidate the mechanism of re-entrainment. Sophisticated theoretical models will be of little practical consequence without the fundamental physical data.

\subsection{DEPOSITION LOOP RESULTS}

Taken as a whole, the results of the deposition loop program are rather disappointing. Many of the difficulties realized can be ascribed to 
fundamental design flaws in the apparatus. It should be appreciated that the original emphasis was on preparation of representative samples for blowdown tests to confirm and extend the GAIL blowdown tests, which was accomplished; the plateout studies were less satisfactory. Limited funding initially available necessitated the extensive use of existing older equipment. Limitations of the deposition loop design are discussed below.

First and foremost, the loop was under-instrumented. Since the only operational $\Delta \mathrm{p}$ measurement was across the blower, one had to assume that the flow split equally between the two parallel legs of the loop - an assumption that was shown to hold for Loop 1 by preoperational flow measurements. However, because of the very small tolerances, each loop was essentially custom-built to fit the available space. Therefore, the equal partition of flow need not hold in all loops (and probably did not for Loop 4 where activities were consistently higher in one of the legs). More seriously, temperature measurements were inadequate, particularly in those experiments using the chill block. Since neither the inlet and outlet gas temperatures nor the inlet and outlet water temperatures were measured, even the simplest of heat balances could not be made. Because of the positioning of the deposition loop relative to the autoclave heaters, a large but rather undefined axial thermal gradient existed (about $400^{\circ} \mathrm{C}$ over about $140 \mathrm{~cm}$ ) which was observed to be nonlinear. In the end, it was necessary to assume that the gas temperature was always equal to the external surface temperature, which was taken as equal to the as-recorded thermocouple measurements. In Loops 4 and 5, where the chill block was omitted, the assumption is probably acceptable; in the other loops, it is questionable at best.

Second, the 10op was designed in such a manner that the blower could not be easily disassembled and decontaminated after each experiment. Since 30-year $\mathrm{Cs}-137$ was used in Loop 1, cesium contamination was present in all 
other experiments. In fact, in Loops 2 and 5, the amount of Cs-137 contamination throughout the 1oop was of the same order of magnitude as the Sr-85 activity released from the source. Admittedly, the fundamental problem was the inadequacy of the source heater to sustain sufficiently high temperatures to provide the desired strontium evaporation rates. Nevertheless, the Cs-137 contamination aggravated the situation.

Third, the entire deposition 1oop was designed to unnecessarily close tolerances. Consequently, binding and straining accompanied each insertion and removal of the loop from the autoclave. Even when in place and operational, there were external loads on various loop components. Indeed, the consequent bending load on the blower drive shaft caused displacement of the impellex relative to the housing. Again tolerances were excessively small so that contact occurred at several locations around the circumference. Finally, during operation of Loop 5, several of the impeller vanes (swaged joints) became dislodged and caused the blower to freeze. Subsequently, the blower housing was cut open and decontaminated, the impeller replaced, and the housing rewelded. The clearance problem was aggravated by this cutting and rewelding, and the impeller froze repeatedly in shakedown tests. During this period, the loop was loaded and unloaded to the autoclave many times; finally, the blower motor leads shorted at the penetration of the bottom head flange thereby burning out the blower motor. This failure contributed heavily to the decision to terminate the deposition loop program.

The plateout distributions measured in the deposition loop program are not easily explained, or even rationalized, by a consistent set of hypotheses. The Cs-137 profile measured in Loop 1 (Fig. 32) is particularly baffling. Portions of the profile are so steep that errors in mass transfer coefficient prediction as large as factors of 5 to 10 are implied; yet other portions of the profile exhibit essentially the predicted slope. Even more dramatic is the order of magnitude increase in specific activity 
observed in the upstream half of the chill section. Probably the most reasonable rationalization would evoke a temperature-dependent sorption effect. However, the temperatures and surface coverages are so low and the expected cesium sorptivity of chromaloy steel so high that sorption effects are completely unanticipated. Or stated more specifically, the available cesium sorption measurements on $\mathrm{SS} 304$ and carbon steel predict that the perfect sink assumption should apply. Furthermore, the bend at the apex of the loop is nearly the hottest location in the 1oop, yet the large local activity peak strongly suggests that turbulent diffusion to the wall is the rate-controlling process. The rapid decrease in specific activity in the downstream half of the chill also cannot be rationalized in terms of a simple adsorption process.

It has also been suggested that the increased plateout activity in the chill section could be, at least in part, due to an increased driving force because of the thermal gradient from the hot gas to the chilled wall. The effect of thermal gradients on deposition has been analyzed by Ozisik (Ref. 38). To describe the relative contribution of thermal diffusion, he has defined a diffusion ratio $\mathrm{K}$ which is the ratio of the thermal diffusion to the ordinary diffusion:

$$
K=\alpha_{t}\left(\frac{P r}{S c}\right)^{1 / 3}\left(\frac{T-T_{W}}{T+T_{W}}\right) \text {, }
$$

where $\mathrm{T}=$ bulk gas temperature, ${ }^{\circ} \mathrm{K}$,

$$
\begin{aligned}
& T_{W}=\text { surface temperature, }{ }^{\circ} \mathrm{K}, \\
& \operatorname{Pr}=\frac{\mu C p}{k}, \text { the Prandtl number, } \\
& S c=\frac{\mu}{\rho D}, \text { the Schmidt number, } \\
& \alpha_{t}=\text { thermal diffusion factor. }
\end{aligned}
$$


All variables under deposition conditions can be easily estimated except for the thermal diffusion factor $\alpha_{t}$. While $\alpha_{t}$ can be estimated from Leonard-Jones parameters, Ozisik states that practically $0<\alpha_{t}<1$; therefore, $\alpha_{t}$ is taken as unity for conservatism. The maximum contribution of thermal diffusion to deposition at the entrance of the chill section is estimated to be

$$
K=(1.0)\left(\frac{0.67}{2.0}\right)^{1 / 3}\left(\frac{400-323}{400+323}\right)=0.074
$$

Clearly, thermal diffusion does not explain the order of magnitude increase in the chill section.

The effect of the chill was also clearly evident in Loop 2 in which the deposited activity was $\mathrm{Sr}-85$ source material and $\mathrm{Cs}-137$ contamination. Interpretation of this experiment was complicated by the inclusion of graphite dust, the exact role of which is undefined. On the other hand, the chill had a very modest effect on the deposition of iodine, in agreement with the reference lodine isotherm (Ref. 15). Thus the chill section affected the deposition of cesium and strontium but not iodine under comparable conditions; the writer cannot provide any rationale for such behavior.

While the effect of the chill observed in Loops 1 and 2 is obviously real, it is the writer's opinion that the plateout distribution reported for Loop 1 is distorted since the large slopes reported upstream of the chill occur in no other loop. Furthermore, the plateout profile for Loop 1 was measured by traversing the intact loop with a mobile detector; in all 
other loops, the loop was cut up into 1 to 2 in. sections prior to counting. It is therefore speculated that systematic counting errors were introduced into the Loop 1 measurements. The exact procedure used in counting Loop 1 was not sufficiently well documented to confirm this supposition.

The Loop 4 plateout distribution is anomalous for a different reason in that the specific activity in one of the two parallel legs was consistently higher than in the other. Furthermore, the profile is steeper in the leg with the higher specific activity. The writer has suggested that this discrepancy may be a consequence of different mass flows in the legs because of different resistances. Although such an argument is logically sound, it is difficult to rationalize how the resistance in one leg could be of the order of four times the other as required to explain the difference in specific activities. Again the difficulty remains unresolved.

\subsection{BATTELLE MEMORIAL INSTITUTE OUT-OF-PILE LOOP}

Figures 41 through 44 show that the PAD code is an adequate tool for predicting plateout distribution providing that the total release is known and the proper sorption isotherms are employed. While these qualifications present formidable problems, they in no way compromise the validity of the code.

The BMI loop experiments are important enough to merit a discussion of each individual profile. In the following discussion the BMI profiles are compared to those appearing in the design document (Ref. 39).

The Ba-La 140 profile (Fig. 41) is not understood. The profile in the high temperature zone would tend to indicate perfect sink conditions; that in the heat exchanger, sorption effects; and that in the low temperature 
zone, decay from gaseous percursor (i.e., a uniform profile). A simplified statement of the relevant decay chain is

$$
140 \mathrm{Xe} \stackrel{13.6 \mathrm{~s}}{\rightarrow} 140 \mathrm{Cs} \stackrel{63.8 \mathrm{~s}}{\rightarrow} 140 \mathrm{Ba} \stackrel{12.8 \mathrm{~d}}{\rightarrow} 140 \mathrm{La} \stackrel{40.2 \mathrm{~h}}{\rightarrow} 140 \mathrm{Ce}
$$

which ignores branching and components from other chains (Ref. 40). The point is that the fuel specimen had decayed some 62 days before the commencement of the experiment (Table C1). Therefore, all the short-lived $\mathrm{Xe}-140$ and $\mathrm{Cs}-140$ would have decayed, and the release of -140 nuclides would have been primarily as Ba-140 and a small amount of La-140. Although the writer knows of no laboratory studies of the sorption behavior of barium on steels, perfect sink conditions might have been expected. Interestingly, had this profile been generated in an in-pile loop, the shape might have been rationalized as the sum of two components: perfect sink plateout of $\mathrm{Ba}-140$ and $\mathrm{La}-140$; and of $\mathrm{Cs}-140$ born from gaseous Xe-140 plating out in accordance with the cesium profile (Fig. 43) in the hottest sections and plating out uniformly in the colder sections. This argument is, of course, invalid under the present circumstances. Laboratory experiments to determine the barium sorption capacities of various steels appear warranted. Since the vapor pressure of strontium metal is significantly higher than that of barium (Ref. 20), which says nothing about the respective oxides or carbides, the possibility of strontium-onsteel sorption effects also might be considered.

The Ce-141, Ce-144 profile (Fig, 41) reflects the expected perfect sink behavior. The predicted distribution (but not the total release and thus absolute activity of cerium) is in excellent agreement with the data although actual profiles are slightly flatter than predicted. Thus, these experimental results confirm the reference Ce-144 profile if the mass transfer coefficients are properly predicted.

The $\mathrm{Zr}-95$ and $\mathrm{Ru}-103$ profiles (Fig. 42) are unique not in their shape (perfect sink) but in their very existence. Current information suggests 
negligible release of such metals or their carbides. However, both metals are known to form volatile tetroxides (Ref. 42). If the $\mathrm{UC}_{2}$ kernels were hydrolyzed, it is conceivable that relatively volatile compounds containing these metals could be formed.

Portions of the fuel specimen could have eroded thereby generating an aerosol resulting in the transport of nonvolatile fission products such as $\mathrm{Zr}-95$ and $\mathrm{Ru}-103$. But this is unlikely since, if true, every conceivable long-lived fission product (including actinides, 1anthanides) and, in addition, transuranium elements would have been so transported giving rise to a very complicated gamma spectrogram which surely would have drawn the comments of Raines et al. Furthermore, it would seem truly remarkable if the deposition of an aerosol over a range of temperatures were almost exactly described by a mass transfer coefficient derived for a molecule of molecular weight 137. Finally, since the PAD code is only an empirical tool, such a mechanistic argument is irrelevant as long as the predictions fit the data.

The Cs-137 profile (Fig. 43) is considered definitive proof that the perfect sink assumption is not in general appropriate for prediction of cesium plateout distribution. Considering that the isotherm used to obtain the profile was derived from data extrapolated to six orders of magnitude, the accuracy of the fit must be somewhat fortuitous. Nevertheless, the agreement indicates that the simplistic model employed by the PAD code (convective transport coupled with equilibrium adsorption at the surface) is an acceptable empirical approach. The pertinent question, of course, is the choice of isotherm. While the sorptivity of various steels appears to vary considerably, the temperature dependence appears to be approximately correct.

While the experimental Cs-137 profile indicates that the surfaces in the high temperature zone were not perfect sinks, there is definitely a 
negative slope to the profile in that region. If the section were indeed isothermal, then the profile would be flat; i.e., uniformly equilibrated. Furthermore, the surface temperature at the exit of the section might be expected to be 10 to $20^{\circ} \mathrm{C}$ lower than at the entrance, which would give rise to a positive slope. No definitive explanation can be offered for the discrepancy. It can be speculated, however, that the sloping profile reflects a similar profile in the surface oxidation state. Since the cesium sorptivity is known to be highly dependent upon the amount of surface oxide (Ref.9), such an explanation seems the most reasonable. The effect could also be rationalized if cesium interacts with the interior phases (oxide or metal) by an activated process having a greater activation energy than the adsorption process. Since the surface temperature is probably slightly higher and the time-average surface concentration clearly higher at the entrance, a situation could occur in which the surface concentration is slightly higher at the exit with the total specific surface activity still higher at the entrance. Questions of mechanism aside, the deposition of cesium is clearly temperature-dependent as shown in the heat exchanger zone.

The Te-129 profile (Fig. 43) indicates perfect sink deposition under the surface temperature and coverages realized in the BMI 1oop. Such an observation is somewhat surprising since tellurium is only moderately less volatile than cesium (Ref. 42). However, since molten tellurium is known to corrode stainless steel (Ref. 41) via a mechanism involving formation of nickel tellurides, minute quantities of tellurium also might react chemically with steel at high temperatures.

The I-131 profile (Fig. 44) shows the strong temperature dependence of iodine deposition. Inspection of Fig. 40 shows the strong dependence of the plateout distribution on iodine inventory. Although the iodine isotherm employed in this study (Ref. 15) gives the proper qualitative 
results, the overall agreement is considerably less good than that for cesium. The experimental data show a negligible anount of iodine in the high temperature zone. While this trend is predicted, the actual activity levels were under-predicted by two to three orders of magnitude. In the heat exchanger, the right profile is approximately obtained. However, in the low-temperature zone (surface at $350^{\circ} \mathrm{C}$ ), the surface appears to be equilibrated as evidenced by the spike in activity at a cold spot. The isotherm employed would predict that the surface concentration of iodine should be about an order of magnitude higher than that observed for equilibrium to occur. These results are in qualitative agreement with the reference iodine profile; however, the relative sorptivities of the various metals need further refinement. That the present iodine-on-steel isotherm derived from $\mathrm{T} 2$ steel does not describe the behavior of iodine on SS316 is not surprising.

Additional information can be deduced from the BMI experiments, such as the effects of flow disturbers (see Fig. C-2); however, the reader is referred to the original report (Ref, 14).

This study shows that the plateout of fission products is not as mysterious as once thought. The proper physical chemical data (e.g., gaseous diffusivities and adsorption isotherms) are simply required.

\subsection{DRAGON HTGR}

Considering the number of assumptions that were necessary in modeling the Dragon primary circuit, the apparent agreement in Fig. 45 is considered truly remarkable. Furthermore, the agreement could be improved by correcting for some obvious modeling flaws. The most conceptually serious flaw is that the PAD code uses the same correlation for prediction of the mass transfer coefficient (Eq. 3-1) throughout the reactor circuit; vis.,

$$
\mathrm{Sh}_{\mathrm{h}}=0.023 \mathrm{Re}^{0.83} \mathrm{Sc}^{0.44}
$$


The Sherwood number Sh, the Reynolds number Re, and the Schmidt number Sc are dimensionless groups whose definitions were given previously (p.76). Actually, this empirically determined correlation is the mass transfer equivalent of the Dittus-Boelter correlation for prediction of heat transfer coefficients:

$$
\mathrm{Nu}=0.023 \mathrm{Re}^{0.8} \mathrm{Pr}^{0.4}
$$

which demonstrates the validity of the heat-mass analogy for turbulent transfer inside circular pipes (Ref. 27).

In its simplest form, the heat-mass analogy presumes that mass transfer coefficients can be predicted from the same correlations as heat transfer coefficients by substitution of the Sherwood number Sh for the Nusselt number $\mathrm{Nu}$ and the Schmidt number $\mathrm{Sc}$ for the Prandt number Pr. The validity of this analogy has been demonstrated for some but not all geometries (Ref. 43). Based upon the analogy, this correlation is not appropriate for flow over multiple banks of tubes where the following correlation applies (Ref. 44) rather than Eq. 3-1:

$$
\mathrm{Sh}=0.33(\mathrm{Re})^{0.6}(\mathrm{Sc})^{0.33}
$$

As a matter of fact, the conditions in the Dragon heat exchanger (helical coils) are such that the actual error is small, as is demonstrated below.

The average fluid properties (based upon bulk fluid temperatures) in the heat exchanger are:

$$
\begin{aligned}
& P=20 \mathrm{~atm}, \\
& T=493^{\circ} \mathrm{C}
\end{aligned}
$$




$$
\begin{aligned}
& \mathrm{Re}=7571 \\
& \mathrm{Sc}=2.0 .
\end{aligned}
$$

Equation $3-1$ gives

$$
\begin{aligned}
k & =\left(\frac{1.543 \times 10^{-1}}{1.8}\right) 0.023(7571)^{0.83}(2.0)^{0.44,} \\
& =4.4 \mathrm{~cm} / \mathrm{sec},
\end{aligned}
$$

and Eq. 4-2 gives

$$
\begin{aligned}
k & =\frac{1.543 \times 10^{-1}}{1.8}(0.33)(7571)^{0.6}(2.0)^{0.33} \\
& =7.5 \mathrm{~cm} / \mathrm{sec} .
\end{aligned}
$$

or about $70 \%$ higher. The practical consequence of this difference would be to increase the surface concentration at the entrance of the heat exchanger by a factor of 1.7 and to increase the negative slope in the section by 1.7; the plateout downstream of the heat exchanger would be slightly lowered to reflect changes in the overall mass balance. While these changes would improve the overall fit, the change is judged insignificant in the present context. In the larger sense, however, it is obviously desirable to modify the PAD code to permit a section-by-section specification of the transport correlation to reflect differences in geometry.

It is also observed that the plateout is consistently overpredicted in the circulator and the annular heat exchanger housing sections. These discrepancies are interpreted as errors in accurately predicting the mass transfer coefficient for these complex flow geometries. 
The first impression given by Fig. 45 is that one profile fits the data about as good as the others; i.e., that cesium sorption considerations have little or no effects on cesium plateout in Dragon. A more considered opinion is that the results are ambiguous since the data are concentrated in one portion of the circuit, the total cesium release was quite low, and the sampled surfaces were reported below $350^{\circ} \mathrm{C}$. Nevertheless, there are strong suggestions of sorption effects in the hottest locations examined. For example, consider the first seven data points as identified in Fig. 45; plateout locations 1 and 2 correspond to hot surfaces that should be nearly at the inlet gas temperature of $740^{\circ} \mathrm{C}$, and the transport characteristics at these points should be similar to those prevailing in the hot duct. From Fig. 45, it is seen that the measured activities at points 1 and 2 are lower than predicted for the exit of the hot duct using the perfect sink assumption. Furthermore, points 3,4,5,6, and 7 should represent a homologous series as one proceeds down the tube bundle. If the surfaces were perfect sinks, then these points would reflect a monotonic exponential decrease in activity with distance; actually, such an exponential profile was observed after fuel charge I (Fig. D-3). Since the data after fuel charge II are noticeably flatter (desorption pressure of the plateout approaching the gaseous partial pressure), it is possible that the hotter surfaces of the heat exchanger are beginning to equilibrate. Such a contention is highly speculative at best; if genuine, then the carbon steel tube surfaces (Mannesmann Specification S135.8/111) would have a cesium sorptivity about a factor of 300 to 2000 less than that of the oxidized SS304 steel used in GA laboratory experiments. Such a presumption is highly unlikely unless the Dragon coolant is highly reducing. On the other hand, such a low sorptivity might be possible for the surfaces at points 1 and 2 (nimonic alloy and austenitic steel, respectively). 
4.5. PEACH BOTTOM HTGR

Figures 46 and 47 show that the total release of Cs-137 must have been of the order of $25 \mathrm{Ci}$ and that reduced surface conditions (low sorptivity) must apply because no other case considered is within an order of magnitude of the data (see Fig. 47). Specific activity is predicted generally to within about $50 \%$.

The most serious flaw in the study is that most of the cesium was released during the last part of Core 1 operation as a consequence of sleeve failure (Core 1 operated for 452 equivalent ful1-power days (EFPD); end-of-1ife was October, 1969). On the other hand, the gamma scans were made during Core 2 after 252 EFPD and 384 EFPD of operation, respectively. In the analysis, it was assumed (rather arbitrarily) that the plateout distribution established during Core 1 operation was not substantially altered during Core 2 operation. Such a presumption is true only if insignificant quantities of cesium are revolatilized (because of a lower cesium partial pressure during Core 2 operation) and/or if the re-entrainment of deposits is insignificant. As a matcer of fact, de Nordwall concluded (by inspection of the data in Tables $E-1$ and E-3) that the cesium plateout activity was decreasing with time. Inspection of the plotted data points in Fig. 47 suggests that this conclusion is particularly tentative. As a matter of fact, if cesium is revolatilizing from hot surfaces, then one would expect the activity in the cold ducts to increase; however, if cesium-laden deposited particulate matter is being re-entrained (or "exchanging" with entrained particulate having a lower cesium burden), then the plateout activity at a particular location could change in time when a clean core replaces an emitting one. At this point, this contention is dismissed as speculation.

The relatively low cesium activity levels measured in the hot duct are strong evidence of cesium sorption effects (contrast the solid and dot-dash profiles in Fig. 47). If the hot duct were a perfect sink for cesium deposition, then the mass transfer coefficient had to have been 
underestimated by a factor of 20. Probably the most convincing evidence for cesium sorption effects results from contrasting the data for Cs-134 and $\mathrm{Cs}-137$ with that for Ce-144; the activity of non-volatile cerium is about an order of magnitude higher in the hot duct than in the cold duct (in qualitative agreement with the perfect sink case in Fig. 47), but the cesium levels in the ducts are about the same.

Since cesium sorption on steel has been shown to be reversible (Refs. $9,10)$, then significant portions of the cesium deposited in the hot duct during Core $1\left(\mathrm{P}_{\mathrm{CS}}=1 \times 10^{-13} \mathrm{~atm}\right)$ might have vaporized during Core 2 operation $\left(P_{c s}=6 \times 10^{-15} \mathrm{~atm}\right)$ before the gamma scans were made. While such a comment is valid, it is probably unimportant if the governing adsorption isotherms are Freundlich in nature. The adsorption isotherm used in this study to model a reduced metal surface is an extrapolated version of that in Fig. F-1 (or, more accurately, of that in Fig. F-2 with the abscissa divided by a factor of 100). Under the prevailing conditions (at least in the model), the slope of the $700^{\circ} \mathrm{C}$ isotherm is so steep that the above change in partial pressure only decreases the equilibrium surface concentration by about $35 \%$.

The apparent agreement between PAD code predictions and gamma scan measurements could be completely fortuitous. There are several critical assumptions inherent in these results. Most have been mentioned earlier in the text. However, two of these assumptions merit repetition: (1) the tota1 Cs-137 inventory was presumed to be about $25 \mathrm{Ci}$ and (2) the adsorption isotherms used were extrapolated some four to six orders of magnitude. While these assumptions compromise the credibility of this study, they again demonstrate the critical need for comprehensive data to characterize the plateout behavior of cesium in gas-cooled reactors. An extensive laboratory program is needed to characterize the sorption behavior of cesium on pertinent metals under conditions as representative of the HTGR environment as is practicable. 


\section{CONCLUSIONS AND RECOMMENDATIONS}

\subsection{CONCLUSIONS}

1. The PAD code is an adequate empirical tool for prediction of plateout activity distribution provided the appropriate physical chemical data are available, the most important of which describe the sorption of fission product nuclides on pertinent structural materials. The primary justification for this conclusion is the successful correlation of the BMI loop profiles and the Dragon heat exchanger profiles. The GA deposition loop results are too ambiguous to serve as code validation data.

2. Results of the GA deposition loop experiments are compromised by fundamental inadequacies in the loop design and in the experimental technique.

3. The pronounced effect of the chill block on the deposition of cesium and strontium, but not iodine, remains unresolved. The available laboratory sorption data for cesium on carbon steel indicate that the deposition loop surfaces should have been perfect sinks at the prevailing surface temperatures and coverages.

4. Based upon the plateout data reviewed in this study, the metal surfaces in an HTGR primary circuit should be perfect sinks for most condensible fission products except for iodine and cesium (and perhaps bromine, selenium, tellurium, rubidium, silver, barium, and strontium).

5. The deposition of iodine on steel is strongly temperaturedependent with plateout virtually negligible above $500^{\circ} \mathrm{C}$. 
Stainless steels and superalloys appear to have iodine sorptivities about an order of magnitude less than carbon and chromaloy steels. The effects of surface oxidation state and the role of volatile metal iodides are unclear.

6. The deposition of cesium on steel is dependent upon surface temperatures above about $400^{\circ} \mathrm{C}$. In this regime the sorptivity is strongly influenced by the nature of the surface with surface oxides increasing sorptivity; the exact nature of this enhancement is undefined.

7. Cesium sorption isotherms derived by considerable extrapolation of the Zumwalt and Milstead data for oxidized SS304 stainless steel appear to represent adequately the temperature dependence of the sorption process. Absolute sorptivities vary widely; however, there appears to be an inverse correlation of cesium sorptivity and general oxidation resistance.

8. Very modest amounts of plateout activity are re-entrained by shear ratios in considerable excess of those predicted for the postulated design basis depressurization accident (DBDA).

9. Cesium and iodine appear to adhere most tenaciously to metal surfaces while cerium adheres the least of the species studied. The adherence of strontium appears to be intermediate. The exact role of particulate matter in fission product re-entrainment needs further definition. In short-term experiments the presence of carbonaceous dust facilitates ease of removal; however, these results may not apply to reactor conditions since cesium, iodine, and strontium appear to migrate from the dust to the metal surface. 


\subsection{RECOMMENDATIONS}

1. No further experimental work should be attempted with the existing GA deposition loop because of generic design flaws.

2. A more versatile blowdown apparatus should be designed and constructed such that possible effects of temperature and moisture content on re-entrainment of plateout can be determined. Provisions should be made for detailed characterization of the re-entrained activity.

3. Careful laboratory experimentation is urgently required to elucidate the sorptivities of pertinent primary circuit structural materials for important volatile fission product nuclides. Of particular importance are sorptivities of Incoloy 800 and $\mathrm{T} 22(2-1 / 4 \mathrm{Cr}, 1 \mathrm{Mo})$ for iodine, cesium, tellurium, silver, and rubidium.

4. The method of correlation and extrapolation of blowdown data should be carefully reviewed and improved if necessary. of particular importance is the confirmation of the applicability of the shear ratio concept. While some theoretical analysis would be required, the primary emphasis should be an experimental program for the systematic characterization of re-entrainment of plateout activity. The exact role of dust should be determined. The work need not be mechanistic, but all empiricism must be firmly supported by definitive experimental data.

5. A11 future in-pile and out-of-pile deposition experiments must include a comprehensive characterization of circulating particulate matter to assess its consequences on fission product transport. 
APPENDIX A

DERIVATION OF SHEAR RATIO FORMULAS

FOR BLOWDOWN CALCULATIONS

It is convenient to relate the shear ratio to the readily measurable quantities of pressure, velocity, and temperature. Consider an arbitrary section of circular pipe as shown in Fig. A-1 (Refs. 25, 45):

The wall shear stress $\tau_{\omega_{N}}$ is simply related to the difference in static pressure $\Delta \mathrm{P}_{\mathrm{N}}$ by $(\operatorname{Ref} .46)$ :

$$
\tau_{\omega}=\frac{\left(P_{i}-P_{0}\right) D}{4 L}=\frac{\Delta P_{N} D}{4 L},
$$

where $\quad D=$ tube diameter, $\mathrm{cm}$,

$L=$ length of tube between points $i$ and $o, \mathrm{~cm}$,

$$
\begin{aligned}
\mathrm{P}_{i}, \mathrm{P}_{0} & =\text { pressure at points } i \text { and o respectively, dyne } / \mathrm{cm}^{2}, \\
\tau_{\omega} & =\text { wall shear stress, dyne } / \mathrm{cm}^{2} .
\end{aligned}
$$

The subscript $N$ refers to normal operating conditions. Since the flow is considered fully developed and undisturbed, the pressure drop is due to fluid friction only, which is given by the Darcy equation:

$$
\frac{\Delta \mathrm{P}_{\mathrm{N}}}{\rho_{\mathrm{N}}}=\mathrm{E}_{\mathrm{N}} \frac{\mathrm{L}}{\overline{\mathrm{D}}}\left(\frac{\mathrm{V}_{\mathrm{N}}^{2}}{2 \mathrm{~g}_{\mathrm{C}}}\right)
$$




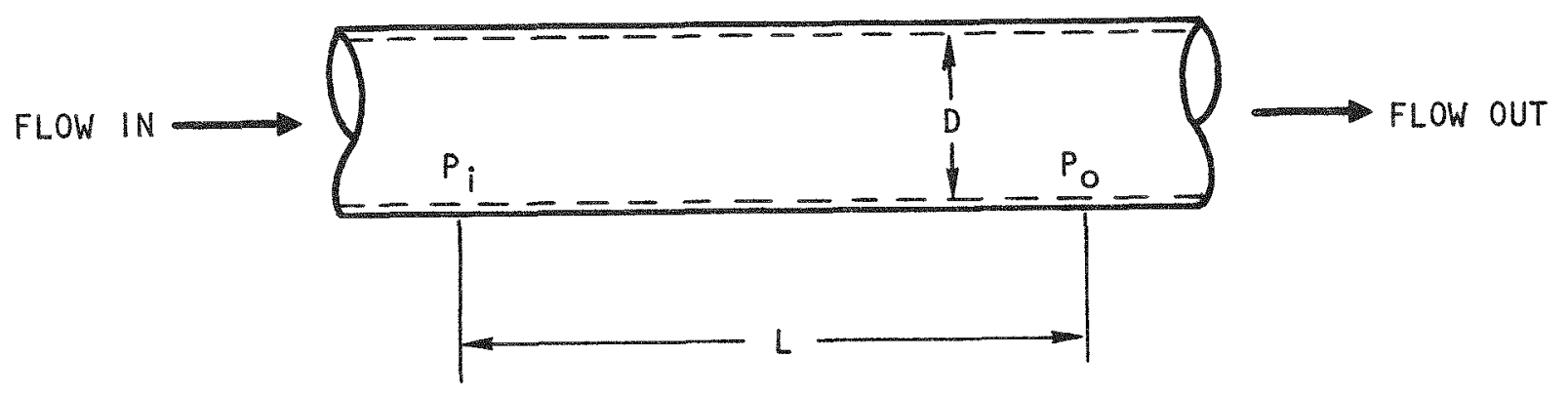

$\vec{\infty}$

Fig. A-1. Section of loop tubing

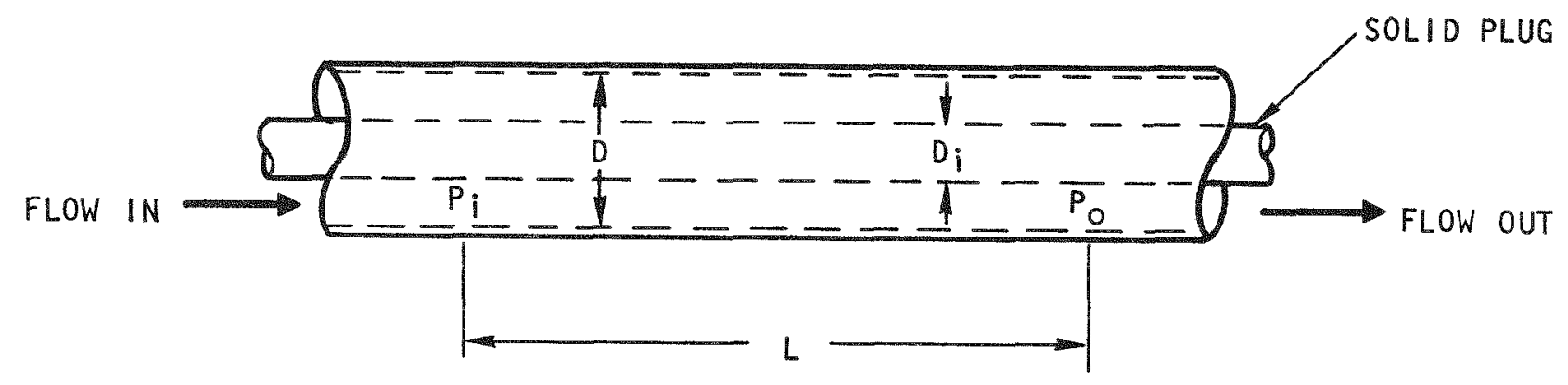

Fig. A-2. Modified blowdown geometry 
where $\mathrm{V}=$ bulk velocity, $\mathrm{cm} / \mathrm{sec}$,

$$
\begin{aligned}
g_{c} & =\text { conversion factor }=1.0 \mathrm{~g}-\mathrm{cm} / \mathrm{sec}^{2}-\text { dyne } \\
\mathrm{f} & =\text { Darcy friction factor } \\
\rho & =\text { density }\left(\mathrm{g} / \mathrm{cm}^{3}\right) .
\end{aligned}
$$

Presuming that the empirical Blasius relation applies, the Darcy friction factor $f_{N}$ is given as

$$
f_{N}=\frac{0.316}{R e_{N}^{0.25}}
$$

and the Reynolds number $\mathrm{Re}_{\mathrm{N}}$ is, of course,

$$
\operatorname{Re}_{N}=\frac{D V_{N} P_{N}}{\mu_{N}},
$$

where $\mu$ = viscosity $(\mathrm{g} / \mathrm{cm}-\mathrm{sec})$.

Substituting Eqs. $A-2$ and $A-3$ into Eq. $A-1$ gives

$$
\tau_{\omega_{N}}=\frac{0.0395 \rho_{N} V_{N}^{2}}{g_{c} R_{e_{N}} 0.25} .
$$

Finally, the shear force $F$ on a deposited particle with an aerodynamic radius a is

$$
F_{N}=\pi a^{2} \tau_{u_{N}}
$$

Now, under conditions of a steady-state blowdown test, an identical development gives 


$$
\begin{aligned}
& \tau_{\omega_{B}}=\frac{0.0395 \rho_{B} V_{B}^{2}}{g_{C} \operatorname{Re}_{B} 0.25}, \\
& F_{B}=\pi a^{2} \tau_{\omega_{B}},
\end{aligned}
$$

where the subscript $B$ refers to blowdown conditions. Thus the shear ratio $\mathrm{SR}$ can be defined as

$$
S R=\frac{F_{B}}{F_{N}}=\frac{\tau_{\omega_{B}}}{\tau \omega_{N}} .
$$

Substituting Eqs. $A-5$ and $A-7$ into Eq. A-9 gives

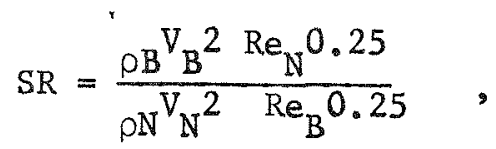

or, substituting for the Reynolds number and simplifying,

$$
S R=\left(\frac{\rho_{B}}{\rho_{N}}\right)^{0.75}\left(\frac{v_{B}}{V_{N}}\right)^{1.75}\left(\frac{\mu_{B}}{\mu_{N}}\right)^{0.25} .
$$

For computational purposes, it is desirable to replace the density $\rho$ and viscosity $\mu$ with the experimentally measured variables of temperature and pressure. The density of helium is given accurately by the ideal gas law

$$
\rho=\frac{P M}{R T}
$$

where $M=$ molecular weight of helium, $\mathrm{g} / \mathrm{mole}$,

$$
\mathrm{T}=\text { absolute temperature, }{ }^{\circ} \mathrm{K} \text {, }
$$




$$
\mathrm{R}=\text { gas constant. }
$$

Thus,

$$
\rho \propto \frac{\mathrm{P}}{\mathrm{T}}
$$

The viscosity of helium in the pressure and temperature range of interest is given by the empirical correlation (Ref. 47):

$$
\mu=6.7 \times 10^{-4} \text { (T) } 0.68 \text {, }
$$

where

$$
\begin{aligned}
& \mu=v i s \operatorname{cosity}, 1 b_{M} / f t-h r, \\
& T=\text { absolute temperature, }{ }^{\circ} R_{。}
\end{aligned}
$$

Thus,

$$
\mu \propto T^{0.68}
$$

Then replacing the ratios of density and viscosity in $\mathrm{Eq} . \mathrm{A}-11$ by the ratios implied in Eqs. $A-13$ and $A-15$ and simplifying, the final result is obtained as

$$
\text { S. R. }=\left(\frac{\mathrm{P}_{\mathrm{B}}}{\mathrm{P}_{\mathrm{N}}}\right)^{0.75}\left(\frac{\mathrm{V}_{\mathrm{B}}}{\mathrm{V}_{\mathrm{N}}}\right)^{1.75}\left(\frac{\mathrm{T}_{\mathrm{N}}}{\mathrm{T}_{\mathrm{B}}}\right)^{0.58} \text {. }
$$

In practice it is desirable to modify the flow geometry during the blowdown test to provide for high velocities at minimum volumetric flow 
rates by insertion of a concentric plug of outside diameter $D_{i}$ into the test specimen. The development for the shear ratio is similar as given below and the geometry is indicated in Fig. A-2.

It can be shown (Refs. 43, 48) that with this geometry the wall shear stress on the outer wall is given by

$$
\tau_{\omega_{B}}=\frac{\Delta P_{B} R}{2 L}\left(1-\lambda^{2}\right),
$$

where

$$
\lambda^{2}=\frac{\left[1-(D i / D)^{2}\right]}{2 \ln (D / D i)}
$$

The pressure drop is

$$
\frac{\Delta P_{B}}{\rho_{B}}=\frac{V_{B}^{2}}{2 g_{C}} \frac{f_{B} L}{D\left(1-\lambda^{2}\right)}
$$

where

$$
f_{B}=\frac{0.316}{\operatorname{Re}_{B} 0.25}
$$

and

$$
\operatorname{Re}_{B}=\frac{\rho_{B} V_{B} D\left(1-\lambda^{2}\right)}{\mu_{B}}
$$


Combining Eqs. A-19 through A-21 with Eq. A-7 yields

$$
\tau_{\omega_{B}}=\frac{0.0395^{\rho_{B} V_{B}^{2}}}{\operatorname{Re}_{B}^{0.25}}
$$

and

$$
F_{B}=\pi a^{2} \tau_{\omega_{B}}
$$

Substitution into the defining equation for the shear ratio (Eq. A-9) yields for the modified geometry

$$
\mathrm{SR}=\left(\frac{\rho_{\mathrm{B}}}{\rho_{\mathrm{N}}}\right)^{0.75}\left(\frac{\mathrm{V}_{\mathrm{B}}}{\mathrm{V}_{\mathrm{N}}}\right)^{1.75}\left(\frac{\mu_{\mathrm{N}}}{\mu_{\mathrm{B}}}\right)^{0.25} \frac{1}{\left(1-\lambda^{2}\right)^{0.25}}
$$

Again replacing $\rho$ and $\mu$, the final expression is then

$$
\mathrm{SR}=\left(\frac{\mathrm{P}_{\mathrm{B}}}{\mathrm{P}_{\mathrm{N}}}\right)^{0.75}\left(\frac{\mathrm{V}_{\mathrm{B}}}{\mathrm{V}_{\mathrm{N}}}\right)^{1.75}\left(\frac{\mathrm{T}_{\mathrm{N}}}{\mathrm{T}_{\mathrm{B}}}\right)^{0.58} \frac{1}{\left(1-\lambda^{2}\right)^{0.25}} .
$$




\section{APPENDIX B}

REVIEW OF THE MATHEMATICAL MODEL EMPLOYED BY THE PAD CODE

The mathematical model employed by the PAD code is thoroughly documented in Ref. 15; however, for convenience, certain sections of that document are excerpted below.

\section{B.1 CONSERVATION EQUATIONS}

The conservation equations presented here describe the mass balance for the coolant and surface fission product concentrations in sections of the reactor circuit with constant cross-sectional areas. The treatment is a simplified analysis giving surface concentrations and average coolant concentrations as a function of axial distance and time. It is assumed that the mass-transport process can be described to be between an average coolant concentration and a surface concentration separated by a thin gaseous boundary layer film. The quantity of fission products contained in the thin film is assumed to be negligible. Figure $B-1$ illustrates the basic mass-transport volume element.

The coolant and surface concentrations of each fission product are dependent on a source term, such as the release of the fission product from the reactor core, on the decay of the parent fission product in the primary circuit, on the decay of the fission product itself, on mass transfer between the coolant and surface, and on axial convection around the reactor circuit. Hence, the time rate of change of the amount of fission product $j$ in an increment of volume of length $\mathrm{dx}$, cross-sectional area $\mathrm{A}$, and wetted perimeter $\mathrm{P}$ is given by 


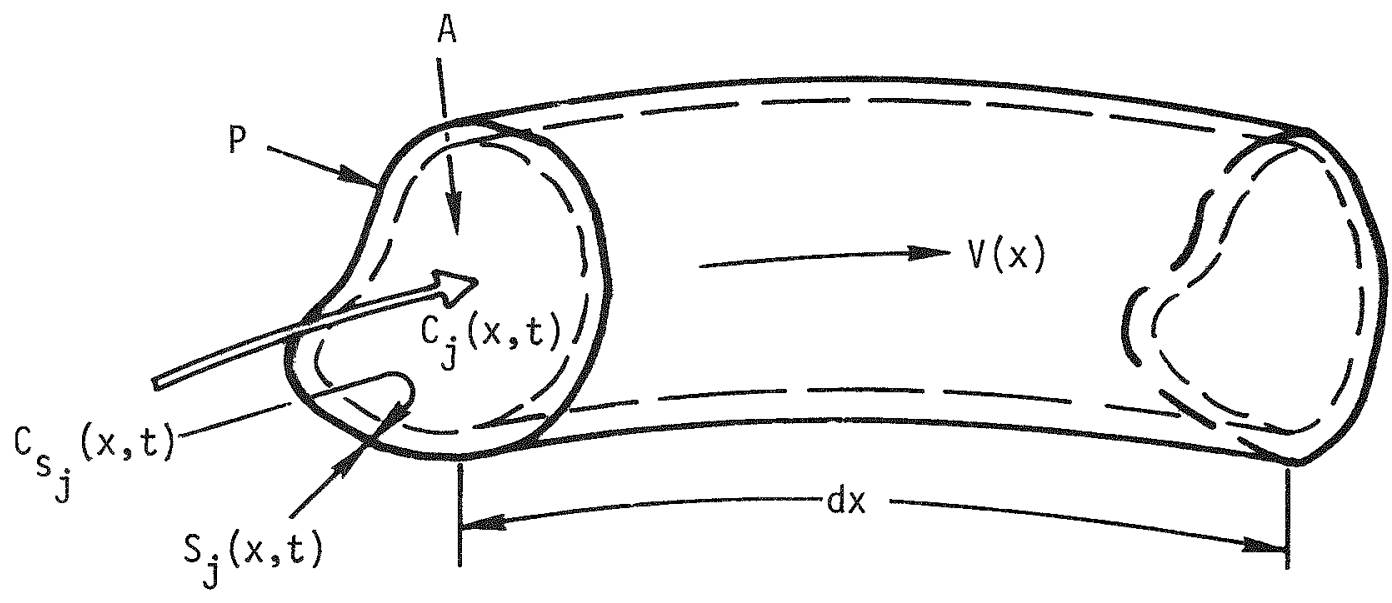

Fig. B-1. Basic mass-transport volume element 


$$
\begin{aligned}
& \frac{\partial C_{j}(x, t)}{\partial t} A d x=B_{j}(x) A d x+\lambda_{i} C_{i}(x, t) A d x-\lambda_{j} C_{j}(x, t) A d x \\
& \underbrace{\begin{array}{c}
\text { Decay from } \\
\text { parent }
\end{array}}_{\begin{array}{c}
\text { Source } \\
\text { term }
\end{array}} \underbrace{\text { sent }}_{\text {Decay }} \\
& -\left[\left(V(x) C_{j}(x, t)+\frac{\partial\left[V(x) C_{j}(x, t)\right]}{\partial x}\right) d x A-V(x) C_{j}(x, t) A d x\right] \\
& \text { Flow out of increment - flow in = loss rate due } \\
& \text { to axial convection } \\
& \underbrace{-k(x)\left[C_{j}(x, t)-C_{s_{j}}(x, t)\right] P d x}_{\begin{array}{l}
\text { Mass transfer from average coolant concentra- } \\
\text { tion to coolant concentration at the surface }
\end{array}}
\end{aligned}
$$

or,

$$
\begin{aligned}
\frac{\partial C_{j}(x, t)}{\partial t} & =B_{j}(x)+\lambda_{i} C_{i}(x, t)-\lambda_{j} C_{j}(x, t)-\frac{\partial\left[V(x) C_{j}(x, t)\right]}{\partial x} \\
& -\frac{k(x) P}{A}\left[C_{j}(x, t)-C_{s_{j}}(x, t)\right],
\end{aligned}
$$

where $C_{j}(x, t), C_{i}(x, t)=$ coolant concentration of fission product $j$ and its precursor $i$ averaged across the coolant channel, $\mu \mathrm{g} / \mathrm{cm}^{3}$,

$$
\begin{aligned}
C_{s_{j}}(x, t)= & \text { coolant concentration of fission product } j \text { at the } \\
& \text { channel surface, } \mu g / \mathrm{cm}^{2},
\end{aligned}
$$




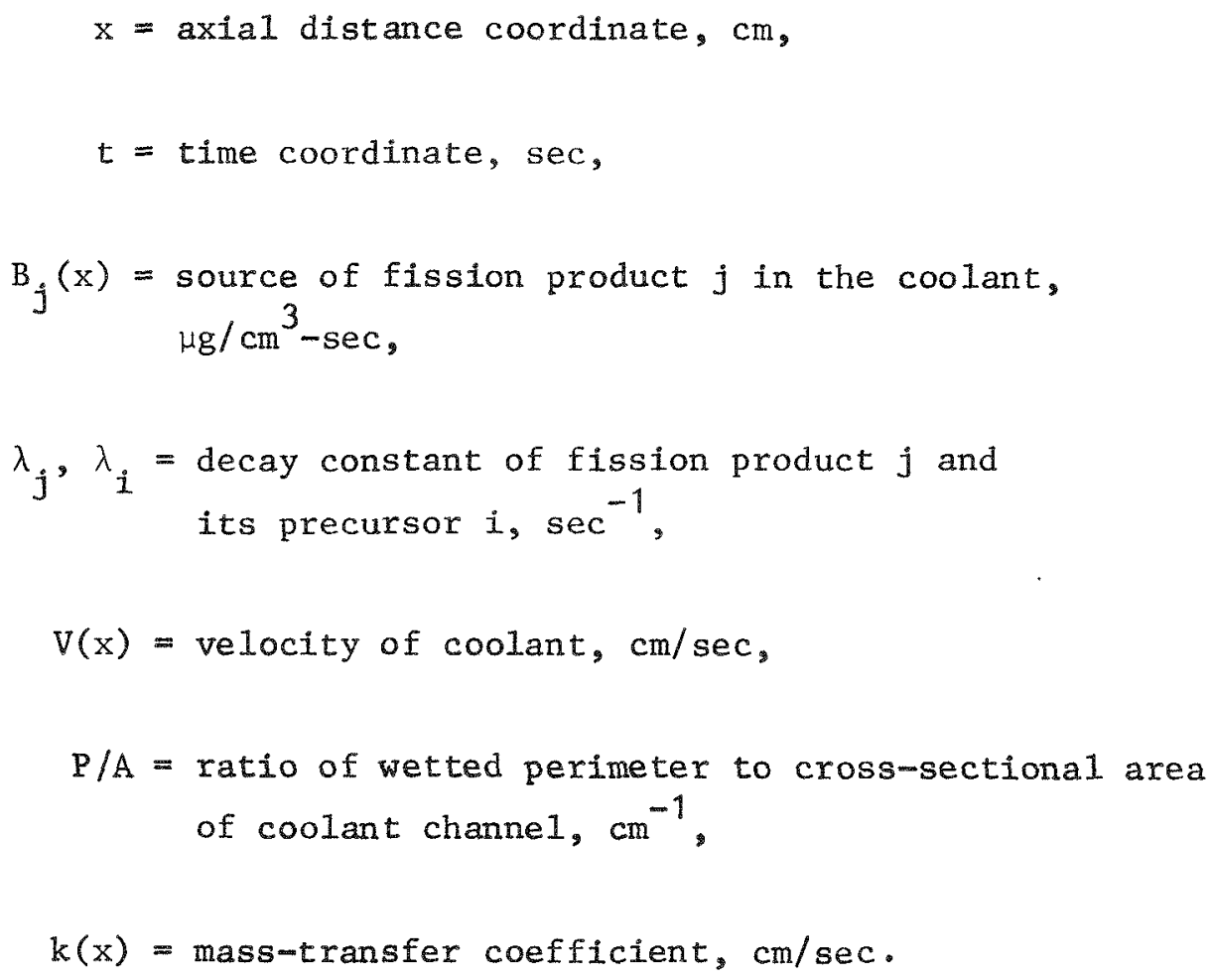

Similarly, the time rate of change of the amount of fission product $j$ on a surface element of length $d x$ and wetted perimeter $P$ is given by

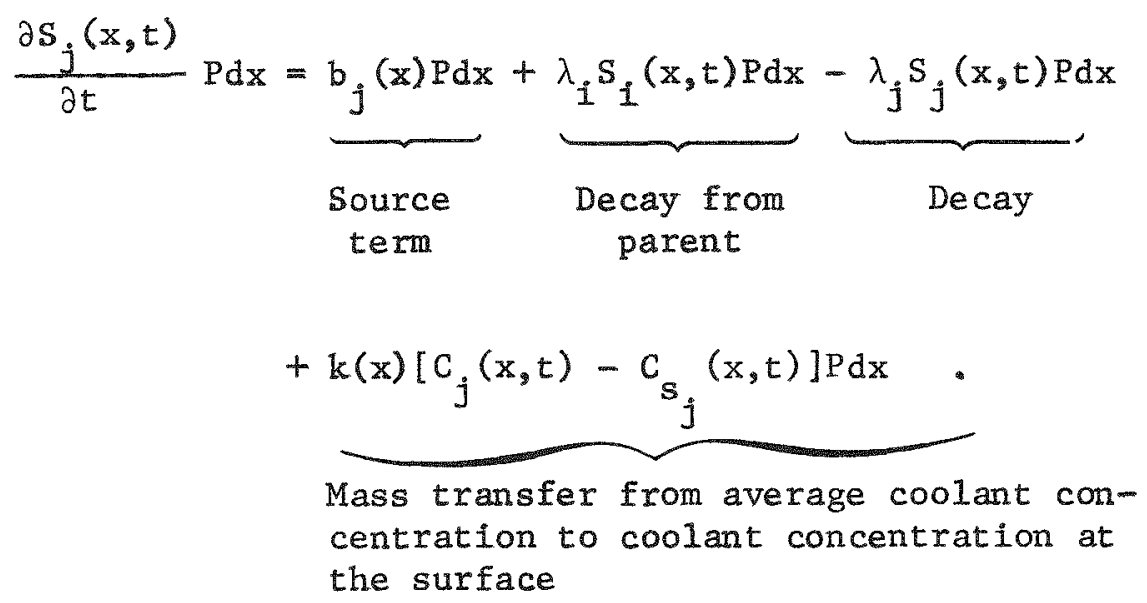


or,

$$
\begin{aligned}
\frac{\partial S_{j}(x, t)}{\partial t} & =b_{j}(x)+\lambda_{i} S_{i}(x, t)-\lambda_{j} S_{j}(x, t) \\
& +k(x)\left[c_{j}(x, t)-c_{S_{j}}(x, t)\right]
\end{aligned}
$$

where $S_{j}(x, t), S_{i}(x, t)=$ surface concentration of fission product $j$ and its precursor $i, \mu g / \mathrm{cm}^{2}$,

$$
\begin{aligned}
b_{j}(x)= & \text { source of fission product } j \text { on the surface, } \\
& \mu g / \mathrm{cm}^{2}-\mathrm{sec},
\end{aligned}
$$

and the remainder of the terms are as previously defined. Equations B-2 and $\mathrm{B}-4$ control the behavior of fission product $\mathrm{j}$ within one section of the reactor circuit. A similar set of equations must be written for each reactor section in order to completely describe the behavior of fission project $j$ throughout the reactor circuit. The initial and boundary conditions are: (1) the initial concentrations are specified and (2) the coolant concentration is continuous around the reactor circuit.

\section{B.2. MASS-TRANSFER COEFFICIENT}

The mass-transfer coefficient $k(x)$ used in Eqs. B-2 and B-4 should be for mass transfer in a turbulently flowing gas stream through a channel of constant cross-sectional area. A formulation for channels of circular cross-section is given by

$$
k(x)=[0.023 D(x) / d][\operatorname{Re}(x)]^{0.83}[\operatorname{Sc}(x)]^{0.44},(B-5)
$$

where $D(x)=$ diffusion coefficient of species in gas stream, $\mathrm{cm}^{2} / \mathrm{sec}$,

$$
\mathrm{d}=\text { diameter of circular conduit, } \mathrm{cm} \text {, }
$$




$$
\begin{aligned}
& \operatorname{Re}(x)=\text { Reynolds number of gas stream, } \\
& \operatorname{Sc}(x)=\text { Schmidt number of gas stream. }
\end{aligned}
$$

Although this expression is primarily for channels of circular crosssection, other shapes can be accommodated by using the hydraulic diameter.

Equation $B-5$ adequately describes the mass-transfer coefficient for an undisturbed boundary layer. However, it has been observed in laboratory plateout experiments that the presence of a flow disturber in the coolant channel causes a perturbation in the surface concentration of the deposited species. The nature of the perturbation is a localized increase in the surface concentration of the deposited species at the axial position of the flow disturber.

Kress (Ref. 49) and Neill et a1. (Ref. 50) have investigated the effect of flow disturbers such as bends in the coolant channel, thermocouples that protrude into the coolant channel, and abrupt changes in the coolant channel diameter. From their experimental results, it can be concluded that:

1. The increased mass transfer is directly analogous to the wel1established increase in heat transfer in such circumstances,

2. The increase of the mass-transfer coefficient caused by the flow disturber may be approximated by

$$
\Delta \mathrm{k}=\mathrm{A} \Delta \mathrm{x} \mathrm{e}^{-B \Delta \mathrm{x}}
$$

where $A$ and $B$ are experimentally determined constants and $\Delta x$ is the axial distance in the coolant channel measured from the flow disturber.

From these two observations, a semi-empirical approach has been attempted. At a distance $x$ downstream from the entrance of the conduit, the mass-transfer coefficient is assumed to be given by 


$$
k(x)=k_{0}(x)+H(\Delta x) A \Delta x e^{-B \Delta x},
$$

where $k_{0}(x)=$ normal mass-transfer coefficient without flow disturbers (as given by $\mathrm{Eq} . \mathrm{B}-5$ ),

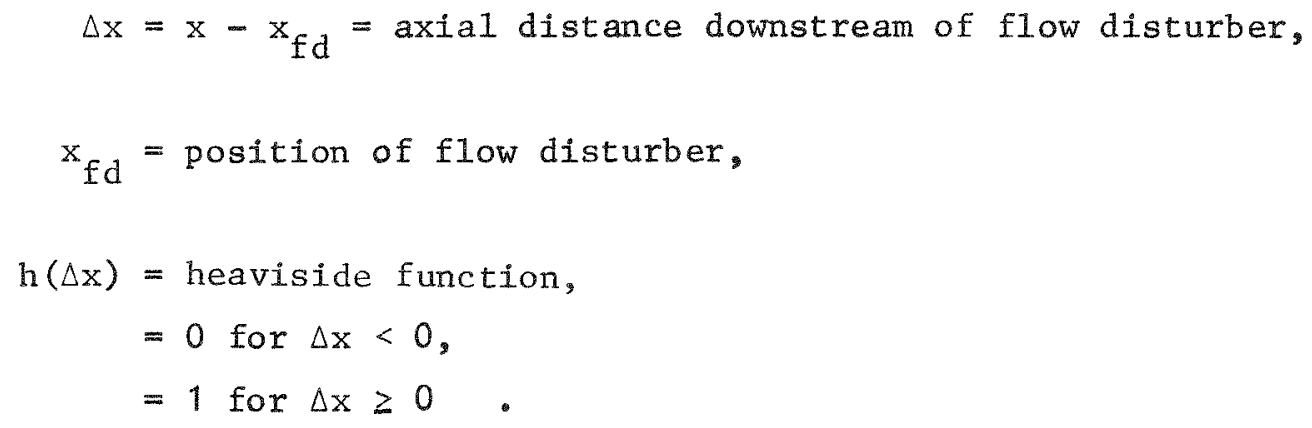

Drawing on the results obtained by Krall and Sparrow (Ref. 51), the maximum value of the mass-transfer coefficient downstream of a flow disturber appears to be proportional to a fractional power of the Reynolds number. By applying a trial and error technique to experimental results obtained by Neill et al. an approximate expression for this maximum would appear to be

$$
\mathrm{k}_{\max }\left(\mathrm{x}_{\mathrm{m}}\right)=\frac{\mathrm{D}\left(\mathrm{x}_{\mathrm{m}}\right)}{\mathrm{d}}\left[\operatorname{Re}\left(\mathrm{x}_{\mathrm{m}}\right)\right]^{2 / 3},
$$

where $\mathrm{x}_{\mathrm{m}}$ is the position of the maximum mass-transfer coefficient measured from the entrance of the channel.

It can be concluded from Refs. 50 and 51 that the maximum enhancement of the mass-transfer coefficient occurs at approximately two coolant channel diameters from the position of the flow disturber. Therefore, for $\mathrm{d} \Delta \mathrm{k} / \mathrm{dx}$ to be equal to zero at $\Delta \mathrm{x}=2 \mathrm{~d}$, it is derived from Eq. B-6 that

$$
B=\frac{1}{2 d}
$$


Also, since $k(x)=k_{\max }$ at $x=x_{m}$, it is derived from Eqs. 7 and 8 that

$$
A=\frac{\frac{D\left(x_{m}\right)}{d}\left[\operatorname{Re}\left(x_{m}\right)\right]^{2 / 3}-k_{0}\left(x_{m}\right)}{2 d \exp (-1)}
$$

Hence, the mass-transfer coefficient is given by

$$
k(x)=k_{0}(x)+H(\Delta x)\left(\frac{\frac{D\left(x_{m}\right)}{d}\left[\operatorname{Re}\left(x_{m}\right)\right]^{2 / 3}-k_{0}\left(x_{m}\right)}{2 d}\right) \Delta x \exp \left(1-\frac{\Delta x}{2 d}\right) \cdot(B-11)
$$

Equations $B-5$ and $B-7$ or $B-11$ define the mass-transfer coefficient to be used in Eqs. $B-2$ and $B-4$. It should be noted that the flow disturber analysis is drawn from overall averages and approximations and that it treats all flow disturbers identically. However, it yields results that are qualitatively consistent with available experimental results. of course, other flow and/or geometry-dependent values of the constants $A$ and $\mathrm{B}$ can be used in Eq. B-7 to more closely approximate other experimental data as it becomes available.

\section{B.3. SURFACE SORPTION}

In order to relate the coolant concentration at the surface, $C_{S}(x, t)$, to the surface concentration, $S(x, t)$, an algebraic expression for the surface sorption equilibrium is needed. Several equations have been found to approximate a large amount of the experimental isotherm data on equilibrium partial pressures versus surface loading. One of these, the Freundich equation, can be written as

$$
C_{s}(x, t)=K_{f}(x) S(x, t)^{n(x)}
$$

where $\mathrm{K}_{\mathrm{f}}(\mathrm{x})$ = the temperature-dependent Freundlich sorption constant relating desorption and adsorption coefficients, 


$$
\begin{aligned}
\mathrm{n}(\mathrm{x})= & \text { the temperature-dependent constant which has been observed to } \\
& \text { be greater than one. }
\end{aligned}
$$

Although this expression is an empirical equation, it is sufficient for describing much of the experimental data.

Another expression, the Langmuir equation, can be written as

$$
C_{s}(x, t)=K_{\ell}(x)\left(\frac{S(x, t)}{1-S(x, t) / S \text { sat }}\right)
$$

where $\mathrm{K}_{\ell}(\mathrm{x})$ = the temperature-dependent Langmuir sorption constant relating desorption and adsorption coefficients,

$$
S_{\text {sat }}=\text { saturated surface concentration. }
$$

This expression was deduced from a definite hypothesis on the mechanism of the sorption process, i.e., that the rate of sorption is dependent on the number of unoccupied surface sites. As the surface concentration approaches the saturated surface concentration, the number of sorption sites becomes vanishingly small, resulting in a rapid increase of the coolant concentration above the surface. Note that at low coverage values the coolant concentration becomes Iinearly proportional to the surface concentration.

A general expression that results in either equation, depending on the values of the constants, can be written as

$$
C_{s}(x, t)=K(x)\left[\frac{s(x, t)^{n(x)}}{1-\delta_{n 1} s(x, t) / S_{\text {sat }}}\right]
$$


where $\delta_{\mathrm{n} 1}=$ Kronecker delta function,

$$
\begin{aligned}
& \delta_{\mathrm{n} 1}=1 \text { if } \mathrm{n}=1, \\
& \delta_{\mathrm{n} 1}=0 \text { if } \mathrm{n} \neq 1 .
\end{aligned}
$$

Since there may be many isotopes of the same chemical species sorbed on the surface, one must consider the surface concentration of each isotope with relation to the total surface concentration of all the isotopes of the same chemical species. Therefore, the surface concentration terms in Eq. B-14 must be summed over all isotopes of the same chemical species and the expression multiplied by the mole fraction of isotope $j$ to obtain the proper concentration for isotope $j$. Hence, Eq. B-14 becomes

$$
C_{s_{j}}(x, t)=K(x)\left[\frac{[\Sigma S(x, t)]^{n(x)}}{1-\delta_{n 1} \Sigma S(x, t) / s_{s a t}}\right] \frac{s_{j}(x, t)}{\Sigma S(x, t)}
$$

Generally, different chemical species can be included in the summation by using weighted values of the constants and concentrations in Eq. B-15.

In order to keep the theoretical treatment relatively simple and straightforward, the explicit temperature dependence of the sorption constants in Eqs. $B-12, B-13$, and $B-14$ has been suppressed. However, most of the experimental sorption data are reported in a form that explicitly shows this temperature dependence. The code input has therefore been designed to accept these experimental constants. This is accomplished by calculating the coolant concentration at the surface for either the Freundlich or the Langmuir type of sorption kinetics from an equation of the form

$$
C_{s}(x, t)=\frac{\exp \left[A C P+B C P \cdot 10^{3} / T(x)\right] S(x, t)\left(C C P+D C P \cdot 10^{3} / T(x)\right)}{\left[1-S(x, t) / D C P \cdot 10^{23}\right]}
$$


where $T(x)=$ the absolute temperature of the surface, ${ }^{\circ} \mathrm{K}$,

$$
\begin{aligned}
S(x, t)= & \text { the surface concentration of the sorbed species (units vary } \\
& \text { with experiment). }
\end{aligned}
$$

and $A C P, B C P, C C P, D C P$ are constants. Hence, the expressions for $K(x)$ and $\mathrm{N}(\mathrm{X})$ in $\mathrm{Eq} . \mathrm{B}-14$ are, respectively,

$$
\begin{aligned}
& K(x)=\exp \left[A C P+B C P \cdot 10^{3} / T(x)\right], \\
& n(x)=C C P+D C P \cdot 10^{3} / T(x) .
\end{aligned}
$$

For Freundich-type behavior, all the constants are determined from the experimental data (the denominator will be approximately equal to one). For Langmuir-type behavior, the constant CCP is set equal to one, the constant DCP is set equal to the product of $10^{-23}$ and the saturated surface concentration $S_{s a t}$, and the constants $A C P$ and $B C P$ are determined from the experimental data. Note that this procedure is numerically equivalent to the Kronecker delta formulation given in Eq. B-14. Of course, the surface concentration terms in Eq. B-16 should be summed over all isotopes of the same chemical species and the result multiplied by the mole fraction of the isotope under consideration (see Eq. B-15).

In addition to simple Freundich or simple Langmuir sorption kinetics, certain systems exhibit Freundlich-type behavior at the higher surface concentrations and Langmuir-type behavior at lower concentrations; that is, the gaseous concentration becomes proportional to the surface concentration at the lower surface loadings. The proportionality constant is determined by evaluating the gaseous concentration at the critical surface loading, CRITSC, and then dividing by the critical loading. The program will automatically make this change in sorption behavior if a critical surface loading, CRITSC, is supplied. 
APPENDIX $C$

APPLICATION OF PAD CODE TO BMI

DEPOSITION OF RESULTS

\section{C.1. REVIEW OF BMI DEPOSITION EXPERIMENTS}

The BPI deposition experiments are judged to be of fundamental importance to the serious student of plateout phenomena; therefore, the reader is urged to consult the original sources (Refs. 14, 18). Excerpts of these references are presented below.

\footnotetext{
"Simulation of high-temperature gas-cooled-reactor conditions established the basic test parameters, with such practical modifications as were dictated by apparatus and space limitations. Helium, at 300 psia, was circulated in an experimental 1oop, with turbulent flow usually prevailing.....Size and shape of the loop were controlled somewhat by the need to contain it in a California hood. The 1oop, constructed of 0.5-in.o.d. by $0.37-i n .-i . d$. Type 316 stainless steel tubing, was fully insulated by a double layer of pipe insulation, with staggered joints. The configuration is shown schematically in Fig. $\mathrm{C}-1$.
}

"The helium, at about $1200^{\circ} \mathrm{F}$, was passed over a mildly irradiated fuel specimen which was heated independent1y to $1800^{\circ} \mathrm{F}$. Leaving the specimen heater, the helium first traversed an approximately isothermal hightemperature zone. The temperature drop was kept as low as practical, 50 to $75^{\circ} \mathrm{F}$. Following this was a heat exchanger consisting of a pair of watercooled chill blocks clamped around the tubing. The purpose of this heat exchanger was to provide information on deposition in heat exchangers as well as to reduce gas temperature to the 500 to $600^{\circ} \mathrm{F}$ upper operating Iimit of the flow-control value and the centrifugal blower. Mass flow rates were 


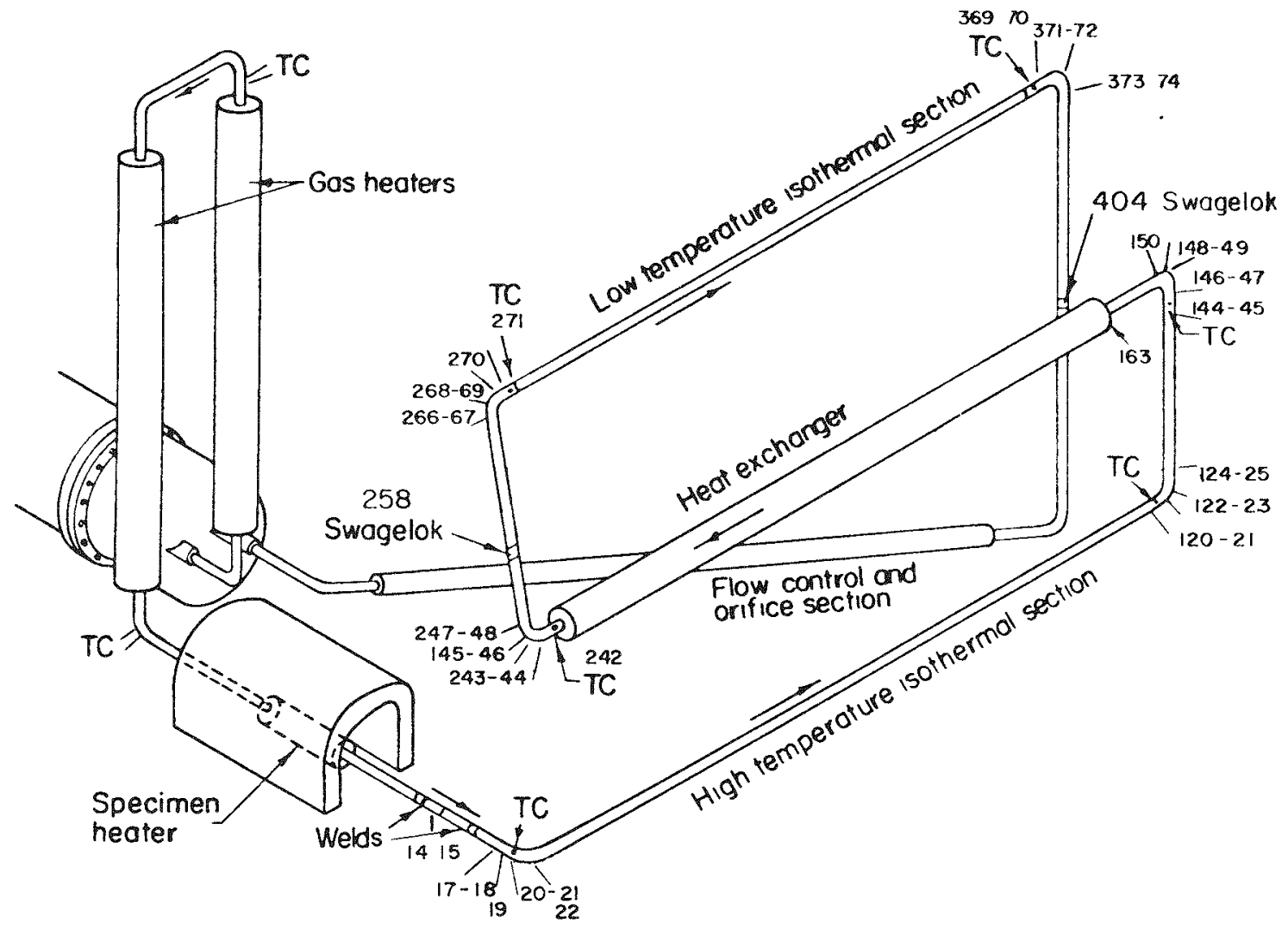

Fig. C-1. Layout of Experiment 10 loop-section numbers (Ref. 14) 
controlled by a pneumatic differential-pressure regulator on the flowcontrol valve assembly following the heat exchanger. The cooled gas then passed through a high-speed variable-frequency centrifugal blower and through a series of heaters to reheat the gas to $1200^{\circ} \mathrm{F}$ before passage over the fuel specimen. Heat duty on the system was fairly rigorous; at normal flow rates of 9 to $14 \mathrm{lb}$ per $\mathrm{hr}$, the helium was being heated and cooled about five times per second.

"The fuel specimen was an annular graphite cylinder approximately 0.75-in. o.d. by 0.5-in. Iong, and with an inside diameter of 0.37-in., matching that of the tubing. Each specimen contained about $100 \mathrm{mg}$ of fully enriched $\mathrm{UC}_{2}$ particles about $100 \mu \mathrm{m}$ in diameter, each with a dense pyrolytic-carbon coating nominally $4 \mu \mathrm{m}$ thick. The purpose of this thin coating was to protect the $\mathrm{UC}_{2}$ from exposure to the atmosphere, while at the same time the thickness was minimized to provide reasonably high fission-product-release rates. The coating successfully accomplished these objectives, although the experimental results indicated that there were significant variations in fractional release rates from specimen to specimen, perhaps due to the difficulty of exactly reproducing this coating thickness. The fuel specimens were irradiated to burnups of 0.01 to 0.1 at. $\%$ and allowed to decay for several weeks before use.

"...Temperature measurements were taken at various points in the loop using sheathed thermocouples located internally, normally at a bend.

"An experiment generally consisted of operation for a period of from 2 to 4 days at prescribed flow and temperature conditions. The loop was then dismantled and cut with a pipe cutter into short sections, normally 1 in. long, for analysis. In Experiment $10 \ldots$ the section length was reduced to $1 / 2 \mathrm{in}$. in order to reduce the quantity of activity in a section to a more desirable level for analysis. With such short sections, there were some variations in lengths, and analyses were normalized to a weight basis. 
"...Upon disassembly of an experimental loop, the sections were first gamma counted with a well-type scintillation counter to establish the gross activity pattern.... Results from Experiment 10 are shown in Fig. C-2. A program was developed... whereby the tubing sections were analyzed directly by instrumental and computer techniques. In this program, the unknown gamma spectra of tubing sections were appraised by least-squares fitting to composite standard spectra using a Control Data G-20 digital computer. This program permitted acquisition of analytical data in a breadth impractical to attain with strictly chemical methods. In Experiment 10, for example, over 150 sections were each analyzed for seven components, providing a total of more than 1000 analytical results (Ref. 14) ....

"(A1though some 10 loop experiments were performed, detailed results and conclusions were presented only for the last experiment:)

"Experiment 10 was conducted with the revised loop configuration containing two isothermal zones and one heat-exchanger zone. Upon the basis of the experience gained in earlier runs, fue1-specimen burnup was increased to about 0.1 at. $\%$. These earlier runs had shown that the precision and accuracy of the computer solution of the gamma spectra improve, overall, as the abundances of the various fission products approached equality. At lower burnups $\mathrm{I}-131$ and $\mathrm{Te}-132$ were overly abundant at short decay times. At longer decay times, when these two had decayed to moderate levels, quantities of other less-abundant, longer-lived isotopes were too low for accurate determination. At 0.1 at. \% burnup, satisfactory quantities of other fission products remained even after I-131 and Te-132 had decayed. The fuel specimen for Experiment 10 differed also in that it was necessary to irradiate it again before use, when the operation of the experiment was postponed considerably beyond its originally scheduled date.

"Principal operating parameters for Experiment 10 are listed in Table C-1. The specimen heater for this run consisted of a platinim-wound 


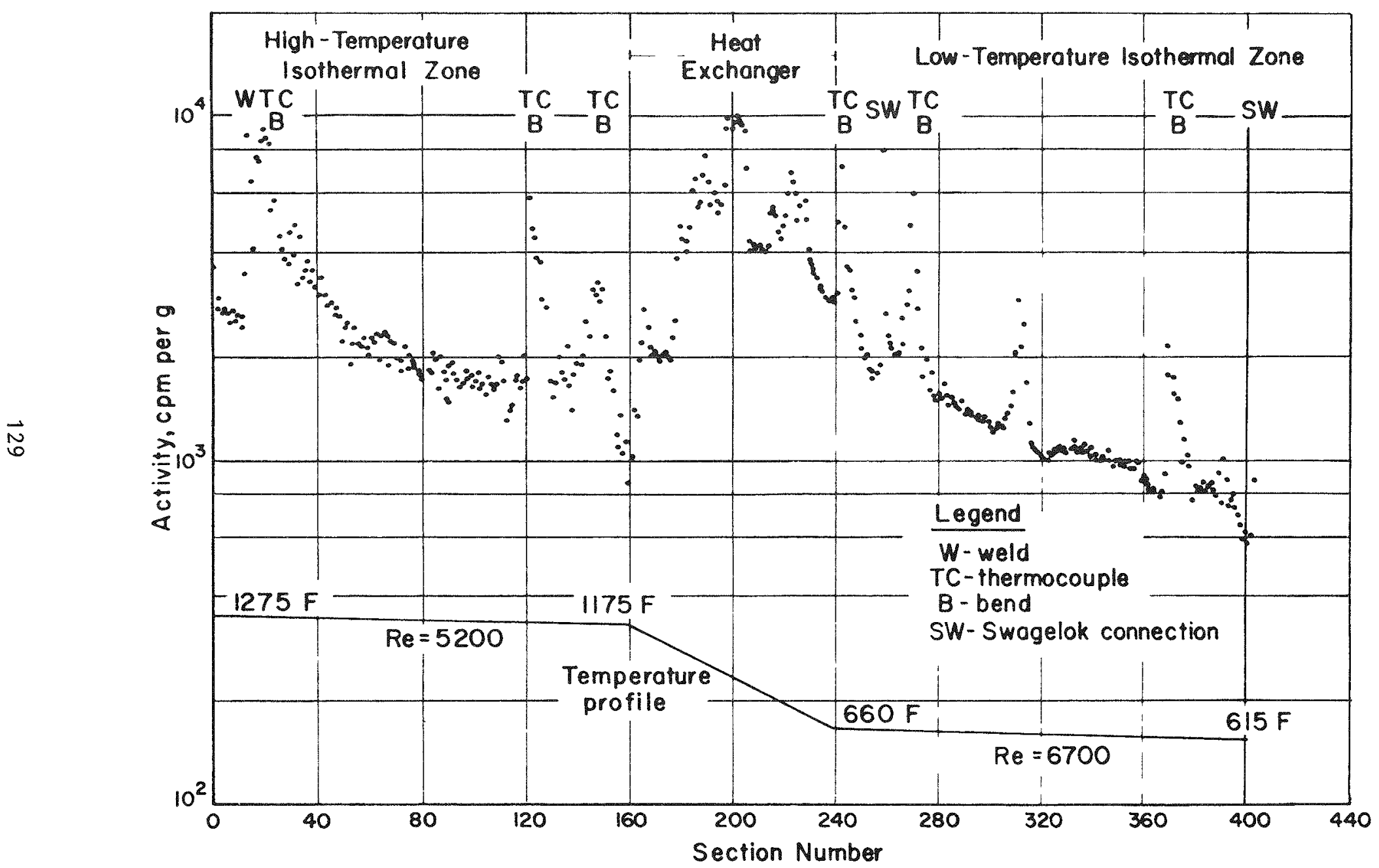

Fig. C-2. Distribution of gross gamma activity in Experiment 10 1oop (Ref. 14) 
TABLE C-1

OPERATING PARAMETERS FOR FISSION-PRODUCT

DEPOSITION EXPERIMENT 10 (Ref. 14)

\begin{tabular}{lc} 
Operating time & $67 \mathrm{hr}$ \\
Specimen temperature & $1800^{\circ} \mathrm{F}$ \\
Gas temperature & \\
Specimen heater - exit & $1275^{\circ} \mathrm{F}$ \\
Heat exchanger - entrance & $1175^{\circ} \mathrm{F}$ \\
Heat exchanger - exit & $660^{\circ} \mathrm{F}$ \\
Low-temperature isothermal zone entrance & $625^{\circ} \mathrm{F}$ \\
Low-temperature isothermal zone exit & $615^{\circ} \mathrm{F}$ \\
Downstream of flow-control valve & $515^{\circ} \mathrm{F}$ \\
Circulating blower - exit & $460^{\circ} \mathrm{F}$ \\
First heater section - exit & $825^{\circ} \mathrm{F}$ \\
Second heater section - exit & $1200^{\circ} \mathrm{F}$ \\
Pressure & $306-294 \mathrm{psia}$ \\
Mass flow & $12.81 \mathrm{~b}$ per hr \\
Reynolds numbers & \\
High-temperature isothermal zone & $5200\left(1200^{\circ} \mathrm{F}\right)$ \\
Heat exchanger - exit & $6700\left(660^{\circ} \mathrm{F}\right)$ \\
Flow control valve & $7300\left(515^{\circ} \mathrm{F}\right)$ \\
Specimen integrated flux & $1.2 \times 10^{18} / 3.1 \mathrm{x} 10^{18} \mathrm{nvt}$ \\
First irradiation & \\
Second irradiation & \\
Specimen decay at end of run & \\
\hline
\end{tabular}


resistance furnace, which was expected to prove superior to previous Nichrome- and Kanthal-wound heaters. Experiment 10 was planned for operation for 4 days, but had to be terminated after $67 \mathrm{hr}$ of operation because of the failure of this heater.

"Deposition concentrations, normalized to a gram basis (approximately proportional to a surface-area basis) are plotted for the seven fission products in Figures... [See Figs. 37-40. Note addition of heavy lines.]... as a function of distance from the fuel specimen. The curves (i.e., profiles) in these figures are fairly representative of those from the previous experiments as far as qualitative trends are concerned.

"Behavior of the fission products in the group comprised of $\mathrm{Ce}-141+$ $\mathrm{Ce}-144, \mathrm{Ba}-\mathrm{La}-140, \mathrm{Zr}-\mathrm{Nb}-95$, and $\mathrm{Ru}-103$ was quite comparable. The volatile elements, Cs -137 and Te-129, showed patterns somewhat alike in isothermal zones but with cesium deposition greatly enhanced in the heat exchanger, where tellurium deposition was little affected. I-131 had its own unique deposition behavior. Small quantities deposited in the high-temperature $\left(1200^{\circ} \mathrm{F}\right)$ isothermal region. The bulk of it deposited in the heat exchanger, where erratic variations suggested an important temperature dependence. In the low-temperature isothermal zone, iodine deposition appeared to be almost independent of distance, a phenomenon also observed in previous experiments. The sharp peak in deposited activity at about Section 312 in this zone, mentioned earlier, and believed due to a cold spot associated with a gap in the insulation, can be seen from the individual fission-product plots to be almost wholly due to I-131. No corresponding increase in deposition of a metallic cation was apparent, suggesting that deposition was of elemental iodine (Ref. 14)."

\section{C.2. BMI CORRELATION PIODELS}

Raines et a1. then attempted to develop correlation models to fit their experimental data. Their first attempt was a fully developed 
boundary layer model whereby an analytical solution was obtained for the one-dimensional steady-state continuity equations for isothermal conditions; this model assumed a series resistance approximation in which the mass transfer process was defined by a gas-phase transfer coefficient and a wall coefficient (i.e., a Henrian sorption process). Although a parametric survey demonstrated the relative importance of the two processes, no attempt was made to relate the wall coefficient to experimental sorption data. Their efforts were further compromised by the isothermal condition which, of course, eliminated modeling of the heat exchanger. Unsatisfied with their correlation, the authors attempted to refine their model. Somewhat surprisingly, they did not attempt to better define the wall coefficient but rather attempted to refine their estimation of the gas-phase coefficient by development of a finite difference computer solution of a steady-state two-dimensional rate equation. Rather than employing an empirical mass-transfer coefficient, they developed elaborate estimates of the turbulent diffusivity and parametrically varied the wallcoefficient. Details are fully discussed by the authors (Refs. 14, 18) and are summarized below:

"The finite difference model consists of the solution of the diffusion equation (in cylindrical coordinates) with axial bulk flow and radial gasphase diffusion by finite difference techniques. Adsorption of the fission-product species takes place at the wall with a linearized coefficient, $k_{w}$, which is related to the kinetics of adsorption. Any flow disturbance, i.e., an orifice, a bend, a thermocouple well, etc., is considered to completely mix the fission products so that the concentration in the gas phase is rendered uniform along the radius at this disturbance. Since turbulent flow was of interest, turbulent diffusivities were estimated and assumed to have no variation with radius. Plug flow was also assumed. However, the approach is general so that eddy diffusivity and velocity as functions of radius can be considered when refinements in the technique are warranted." (Ref. 14). 
Results of their modeling efforts appear as the thin solid lines in Figs. $\mathrm{C}-3, \mathrm{C}-4$, and $\mathrm{C}-5$; no attempt was made to correlate the $\mathrm{I}-131$ profile because of its reverse slope. The ratio $k_{w} x_{0} / D_{t}$ - where $k_{w}$ is the wall coefficient; $r_{0}$, the inside tube radius; and $D_{t}$, the turbulent diffusivity - is a measure of the relative importance of the two transport processes.

\section{C.3. APPLICATION OF THE PAD CODE}

Inspection of the profiles in Figures $\mathrm{C}-3$ through $\mathrm{C}-6$ indicated that these data could serve as an excellent test for the PAD code. The deposition of Ce-144, $\mathrm{Zr}-95, \mathrm{Ru}-103$, and Te-129 showed, in general, an exponential decrease with distance from the source indicating the surface was a perfect sink for these nuclides (at least under the conditions encountered in these experiments). However, the deposition of $\mathrm{Cs}-137$ and I-131 was clearly temperature dependent with imperfect sink conditions prevailing in the high-temperature isothermal zone.

\section{C.3.1. Modeling BMI Loop}

A PAD model of the BMI deposition loop was prepared from information taken directly from Refs. 14 and 18. Since almost a11 the necessary information was explicitly stated, and the geometry was particularly simple, there should be little modeling error with the exception of surface temperatures, which were (apparently) neither measured nor estimated. However, since sufficient information was given to perform a heat balance, these surface temperatures were readily estimated by the following methods.

Over some $180 \mathrm{~cm}$ of tubing before the heat exchanger (high temperature isothermal zone plus transition zone), a temperature drop from 1275 to $1175^{\circ} \mathrm{F}$ was realized; since the mass flow rate was $12.8 \mathrm{lb} / \mathrm{hr}$, the heat loss Q was 


$$
\begin{aligned}
Q & =\dot{\mathrm{m}} \mathrm{C} \Delta \mathrm{T}, \\
& =(12.8)(1.242)(100), \\
& =1590 \mathrm{Btu} / \mathrm{hr} .
\end{aligned}
$$

The total inside surface area was

$$
\begin{aligned}
A_{S} & =\pi D L, \\
& =\frac{\pi(0.37) \frac{180}{2.54}}{144}, \\
& =0.572 \mathrm{ft}^{2} .
\end{aligned}
$$

Therefore, the average flux $\bar{q}$ at the inside pipe surface was approximately

$$
\begin{aligned}
\bar{q} & =\frac{Q}{A_{s}}=\frac{1590}{0.572}, \\
& =2780 \mathrm{Btu} / \mathrm{hr} \mathrm{ft}{ }^{2} .
\end{aligned}
$$

Next, an estimate of the inside flim coefficient was needed. In the hightemperature isothermal zone, the Reynolds number is given as 4962 and L/D = 135; then from Fig. 8-15 in Kreith (Ref. 44, P. 360):

$$
\frac{\overline{\mathrm{h}}}{\mathrm{CVP}} \operatorname{Pr}_{\mathrm{b}}{ }^{2 / 3}\left(\frac{\mu_{\mathrm{s}}}{\mu_{\mathrm{b}}}\right)^{0.14}=0.004
$$

where $\overline{\mathrm{h}}=$ average film coefficient, Btu/hr-ft${ }^{2}-{ }^{\circ} \mathrm{F}$,

$$
\mathrm{C}=\text { heat capacity, } \mathrm{Btu} / 1 \mathrm{~b}-{ }^{\circ} \mathrm{F} \text {, }
$$




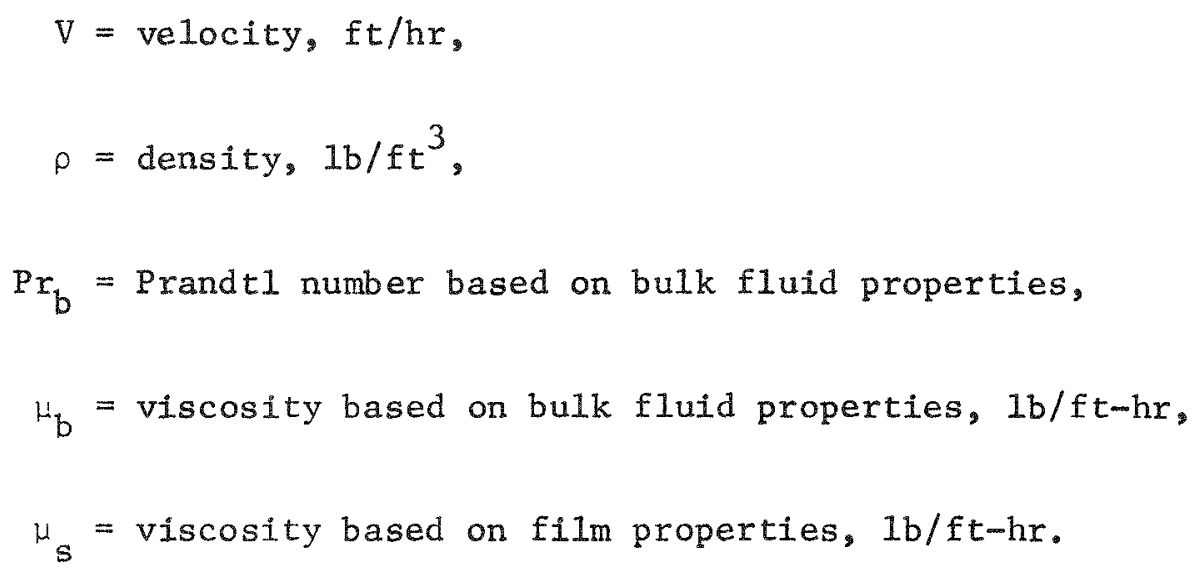

Ignoring the small viscosity correction and solving for $\bar{h}$, the average film coefficient is determined to be

$$
\mathrm{h}=120 \mathrm{Btu} / \mathrm{hr} \mathrm{ft}^{2}{ }^{\circ} \mathrm{F}
$$

Finally, the average film drop is estimated to be

$$
\begin{aligned}
\Delta T=T_{g}-T_{W} & =\bar{q} / \overline{\mathrm{h}}, \\
& =\frac{2780}{120} \\
& =23^{\circ} \mathrm{F}, \\
& =13^{\circ} \mathrm{C} .
\end{aligned}
$$

For simplicity then, it was assumed that the surface temperature in the isothermal zone was roughly constant at about $670^{\circ} \mathrm{C}$ since about a $20^{\circ} \mathrm{C}$ film drop might be expected at the entrance of the section (increased film coefficient because of bend) and the gas exit temperature from the isothermal zone should have been about $650^{\circ} \mathrm{C}$ (assuming a linear temperature drop). 
The heat flux was considerably higher in the heat exchanger because the gas was cooled from 1175 to $660^{\circ} \mathrm{F}$ in a distance of $100 \mathrm{~cm}^{2}$. Substituting the appropriate values into Eqs. $\mathrm{C}-1$ and $\mathrm{C}-2$, the average flux was determined to be

$$
\mathrm{q}=25,762 \mathrm{Btu} / \mathrm{ft} \mathrm{t}^{2}-\mathrm{hr}
$$

Using bulk fluid properties at an average gas temperature of $920^{\circ} \mathrm{F}$, the average film coefficient was estimated, using Eq. C-4, to be

$$
\bar{h}=133 \mathrm{Btu} / \mathrm{hr} \mathrm{ft}^{2}-{ }^{\circ} \mathrm{F}
$$

when ignoring the viscosity correction (which thus underestimates slightly the film drop). Finally, the average film drop was estimated to be $100^{\circ} \mathrm{C}$. However, since the heat exchanger was of counter current design, the heat flux, and thus the film drop, will actually be higher at the exit of the heat exchanger (Ref. 55); furthermore, there obviously was some axial heat conduction at ends of the heat exchanger since the water chill block was simply clamped to the exterior of the loop piping. Since no information was given about the water coolant temperatures, these effects are difficult to quantify. In addition, the above factors would tend to give an approximately exponentially decreasing surface temperature profile rather than a linear one as required by the PAD code (Ref. 15). However, these modeling difficulties are considerably lessened by previous observations that cesium sorption effects are important only above about $400^{\circ} \mathrm{C}$ and iodine sorption effects above about $300^{\circ} \mathrm{C}$ under the conditions prevailing in this experiment (these qualitative conclusions were deduced from inspection of the profiles). By assuming the inlet surface temperature to be $575^{\circ} \mathrm{C}$ (approximately the average of what the surface temperature just before and after the heat exchanger entrance would have been had there been no axial transmission) and the outlet surface temperature to be $100^{\circ} \mathrm{C}$ (very conservative lower limit); the surface temperature profile in the upstream 
half of the heat exchanger (where sorption effects are evident) is judged to be approximately correct.

The surface temperature in the low temperature isothermal zone was taken as the gas temperature.

\section{C.3.2. Estimation of Fission Product Release}

Since the deposition of cesium and iodine was influenced by sorption effects, the plateout distribution of these nuclides will be strongly influenced by the total release. Since no estimates of releases were provided by the authors, and since no counting efficiencies were specified, such estimation is difficult. There is also ambiguity over the total burnup of the source fuel specimen (see Section $\mathrm{C}-1$ ): it was remarked that a burnup of 0.1 at. \% was desired for experimental convenience, but also that the sample had to be irradiated a second time because of scheduling delays. Furthermore, in Table $\mathrm{C}-1$ the "specimen integrated flux" for these two irradiations was given to be $1.9 \times 10^{18}$ and $1.2 \times 10^{18}$ nvt, respectively. Since the short-lived nuclides such as I-131 produced during the first irradiation would have decayed completely before the experiment, it is this writer's opinion that the second irradiation resulted in an additional burn-up of $1.2 /(1.9+1.2)(0.1 \%)$ or 0.06 at. $\%$, or the total burnup was about 0.2 at. $\%$.

The next problem was to choose appropriate fractional release values for cesium and iodine. Since the fuel specimen consisted of virtually bare kernels (with a $4 \mu \mathrm{m}$ PyC coating), total release of cesium and iodine was presumed a reasonable approximation even though the source temperature was only about $1800^{\circ} \mathrm{F}$ (Ref. 18). Since the other plateout nuclides (Ce, Ru, $\mathrm{Te}, \mathrm{Zr}$ ) showed no sorption effects, their plateout distributions are independent of amount released. Therefore, for convenience, a fractional release of $1 \%$ was assumed for these nuclides, and no corrections were made for decay. 
Several cases were considered corresponding to total burnups of 0.05 , $0.1,0.2,0.3$, and 0.5 at. $\%$. Decay considerations demonstrated that virtually all the Cs -137 born and none of the I-131 born during the first irradiation would have been present during the loop experiment. However, more than $99 \%$ of the iodine atoms present at the time of the experiment would have been stable I-127 and essentially stable I-129 from both irradiations; it is these isotopes that determine the shape of the iodine profile; the I-131 simply serves as a tracer. Best guess then is that 2.4 $\times 10^{16}$ atoms $\left(4.6 \times 10^{-4} \mathrm{Ci}\right)$ of $\mathrm{Cs}-137$ were born and presumed released along with stable $\mathrm{Cs}-133$ and Cs-135. Analogously, $2.4 \times 10^{15}$ atoms of ioline were present at the time of the experiment (of which $1.5 \times 10^{13}$ atoms or $400 \mu \mathrm{Ci}$ were $I-131)$.

It was then desirable to perform a rough mass balance by approximately integrating the plateout profiles. However, no counting efficiencies were reported for the machine-interpreted gamma spectra. Iterative calculations demonstrated that a consistent assumption of $5 \%$ counting efficiency gave an excellent fit of the experimental data.

\section{C.3.3. Cesium/Stee1 and Iodine/Steel Adsorption Isotherms}

The isotherms obtained from the extrapolation of the Milstead and Zumwalt data (Refs. 9, 10) were employed in this study. These isotherms were obtained on "as-received" and "preoxidized" ss304 specimens; the former had about $1 / 100$ the cesium sorptivity of the latter. The BMI 100 p was constructed of SS316 stee1, which is generally more oxidation resistant than S\$304 because of the inclusion of 2 to $3 \%$ Mo (Ref. 52). Iterative calculations demonstrated that to obtain the observed sorption effects with the available isotherm, one must assume that $\mathrm{SS} 316$ has a relative sorptivity considerably less than that of oxidized SS304. If the counting 
efficiency were really $5 \%$, then a relative sorptivity of $1 / 333$ gives an almost exact fit of the data (see Fig. C-5). If the actual counting efficiency were $100 \%$, then the relative capacity would be $1 / 6667$, which is rather unlikely. Or, put another way, it appears that the SS316 in the BMI loop was relatively oxide free and that as-received SS316 probably has a cesium sorptivity about an order of magnitude less than as-received s\$304.

The isotherm derived by Mears (Ref. 15) from the data of Hoinkis (Ref. 33) was used to describe the sorption behavior of iodine on steel. Again iterative calculations indicated that the iodine sorptivity of SS316 appeared to be about an order of magnitude less than that of the Cr-Mo chromaloy steel for which the isotherms were obtained (Ref. 15); this conclusion follows from comparison of the dotted and solid line profiles for the hot portion of the heat exchanger and is in agreement with the desorption data of Neill et al. (Ref, 50).

The results of the modeling effort are summarized in Section 3.2.2.1. 
APPENDIX D

PAD MODELING OF THE DRAGON HTGR

Probably the most detailed in-pile plateout data available were obtained by Dragon researchers. They obtained considerable plateout information by analysis of the primary circuit of the Dragon helium-cooled reactor; their efforts have included the disassembly of primary heat exchangers to measure the plateout distributions of such important fission products as $\mathrm{Cs}-137$ and $\mathrm{I}-131$. Since much of these data are available in Dragon Project reports, they can be of use in verification of the PAD code.

\section{D.1. DRAGON PRIMARY CIRCUIT}

The Dragon reactor, shown schematically in Fig. D-1, is a $20 \mathrm{MW}(t)$ helium-cooled test reactor of zero electrical output (Ref. 28). It is in many ways similar to the Peach Bottom reactor. Helium at $350^{\circ} \mathrm{C}$ and 20 atm passes upward through the core consisting of 37 fuel element clusters (each comprised of seven fuel tubes) which closely resemble Peach Bottom fuel elements. Hot helium at $750^{\circ} \mathrm{C}$ exits the core and enters the large upper plenum. From the plenum, the flow is split between six loops arranged symmetrically around the main pressure vessel (identified as loops A, B, C, $D$, E, and $F$ ).

Considering an individual loop (as shown in Fig. D-1), the gas flows through the inner pipe of a concentric duct and enters the primary heat exchanger shown in Fig. D-2.

\footnotetext{
"The exchanger is a forced convection He/water evaporator having He on the she11-side, and secondary circuit water entering at nominally saturation temperature on the tube side.... Hot He enters at the bottom via the inner concentric duct, passes over the tube bundle and
} 


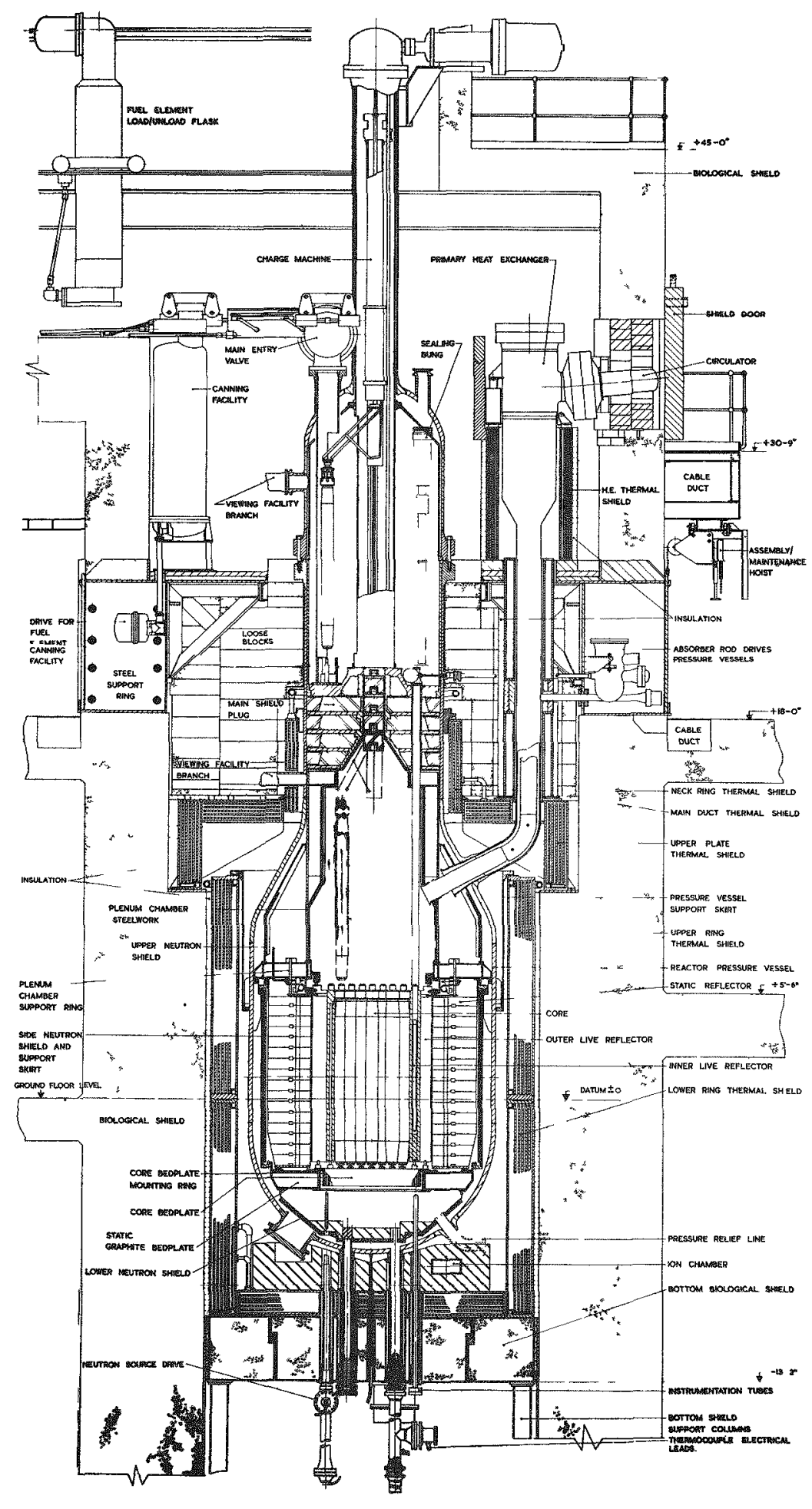

Fig. D-1. General assembly of Dragon reactor (Ref. 28) 


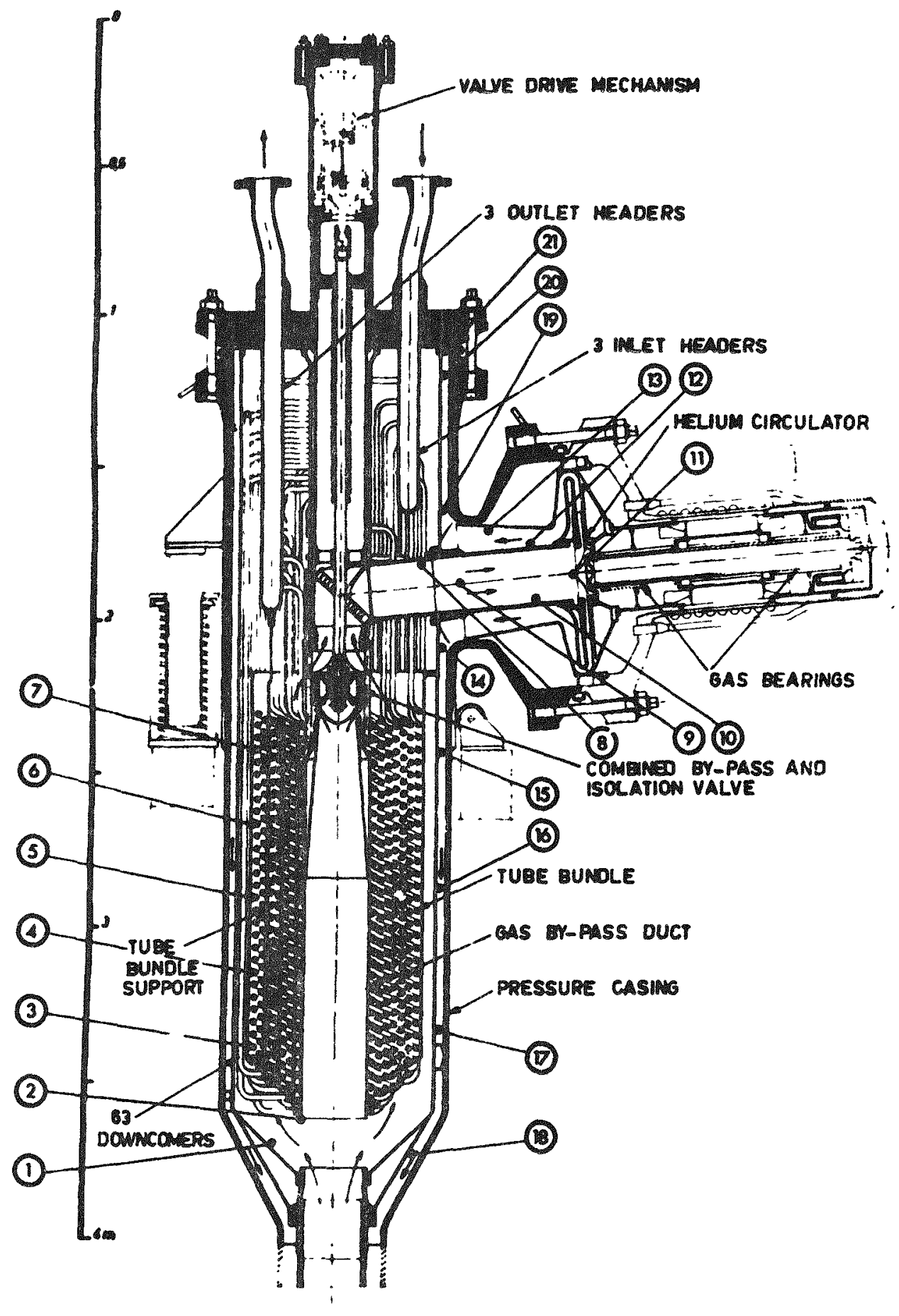

Fig. D-2. Positions of swab samples from heat exchanger $E$ and circulator $\mathrm{E}(\operatorname{Ref}, 21)$ 
thence to the eye of the circulator impellor via the bypass valve assembly, and duct. The gas leaving the circulator passes down the annular space between tube bundle skirt and pressure vessel, back to the bottom of the exchanger and thence to the reactor (pressure vessel) through the outer annulus of the concentric ducting." (Ref. 29).

Upon return to the pressure vessel, the cold helium is distributed among multiple flow paths for cooling the control rods, side reflector, thermal barrier, pressure vessel, etc. Having cooled the core internals, the flow is recombined in the lower plenum and re-enters the core.

Using information selected from a series of Dragon Project Reports (Refs. 28, 29, 53-59), a PAD code model was prepared of the primary circuit of the Dragon reactor; details are summarized in Table D-1. The calculated velocities and Reynolds numbers for the core, ducts, and heat exchangers are in excellent agreement with published Dragon results.

\section{D.2. PLATEOUT IN DRAGON PRIMARY CIRCUIT}

Dragon researchers have published considerable plateout information (Refs. 22, 36, 59). The most recently published work (Ref. 22) discusses rapid disassembly of a heat exchanger after reactor shutdown so that the plateout distribution of short-lived I-131 (8-day half-Iife) could be determined. While these results are important in understanding plateout, the results are difficult to model accurately with the PAD code because the documentation of reactor conditions was, in general, incomplete. However, the plateout results obtained after fuel charge II (Ref. 21) are a notable exception. Although the elapsed time between reactor shutdown and plateout measurement was too long for accurate determination of $\mathrm{I}-131, \mathrm{Ba}-140$, and $\mathrm{La}-140$, good Cs-137 plateout information was gathered. Thus, PAD simulation was directed toward prediction of Cs-137 plateout distribution after fuel charge II. 
TABLE D-1

DRAGON PRIMARY CIRCUIT

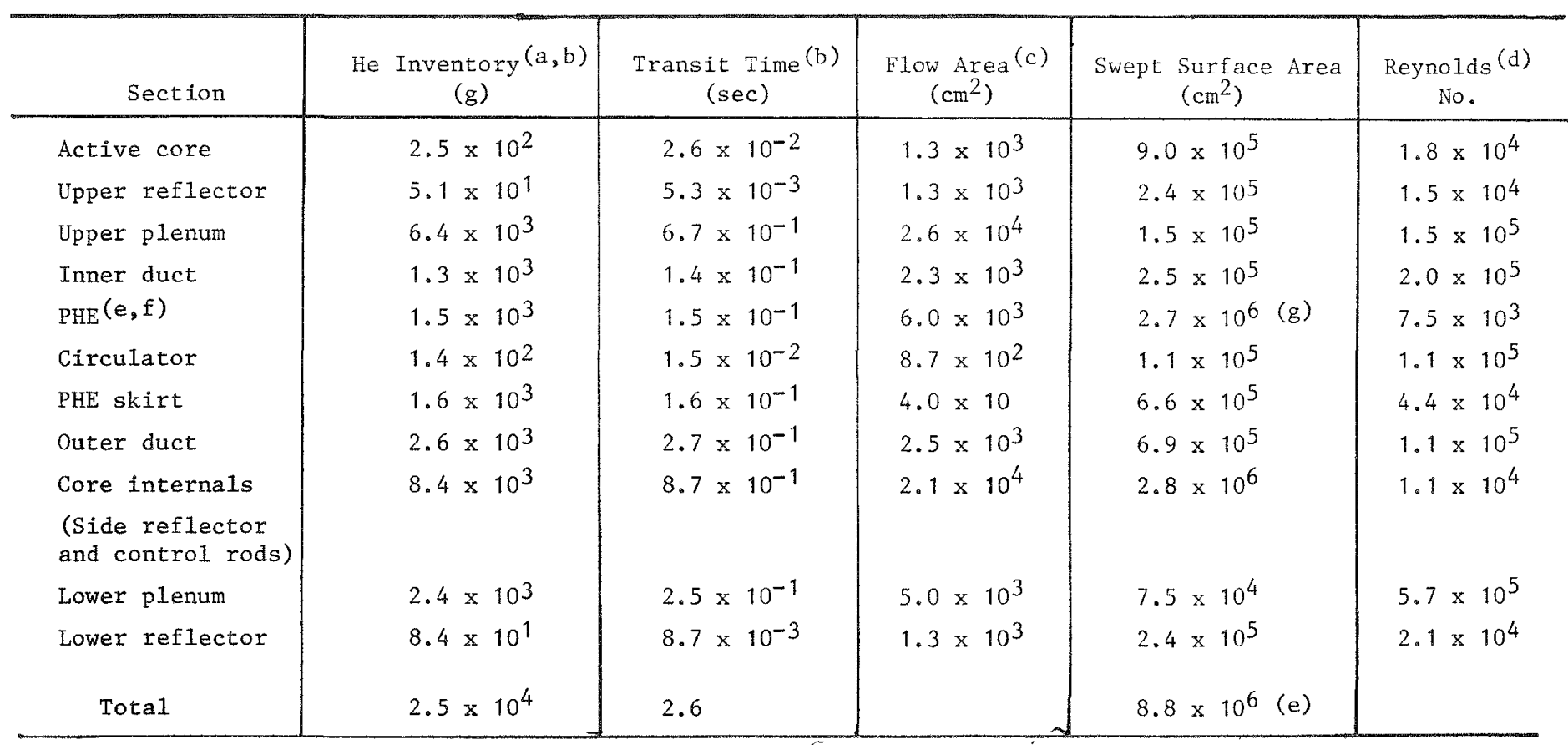

(a) At $100 \%$ power, $100 \%$ flow; includes all six loops.

(b) Areas of flow stagnation (e.g., above PHE Tube Bundle) are ignored.

(c) ${ }_{A_{f l o w}}=\# \frac{\pi D_{h}^{2}}{4}$ where $D_{h}$ is mean hydraulic diameter and $\#$ is number of equivalent cylindrical

channels (such that proper flow areas and transit times are obtained).

(d) Re based on hydraulic diameter and fluid properties evaluated at bulk coolant temperature (section average).

(e) Not in agreement with value of $1.3 \times 10^{7} \mathrm{~cm}^{2}$ cited in DP 564 (Ref. 21).

(f) Not in agreement with value of $6 \mathrm{sec}$ cited in DP 702 (Ref.59).

(g) Total swept surface in PHE's available for plateout. 


\section{D.3. BACKGROUND INFORIMTION}

The following background information (Ref. 21) is provided to permit the reader to appraise critically the results obtained.

\footnotetext{
"In assessing the safety and maintenance problems of an HTGR, it is important to know the levels of fission products that may accumulate in the primary coolant circuit. Therefore when the first major shutdown of the Dragon reactor took place in August 1966, to change the first fuel charge, one of the six heat exchangers, $C$, and its associated circulator was removed from the primary circuit and radioactive deposits measured...."
}

"During the operation of the reactor with the second fuel charge a leak occurred in the cooling tubes of the heat exchanger $\mathrm{E}$, so when $\mathrm{a}$ power failure tripped the reactor in July 1967 this heat exchanger and its circulator were removed to investigate, primarily, the cause of the leak. Since this required the unit to be completely dismantled the opportunity was taken to repeat the examination for radioactive deposits. Some swab samples were at that time taken also from circulator $D$ which had experienced similar exposure to circulator $E$.

"Circulator D had given trouble during the operation of the second charge, so arrangements were made to replace it with circulator $E$. Therefore circulator $E$ could not be taken to pieces but could be swabbed in the most accessible places to give an indication of activity deposition."

Fuel charge I operated for 104 equivalent full-power days (EFPD), and charge II operated for an additional 84 EFPD (Ref. 21). Plateout activities measured in loop $\mathrm{E}$ after exposure during a total of $188 \mathrm{EFPD}$ are summarized in Table $\mathrm{D}-2$; the results in parentheses are from the corresponding position in Heat Exchanger $C$ after the first charge (Ref. 21). The 
TABLE D-2

DEPOSITION ON HEAT EXCHANGERS C AND E AND CTRCULATORS C, E, AND D AS MEASURED ON SWABS (REF. 21)

\begin{tabular}{|c|c|c|c|c|c|c|c|c|c|c|c|c|c|}
\hline \multirow[b]{2}{*}{ Position of Sample } & \multirow{2}{*}{$\begin{array}{l}\text { Sample } \\
\text { No. }\end{array}$} & \multicolumn{11}{|c|}{ Activity $\left(\mathrm{m} \mu \mathrm{o} / \mathrm{cm}^{2}\right)$} & \multirow{2}{*}{$\begin{array}{c}\text { Cumulative } \\
\text { Surface } \\
\text { Area }\left(\mathrm{cm}^{2}\right)(a)\end{array}$} \\
\hline & & $\mathrm{Cs}-134$ & $\mathrm{Cs}-137$ & $\mathrm{Ba}-140$ & $\mathrm{Sr}-89$ & $\mathrm{Sr}-90$ & $I-131$ & $\mathrm{Cr}-51$ & $\mathrm{Mn}-54$ & $2 n-65$ & $\mathrm{Ag}-110 \mathrm{~m}$ & $\mathrm{Sb}-124$ & \\
\hline \multirow{6}{*}{$\begin{array}{l}\text { Inlet cone } \\
\text { Bottom of duct }\end{array}$} & 1 & 3 & 12 & 3 & 8 & 0.2 & 14 & 433 & 18 & -- & 3 & -- & $2.8 \times 10^{5}$ \\
\hline & 2 & & 49 & & -- & -- & 6 & 44 & 3 & -- & 1 & -- & $3.2 \times 10^{5}$ \\
\hline & & $(0.4)(b)$ & & $(8)(c)$ & & & & $(300)$ & (6) & & & $(0.6)$ & \\
\hline & 3 & & $\begin{array}{l}60 \\
(15)\end{array}$ & $11(c)$ & 31 & 0.3 & $210^{(c)}$ & $-\overline{0}$ & 3 & 14 & 12 & & $3.9 \times 10^{5}$ \\
\hline & 4 & 17 & 103 & 20 & 72 & 0.9 & $370(c)$ & $\begin{array}{l}(2000) \\
--\end{array}$ & $\begin{array}{l}(40) \\
6\end{array}$ & 28 & $\begin{array}{l}(100) \\
29\end{array}$ & $\begin{array}{l}(20) \\
6\end{array}$ & $4.7 \times 10^{5}$ \\
\hline & & (6) & (12) & (c) & & & & $(2000)$ & $(40)$ & $(100)$ & $(90)$ & $(10)$ & (1) \\
\hline \multirow[t]{4}{*}{ Outer tube bundle } & 5 & $\begin{array}{l}11 \\
(5)\end{array}$ & 83 & 16 & 48 & 0.6 & $300(c)$ & $-\overline{0}$ & & 22 & 21 & & $5.5 \times 10^{5}$ \\
\hline & 6 & 10 & 76 & 15 & 37 & 0.4 & $270^{(c)}$ & $-\infty$ & 5 & 17 & 13 & 4 & $6.5 \times 10^{5}$ \\
\hline & & (4) & (6) & (c) & & & & $(2000)$ & $(40)$ & $(60)$ & $(50)$ & (3) & \\
\hline & 7 & 5 & 37 & & -- & - & $130(\mathrm{c})$ & $-\overline{10}$ & & & & & $7.5 \times 10^{5}$ \\
\hline \multirow{3}{*}{ Outlet duct } & 8 & 1.5 & & 9 & 33 & 0.4 & 11 & $\begin{array}{l}(1000) \\
9\end{array}$ & $\begin{array}{l}(30) \\
0.5\end{array}$ & ${ }_{2}^{(60)}$ & $\begin{array}{l}(50) \\
1\end{array}$ & $\begin{array}{l}(4) \\
2\end{array}$ & $8.5 \times 10^{5}$ \\
\hline & & $(0.1)$ & $(0.2)$ & (4) & & & -- & $(10)$ & $(0.3)$ & $(0.4)$ & $(0.7)$ & (1) & 然 \\
\hline & 9 & $\begin{array}{l}0.5 \\
(0.2)\end{array}$ & 3 & $\begin{array}{l}2 \\
(8)\end{array}$ & -- & - & 7 & $\begin{array}{l}31 \\
(60)\end{array}$ & & $\begin{array}{l}0.9 \\
(4)\end{array}$ & $\begin{array}{l}0.5 \\
(3)\end{array}$ & $\begin{array}{l}0.5 \\
(5)\end{array}$ & $8.5 \times 10^{5}$ \\
\hline \multirow{2}{*}{ Inlet circulator } & 10 & & 11 & 13 & 42 & 0.4 & 10 & 283 & & 8 & 1 & 4 & $8.7 \times 10^{5}$ \\
\hline & & $(0.4)$ & & $(20)$ & $(59)$ & $(0.2)$ & & $(50)$ & $(0.9)$ & (5) & (2) & (9) & \\
\hline Impeilor & 11 & $\begin{array}{l}3 \\
(0.2)\end{array}$ & 16 & 9 & -- & - & 6 & 18 & 1 & & 0.8 & 4 & $8.8 \times 10^{5}$ \\
\hline \multirow{5}{*}{ Outlet circulator } & 12 & $\begin{array}{l}(0.2) \\
1.5\end{array}$ & 8 & $\begin{array}{l}\text { (3) } \\
11\end{array}$ & -- & - & 9 & $\begin{array}{l}(200) \\
10\end{array}$ & $\begin{array}{l}(3) \\
2\end{array}$ & $\begin{array}{l}(0.7) \\
5\end{array}$ & $(0.4)$ & (1) & $89 \times 10^{5}$ \\
\hline & 13 & 1 & 7 & 9 & 25 & 0.3 & 17 & & 1 & 7 & 1 & 2 & $9.0 \times 10^{5}$ \\
\hline & & & & (34) & $(51)$ & $(0.2)$ & & $(2000)$ & (30) & (2) & (3) & (6) & \\
\hline & 14 & 0.7 & 5 & 4 & - & - & 8 & 13 & 0.8 & 2 & 0.6 & 1.5 & $9.4 \times 10^{5}$ \\
\hline & 15 & 1.0 & & & 26 & 0.3 & 8 & & 0.7 & 2 & 1 & 2 & $9.6 \times 10^{5}$ \\
\hline \multirow[t]{4}{*}{ Skirt below circulator) } & & $(0.3)$ & $(0.4)$ & (10) & & & & $(100)$ & (1) & (1) & (2) & (5) & \\
\hline & 16 & 0.4 & 3 & 2 & - & - & 2 & 2 & 0.3 & 2 & 0.8 & 0.7 & $10.1 \times 10^{5}$ \\
\hline & 17 & 0.2 & 1 & 1.5 & - & $\cdots$ & 2 & 1 & 0.2 & 0.1 & 0.4 & 0.1 & $10.5 \times 10^{5}$ \\
\hline & 18 & 0.9 & & 3 & 11 & 0.4 & 4 & 3 & 0.4 & 1.0 & 1.0 & 0.6 & $12.3 \times 10^{5}$ \\
\hline \multirow[t]{2}{*}{ Outer cone } & & $(0.1)$ & $(0.2)$ & (3) & $(29)$ & $(0.1)$ & & $(20)$ & $(0.4)$ & $(0.8)$ & (1) & (1) & \\
\hline & 19 & 0.4 & 4 & 5 & -- & - & 9 & 4 & 0.6 & 3 & & 2 & \\
\hline Skirt above circulatory & 20 & 0.2 & 1.5 & -- & 7 & 0.4 & -- & 17 & 2 & 0.4 & 0.3 & 0.1 & \\
\hline Top flange groove & 21 & - & 0.01 & -- & $\stackrel{(7)}{--}$ & - & -- & $(200)$ & (7) & (1) & $\stackrel{(2)}{--}$ & (2) & \\
\hline
\end{tabular}

(a) Cumulative surface area is the total surface area swept by the coolant gas, measured from the core and including one-sixth of the reactor circuit.

(b) Results in parenthesis are from the corresponding position in Heat Exchanger $C$ after first charge.

(c) Estimated results 
sample numbers in Table D-2 identify sampling positions shown in Fig. D-2. Some of these results are also shown graphically in Fig. D-3. "The accuracy of (these) surface contamination measurements is estimated to be within a factor of 2 for heat exchanger $E$ and circulators $D$ and $E$ results, but within a factor of 5 for heat exchanger $C$ results" (Ref, 21).

"... [n Table III]... the measured deposition levels have been integrated over the entire surface area of the Dragon primary circuit $\left(1.3 \times 10^{7} \mathrm{~cm}^{2}\right)$ [sic] and corrected to the reactor shutdown date. Using the measured steady state fractional release data for $\mathrm{Kr}$ and Xe isotopes, as obtained from purge gas monitoring, and extrapolating by means of the relation $R / B \propto 1 / \sqrt{\lambda}$ to obtain estimates of those isotopes not measured, the primary circuit contamination due to decaying rare gases has been calculated. After subtracting these quantities from the measured contamination, the residues have been expressed, (in Table $\mathrm{D}-3$ ), as fractional releases of the entire reactor inventory." (Ref. 21). 


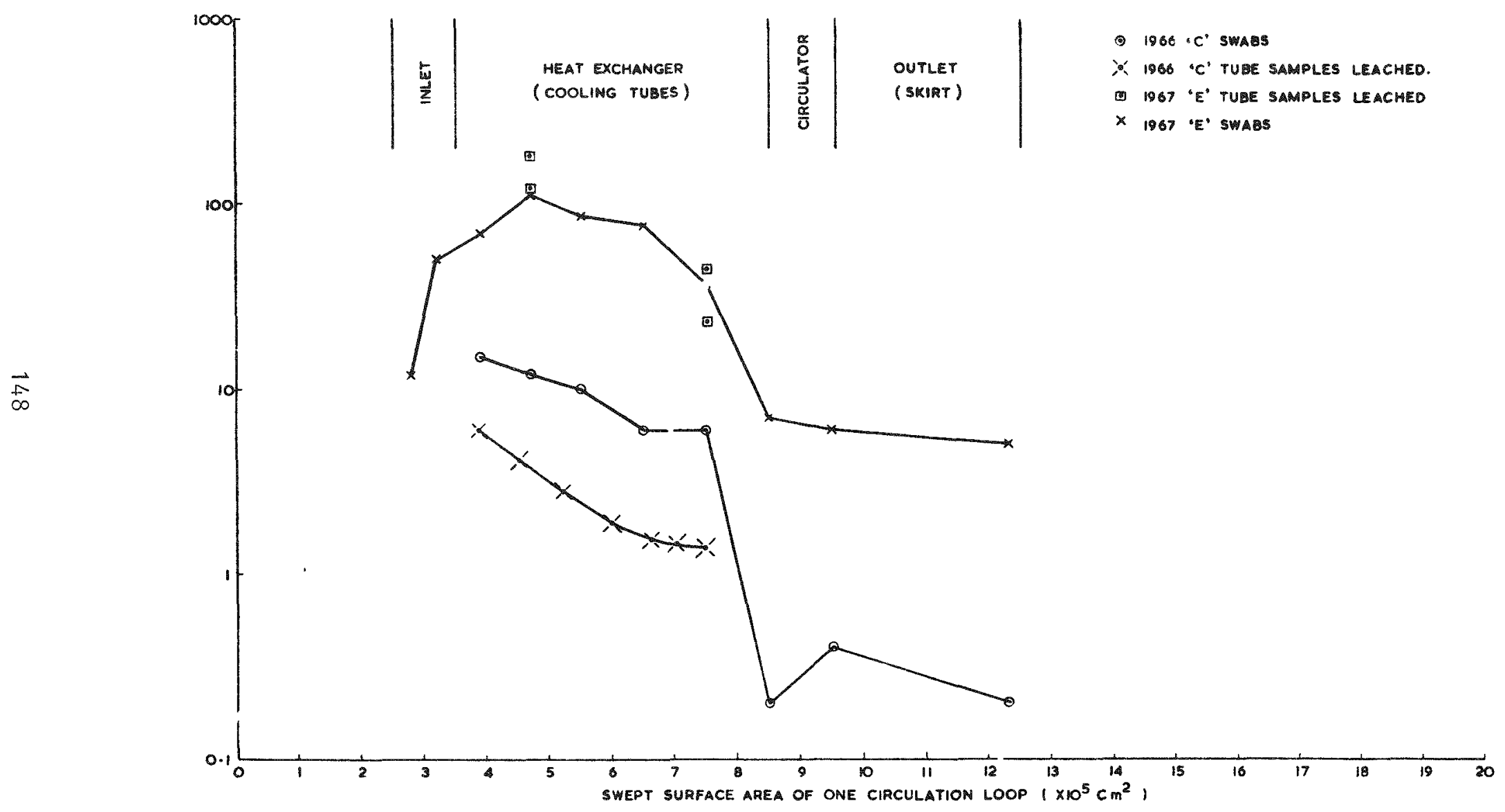

Fig. D-3. Heat exchangers $C$ and E Cs-137 deposition profiles (Ref. 21) 
TABLE $D-3$

FRACTIONAI RELEASE OF FISSION PRODUCTS INTO THE PRIMARY CIRCUIT (REF. 21)

\begin{tabular}{|c|c|c|c|c|c|}
\hline \multicolumn{6}{|c|}{ Charge I - based upon heat exchanger C (104 days) } \\
\hline Nuclide & $\begin{array}{l}\text { Reactor } \\
\text { Inventory } \\
\text { at Shutdown (C) }\end{array}$ & $\begin{array}{c}\text { Measured } R / B \text { of } \\
\text { Parent Rare Gas }(a)\end{array}$ & $\begin{array}{l}\text { Calculated Primary } \\
\text { Circuit Activity due } \\
\text { to Rare Gas Decay (mc) }\end{array}$ & $\begin{array}{l}\text { Measured Primary } \\
\text { Circuit Activity } \\
\text { at Shutdown(mc) }\end{array}$ & $\begin{array}{l}\text { Fractional Release } \\
\text { (extra to rare gas } \\
\text { contribution) }\end{array}$ \\
\hline $\mathrm{Cs}-134$ & $5.7 \times 10^{2}$ & & & 8.5 & $1.5 \times 10^{-5}$ \\
\hline $\mathrm{Cs}-137$ & $7.2 \times 10^{3}$ & $1.6 \times 10^{-7}$ & 1.1 & 17 & $2.2 \times 10^{-6}$ \\
\hline \multicolumn{6}{|c|}{ Charge II - based upon heat exchanger E (984 days) (b) } \\
\hline & & & (c) & (d) & \\
\hline $\operatorname{CS}-134$ & $3.7 \times 10^{2}$ & & & 26 & $7.0 \times 10^{-5}$ \\
\hline $\mathrm{CS}-137$ & $5.8 \times 10^{3}$ & $3.0 \times 10^{-7}$ & 2.8 & 200 & $3.4 \times 10^{-5}$ \\
\hline$S r-89$ & $5.3 \times 10^{5}$ & $4.7 \times 10^{-7}$ & 260 & 190 & $1.3 \times 10^{-7}$ \\
\hline $\mathrm{Sr}-90$ & $6.2 \times 10^{3}$ & $2.0 \times 10^{-7}$ & 1.5 & 1.3 & $1.3 \times 10^{-7}$ \\
\hline $\mathrm{Ba}-140$ & $1.0 \times 10^{6}$ & $7.8 \times 10^{-8}$ & 52 & 46 & $6 \times 10^{-9}$ \\
\hline$I-131$ & $4.9 \times 10^{5}$ & & & 700 & $1.4 \times 10^{-6}$ \\
\hline
\end{tabular}

(a) Charge I data from DPCPWP D 154 and Charge II data from DPCPWP D 201.

(b) Should read "84 days", not "984" days (Ref. 21).

(c) These figures include the $\mathrm{Cs}-137$ and $\mathrm{Sr}-90$ deposited by rare gases during Charge I operation.

(d) These figures have been adjusted to represent Charge II deposition alone, by subtracting the small Charge I components of $\mathrm{Cs}-134$ and $\mathrm{Cs}-137$. 
APPENDIX E

PAD MODELING OF THE CS-137 DISTRIBUTION

IN THE PEACH BOTTOM HTGR

E.1. INTRODUCTION

Some estimates of the plateout activity in the Peach Bottom HTGR (Fig. E-1) (Ref. 64) have been made by ORNL personnel by gamma scanning the accessible ducts and extrapolating diffusion probe results (Refs. 2-5, 23). These measurements were made during Core 2 operation (after 252 EFPD and 384 EFPD) subsequent to partial failure and replacement of Core 1 ; consequent1y, more than $90 \%$ of the plateout activity measured at these times had been depositied during Core $I$ operation. The results of these gamma scans are summarized in Tables $E-1$ and $E-2$. While these data are by no means complete, the subject of plateout is of sufficient importance (and in-pile plateout data of sufficient scarcity) that these tentative results merit investigation. Consequently, the Cs-137 distribution was predicted with the $\mathrm{PAD}$ code for comparison with these experimental results.

If sorption effects are important, then the plateout distribution of cesium in Peach Bottom is dependent upon not only the fluid dynamics but also the surface temperature distribution and the total plateout inventory. Consequently, it is necessary to obtain an accurate estimate of the total Cs-137 inventory in the primary circuit at the time of the gamma scan measurements. Such an estimate is not readily obtained because the cesium release underwent step-change increases during Core 1 operation as a consequence of fuel element sleeve failures as reviewed below:

"During the initial period of reactor operation (June 1967 to January 1968), gaseous activity in the primary coolant remained less than 0.4 


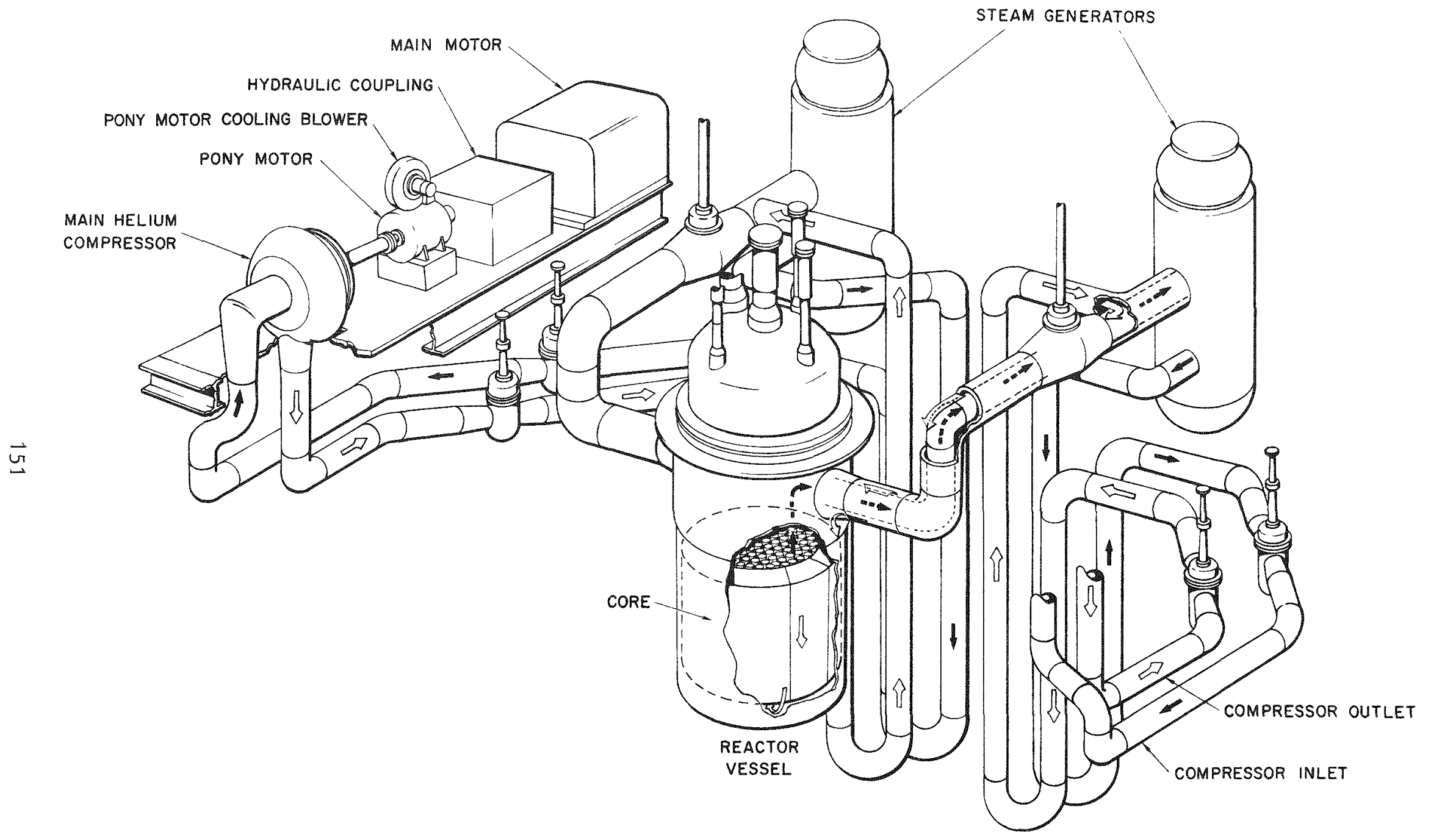

Fig. E-1. Isometric of Peach Bottom primary coolant system (Ref. 64) 
SUIMARY OF ACTIVITIIS FOUND ON PEACH BOTTOM PRTMARY CIRCUIT LARGE DUCTS - 1971 (RLF, 62)

\begin{tabular}{|c|c|c|c|c|c|c|c|c|c|c|c|c|c|c|c|}
\hline & \multicolumn{15}{|c|}{ Activity $\left(\mu \mathrm{c} / \mathrm{cm}^{2}\right)$} \\
\hline & $C S-134$ & cs-137 & $\mathrm{Ce}-144$ & $\mathrm{BA}-140$ & $\mathrm{AG}=110 \mathrm{~m}$ & $z r-95$ & FE-59 & $C 0-60$ & $M n-54$ & $2 n-65$ & $R u-103$ & Ru-106 & $5 b-124$ & Lu-154 & CS-137/134 \\
\hline Hot Duce 1 & & & & & & & & & & & & & & & \\
\hline Hot Duct 2 & & & & & & & & & & & & & & & \\
\hline Steam generator exit & 0.71 & 2.1 & 0.39 & $6.8 \times 10^{-3}$ & $2.7 \times 10^{-2}$ & $N_{D}(a)$ & $1.6 \times 10^{-2}$ & $1.5 \times 10^{-2}$ & $9.1 \times 10^{-3}$ & $2.9 \times 10^{-2}$ & & & $1.3 \times 10^{-3}$ & & 2.96 \\
\hline Compressor entry & 0.78 & 2.4 & & $6.1: 10^{-3}$ & $2.6 \times 10^{-4}$ & Dי & $4.6 \times 10^{-3}$ & $2.0 \times 10^{-3}$ & $7.6 \times 10^{-3}$ & $2.5 \times 10^{-2}$ & & & & & 3.07 \\
\hline Compressor exit & 0.73 & 2.2 & & $6.3 \times 10^{-3}$ & $2.2 \times 10^{-2}$ & $\mathrm{ND}$ & $2.3 \times 10^{-3}$ & $9.4 \times 10^{-3}$ & $6.3 \times 10^{-3}$ & $2.6 \times 10^{-2}$ & & & & & 3.01 \\
\hline $\begin{array}{l}\text { Compressor exit line } \\
\text { near steam generator }\end{array}$ & 0.18 & 0.54 & & $2,5 \times 10^{-3}$ & $5.6 \times 10^{-3}$ & D & $1.1 \times 10^{-3}$ & $7.3 \times 10^{-3}$ & $3.6 \times 10^{-3}$ & $5.7 \times 10^{-3}$ & & & $6.5 \times 10^{-4}$ & & 3.00 \\
\hline $\begin{array}{l}\text { Compressor exit } \\
\text { Vert } \perp \text { cal duct }\end{array}$ & 0.16 & 0.45 & $7.0 \times 10^{-3}$ & $3.9 \times 10^{-3}$ & $7.3 \times 10^{-2}$ & $7.2 \times 10^{-3}$ & $1.9 \times 10^{-3}$ & $2.1 \times 10^{-2}$ & $4.1 \times 10^{-3}$ & $4.7 \times 10^{-3}$ & $1.3 \times 10^{-3}$ & $1.6 \times 10^{-2}$ & $7.1 \times 10^{-4}$ & $1.09: 10^{-3} \mid$ & $\begin{array}{l}2.81 \\
=2.97 \\
2.97\end{array}$ \\
\hline
\end{tabular}

${ }^{(a)}$ Not detected 
SUMARY OF ACTIVITIES FOUND ON PEACH BOTTOM PRIMARY CIRCUIT LARGE DUCTS - 1972 (REF * 62)

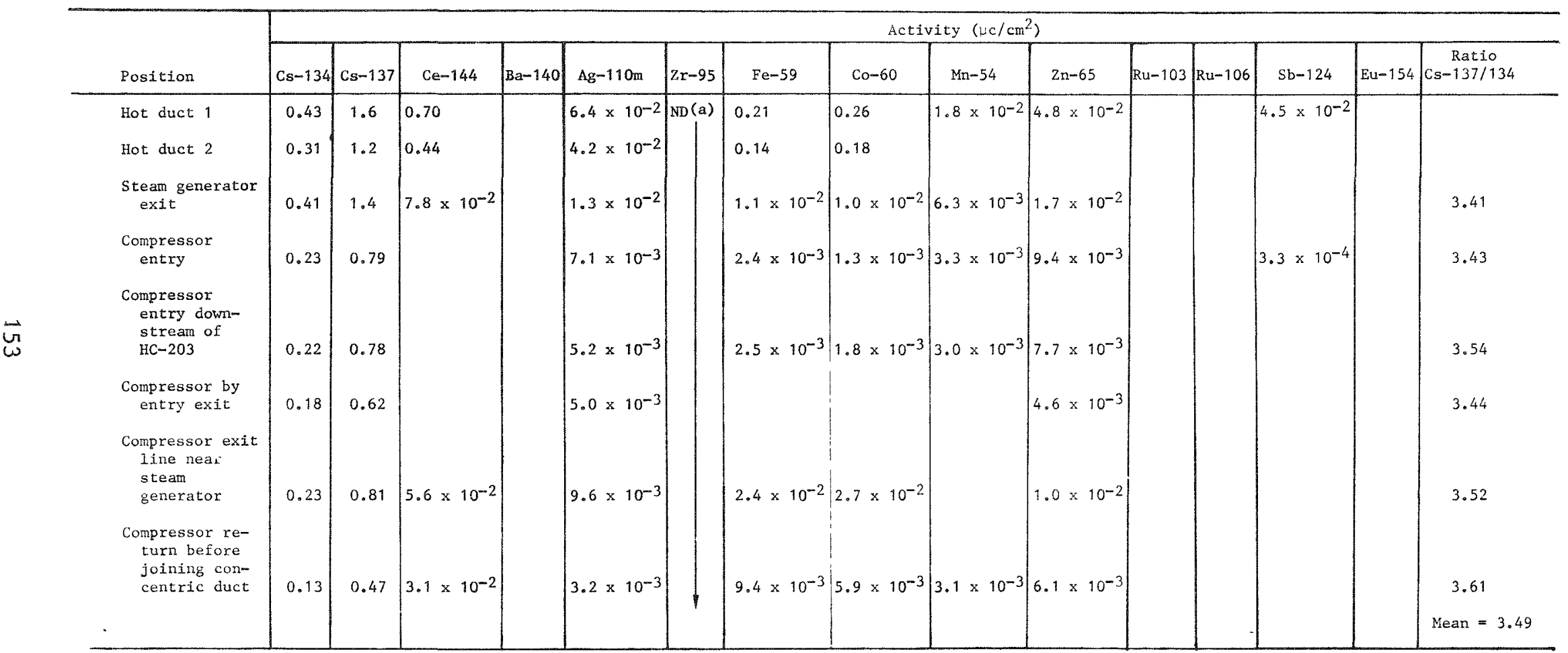

(a) Not detected 
curie. This level was well below the expected activity at beginning of life (108 curies) and the design activity (4225 curies).

"Starting in January 1968, the Cary electrometer showed periodic step increases in main loop activity with time. This behavior was related to fuel element sleeve fallures. One step increase occurred prior to the January 11, 1968 shutdown, and one fuel element with a cracked sleeve was located and removed. Eleven or twelve abnormally purged elements with cracked sleeves were indicated by the Cary during the period of operation ending October 23, 1968. Eleven were located and removed. During the period of operation ending with the October 3 , 1969 shutdown, the electrometer continued to indicate fuel element sleeve failures, and 78 abnormally purged elements were found (out of 804 fuel elements).

"Main 1oop gaseous activity increased to 36 curies at 300 equivalent ful1-power days (EFPD) and to nearly 300 curies at 452 EFPD (measurements at full power), still below the design activity level.

\footnotetext{
"Small amounts of fuel compact meterial and sleeve graphite could be released from fuel elements with cracked sleeves. Amounts of fuel compact material released were measureable, but were extremely sma1l." (Ref. 64).
}

From the above, it is obvious that the release of cesium varied significantly during Core 1 operation as fuel element failure progressed, thereby complicating the estimation of cesium plateout inventory. Several such estimates have been made. Mears (Ref. 65) estimated from diffusion probe data (Ref. 63) that the time-average fractional release for $\mathrm{Cs}-137$ (from fuel to coolant) was $1 \times 10^{-4}$ prior to onset of sleeve failure (168 EFPD) and $1 \times 10^{-3}$ from onset of failure to end of core life (284 EFPD of operation). These data translate to about $6 \mathrm{CI}$ of $\mathrm{Cs}-137$ released during the first 168 EFPD of operation, and an additional $106 \mathrm{Ci}$ released during 
the failure period. De Nordwall (Ref. 66) has estimated from the gamma scan measurements that 25 to $50 \mathrm{Ci}$ of $\mathrm{Cs}-137$ were released into the primary circuit during Core 1 operation; these estimations, however, assumed that the specific plateout activity on the steam generator tube bundles was the same order of magnitude as that in the ducts (Ref. 66). Such an assumption should be contrasted with the observation of Dragon researchers who reported that the specific activity on the relatively cold heat exchanger tube bundles was, in general, about an order of magnitude higher than on adjacent hot surfaces (Ref. 30).

\section{E.2. RESULTS}

The total primary circuit Cs-137 inventory was estimated by two methods. The first method is based upon the diffusion probe data summarized in Table E-3. By inspection, it is obvious that most of the $\mathrm{Cs}-137$ inventory was released during the sleeve failure period; thus, for simplicity, the failure period alone was modeled for calculational purposes since about $90 \%$ of the Cs-137 plateout was released during this period. A time-weighted average cesium partial pressure of $7.5 \times 10^{-14}$ atm was obtained from the data for probes JM-15-2 and -3 ; however, this partial pressure corresponds to a total plateout inventory of only about $13 \mathrm{Ci}$ of Cs-137. [For a total release of $50 \mathrm{Ci}$ during the 284 EFPD of sleeve failure, the time-average cesium partial pressure would have to have been about $3 \times 10^{-13} \mathrm{~atm}$ (PAD code calculation).]

The Cs-137 plateout inventory was also estimated from the ORNL measurements. The average specific activity measured in the cold ducts was about $1.5 \times 10^{-6} \mathrm{Ci} / \mathrm{cm}^{2}$ in 1971 and about $0.8 \times 10^{-6} \mathrm{Ci} / \mathrm{cm}^{2}$ in 1972 . Furthermore, the total area available for plateout in the Peach Bottom primary circuit has been estimated to be $2.4 \times 10^{7} \mathrm{~cm}^{2}$ (Ref. 67). Thus, if these values reflect the "circuit-average," or if the $\mathrm{Cs}-137$ plateout distribution is "relatively flat," as has been suggested (Ref. 66), then 


\section{TABLE $E-3$}

Cs-137 PARTIAL PRESSURES FROM DIFFUSION PROBES

\begin{tabular}{|c|c|c|c|}
\hline Probe & $\begin{array}{c}\text { Removal Time } \\
\text { (EFPD) }\end{array}$ & $\begin{array}{l}\text { No. of } \\
\text { Failures }\end{array}$ & $\begin{array}{l}\text { Average } \\
\quad \text { (atm) }\end{array}$ \\
\hline$J M-15-1(\operatorname{Ref} \cdot 31)$ & 168 Core 1 & 1 & $1 \times 10^{-14}$ \\
\hline$J M-15-2(\operatorname{Ref} \cdot 31)$ & 300 Core 1 & 11 & $4 \times 10^{-14}$ \\
\hline$J M-15-3(\operatorname{Ref} \cdot 31)$ & 452 Core 1 (EOL) & 78 & $1 \times 10^{-13}$ \\
\hline $4 \mathrm{DP}-2(\operatorname{Ref} \cdot 60)$ & 252 Core 2 & 0 & $6 \times 10^{-15}$ \\
\hline
\end{tabular}


the plateout inventory would be 20 to $36 \mathrm{CI}$ of $\mathrm{Cs}-137$. However, a more reasonable assumption might be to consider the specific activity on the steam generator tube bundles to be 3 to 5 times higher than on the ducts (Ref. 30). Since the tube bundles represent about $40 \%$ of the total surface, the corresponding range of inventory would be about 30 to $100 \mathrm{Ci}$ of $\mathrm{Cs}-137$. Under the circumstances, it was decided to consider two cases of 10 to $50 \mathrm{Ci}$ total $\mathrm{Cs}-137$ release, which is believed to represent a practical bound.

The modeling was further simplified by ignoring the production of Cs137 from decay of $\mathrm{Xe}-137$ and presuming the entire inventory was directly released as cesium metal. This assumption reflects the observation made by Dragon that more than $90 \%$ of $\mathrm{Cs}-137$ was directly released (Ref. 30); the suggestion was also made by de Nordwall (Ref. 31). In addition, the contribution of Cs-134 was ignored because the amount of Cs-134 is sma11 compared to $\mathrm{Cs}-137$ on an atom basis. 


\section{APPENDIX F}

DERIVATION OF CESIUM SORPTION ISOTHERMS

\section{F.1. AVAILABLE CESIUN SORPTION DATA}

Many experiments have been performed to characterize the sorption behavior of cesium on various nuclear grade graphites (Ref. 8). These experiments were performed in the temperature range of interest, but because of practical experimental considerations, at much higher cesium partial pressures than predicted for the primary circuit $\left(10^{-9}\right.$ to $10^{-6}$ atm versus $10^{-15}$ to $10^{-12} \mathrm{~atm}$.

The sorption behavior of cesium on steels has received much less attention in the open 1iterature. The Zumwalt and Milstead Work (Refs. 9, 10) is probably the most definitive. Again the experimental partial pressures were in the $10^{-9}$ to $10^{-6}$ atm range. In addition, the minimum temperature for which equilibrium data were obtained was about $350^{\circ} \mathrm{C}$. Surface temperatures as $10 \mathrm{w}$ as $220^{\circ} \mathrm{C}$ are predicted in the economizer section of the steam generator. Zumwalt and Milstead's results demonstrated that sorption of cesium on SS304 stainless steel was profoundly influenced by the oxidation state of the surface. When the specimen was pre-oxidized by exposure to aix at $835^{\circ} \mathrm{C}$ for 18 hours, the amount of cesium sorbed at a given partial pressure and temperature increased by a factor of 40 to 60 over that of an "as-received" specimen; the effect is demonstrated in Figs. F-1 and F-2. The explanation for the increased sorptivity of an oxidized surface is not understood. It may be strictly a physical effect (increased specific surface area), a chemical effect (reaction between cesium and the oxide), or a combination. On the basis of these observations, steels of different compositions are expected to have different sorptive capacities for cesium; this expectation has been 


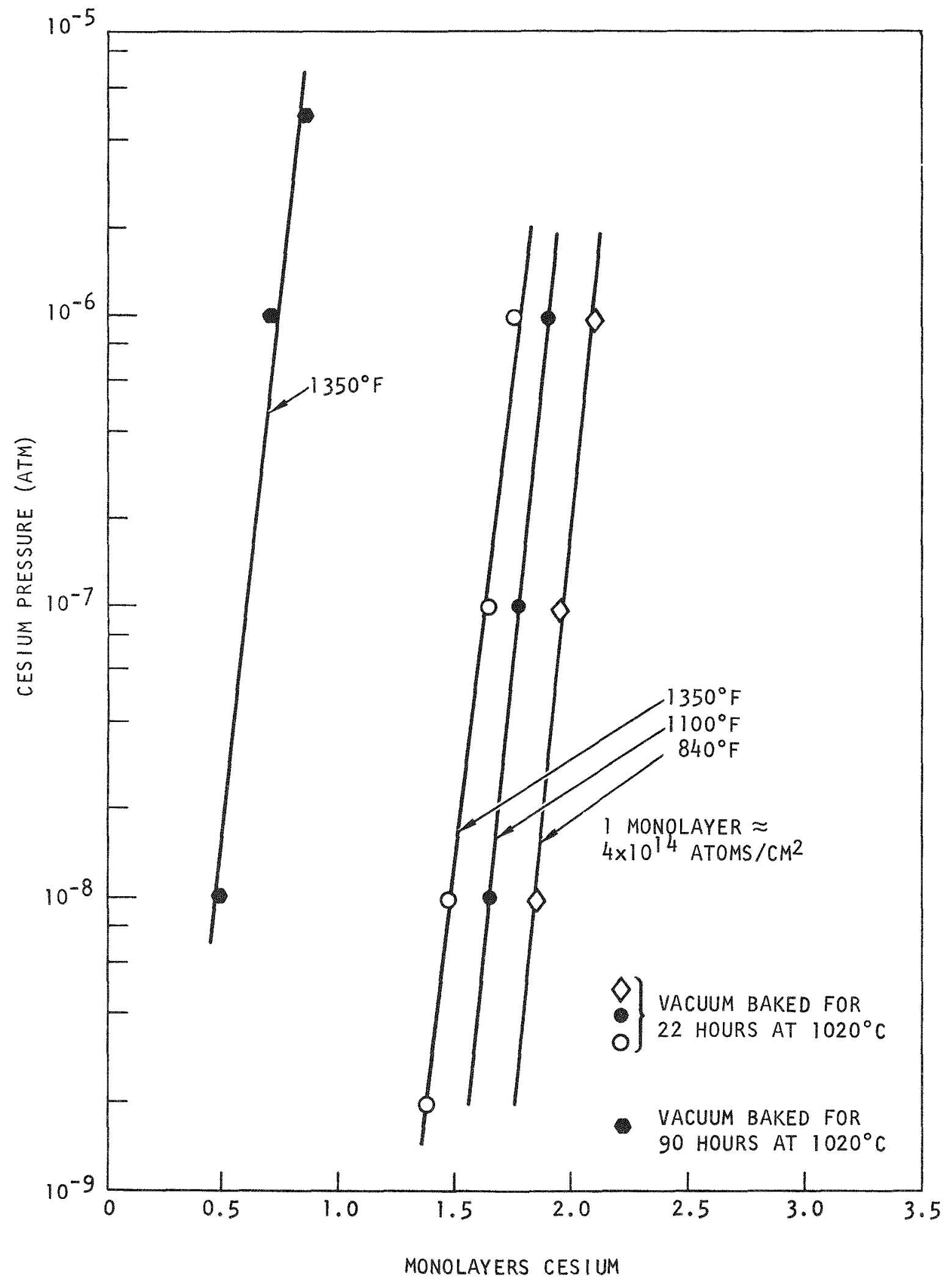

Fig. F-1. Deposition of cesium on 304 stainless steel (Ref. 10) 


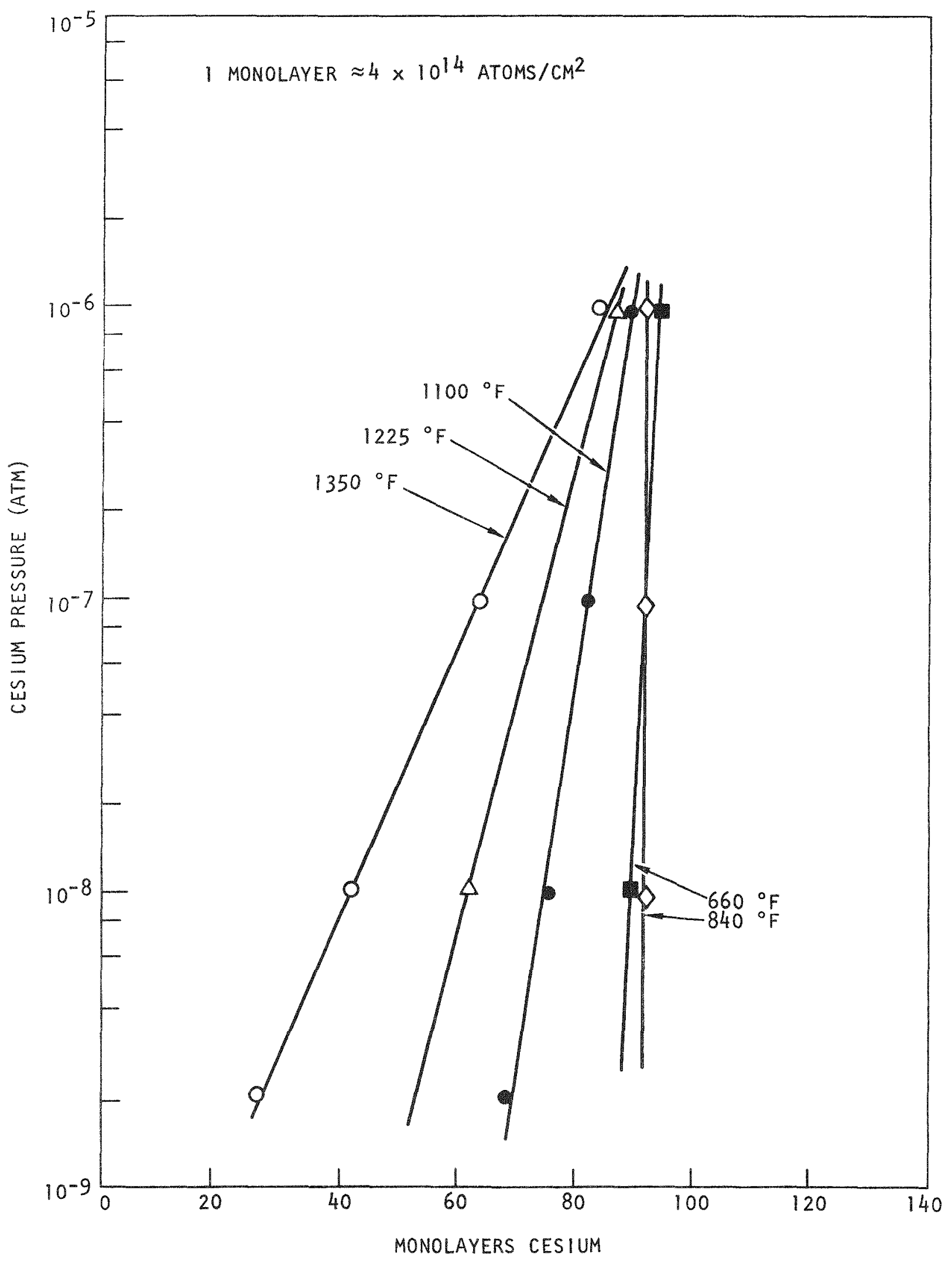

Fig. F-2. Deposition of cesium on oxidized 304 stainless steel (Ref. 10) 
qualitatively confirmed (Refs. 9, 68) with high-grade stainless steels sorbing the least and carbon steels the most under comparable conditions. It is not clear whether alloy composition, and thus oxide composition, is important per se; the differences in alloys may be strictly a measure of the general oxidation resistances. Careful laboratory experiments would be required to resolve these questions.

\section{F.2. CHOICE OF ISOTHERMS}

A four-constant Freundlich isotherm fit, Eq. F-1, of the most recent (at the time of the analysis) Cs-on-H-327 graphite data (Ref.69) was employed in the core and reflector portions of the Dragon and Peach Bottom primary circuits.

$$
\text { In } P=\left(7.8-\frac{29.84 \times 10^{3}}{\mathrm{~T}}\right)+\left(0.2351+\frac{1.873 \times 10^{3}}{\mathrm{~T}}\right) \text { In } \mathrm{C} \quad(\mathrm{F}-1)
$$

where $C=$ surface concentration, $\mu$ mole/g,

$$
\begin{aligned}
& \mathrm{T}=\text { absolute temperature, }{ }^{\circ} \mathrm{K}, \\
& \mathrm{P}=\text { equilibrium vapor pressure, atm. }
\end{aligned}
$$

The adsorption isotherm data for pre-oxidized SS304 (Fig. F-2) was also fit with a four-constant Fruendich equation:

$$
\text { In } P=\left(74.84-\frac{100.1 \times 10^{3}}{T}\right)+\left(-37.82+\frac{43.12 \times 10^{3}}{T}\right) \operatorname{ln~S}
$$

where $\mathrm{S}=$ surface concentration, $\mu \mathrm{g} / \mathrm{cm}^{2}$. 


\section{ACKNOWLEDGMENTS}

The author gratefully acknowledges the efforts of many other GA personne1 who contributed to the deposition loop program, especially $\mathrm{R}$. Lansley, F. Vanslager, D, Mears, and W. Hodgson. 


\section{REFERENCES}

1. Winkler, E. O., et al., "Irradiation Test and Postirradiation Examination of the GAIL IV Fuel Element in the General Atomic In-Pile Loop," USAEC Report GA-7997, General Dynamics, General Atomic Division, June $30,1967$.

2. "Public Service Company of Colorado 333 MW(e) High-Temperature GasCooled Reactor Research and Development Program Quarterly Report for the Period Ending September 30, 1967," USAEC Report GA-8270, General Dynamics, General Atomic Division, October 30, 1967.

3. "HTGR Base Program Quarterly Progress Report for the Period Ending November 30, 1970," USAEC Report GA-10399, Gulf General Atomic, December 31, 1970.

4. "HTGR Base Program Quarterly Progress Report for the Period Ending February 29, 1972," USAEC Report Gulf-GA-A10999, Gulf General Atomic, March 31, 1972.

5. "HTGR Base Program Quarterly Progress Report for the Period Ending May 31, 1972," USAEC Report Gulf-GA-A12150, Gulf General Atomic, June 30, 1972 .

6. "HTGR Base Program Quarterly Progress Report for the Period Ending November 30, 1972," USAEC Report Gulf-GA-A12422, Gulf General Atomic, January $25,1973$.

7. "HTGR Base Program Quarterly Progress Report for the Period Ending February 28, 1973," USAEC Report Gulf-GA-A12515, Gulf General Atomic, March 30, 1973.

8. Milstead, C. E., W. E. Be11 and J. H. Norman, "Deposition of Iodine on Low Chromium-Alloy Stee1," Nuc. App1.\& Tech. 7, October 1969.

9. Milstead, C. E., and L. R. Zumwa1t, "Cesium Plateout on Stainless and Carbon Steels," Informal AEC R\&D Report GAMD-7525, General Dynamics, General Atomic Division, October 25, 1966. 
10. Milstead, C. E., and L. R. Zumwalt, "Cesium Deposition on Stainless Stee1," Nuclear App1ications 3, 495-499, 1967; also USAEC Report GA7433, General Dynamics, General Atomic Division, September 1, 1966.

11. "Public Service Company of Colorado $330 \mathrm{MW}(\mathrm{e})$ High Temperature GasCooled Reactor Research and Development Program Quarterly Report for the Period Ending June 30, 1967," USAEC Report GA-8038, General Dynamics, General Atomic Division, July 28, 1967.

12. Epstein, L. F., and T. F. Evans, "Deposition of Matter from a Flowing Stream," GEAP-4140, Part I, Vallecitos Atomic Laboratory, December 1962.

13. Ozisik, M. N., "An Analytical Model for Fission Transport and Deposition from Gas Streams," USAEC Report ORNL-3370, Oak Ridge National Laboratory, July 1963.

14. Raines, G. E., et al., "Experimental and Theoretical Studies of Fission-Product Deposition in Flowing Helium," USAEC Report BMI-1688, Battelle Memorial Institute, August 21, 1964.

15. Vanslager, F. E., and L. D. Mears, "PAD: A Computer Code for Calculating the Plateout Activity Distribution in a Reactor Circuit," GuIf General Atomic Report GA-10460, January 1971.

16. Ozisik, M. N., and F. H. Neill, "An Analysis of Fission Product Deposition and Correlation with Experiment," CONF-650407 (Vo1 2), International Symposium on Fission Product Release and Transport Under Accident Conditions, Oak Ridge National Laboratory, Apri1 5-7, 1965.

17. Silverman, M. D., and G. E. Mills, Oak Ridge National Laboratory, "Cesium Transport and Deposition in the Fission Product Deposition Loop," unpublished data.

18. Raines, G. E., et al., "Studies of Fission-Product Deposition in Outof-Pile Loops," CONF-650407 (Vol. 2), International Symposium on Fission Product Release and Transport Under Accident Conditions, Oak Ridge National Laboratory, April 5-7, 1965.

19. Kress, T. S., and F. H. Neil1, "A Model for Transport and Deposition Under Isothermal Conditions," USAEC Report ORNL-TM-1274, Oak Ridge National Laboratory, October 1965. 
20. Kress, T. S., and F. H. Neill, "Calculating Convective Transport and Deposition of Fission Products," USAEC Report ORNL-TM-2218, Oak Ridge National Laboratory, September 1968.

21. Brown, P. E., et a1., "Measurements of Fission Product Deposition on the Heat Exchangers and Gas Circulators of the Dragon Reactor," Dragon Project Report DP-564, United Kingdom Atomic Energy Authority, July 1968.

22. Rowland, P. R., W. E, Browning, and M. Carlyle, "The Behavior of Iodine Isotopes in a High Temperature Gas Reactor Coolant Circuit," Dragon Report DP-736, United Kingdon Atomic Energy Authority, November 1970.

23. de Nordwa11, H. J., et al., "An Interim Report on Fission Product Release During Operation of the Second Peach Bottom Core," Proceedings of International Conference on Nuclear Fuel Performance, British Nuclear Energy Society, London, October 15-19, 1973.

24. Lansley, R. J., General Atomic Company, "Dua1 Chambered Autoclave: Operations Manual," unpublished data.

25. Winkler, E. O., General Atomic Company, unpublished data.

26. Mears, L. D., General Atomic Company, unpublished data.

27. Treybal, R. E., llass Transfer Operations, 2nd ed., McGraw-Hill Book Company, New York, 1968, p. 62.

23. "Design Safety Report of the Dragon Reactor Experiment," ed. by A. N. Dickson, Dragon Project Report DP 323, United Kingdom Atomic Energy Authority, May 1965.

29. Husain, L. A., "Estimate of Film Boiling Safety Margin in Dragon Primary Heat Exchanger," Dragon Project Report DP 113, United Kingdom Atomic Energy Authority, October 1964.

30. Busch, D. D. "Particulate Matter in the Peach Bottom HTGR Primary Coolant System," Gulf General Atomic Report Gulf-GA-B10034, July 7 , 1972.

31. "40 MW(e) Prototype High-Temperature Gas-Cooled Reactor Postconstruction Research and Development Program, Quarterly Progress Report for the Period Ending October 31, 1969," USAEC Report GA-9797, Gu1f General Atomic, November 26, 1969. 
32. Mears, L. D., General Atomic Company, unpublished data.

33. Hoinkis, E., "A Review of the Adsorption of Iodine on Metal and Its Behavior in Loops," USAEC Report ORNL-TM-2916, Oak Ridge National Laboratory, May 1970.

34. "Pub1ic Service Company of Colorado 333 MW(e) High-Temperature GasCooled Reactor Research and Development Program Quarterly Report for the Period Ending June 30, 1967," USAEC Report GA-8038, General Dynamics, General Atomic Division, July 28, 1967.

35. "Public Service Company of Colorado $330 \mathrm{MW}(\mathrm{e})$ High-Temperature GasCooled Reactor Research and Development Program Quarterly Report for the Period Ending June 30, 1968," USAEC Report GA-8725, Gulf Genera1 Atomic Company, July 29, 1968.

36. Rowland, P. R., "New Methods for the Investigation of Radioisotope Transport in a Gas-Cooled Reactor," Dragon Project Report DP-639, United Kingdom Atomic Energy Authority, March 1969.

37. Craig, G. T., General Atomic Company, unpublished data.

38. Ozisik, M. N. "Effects of Temperature on Fission Product Deposition," USAEC Report ORNL-3542, Oak Ridge National Laboratory, March 1964.

39. "Design Criteria: Levels of Fission Product, Activation Product, and Actinide Nuclides," General Atomic Company, unpublished data, January $15,1974$.

40. Meek, M. E., and B. F. Rider, "Compilation of Fission Product Yields: Vallecitos Nuclear Center-1972,"NEDO-12154, Vallecitos Nuclear Center, January 1972.

41. Weast, R. C., and S. M. Selby, Handbook of Chemistry and Physics, the Chemical Rubber Co., 47th ed., Cleveland, 1966.

42. Perry, R, H, C. R. Chilton, and S. D. Kirkpatrick, Perry's Chemical Engineer's Handbook, 4th ed., McGraw Hill Book Co., New York, 1963.

43. Bird, R. B., W. E. Stewart, and E. N. Lightfoot, Transport Phenomena, John Wiley \& Sons, Inc., New York, 1960. 
44. Kreith, F., Principles of Heat Transfer, International Textbook Co., Scranton, Pa., 1965.

45. Mears, L. D., General Atomic Company, unpublished data.

46. Daly, J. W., and D. R. F. Harleman, Fluid Dynamics, Addison-Wesley Publishing Co., Reading Mass., 1966, p. 259.

47. Wilson, M. P., "Thermodynamics and Transport Properties of Helium," General Dynamics, General Atomic Division Report GA-1355, January 1960.

48. Rothfus, R. R., J.E. Walker, and G. A. Whan, "Correlation of Local Velocities in Tubes, Annuli, and Parallel Plates," A. ICh.E.J. 4, 240 (1958).

49. Kress, T. S., "Parameters of Isothermal Fission-Product Deposition," USAEC Report ORNL-TM-1330, Oak Ridge National Laboratory, 1965.

50. Nei11, F. H., D. L. Gray, and T. S. Kress, "Iodine Transport and Deposition in a High Temperature Helium Loop," USAEC Report ORNL-TM1386, Oak Ridge National Laboratory, 1966.

51. Kral1, K. M., and M. R. Sparrow, "Turbulent Heat Transfer in the Separated, Reattached, and Redevelopment Regions of a Circular Tube," J. Heat Transfer, ASME Winter Meeting, November 1965, Paper No. 65WA $/ \mathrm{HT}-12$.

52. Brick, R. M., R. B. Gordon, and A. Phillips, Structure and Properties of Alloys, McGraw-Hi11 Book Co., New York, 1965, p. 354.

53. Dickson, A. N., and H. Schmidt, "Preliminary Safety Evaluation of the Dragon Reactor Experiment," Dragon Project Report DP4, United Kingdom Atomic Energy Authority, April 1962.

54. Lockett, G. E., "Engineering Aspects of the Dragon Reactor Experiment," Dragon Project Report DP63, United Kingdom Atomic Energy Authority, November 1961.

55. Hart, J. D., "The Design and Operation of the Inner Reflector of the Dragon Reactor," Dragon Project Report DP216, United Kingdom Atomic Energy Authority, September 1963. 
56. "Design Features and Test Results of the Main Circulators for the Dragon Reactor," Dragon Project Report DP217, Brown Boveri (Switzerland), October 1963.

57. Smith, E., "The Dragon Core," Dragon Project Report DP507, United Kingdom Atomic Energy Authority, May 1963.

58. Salter, W. B., "Dragon Operations Group Sixteenth Quarterly Progress Report March to May, 1969," Dragon Project Report DP710, United Kingdom Atomic Energy Authority, March 1970.

59. Rowland, P. R., M. Carlyle, and G. D. Soubelet, "The Distribution of Fission Products in a High-Temperature Gas-Cooled Reactor," Dragon Project Report DP702, United Kingdom Atomic Energy Authority, November 1969.

60. de Nordwall, H. J., Oak Ridge National Laboratory to S. L. Daltroff (Philadelphia Electric Co.), private communication, October 12, 1971.

61. Dyer, F. F., Oak Ridge National Laboratory to S. L. Daltroff (Philadelphia Electric Co.), private communication, December 18, 1972.

62. KoIb, J., Oak Ridge National Laboratory to L. D. Mears (GuIf General Atomic), private communication, November 8, 1972.

63. Cottre11, W. B., "ORNL Nuclear Safety Research and Development Program Bimonthly Report for July-August 1971," Oak Ridge National Laboratory Report ORNL-TM-3554, October 1971.

64. Busch, D. D., "Particulate Matter in the Peach Bottom HTGR Primary Coolant System," Gulf General Atomic Report Gulf-GA-B10034, July 7, 1972.

65. Mears, L. D., Genera1 Atomic Company, unpublished data.

66. de Nordwal1, H. J., Oak Ridge National Laboratory, private communication, August 4, 1973.

67. Mears, L. D., General Atomic Company, unpublished data.

68. Browning, W. E., and M. E. Davis, "Sorption of Fission Product Vapors on Structural Metals," Gas-Cooled Reactor Program Semiannual Progress Report ORNL-3807, Oak Ridge National Laboratory, March 31, 1965.

69. Rovner, L. H, General Atomic Company, unpublished data. 